\section{Consejo de Editores (Editors Board)}

Editores Jefe (Editor-in-Chief)

- Dra. Rosa García-Ruiz, Universidad de Cantabria, España

- Jaime Padilla-Verdugo, Universidad Politécnica Salesiana, Ecuador

Editores Adjuntos (Assistant Editors)

- Dr. Napoleón Esquivel, Universidad Politécnica Salesiana, Ecuador

Editores temáticos (Thematic Editors)

- Dra. María-Soledad Ramírez-Montoya, Tecnológico de Monterrey (México)

- Dra. Natalia González-Fernández, Universidad de Cantabria (España)

Co-Editores internacionales (International Coeditors) Dr. Geraldo Caliman, Universidade Católica de Brasília, Brasil

\section{Consejo Científico (Advisory Board)}

- Dr. Alejandro Rodríguez-Martín, Universidad de Oviedo, España

- Dra. Ana Castro Zubizarreta, Universidad de Cantabria, España

- Dra. Ana Rosa Arias Gago, Universidad de León, España

- Dr. Antonio Bautista García-Vera, Universidad Complutense de Madrid, España

- Dra. Armanda Matos, Universidad de Coímbra, Portugal

- Dra. Carmen Martínez Novo, Universidad de Kentucky, USA

- Dra. Cristina Allemann-Ghionda, Universidad de Colonia, Alemania

- Dr. Daniel Mato, Universidad Nacional Tres de Febrero, Argentina

- Dra. Diana Rivera Rogel, Universidad Técnica Particular de Loja, Ecuador

- Dr. Emilio Álvarez-Arregui, Universidad de Oviedo, España

- Dr. Felipe Trillo Alonso, Universidad de Santiago de Compostela, España

- Dra. Gabriela Borjes, Universidade Federal de Juiz de Fora, Brasil

- Dr. Geraldo Caliman, Universidade Católica de Brasília, Brasil

- Dr. Gunther Dietz, Universidad Veracruzana, México

- Dr. Ignacio Aguaded, Universidad de Huelva, España

- Dr. Jaime Valenzuela González, Tecnológico de Monterrey, México

- Dr. Jairo Lugo-Ocando, Universidad de Leeds, UK

- Dr. Javier Loredo Enríquez, Universidad Iberoamericana, México

- Dr. José Joaquín Brunner, Universidad Diego Portales, Chile

- Dr. Julio Cabero-Almenara, Universidad de Sevilla, España

- Dra. Leonor Buendía Eisman, Universidad de Granada, España

- Dr. Lorenzo Cantoni, Università della Svizzera Italiana, Suiza

- Dr. Luis Miguel Pedrero Esteban, Universidad Pontificia de Salamanca, España

- Dr. Luis Miguel Romero Rodríguez, Universidad Internacional de La Rioja, España

- Dr. Manuel Area, Universidad de La Laguna, España

- Dra. María Isabel Punín, Universidad Técnica Particular de Loja, Ecuador

- Dra. María-Soledad Ramírez-Montoya, Instituto Tecnológico y de Estudios Superiores de Monterrey, México

- Dra. Natalia González Fernández, Universidad de Cantabria, España
- Dra. Paloma Antón Ares, Universidad Complutense de Madrid, España

- Dra. Paula Renés Arellano, Universidad de Cantabria, España

- Dra. Pilar Arnáiz Sánchez, Universidad de Murcia, España

- Dr. Ronaldo Zacharias, Centro Universitário Salesiano de São Paulo, Brasil

- Dra. Rosa García-Ruiz, Universidad de Cantabria, España

- Dra. Sylvia Irene Schmelkes del Valle, Universidad Iberoamericana, México

- Dra. Soraya Ferreira Vieira, Universidade Federal de Juiz de Fora, Brasil

- Dr. Vicent Gozálvez Pérez, Universidad de Valencia, España

Consejo Internacional de Revisores (International Reviewers Board)

- Dra. Adelina de Oliveira Novaes, Universidade Cidade de São Paulo, Brasil

- Dra. Adir Casaro Nascimento, Universidade Catolica Dom Bosco, Brasil

- Dra. Águeda Delgado-Ponce, Universidad de Huelva, España

- Dr. Alejandro Rodríguez-Martín, Universidad de Oviedo, España

- Dra. Aleksandra Jablonska, Universidad Pedagógica Nacional, México

- Dra. Alessandra Diehl, Universidade de Ribeirão Preto, Brasil

- Dra. Alethia Fernández de la Reguera Ahedo, Universidad Nacional Autónoma de México, México

- Dr. Alexandre Godoy Dotta, Centro Universitário Autônomo do Brasil, Brasil

- Dr. Alexandre Martins, Marquette University, USA

- Dra. Alicia Inés Villa, Universidad Nacional de La Plata, Argentina

- Dra. Alma Rosa Hernández Mondragón, Universidad La Salle, México

- Lic. Álvaro Guaymás, Universidad Nacional de Salta (UNSa), Argentina

- Dr. Amauris Laurencio Leyva, Universidad de La Habana, Cuba

- Dra. Amelia Gort Almeida, Universidad de La Habana, Cuba

- Dra. Amneris Chaparro Martínez, Universidad Nacional Autónoma de México, México

- Dra. Ana Castro Zubizarreta, Universidad de Cantabria, España

- Ps. Ana Cristina Canosa, Centro Universitário Salesiano de São Paulo, Brasil

- Dra. Ana Lucia Braz, Universidade do Grande ABC, Brasil

- Dra. Ana Lupita Chaves, Universidad de Costa Rica, Costa Rica

- MSc. Ana Marcela Castellanos Guzmán, Universidad La Salle, México

- Dra. Ana María Eyng, Pontificia Universidad Católica de Paraná, Brasil

- Dra. Ana Pérez-Escoda, Universidad Internacional de La Rioja, España

- Dra. Ana Rosa Arias Gago, Universidad de León, España

- Dr. André Almeida, Pontifícia Universidade Católica de São Paulo, Brasil

- Dra. Ángela Santamaría Chavarro, Universidad del Rosario de Bogotá, Colombia 
- Dra. Anita Gramigna, Università degli Studi di Ferrara, Italia

- Dra. Annachiara Del Prete, Universidad Autónoma de Chile, Chile

- MSc. Anne Köster, European University Viadrina, Alemania

- Dra. Antonella Cagnolati, Università degli Studi di Foggia, Italia

- Dra. Antonia Ramírez García, Universidad de Córdova, España

- Dr. Antonio Bautista García-Vera, Universidad Complutense de Madrid, España

- Dr. Antonio Hilario Aguilera Urquiza, Universidade Federal de Mato Grosso do Sul, Brasil

- Dr. Antônio Igo Barreto Pereira, Universidade Federal do Acre, Brasil

- Dr. Aristeo Santos López, Universidad Autónoma del Estado de México, México

- Dra. Armanda Matos, Universidad de Coímbra, Portugal

- Dra. Azucena Ochoa Cervantes, Universidad Autónoma de Querétaro, México

- Dra. Beatriz Gualdieri, Universidad Nacional de Luján, Argentina

- Dra. Bianca Thoilliez Ruano, Universidad Autónoma de Madrid, España

- Dra. Carla Förster Marín, Pontificia Universidad Católica de Chile, Chile

- MSc. Carlos Manuel Crespo Burgos, Universidad Andina "Simón Bolívar", Ecuador

- Dr. Carlos Paladines Escudero, Pontificia Universidad Católica del Ecuador, Ecuador

- Dra. Carmen Martínez Novo, Universidad de Kentucky, USA

- Dra. Cecilia Dolores Correa de Molina, Universidad Simón Bolívar, Colombia

- Dra. Claudia Araújo de Lima, Universidade Federal de Mato Grosso do Sul, Brasil

- Dra. Claudia del Pilar Vélez De La Calle, Universidad de San Buenaventura de Cali, Colombia

- Ps. Claudia Moreno Standen, Universidad de Chile, Chile

- Dra. Constantina Xavier Filha, Universidade Federal de Mato Grosso do Sul, Brasil

- Dr. Cristian Desbouts, Università Pontificia Salesiana, Italia

- Dra. Damian Mendoza-Zambrano, Universidad Laica Eloy Alfaro de Manabí, Ecuador

- Dr. Daniel Llanos Erazo, Universidad Politécnica Salesiana, Ecuador

- MSc. Diana Ávila, Universidad Politécnica Salesiana, Ecuador

- Dra. Diana Rivera Rogel, Universidad Técnica Particular de Loja, Ecuador

- Dr. Eduardo Fabara Garzón, Universidad Andina "Simón Bolívar", Ecuador

- Dr. Eduardo Mercado Cruz, Instituto Superior de Ciencias de la Educación del Estado de México, México

- MSc. Elena Guadalupe Rodríguez-Roa, Universidad La Salle, México

- Dra. Elisabete Oliveira, ECOS - Comunicação em Sexualidade, Brasil

- Dra. Elsa Celina Gatti García, Universidad de la República, Uruguay

- Dra. Emiko Saldivar, University of California - Santa Barbara, USA

- Dr. Emilio Álvarez-Arregui, Universidad de Oviedo, España

- Dr. Enrique Arturo Parra Marín, Universidad de Chile, Chile
- Dr. Enrique Sánchez Rivas, Universidad de Málaga, España

- Dr. Ernesto Guerra García, Universidad Autónoma Indígena de México, México

- Dr. Felipe de Jesús Perales Mejía, Universidad Pedagógica Nacional - Unidad Torreón, México

- Dr. Felipe Trillo Alonso, Universidad de Santiago de Compostela, España

- Dr. Fernando Lara, Pontificia Universidad Católica del Ecuador, Ecuador

- MSc. Fernando Paladines Jaramillo, Universidad Politécnica Salesiana, Ecuador

- Dra. Flor Marina Bermúdez-Urbina, Universidad de Ciencias y Artes de Chiapas, México

- Dr. Francisco Javier Merchán Iglesias, Universidad de Sevilla, España

- Dra. Gabriela Borjes, Universidade Federal de Juiz de Fora, Brasil

- Dra. Gema Sáez Rodríguez, Universidad Francisco de Vitoria, España

- Dr. Gersem José dos Santos Luciano, Universidade Federal do Amazonas, Brasil

- Dra. Gina Benavides Llerena, Universidad Andina "Simón Bolívar", Ecuador

- MSc. Giovanna Barroca de Moura, Universidade Estadual dal Paraíba, Brasil

- Dr. Greby Uriel Rioja Montaño, Universidad Mayor de San Simón, Bolivia

- Dr. Gunther Dietz, Universidad Veracruzana, México

- Dr. Henry Chero Valdiviezo, Universidad Católica Los Ángeles de Chimbote, Perú

- Dra. Herminia Hernández, Universidad de La Habana, Cuba

- Dr. Hugues Ribeiro, Universidade Estadual Paulista Júlio de Mesquita Filho, Brasil

- Dra. Irene Melgarejo Moreno, Universidad Católica de Murcia, España

- Dra. Irina Salcines Talledo, Universidad de Cantabria, España

- Dr. Ivar César Oliveira de Vasconcelos, Universidade Católica de Brasília, Brasil

- Dr. Jaime Valenzuela González, Tecnológico de Monterrey, México

- Dr. Jaime Rivas Castillo, Universidad Don Bosco, El Salvador

- Dr. Jairo Lugo-Ocando, Universidad de Leeds, UK

- Dr. Javier Loredo Enríquez, Universidad Iberoamericana, México

- Dr. Jean Carlos García Zacarías, Pontificia Universidad Católica del Ecuador, Ecuador

- Dra. Jennie Brand Barajas, Universidad La Salle, México

- Dr. José Andrés García Méndez, Escuela Nacional de Antropología e Historia, México

- Dr. José Antonio Fernández Bravo, Universidad Camilo José Cela, España

- Dr. José Antonio Trasferetti, Pontifícia Universidade Católica de Campinas, Brasil

- Dr. José Francisco Alvarado García, Universidad Iberoamericana, México

- Dr. José Guilherme dos Santos Fernandes, Universidade Federal do Pará, Brasil

- Dr. José Luis Guzón Nestar, Universidad Pontificia de Salamanca, España 
- Dr. José Luis Moral, Università Pontificia Salesiana, Italia

- Dr. José Raúl Jiménez Ibáñez, Universidad de La Salle, Colombia

- Dra. Josiane Peres Gonçalves, Universidade Federal de Mato Grosso do Sul, Brasil

- Dr. Juan Vicente Ortiz Franco, Fundación Universitaria Los Libertadores, Colombia

- Dr. Julio Cabero-Almenara, Universidad de Sevilla, España

- Dra. Kathie Njaine, Fundação Oswaldo Cruz, Brasil

- MSc. Laura Liliana Rosso, Universidad Nacional de Nordeste, Argentina

- Dra. Laura Selene Mateos Cortés, Universidad Veracruzana, México

- Dra. Leonor Buendía Eisman, Universidad de Granada, España

- Dra. Liliana Inés Ávila Garzón, Universidad Pedagógica y Tecnológica de Colombia, Colombia

- Dra. Liliana Mayer, Universidad Metropolitana para la Educación y el Trabajo, Argentina

- Dra. Lisset Coba Mejía, Facultad Latinoamericana de Ciencias Sociales, Ecuador

- Dr. Lorenzo Cantoni, Università della Svizzera Italiana, Suiza

- Dr. Luis Antonio Reyes Ochoa, Universidad Católica Silva Henríquez, Chile

- Dr. Luis Enrique Sime Poma, Pontificia Universidad Católica del Perú, Perú

- Dr. Luis Fernando Cuji Llugna, Universidad Nacional de Tres de Febrero, Argentina

- MSc. Luis Fernando García Álvarez, Centro INAH Nuevo león, México

- Dr. Luis Huerta-Charles, New Mexico State University, USA

- Dr. Luis Miguel Pedrero Esteban, Universidad Pontificia de Salamanca, España

- Dr. Luis Miguel Romero Rodríguez , Universidad Internacional de La Rioja, España

- Dr. Manuel Area, Universidad de La Laguna, España

- Dra. Marcela Rosario Salazar Ibáñez, Universidad La Salle, México

- Dr. Márcio Roberto de Lima, Universidade Federal de São João Del-Rei, Brasil

- Dra. Maria Alfredo Lopes Moreira, Universidade do Minho, Portugal

- Salesiana, Ecuador

- Dra. María Bertha Fortoul Ollivier, Universidad La Salle, México

- Dra. María Cristina Rinaudo, Universidad Nacional de Río Cuarto, Argentina

- Dra. Maria de Fátima Pereira, Universidade do Porto, Portugal

- Dra. María del Mar Rodríguez Rosell, Universidad Católica de Murcia, España

- Dra. María Domingo Coscollola, Universitat Internacional de Catalunya, España

- Dra. María Elena Ortiz, Universidad Politécnica Salesiana, Ecuador

- Dra. María Inés Copello Danzi, Universidad de la República, Uruguay

- Dra. Maria Inês Millen, Centro de Ensino Superior de Juiz de Fora, Brasil
- Dra. María Isabel Punín, Universidad Técnica Particular de Loja, Ecuador

- Dra. María José Batista Pinto, Universidade Federal de Minas Gerais, Brasil

- MSc. María Margarita Marhx Bracho, Universidad La Salle, México

- Dra. María Sol Villagómez, Universidad Politécnica Salesiana, Ecuador

- Dra. María Teresa Prieto Quezada, Universidad de Guadalajara, México

- Dra. Maria-Carmen Caldeiro-Pedreira, Universidad Pública de Navarra, España

- Dra. Mariana Coralina Carmo, Universidade Estadual de Campinas, Brasil

- Dra. Maria-Soledad Ramírez-Montoya, Instituto Tecnológico y de Estudios Superiores de Monterrey, México

- Dra. Maribel Enaida Alegre Jara, Universidad Nacional del Santa, Perú

- Dra. Maribel Pinto, Instituto Politécnico de Viseu, Portugal

- Dr. Mário Marcelo Coelho, Pontifícia Universidade Católica de São Paulo, Brasil

- Dr. Marlécio Maknamara, Universidade Federal da Bahia, Brasil

- Dra. Meireluci Costa Ribeiro, Universidade Federal de São Paulo, Brasil

- Dra. Mirtes Lira, Universidade de Pernambuco, Brasil

- Dra. Mistli López Pérez, Universidad Autónoma del Estado de Morelos, México

- Dra. Mónica Cecilia Sáenz Amaguaya, Universidad Politécnica Salesiana, Ecuador

- Dra. Mónica Montenegro, Universidad de Buenos Aires, Argentina

- Dra. Natalia González Fernández, Universidad de Cantabria, España

- MSc. Nelson Rubén Martínez Reyes, Universidad Don Bosco, El Salvador

- Dra. Olga Espinoza Aros, Pontificia Universidad Católica de Chile, Chile

- Dra. Paloma Antón Ares, Universidad Complutense de Madrid, España

- Dra. Patricia Carla da Hora Correia, Universidade do Estado da Bahia, Brasil

- Dra. Patricia Muñoz Borja, Universidad Santiago de Cali, Colombia

- Dra. Paula Renés Arellano, Universidad de Cantabria, España

- Dr. Paulo César Nodari, Universidade de Caxias do Sul, Brasil

- Dr. Pierre André Garcia Pires, Universidade Federal do Acre, Brasil

- Dra. Pilar Arnáiz Sánchez, Universidad de Murcia, España

- MSc. Raimundo França, Universidade Federal de Alagoas, Brasil

- Dr. Ramon Luis de Santana Alcântara, Universidade Federal do Maranhão, Brasil

- Dra. Regina Ferreira Barra, Universidade Federal de Juiz de Fora, Brasil

- Dra. Renata Nunes Vasconcelos, Universidade Federal de Alfenas, Brasil

- Dra. Rita Gomes do Nascimento, Ministério da Educação, Brasil 
- Dr. Robério Pereira Barreto, Universidade do Estado da Bahia, Brasil

- MSc. Roberto López Chila, Universidad Politécnica Salesiana, Ecuador

- Dra. Romilda Teodora Ens, Pontifícia Universidade Católica do Paraná, Brasil

- Dr. Ronaldo Zacharias, Centro Universitário Salesiano de São Paulo, Brasil

- Dra. Ruth Aguilar Feijoo, Universidad Técnica Particular de Loja, Ecuador

- Dra. Ruth Amanda Cortes Salcedo, Instituto para la Investigación Educativa y el Desarrollo Pedagógico - IDEP, Colombia

- Dra. Salomé Sola-Morales, Universidad de Santiago de Chile, Chile

- Dra. Sandra Alves da Silva Santiago, Universidade Federal da Paraíba, Brasil

- Dra. Sandra Liliana Londoño Calero, Pontificia Universidad Javeriana, Colombia

- Dr. Sebastián Granda Merchán, Universidad Politécnica Salesiana, Ecuador

- MSc. Sergio Enrique Hernández Loeza, Universidad Nacional Autónoma de México, México

- Dra. Shirlei Rezende Sales, Universidade Federal de Minas Gerais, Brasil

- Dra. Shirley Silva, Universidade de São Paulo, Brasil

- MSc. Silvia Barco, Universidad Nacional del Comahue, Argentina

- Dra. Sílvia Ester Orrú, Universidade de Brasília, Brasil

- Dra. Sonia Koehler, Centro Universitário Salesiano de São Paulo, Brasil

- Dra. Sonia Liliana Ivanoff, Universidad Nacional de la Patagonia San Juan Bosco, Argentina

- Dra. Sonia Sampaio, Universidad Federal de Bahía, Brasil

- Dra. Soraya Ferreira Vieira, Universidade Federal de Juiz de Fora, Brasil

- MSc. Susana Barco, Universidad Nacional del Comahue, Argentina

- Dra. Suyai Malen García Gualda, Universidad Nacional del Comahue, Argentina

- Dra. Suzana dos Santos Gomes, Universidade Federal de Minas Gerais, Brasil

- Dra. Sylvia Irene Schmelkes del Valle, Universidad Iberoamericana, México

- Dra. Tânia Regina Dantas, Universidade do Estado da Bahia, Brasil

- Dra. Tania Suely Azevedo Brasileiro, Universidade Federal do Oeste do Pará, Brasil

- Dra. Teresa Laura Artieda, Universidad Nacional del Nordeste, Argentina

- Dr. Tiago Duque, Universidade Federal de Mato Grosso do Sul, Brasil

- Dra. Vanessa Figueiredo, Universidade Federal de Mato Grosso do Sul, Brasil

- Dra. Vania Tanira Biavatti, Universidade Regional de Blumenau, Brasil

- Dr. Vicent Gozálvez Pérez, Universidad de Valencia, España

- Dra. Victoria Jara, Universidad Politécnica Salesiana, Ecuador
- Dra. Wedja Maria Oliveira Leal, Pontifícia Universidade Católica de São Paulo, Brasil

- Dr. Wellington de Oliveira, Universidade Federal dos Vales do Jequitinhonha e Mucuri, Brasil

- Dr. Welson Barbosa Santos, Universidade Federal de Goiás, Brasil

- MSc. Willy Chambi Zabaleta, Universidad Salesiana de Bolivia, Bolivia

- Lcda. Yamila Irupé Núñez, Universidad Nacional de Misiones, Argentina

- Dra. Yamirlis Gallar Pérez, Universidad Internacional SEK, Ecuador

- Dra. Yolanda Castro Robles, Pontificia Universidad Javeriana, Colombia

Consejo Técnico (Board of Managment)

MSc. Tania X. Barrezueta (Soporte OJS)

Dr. Ángel Torres-Toukoumidis (Soporte OJS)

Wilson Verdugo (Soporte OJS)

Marco Gutiérrez (Soporte OJS)

Paulina Torres (Redacción y estilo)

Raysa Andrade (Maquetación)

Martha Vinueza Manosalvas (Maquetación)

Joaquín Crespo (Traducción)

Anthony Loyaga (Difusión)

\section{Edita (Published by)}

Universidad Politécnica Salesiana

www.ups.edu.ec

Consejo de Publicaciones

(Board of Publication)

Dr. Javier Herrán Gómez, sdb

Dr. Juan Bottasso Boetti, sdb

Dr. Juan Pablo Salgado Guerrero

Dr. José Juncosa Blasco

MSc. Jaime Padilla Verdugo

Dra. Floralba Aguilar Gordón

MSc. Sheila Serrano Vincenti

MSc. Fabricio Freire Morán

MSc. John Calle Sigüecia

MSc. René Unda Lara

MSc. Betty Rodas Soto

MSc. Andrea De Santis

MSc. Mónica Ruiz Vásquez

Editor General UPS (General Editor UPS)

Dr. Luis Álvarez-Rodas

Editorial Universitaria Abya-Yala

(Quito, Ecuador)

Hernán Hermosa (Coordinación General)

Av. 12 de Octubre N23-116 y Wilson, Bloque A, UPS

Casilla 17-12-7-19

Teléfono: (593-2)3962-800 ext. 2638

E-mail: editorial@ayayala.org

Portal electrónico: http://www.abyayala.org 


\section{ALTERIDAD \\ enero-junio 2019 \\ Vol. 14, No. 1, 5 \\ Índice}

Editorial.

SECCIÓN MONOGRÁFICA (MONOGRAPHIC SECTION)

“INNOVACIÓN EDUCATIVA. POSIBILIDADES Y RETOS DE LAS PRÁCTICAS ABIERTAS EN LA SOCIEDAD DIGITAL" EDUCATIONAL INNOVATION. POSSIBILITIES AND CHALLENGES OF OPEN PRACTICES IN THE DIGITAL SOCIETY

EDITORES Temáticos

Dra. María-Soledad Ramírez-Montoya, Tecnológico de Monterrey (México)

Dra. Natalia González-Fernández, Universidad de Cantabria (España)

MARCIO ROBERTO DE LIMA e ISADORA MOREIRA DE ANDRADE

Significado que los docentes le dan a la integración de tecnologías digitales en sus prácticas docentes

The meaning that teachers give to the integration of digital technologies in their teaching practices

ESTELA NÚÑEZ-BARRIOPEDRO, INGRID MIGUELINA y RAFAEL RAVINA-RIPOLL

El impacto de la utilización de la modalidad B-Learning en la educación superior

The impact of the use of the B-Learning modality in higher education

DIEGO BERNASCHINA CUADRA

Las TIC y Artes mediales: La nueva era digital en la escuela inclusiva

ICTs and Media Arts: The new digital age in the inclusive school

EDNA MANOTAS SALCEDO, AMOR PÉREZ RODRÍGUEZ y PALOMA CONTRERAS PULIDO

Propuesta de diseño de instrumento para analizar vídeo-lecciones en MOOC

Proposal for design an instrument for video lectures analysis in MOOC

LANDER CALVELHE PANIZO

Adolescentes gays en la era digital: orientaciones para la educación

Gay teenagers in the digital age: orientations for educators

\section{SECCIÓN MISCELÁNEA (MISCELLANEOUS SECTION)}

JACQUELINE MARILÚ AGUAVIL ARÉVALO y RAMIRO ANDRÉS ANDINO JARAMILLO.....

Necesidades formativas de docentes de Educación Intercultural Tsáchila

Training needs of teachers of Intercultural Education Tsáchila

JHON FREDY ORREGO NOREÑA y DIEGO ARMANDO JARAMILLO OCAMPO

Educación, cuerpo y alteridad: Encuentros cara a cara para la formación del Otro

Education, body and alterity: Meetings face to face for the formation of the other

MIGUEL ÁNGEL SÁNCHEZ JIMÉNEZ y ARACELI GALIANO CORONIL

Desarrollo de un equipo docente en la coordinación del profesorado en el ámbito universitario

Development of a teaching team in the coordination of the teaching staff in the university environment

CÉSAR SILVA MONTES

La escuela zapatista: educar para autonomía y la emancipación

The zapatista school: educating for autonomy and emancipation

ALBEIRO BEJARANO CASTELLANOS, MARÍA FERNANDA SERRANO GUZMÁN y DIEGO DARÍO PÉREZ RUIZ .......... Estrategia de reflexión para enseñanza de proyectos de construcción en Ingeniería Civil

Reflection strategy for teaching construction projects in Civil Engineering

Normas de Publicación en "Alteridad" 


\section{ALTERIDAD}

enero-junio 2019

Vol. 14, No. 1.6

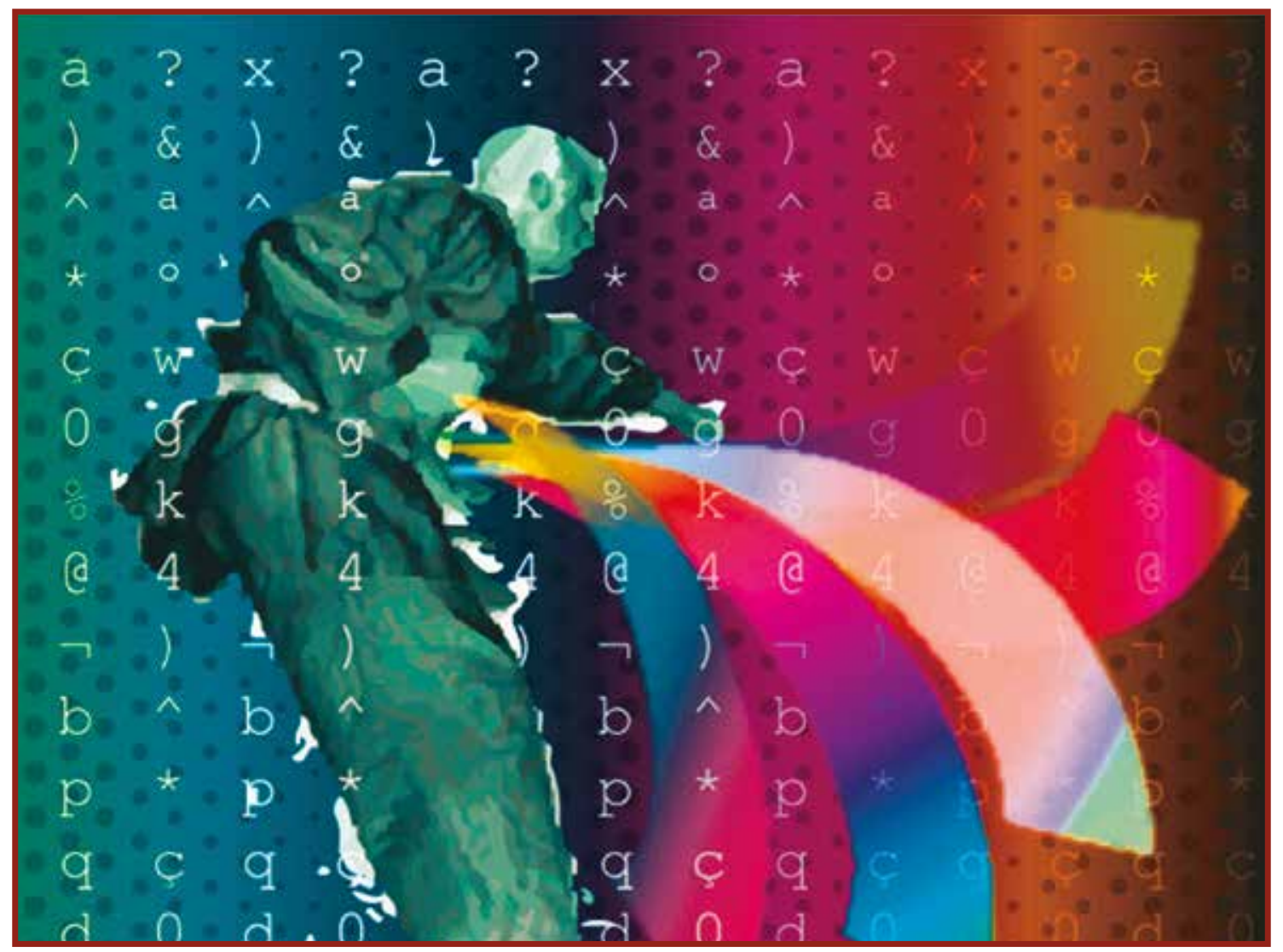

Infoxicación, ilustración digital, $15 \mathrm{~cm} \times 12 \mathrm{~cm}$

GALERÍA DE ARTE

Ivonne López

Antropóloga y artista ecuatoriana, nacida en Quito, ha estado vinculada desde su juventud en acciones artísticas y educativas; durante los primeros diez años trabajó en proyectos editoriales como diseñadora gráfica e ilustradora; en lo posterior, participó en proyectos de gestión cultural y promoción de las artes en la Universidad Politécnica Salesiana. En los últimos diez años se ha vinculado a la docencia en el ámbito de la educación y las tecnologías de la información y la comunicación. Las obras digitales presentadas en esta edición fueron realizadas para ilustrar el material educativo para la modalidad virtual ofertados por la UPS en Quito. 


\section{ALTERIDAD \\ enero-junio 2019 \\ Vol. 14, No. 1, 7-10 \\ Editorial}

La vertiginosa proliferación digital, especialmente en el ámbito educativo, y el consiguiente interés y motivación generada académica y socialmente, demandan un impulso innovador de tendencias educativas, que promuevan la igualdad y justicia social, mediante prácticas abiertas a toda la población.

A través de ejemplos concretos de buenas prácticas digitales, en los que se aplican técnicas pedagógicas basadas en aprendizaje activo y con apoyo de medios digitales, vemos cómo el sistema educativo puede incrementar las oportunidades formativas para ejercitar actitudes y aptitudes necesarias en una sociedad sostenible, es decir, que emprende con base en la innovación.

Para contribuir con la formación de los educadores en este campo, la Sección Monográfica de Alteridad que aquí presentamos propone cinco artículos.

El primero, de Marcio Roberto de Lima e Isadora Moreira de Andrade, titulado Significaciones docentes sobre la integración de tecnologías digitales en prácticas pedagógicas, aborda desde un enfoque exploratorio, una investigación-acción mediante la que se identifica conceptos de una docente, en una escuela del interior de Minas Gerais, Brasil, en cuanto a la incorporación de las Tecnologías Digitales de Información y Comunicación en sus prácticas pedagógicas, y, comprehender cómo esos recursos pueden ser significativos en la práctica docente en la cibercultura, potencializando e instrumentalizando estrategias participativas/ colaborativas. El trabajo de campo abarca espacios tradicionales de lugar y ciberespacio, realizando observaciones, acompañamiento de producciones virtualizadas y una entrevista semi-estructurada con la profesora colaboradora de la investigación. La compilación de los datos empíricos fue realizada en el software Atlas.ti, y posteriormente se llevó a cabo un análisis de contenido. La sistematización analítica indica la existencia de pocas políticas públicas educacionales enfocadas hacia la inclusión de las TDIC en la escuela investigada, constatándose el precario soporte de infraestructura y la inexistencia de apoyo pedagógico para la orientación de los docentes en actividades con aquellas tecnologías. Concluye que determinadas acciones de autoría en el ciberespacio, sugieren aportaciones en el aprendizaje e indicios de reconfiguraciones de la postura estudiantil frente a las propuestas de enseñanza, lo que favorece un proceso de revisión de las creencias pedagógicas de la profesora colaboradora de la investigación.

El segundo artículo, El impacto de la utilización de la modalidad B-Learning en la educación superior, de Estela Núñez-Barriopedro, Ingrid Miguelina Monclúz y Rafael Ravina-Ripoll, expone cómo los nuevos escenarios educativos plantean adaptar el proceso de enseñanza- 
aprendizaje al uso de las TIC colaborativamente. El principal objetivo de esta investigación se centra en analizar los condicionantes del proceso de enseñanza-aprendizaje de la universidad latinoamericana para la adopción de los nuevos planteamientos educativos. El diseño de la investigación es mixto con triangulación recurrente DITRIAC. Concretamente, en la fase cuantitativa, el método empleado es descriptivo-transversal, a través de cuestionario con Escala de Likert a cincuenta profesores, 402 estudiantes y seis autoridades. Y, en la fase cualitativa el método es etnográfico, mediante entrevistas a diez docentes, 38 estudiantes y dos autoridades. En las conclusiones se resalta, la necesidad de fomentar el factor social del aprendizaje y darle mayor protagonismo al estudiante. Asimismo, los tres aspectos que más les cuesta cambiar a los docentes en su paso de la modalidad presencial a la B-learning son: dejarle el protagonismo al estudiante, cambiar de la clase transmisiva al aprendizaje colaborativo, y de la evaluación sumativa a la formativa.

El tercer artículo, del profesor Diego Bernaschina Cuadra, aborda el tema de Las TIC y Artes mediales: La nueva era digital en la escuela inclusiva, describiendo una experiencia educativa sobre el impacto de las prácticas pedagógicas de los medios digitales en el aula. $\mathrm{Su}$ objetivo es comprender la relación entre la Educación Artística y Educación Tecnología y la metodología interdisciplinaria. Para ello propone el desarrollo de actividades realizadas en distintos talleres de Animación Stop Motion, para la educación primaria y Video Arte, para la educación secundaria, compartiendo y promoviendo el trabajo colaborativo como método alternativo de aprendizaje y participación de los estudiantes dentro del aula virtual.

El cuarto artículo, Propuesta de diseño de instrumento para analizar vídeo-lecciones en MOOC, de los profesores Edna Manotas Salcedo, Amor Pérez-Rodríguez y Paloma Contreras-Pulido, presentan el proceso seguido en la construcción y validación de un instrumento para valorar la estructura de vídeo-lecciones de cursos masivos en línea, MOOC. Basan su propuesta en la necesidad de generar propuestas para la producción de vídeos en cursos masivos, planteando, en primer lugar, el proceso de diseño y los soportes teóricos en los que han enmarcado los bloques de preguntas, así como el resultado de la valoración de los expertos, el pilotaje del instrumento y los resultados. Finalmente, los autores ofrecen perspectivas para el diseño de vídeo-lecciones e instrumentos que les ayuden a docentes y diseñadores instruccionales de cursos virtuales a reforzar sus discursos y contenidos en las vídeo-lecciones. Concluyen con una propuesta de uso del instrumento para abrir nuevas líneas de investigación que apoyen la producción de vídeo-lecciones y con el planteamiento de ideas para usar elementos de televisión vía streaming a las secuencias didácticas de cursos virtuales. El quinto artículo, titulado Adolescentes gays en la era digital: orientaciones para la educación, es el resultado de la investigación hecha por Lander Calvelhe Panizo, sobre las múltiples oportunidades de acceso a información e interacciones con distintas personas de manera rápida y fácil que ofrece Internet. Presentan los resultados de una investigación sobre los procesos de auto-identificación y socialización como gays de doce jóvenes entre los 14 y los 19 años, analizando cualitativamente experiencias y prácticas a partir de testimonios en los que aparece la necesidad de conexión con sus iguales, y la vez que, el miedo subyacente a la homofobia. Por otro lado, Internet es percibido como un lugar de esperanza e incertidumbre, 
evidenciando cómo este tipo de prácticas en Internet son más comunes durante un periodo de confusión sobre su sexualidad. El autor finaliza proponiendo una serie de orientaciones educativas basadas en los resultados del estudio.

La Sección Miscelánea inicia con el artículo titulado Necesidades formativas de docentes de Educación Intercultural Tsáchila de Jacqueline Marilú Aguavil Arévalo y Ramiro Andrés Andino Jaramillo donde evidencian las falencias formativas de los docentes interculturales bilingües, los efectos en los procesos educativos y los problemas en la ejecución del Modelo del Sistema de Educación Intercultural Bilingüe (MOSEIB). La metodología del estudio se basó en un diseño no experimental apoyado en la investigación cualitativa y cuantitativa; la muestra estuvo formada por 19 docentes tsáchilas y diez docentes mestizos; las técnicas fueron la encuesta y el análisis estadístico. Los resultados demuestran que los docentes presentan necesidades formativas y de capacitación evidenciando la importancia de la formación inicial y continua, la necesidad de la investigación y el desarrollo de propuestas educativas. Educación, cuerpo y alteridad: Encuentros cara a cara para la formación del Otro de Jhon Fredy Orrego Noreña y Diego Armando Jaramillo Ocampo afirma que no es posible educar al margen de la relación con el Otro lo cual depende de la idea de sujeto y de mundo. El encuentro implica un escenario en el que el sujeto ya no se halla solo ante sí-mismo, sino que se relaciona con Otro, diferente de él, generando una educación que supera la preminencia del conocimiento y parte de una relación con el Otro. Esta perspectiva, abordada desde el pensamiento de Levinas y Mèlich, fundamenta una educación moral centrada en el conocimiento, reglas y valores socialmente aceptados y en una educación ética puesta sobre las necesidades formativas de los sujetos que responden responsablemente al y del Otro.

Desarrollo de un equipo docente en la coordinación del profesorado en el ámbito universitario de Miguel Ángel Sánchez Jiménez y Araceli Galiano Coronil manifiesta que la coordinación en la docencia es uno de los elementos relevantes para el desempeño, desarrollo profesional y organizacional. Ante la baja satisfacción de los alumnos de Marketing e Investigación de Mercados de la Universidad de Cádiz con la coordinación docente se planteó la creación de un equipo con el objetivo de crear procedimientos comunes para mejorar la comunicación entre estudiantes y profesores. En esta línea se establecieron reuniones durante el curso académico 2016/2017, proponiendo actividades que mejoren la coordinación docente cuyos resultados generaron una mayor satisfacción por parte del alumnado y el profesorado surgiendo la necesidad que el equipo docente se siga realizando.

La escuela zapatista: educar para autonomía y la emancipación de César Silva Montes, expone el desarrollo de una propuesta educativa desde la comunidad, basada en la sabiduría ancestral pero ligada al pensamiento contemporáneo, orientada a formar generaciones autónomas y dignas. La experiencia, en parte, se apoya en las ideas de Paulo Freire sobre cómo alfabetizar para leer el mundo y transformarlo; es anticapitalista, no se rige por normas del mercado ni es un aparato de Estado porque cada pueblo elige los contenidos académicos. A diferencia de las escuelas que promueven el emprendimiento, el mérito y el autoempleo, en la educación zapatista se aspira a que los jóvenes sirvan a su pueblo solidariamente y que los conocimientos no jerarquicen, eviten la burocratización y la homogeneización. 
Estrategia de reflexión para enseñanza de proyectos de construcción en Ingeniería Civil de Albeiro Bejarano Castellanos, María Fernanda Serrano Guzmán y Diego Darío Pérez Ruiz visibiliza que los programas educativos de las universidades exigen que los contenidos ayuden a responder a las problemáticas del entorno. La propuesta didáctica se fundamenta en conceptos como administración de proyectos de construcción empleando la reingeniería y la filosofía de construcción sin pérdidas (Lean). Se parte de información recolectada en proyectos de construcción de vivienda en donde se evaluaron las prácticas que conjugaron conocimientos técnicos, administración de recursos humanos y financieros, pensamiento crítico, solución de problemas, compromiso social, trabajo en equipo, habilidades comunicativas, ética y responsabilidad social. El estudio concluye que la reflexión del futuro profesional es una herramienta útil del proceso de enseñanza-aprendizaje.

Finalizamos este editorial invitándoles a enviar sus producciones científicas para ser arbitradas en la Revista. El tema monográfico del volumen 14, número 2 (julio-diciembre de 2019), es Educación Inclusiva: Avances, dilemas y retos para un contexto intercultural; el cual está coordinado por los editores temáticos, Dra. Sílvia Ester Orrú, Universidade de Brasilia, (Brasil), Dr. Alejandro Rodríguez-Martín, Universidad de Oviedo (España), Dra. Auxiliadora Sales Ciges, Universitat Jaume I (España); así como para la sección Miscelánea que recibe resultados de investigación, siempre que aborden el tema de la educación. También les recordamos que «Alteridad» está presente en alrededor de 100 bases de datos, repositorios y bibliotecas, como: ESCI, DOAJ, REDIB, REDALYC, MIAR, CAPES, SciELO entre otras; y está siendo evaluada para pasar a formar parte de SCOPUS.

Dra. María-Soledad Ramírez-Montoya

Coordinadora Temática

Tecnológico de Monterrey

Dra. Natalia González-Fernández

Coordinadora Temática

Universidad de Cantabria

Dr. Napoleón Esquivel Editor adjunto Revista Científica "Alteridad" 


\section{ALTERIDAD \\ enero-junio 2019 \\ Vol. 14, No. 1, 11 \\ Sección Monográfica (Monografic section)}

"Innovación educativa. Posibilidades y retos de las prácticas abiertas en la sociedad digital"

Educational innovation. Possibilities and challenges of open practices in the digital society

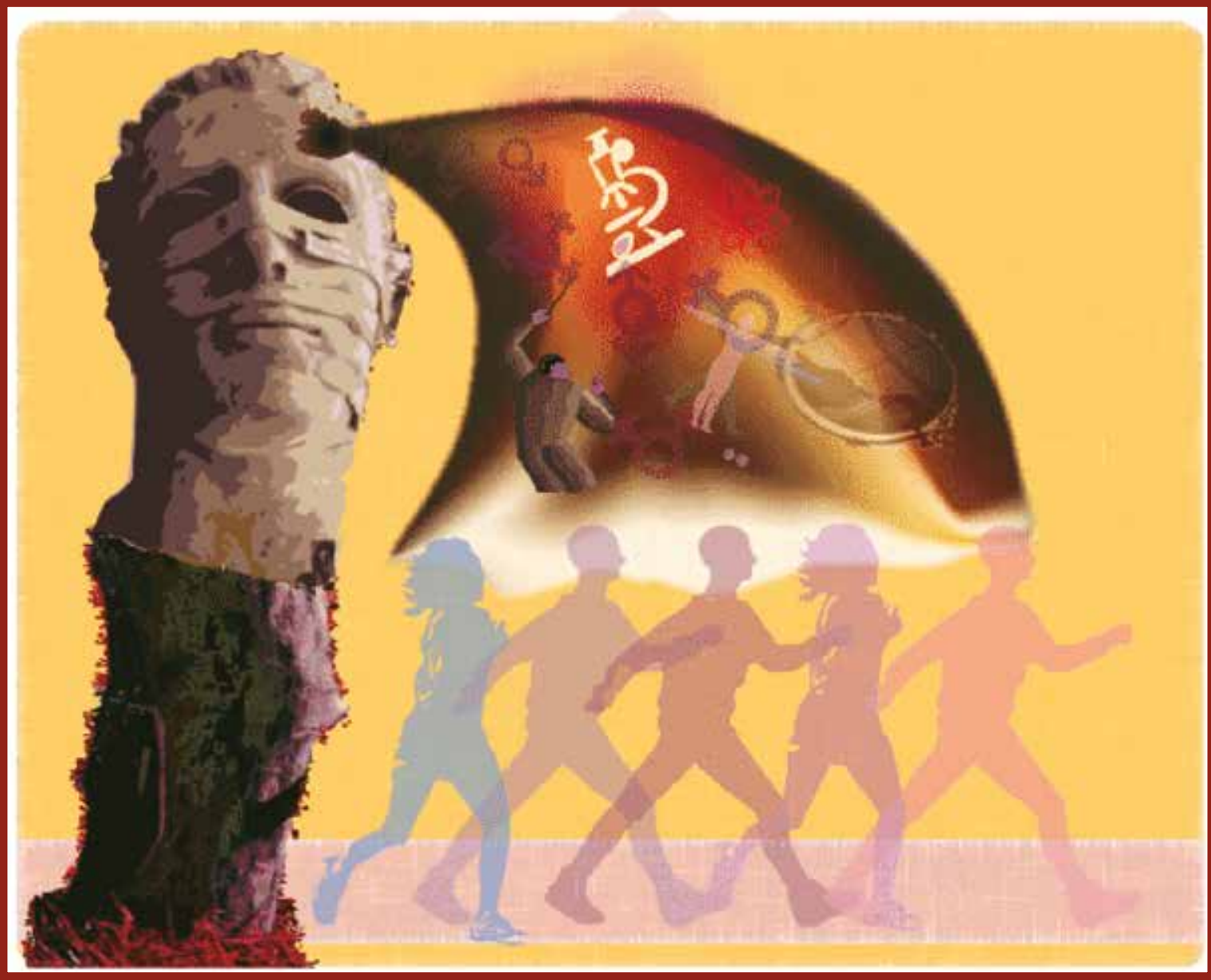




\section{Significado que los docentes le dan a la} integración de tecnologías digitales en sus prácticas pedagógicas

\section{The meaning that teachers give to the integration of digital technologies in their teaching practices}

Marcio Roberto de Lima es Profesor Investigador de la Universidad Federal de São João del-Rei (Brasil) (marcinholima@ufsj.edu.br) (http://orcid.org/0000-0003-3790-1104)

Isadora Moreira de Andrade es maestranda en el Programa de Pós-graduación en Procesos Socioeducativos y Prácticas Escolares, de la Universidad Federal de São João del-Rei (Brasill) (moreiraisadora40@yahoo.com.br) (https://orcid.org/0000-0001-6219-3782)

Recibido: 2018-01-09 / Revisado: 2018-10-17 / Aceptado: 2018-11-07 / Publicado: 2019-01-01

\section{Resumen}

Este trabajo tuvo carácter exploratorio, configuró una investigación-acción y buscó identificar conceptos de una profesora en cuanto a la incorporación de las Tecnologías Digitales de Información y Comunicación (TDIC)/ciberespacio en sus prácticas pedagógicas. Debido a este propósito, se buscó, también, comprender cómo esos recursos pueden ser significativos en la práctica docente en la cibercultura, potencializando e instrumentalizando estrategias participativas/colaborativas. La base teórica de este estudio dice respecto a la cibercultura y sus desdoblamientos en la educación. Las acciones de intervención y de recolección de datos involucran a una profesora y a los alumnos de dos aulas de $6^{\circ}$ año de Enseñanza Fundamental en una escuela del interior de Minas Gerais, Brasil. Las incursiones en el campo abarcarán espacios tradicionales de lugar y ciberespacio, habien- do sido realizadas observaciones, acompañamiento de producciones virtualizadas y una entrevista semiestructurada con la profesora colaboradora de la investigación. La compilación de los datos empíricos fue realizada en el software Atlas.ti, lo cual auxilió en el proceso de tratamiento, relacionamiento e inferencias que compusieron un Análisis de Contenido. La sistematización analítica indicó la existencia de pocas Políticas Públicas Educacionales enfocadas hacia la inclusión de las TDIC en la escuela investigada, constatándose el precario soporte de infraestructura y la inexistencia de apoyo pedagógico para la orientación de los docentes en actividades con aquellas tecnologías. Notablemente, la intervención realizada en el campo de la investigación consolidó un momento de originalidad para los involucrados, ocasionando un impacto cultural docente en el uso pedagógico de las TDIC. Al final, acciones de autoría en el ciberespacio sugirieron ganancias en el aprendizaje e indicios de reconfiguraciones de la pos-

Forma sugerida de citar: de Lima, M. R., \& Moreira de Andrade, I. (2019). Significaciones docentes sobre la integración de tecnologías digitales en prácticas pedagógicas. Alteridad, 14(1), 12-25. https://doi.org/10.17163/alt.v14n1.2019.01. 
tura estudiantil frente a las propuestas de enseñanza, lo que favoreció el inicio de un proceso de revisión de las creencias pedagógicas de la profesora colaboradora de la investigación.

Descriptores: Significaciones docentes Tecnologías Digitales de Información y Comunicación, práctica pedagógica, cibercultura, ciberespacio.

\begin{abstract}
This scientific paper reports an exploratory study conducted in the form of an action research and sought to identify the meanings of a teacher about the incorporation of Digital Information and Communication Technologies (DICT) / cyberspace in their pedagogical practices. Due to this purpose, we also sought to understand how these resources can be meaningul to the teaching practice in cyberculture, potentializing and instrumentalizing participatory / collaborative strategies. The intervention and data collection actions involved a teacher and her students from two classes of the 6th year of primary education in a school in the interior of Minas Gerais, Brazil. The field
\end{abstract}

\section{Introducción}

La apropiación social de las Tecnologías Digitales de Información y Comunicación (TDIC) indica un nuevo modus vivendi en el cual la facilidad de acceso a la información virtualizada, la autoría y la comunicación en redes telemáticas potencializan las formas de producción de conocimientos y reconfiguran la acción humana. Ese movimiento creativo y expansivo de posibilidades, de (re)pensar o "hacer" y las formas de interacción social acaban por señalar nuevos hábitos y modificación de comportamientos instaurando la cibercultura (Lévy, 1999). Este escenario - aunque aún no totalizado ${ }^{1}$ - evidencia que las tecnologías digitales asumen un lugar significativo en cuanto mediadoras de actividades, constituyéndose como una dimensión de la cultura (Pinto, 2005) contemporánea. Consecuentemente, la apropiación social de las TDIC trae "[...] consigo representaciones no solo en la vida cotidiana, mas, también, en lo que se refiere a las formas y posibilidades de aprendizaje académico" incursions were carried out in traditional spaces of place and cyberspace, with observations, monitoring of virtualized productions and a semi-structured interview with the teacher.The compilation of empirical data was performed in Atlas.ti software, which assisted in structuring a Content Analysis. The analytical systematization indicated that there are few Educational Public Policies for the inclusion of the DICT in the school, precarious support of infrastructure and lack of pedagogical support that guides the teachers in activities with those technologies. Another expressive suggestion was that the intervention in the field of research consolidated a moment of unprecedentedness, causing a cultural impact on the pedagogical use of DICT. Finally, the actions of authorship in cyberspace suggested learning gains and signs of reconfiguration of the student's posture towards the teaching proposals, which favored the beginning of a process of revision of pedagogical beliefs of the teacher collaborating the research.

Keywords: Teachers meanings, Digital Information and Communication Technologies, pedagogical practice, cyberculture, cyberspace.

(Moraes \& Lima, 2018, p. 300). En ese sentido, "no se puede pensar en la escuela como una instancia oprimida de la sociedad y de sus dimensiones culturales, políticas y económicas" (Souza \& Schneider, 2016, p. 421). La educación necesita integrarse a la cibercultura y acompañar su dinámica de renovación sociocultural, sabiéndose incluida y promoviendo la (ciber) inclusión.

Sin embargo, es importante registrar que las TDIC no determinan - por sí solas - cambios en el ámbito educacional. Entendemos esas tecnologías como condicionantes de eventuales transformaciones, cuando se utilicen de forma a estimular los potenciales dialógicos, reflexivo, creativo, cognitivo y afectivo de los sujetos involucrados. Nuestro pensamiento encuentra sintonía en Santaella (2013), quien indica que la forma de producir/adquirir conocimientos en la cibercultura, cuando asociada a la educación, puede conducir a un aprendizaje continuo y a la comunicación ubicua. De esa forma, consideramos que el primer momento de aproximación de la educación de la cibercultura pasa por el 
equipamiento de sus espacios de enseñanza y de aprendizaje. Sin embargo, destacamos el carácter fundamental de esa iniciativa: la indispensable renovación de la intencionalidad pedagógica y su adecuación a la cibercultura.

En ese sentido, la reconfiguración educacional con la integración de las TDIC debe ultrapasar el paradigma de la pedagogía pautada en la transmisión de contenidos para memorización y repetición (Freire, 2005). Y, en sintonía de pensamiento con otros investigadores (Bonilla, 2009; Medeiros, 2011; Silva, 2010), asumimos la utilización de las TDIC en los procesos educacionales de forma que rompa con el paradigma utilitarista o de adopción de tecnologías para la modernización del modelo tradicional. Por otro lado, si la cibercultura establece una inter-relación entre las tecnologías digitales y el modus operandi social, asumimos que la práctica pedagógica con TDIC puede potencializar acciones interactivas mediadas en el ciberespacio, las cuales incentivan la producción estudiantil de forma individual y colectiva en la red (Passarelli, 2017).Para ello, es fundamental que el profesor - por intermedio de la formación inicial y continuada - pueda apropiarse de las TDIC de forma que compatibilice su práctica en el contexto de la cibercultura, integrándose a un "[...] proceso de transformación humana y de cambio educacional, [lo que no significa la] substitución de métodos, modalidades y técnicas [...]" (Almeida, 2004, p. 28). Por otro lado, Ally y Prieto-Blázquez (2014) constatan la desactualización del modelo educacional y de la formación de profesores mediante el advenimiento de las TDIC. Consecuentemente, estos autores indican que tales procesos necesitan ser reinventados para ser más efectivos frente a las interposiciones de la cultura contemporánea.

Ante eso, comprendemos que el profesor en formación (inicial o continuada) necesita tener oportunidades de experimentar pedagógicamente y tomar para sí las tecnologías digitales, incorporándolas a su modo de ser y de hacer. Pueden ocurrir de allí transformaciones de comportamiento y re significaciones, las cuales invo- lucran readaptación de costumbres, de valores, de creencias, de actitudes y de prácticas pedagógicas (Lima, 2015). De esa forma, para que los cambios sean viables, "incluso en niveles sutiles, es imprescindible, por parte de los profesores, la adecuación a esta nueva realidad, la cual se difiere bastante de la que se vivió en otro tiempo y esto, es claro, exige tiempo, trabajo y dedicación" (Quintanilha, 2017, p. 251).

Ante tales perspectivas, la investigación científica aquí sintetizada pretendió propiciar una formación continua a una docente de la educación básica y enriquecer sus prácticas pedagógicas, aproximándolas a la cibercultura. Para ello, proyectamos la utilización de las TDIC/ ciberespacio por la profesora en su práctica educativa de forma que fomente estrategias participativas/colaborativas en su proceso de enseñanza e incentivar autoría, comunicación y reflexión estudiantil. Para ello proyectamos la utilización las tecnologías digitales a las prácticas pedagógicas, nuestro principal objetivo con este estudio fue identificar los significados que esta profesora le dió a la integración de tecnología.

\section{Metodología}

Para desarrollar la investigación aquí relatada, partimos de un estudio acerca de recursos de software y/o ambientes del ciberespacio, los cuales podrían favorecer el delineamiento de estrategias interactivas/colaborativas para la enseñanza mediada por TDIC. Posteriormente, proyectamos, implementamos y acompañamos prácticas pedagógicas mediadas por las TDIC junto a una profesora y sus alumnos. Las acciones de intervención pedagógica ocurrieron en una escuela del interior del estado de Minas Gerais (Brasil) en dos aulas de sexto año de Enseñanza básica. El criterio de selección de la escuela donde desarrollamos la investigación involucró la estructura de tecnologías digitales disponibles en el local y la aceptación de una profesora ${ }^{2}$ colaboradora (en adelante tratada ficticiamente como Profesora X). 
Desde el punto de vista metodológico, emprendemos una investigación-acción (Thiollent, 1996). Nuestras acciones de investigación pretenderán valorar las percepciones y experiencias de la profesora colaboradora y, también, promover una intervención en el campo de sus acciones. Fue en ese delineamiento que estuvimos presentes en la escuela y acompañamos a la Profesora $\mathrm{X}$ y sus alumnos construyendo y emprendiendo estrategias pedagógicas para uso de las TDIC/ciberespacio. En ese sentido, procedemos a las observaciones, acompañamos e interactuamos con estudiantes de la unidad curricular de Lengua Portuguesa en acciones pedagógicas mediadas en el ciberespacio, en el salón de clase, en el laboratorio de informática de la escuela. Nuestras observaciones e intervenciones se produjeron entre el 23/08/2016 y 04/10/2016.

En nuestra intervención escolar, buscamos, también, constituir una oportunidad de formación continua a la Profesora $\mathrm{X}$, objetivando la superposición de su trabajo pedagógico a la cibercultura y al uso intencional de las TDIC/ciberespacio. Asumimos la perspectiva en la cual la formación continua en servicio (Almeida, 2004) podría colaborar para ampliar el campo de trabajo de la profesora, fomentando reflexiones y transformaciones en el proceso de enseñanzaaprendizaje, pues creemos que es "la experiencia, [...] lo que da sentido a la educación. Educamos para transformar lo que sabemos, no para transmitir lo ya sabido" (Rancière, 2002, p. 11).

Reiteramos que, en nuestra investigaciónacción - más allá de la imbricación de las TDIC en las prácticas pedagógicas -, buscamos identificar las (re)significaciones de la experiencia para la Profesora X. De esta forma, emprendimos un trabajo de naturaleza cualitativa y exploratoria, habiendo sido utilizada una entrevista semiestructurada como instrumento generador de datos. En un encuentro realizado fuera del ambiente escolar, tomamos el testimonio de nuestra colaboradora, lo cual fue transcrito y generó un corpus para nuestro Análisis de Contenido (Bardin, 1977). Más allá de la entrevista, el análisis de datos fue enriquecido con elementos procedentes de nuestras observaciones durante las acciones de intervención en el contexto escolar.

Franco (2008) asume como punto de partida del Análisis de Contenido el mensaje, sea el verbal (oral o escrita), gestual, silenciosa, figurativa, documental o directamente provocada. Así, teniendo como base la transcripción del habla de la Profesora X, utilizamos ese corpus para proceder a la identificación de fragmentos de interés, los cuales fueran categorizados en conformidad a nuestro foco de investigación. teniendo en cuenta la concepción de nuestro análisis, optamos por su estructuración en el software Atlas.ti, lo cual auxilió en el proceso de tratamiento, relacionamiento e inferencias de los/con los dados.

\section{Discusión analítica y resultados}

La construcción del Análisis de Contenido (Bardin, 1977) de los datos empíricos en el Atlas.ti tuvo como guía nuestro referencial teórico y foco de investigación. Todavía, de las muchas relecturas realizadas en la transcripción, emergieron también contribuciones que simbolizaban algunas reflexiones/impresiones de la Profesora X. Esos indicativos no fueran ignorados. Estructuralmente, realizamos 20 códigos/categorías semánticas(as), los (las) cuales fueran asociados(as) a 76 fragmentos discursivos de la transcripción de la entrevista con la Profesora X (Figura 1). En el software utilizado, son los códigos (o categorías) que permiten marcar partes de la transcripción, las cuales identifican semánticamente las unidades de significado de la investigación. Es ese proceso de asociación que estructura el Análisis de Contenido de los datos en el Atlas.ti. 


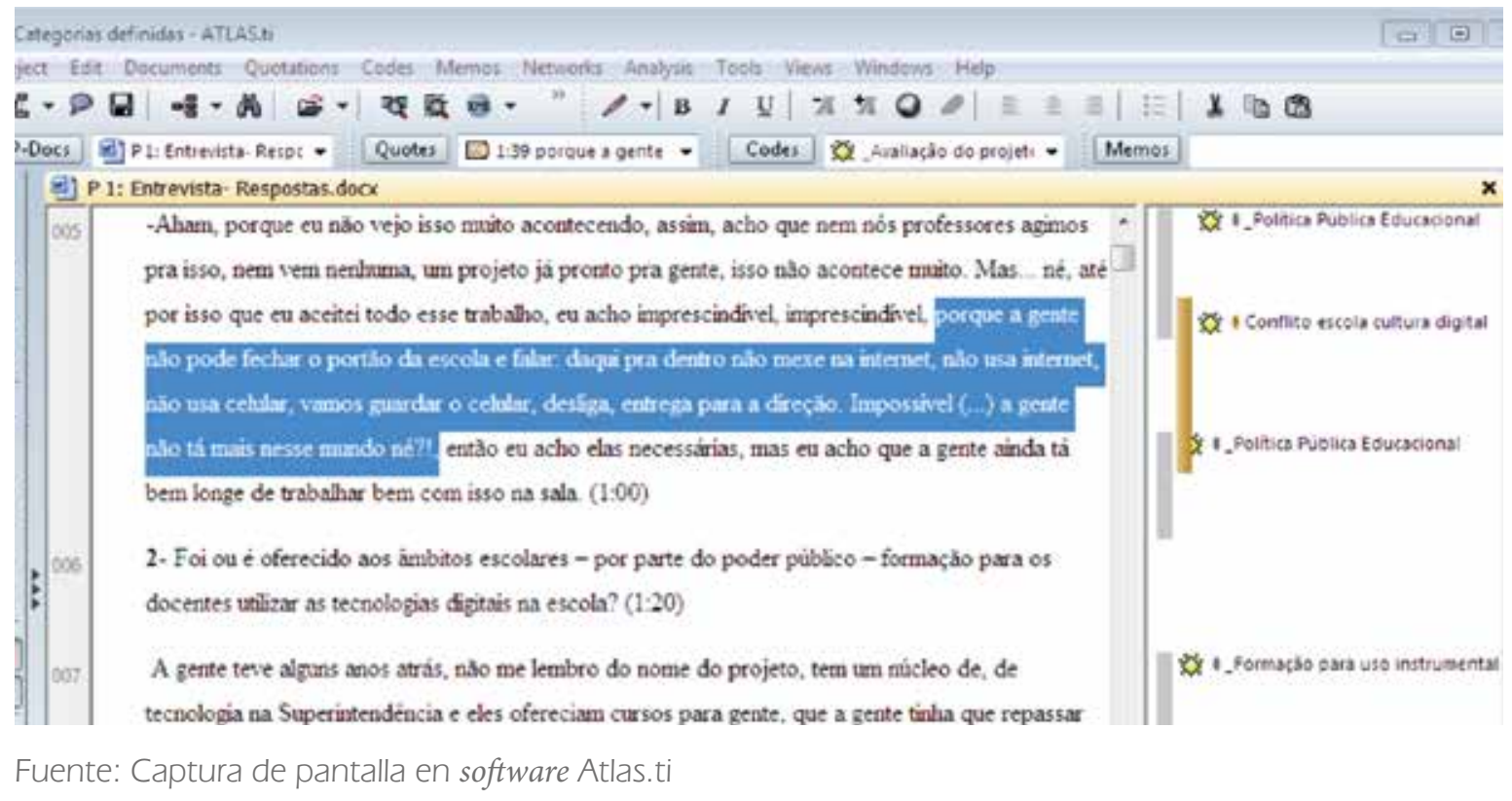

Las siguientes subsecciones presentan fragmentos de las discusiones de la Profesora $\mathrm{X}$ acompañados de una discusión analítica. En este estudio exploratorio, buscamos sistematizar significados que le da la docente relacionadas a la experiencia del trabajo pedagógico con las TDIC. Para ello, organizamos nuestros descriptores de la siguiente manera: Políticas públicas educativas para las tecnologías digitales, Impacto cultural docente frente a las TDIC, Recursos del ciberespacio/TDIC, Reconfiguraciones de la acción estudiantil, Potenciación de la práctica pedagógica con las TDIC, evaluación del Proyecto y Perspectiva para nuevos trabajos con las TDIC.

\subsection{Políticas públicas educativas para las tecnologías digitales}

Con el código "Políticas Públicas Educacionales", buscamos identificar las impresiones de la profesora con respecto de las políticas públicas educacionales para el uso de las TDIC en la escuela investigada. Directamente vinculadas a ese foco de análisis, otras categorías complementarán nues- tros entendimientos, a saber: Soporte técnico para TDIC, Infraestructura de TDIC, Formación para uso instrumental de las TDIC y Soporte pedagógico para TDIC. Estas últimas categorías están directamente relacionadas a la implementación de las políticas públicas en las escuelas, trayendo consigo desdoblamientos que no deberían ser analizados aisladamente. Por ese motivo, agregamos nuestras consideraciones en este eje analítico.

En sus consideraciones, la Profesora X nos reveló que no identificaba acciones de políticas públicas educacionales dirigidas a la inclusión digital en las escuelas públicas y que también, a veces, los profesores no hacen exigencias al poder público cuanto a esa inversión. Nos advirtió el hecho que, aunque aquella escuela contara con un laboratorio de informática bien estructurado, existían problemas en su funcionamiento. Durante nuestra permanencia en el espacio escolar para observaciones, notamos - a pesar de la poca frecuencia de los alumnos en la sala de informática durante el tiempo de los encargos didácticos de los profesores de la escuela - la utilización de los ordenadores escolares en cursos 
libres ofrecidos para la comunidad. Así mismo, aquella escuela no contaba con soporte técnico continuo para la manutención de sus equipos.

Específicamente acerca de las cuestiones relacionadas a las políticas públicas sobre la ampliación del acceso al internet en el ambiente escolar, registramos que, desde el 4 de abril de 2008, el Gobierno de Brasil ha lanzado el "Programa Banda Ancha en las Escuelas". En su Decreto 6.424, consta "el objetivo de conectar todas las escuelas públicas urbanas a la internet, rede mundial de ordenadores, por medio de tecnologías que propicien cualidad, velocidad y servicios para incrementar la enseñanza pública en País" (Brasil, 2008). Aun así, la Profesora X alegó necesidad de mejoría de ese recurso, pues, muchas veces, el internet no funcionaba adecuadamente durante el período de nuestras intervenciones.

En nuestro análisis - después de la apreciación resumida del contexto en discusión -, comprendemos que la Profesora $\mathrm{X}$ considera que las condiciones materiales de infraestructura no deberían constituir obstáculos para el desarrollo de actividades pedagógicas. En común acuerdo, entendemos la infraestructura material como condición fundamental para estimular a cambiar experiencias virtuales y fomentar la construcción de una inteligencia colectiva (Lévy, 1999), lo que puede favorecer la utilización pedagógica de las TDIC/ciberespacio.

También, es relevante destacar que, paralelas a las condiciones de infraestructura, las políticas públicas de formación docente continua son primordiales para crear oportunidades para el contacto y comprensión de las potencialidades pedagógicas de las tecnologías digitales. En ese aspecto, la Profesora X destacó:

[07...] Nosotros tuvimos algunos años atrás [...] cursos [...] que teníamos que repasar para los alumnos, pero eran cursos, por ejemplo, [... de] Linux [...] No tenía nada que ver con lo pedagógico, de adentro del salón de clases, y nosotros hacíamos grupos con los niños y repasaba lo que nosotros aprendimos, era eso. Pero no había ningún proyecto dirigido para el salón de clases, para la clase de portugués, para la clase de matemática. [...] (Profesora X).

En ese fragmento discursivo, la profesora indica la importancia de una formación continua contextualizada en la cibercultura y adecuada a las necesidades de los docentes. Tales iniciativas extrapolan cuestiones técnicas e instrumentales del uso de las TDIC. Con eso, lógicamente, los cursos favorecidos necesitan tener mayor enfoque pedagógico. O sea, los profesores necesitan “[...] ser capacitados para saber usar los microordenadores, desarrollar una educación más centrada en el alumno, poder ayúdalo y criar un ambiente de aprendizaje favorable al uso de esas nuevas tecnologías" (Valente, 2011, p. 28). Y la Profesora X complementó:

[034...] Yo pienso que es interesante, porque nosotros decimos mucho que los alumnos necesitan de ese internet en la escuela, que el alumno tiene que ser incluido en ese medio digital, pero los profesores no están incluidos en eso, tanto que los profesores no van hasta el salón de informática. [...] (Profesora X).

Notablemente, el discurso de la profesora deja explícito el pensamiento de que solamente intentar incluir/aproximar el alumno en el/del medio digital es insuficiente. En ese sentido, la Profesora X indica la necesidad de una efectiva inclusión digital de los profesores. Esto es:

Más que equipar las escuelas [con TDIC], [lo fundamental es] saber qué hacer con los recursos que están en la escuela. Y eso pasa, necesariamente, por la inversión en la formación y en la carrera del profesor y por la construcción de un proyecto pedagógico bien estructurado, que garantice una práctica profesional efectivamente transformadora (Hanauer \& Abegg, 2017, p. 14).

\subsection{Impacto cultural docente frente a las TDIC}

El código "Impacto cultural docente frente a las TDIC" fue destinado al registro de los desdo- 
blamientos de nuestra investigación-acción en la práctica pedagógica de la Profesora X. En esta línea, identificamos un impacto cultural ocasionado por el trabajo con las TDIC. En un primero momento, la profesora reveló recelo en llevar los alumnos para el laboratorio de informática, pues tanto ella como los alumnos no estaban acostumbrados a trabajar en aquella perspectiva. La docente temía que la actividad no ocurriera bien: "[048...] ay, caramba, salir con los niños para el laboratorio, ellos no están acostumbrados, será que va a funcionar? [...]" (Profesora X). Al respecto de esto Teixeira (2016, p. 149) comenta que:

A pesar de los debates acerca de la efectiva articulación de la educación con la tecnología ya venían siendo realizados hace décadas, aun se observa la utilización de los recursos tecnológicos de modo bastante tímido en el escenario educacional contemporáneo.

Teniendo en cuenta nuestras observaciones de campo sumadas al discurso de la profesora, notamos que las actividades con las TDIC eran inusuales. Eso nos sugirió que la propuesta de un trabajo real con las tecnologías digitales y el reubicación para un espacio diferente del habitualmente frecuentado estaban ocasionando un impacto en sus creencias pedagógicas. Eso porque, en diferentes momentos del discurso de la Profesora X, identificamos: incertezas, miedos, recelos y rompimiento de rutina, todos ellos constituyendo un contexto que, dada la presencia y uso intencional de las TDIC, era desafiante. De esa forma, reiteramos que:

[...] el análisis de la cuestión del impacto cultural vivenciado por el profesor en su adaptación pedagógica para la incorporación de tecnologías a sus prácticas está vinculada a la cultura organizacional escolar $y$, fundamentalmente, a las creencias docentes (Lima, 2015, p. 154).

Aunque hayan constituidos eventuales impactos para la Profesora X, los recelos y el rompimiento de rutina pedagógica de la profesora no fueran obstáculos para el uso de las
TDIC dado su reconocimiento de los desafíos interpuestos por la cibercultura a la educación. Innegablemente, vivenciamos una "transformación en los modos de crianza tanto ética cuanto estéticamente. El acto creativo humano fue, por lo tanto, alterado" (Coelho, Costa, \& Mattar Neto, 2018, p. 1079). Al aceptar nuestra propuesta de uso de las TDIC en sus clases y colaborar con las actividades, la docente tenía noción de la necesidad de acompañar los cambios socioculturales. Esa postura fue preponderante para el éxito de nuestro trabajo y puede ser contextualizada con la siguiente declaración:

[054...] yo ya tengo diez años en el salón de clases, pero no es una profesión que tú digas: ¡tengo diez años, entonces, ahora ya estoy preparada, ya sé cómo enseñar! Entonces, no es eso, es una cosa que tú estás siempre en evolución, si no evolucionas (...) ya era. Va a quedarse con aquel discurso que algunos profesores tienen: Los niños de antes que eran buenos, obedecían, querían estudiar, ahora mire, no toman un cuaderno, tú ves que no estudió para la prueba. (...) (Profesora X).

El fragmento discursivo evidenció consciencia de la docente en relación a las constantes transformaciones relacionadas a los procesos educacionales $y$, también, de la indispensable necesidad de acompañamiento de esos cambios por los profesores y sistemas de educación. Así, los profesores son los principales agentes de los cambios (Sandholtz, Ringstaff, \& Dwyer, 1997) involucrados en la aproximación escuelacibercultura, pues son ellos quienes delimitan las formas por las cuales las tecnologías pueden influenciar la educación de manera significativa.

\subsection{Recursos del ciberespacio/TDIC}

El código "Recursos ciberespacio/TDIC" fue destinado a la identificación de las TDIC, las cuales podrían ser significativas a la práctica docente en la cibercultura, posibilitando efectiva potenciación de estrategias participativas/colaborativas 
en el proceso de enseñanza. Nuestra intención fue buscar recursos que contribuyera para:

La formación de estudiantes críticos, con capacidad de interpretar y transformar su contexto, reconociendo que el ordenador y otras tecnologías pueden ser aprovechados para la comunicación, obtención de informaciones, ampliación de conocimientos [...] (Maldonado, 2018, p. 41, libre traducción).

La planificación de las actividades con los alumnos de la Profesora X utilizó -además de los ordenadores- dos recursos del ciberespacio. El primero fue el site Comic Creator - Boys' Life, en el cual los alumnos crearán historietas virtualizadas. Para las producciones, los alumnos dialogaron entre ellos, cambiaron experiencias y cuestionaron, ejerciendo la autoría de sus historias con autonomía de pensamiento e interaccionando con sus parejas.

El segundo recurso virtual fue el del grupo de Facebook, por el cual fueron publicadas las historietas de autoría de los alumnos. Optamos por ese ambiente debido a dos razones: su popularización entre los alumnos y el hecho de permitirles compartir sus producciones. Facebook es la red social más popular del mundo, con más de 2,23 billones de usuarios activos ${ }^{3}$ (https://goo.gl/ PT0dX2, accedido el 24 de octubre de 2018).El posteo de las actividades en el ciberespacio posibilitó a los alumnos compartir, visualizar, "gustar" y comentar las producciones de sus iguales. Identificamos, junto a la Profesora X, el reconocimiento de aquel trabajo y haber posibilitado a sus alumnos una oportunidad de (re)construcción de conocimientos por intermedio del cambio de experiencia (Panuci, Bianchini, Souza, Silva, \& Munhoz, 2016). En la práctica, el trabajo realizado acabó por revelar producciones - antes privadas y aisladas - colectivas y accesibles a los demás estudiantiles. Para la docente, emergió un trabajo reconfigurado, más interactivo y compatible con los presupuestos de la cibercultura. A ese respeto, la Profesora X aclaró:
[042...] Bueno, yo pienso que es interesantísimo el uso del Facebook, es genial [...] yo pienso que el Facebook es bueno por eso, porque tomó una herramienta que ellos usan mucho, que a ellos les gusta, que es divertida, que no es aburrida, verdad, que no está vinculada a un trabajo aburrido, pesado, y trajo eso al salón de clases. Eso para mí fue lo más interesante. (...) (Profesora X).

Notoriamente, la profesora reforzó la idea de que en el uso de aquel ambiente respetó y valoró la individualidad de cada uno de los alumnos, los cuales crearon, publicaron, comentaron y describieron sus sentimientos y pensamientos sin la imposición de una estructura linear y rígida a ser seguida. Este relato de la docente refuerza que:

(...) la inserción de las tecnologías en el ámbito escolar, [puede favorecer la reconfiguración de las] prácticas docentes, no más apenas la perspectiva estructural y linear de presentación y desarrollo metodológico del contenido a ser enseñado [pero siguiendo] una otra lógica, basada en la exploración de nuevos tipos de raciocinios nada excluyentes, en que se enfaticen variadas posibilidades de encaminamiento de las reflexiones, en que se estimule la posibilidad de otras relaciones entre áreas del conocimiento aparentemente distintas (Kenski, 2006, p. 38).

Esas contribuciones nos sugirieron que las prácticas pedagógicas con las TDIC permitieran a la Profesora X comprender que, cuando son debidamente planeadas y ejecutadas, las acciones con tecnologías acaban por favorecer la reconfiguración de la acción estudiantil, la cual es tratada en próxima subsección.

\subsection{Reconfiguración de la acción estudiantil}

El código "Reconfiguración de la acción estudiantil" fue destinado a la identificación de elementos que sugirieran el reconocimiento de la Profesora $\mathrm{X}$ cuanto a un proceso de reconfiguración de la acción estudiantil (a partir del uso de las TDIC). 
Entendemos que la docente habría de considerar el uso de las TDIC en su práctica pedagógica como uno de los caminos para intentar expandir el proceso de enseñanza-aprendizaje. La Profesora $\mathrm{X}$ nos relató sus percepciones sobre las consideraciones de los alumnos con las actividades realizadas por intermedio de las TDIC:

[036...] Ayer, por ejemplo, (...) El alumno habló de algún tipo de trabajo que nosotros íbamos hacer, que él dijo así, vamos hacer en el internet, vamos poner en el internet, vamos hacer un grupo. Entonces, yo pensé, mira la semillita, porque ellos no hablaban eso antes, entonces a ellos le gustó esa idea de está todo el mundo allí, entonces ya es así, aquella voluntad de ellos de continuar haciendo. (...) (Profesora X).

Ese fragmento discursivo nos sugirió que la actividad realizada fue significativa para los alumnos y posibilitó un repensar del campo de acción estudiantil (Papert, 1985). Después de la ejecución del proyecto, los alumnos pasarán a reivindicar nuevas formas de trabajo utilizando las TDIC por intermedio de las cuales pudiera crear, interaccionar y compartir, así como pasó en la creación de las historietas y publicación en Facebook: "[099...] Ellos destacaron eso en sus comentarios, 'la clase fue muy buena', 'quiero ir más veces' [...]” (Profesora $\mathrm{X}$ ).

$\mathrm{Y}$, en otro momento de su entrevista, la docente reforzó el éxito de la propuesta para la resignificación de las acciones estudiantiles:

[046...] entonces, yo pienso que lo interesante fue eso, que él creó, él fue protagonista. Él creó, él mismo se analizó, él se corrigió, verdad, él analizó lo del otro, entonces, yo pienso, en ese sentido del protagonismo mismo, del alumno, allí en el trabajo que fue hecho. (...) (Profesora X).

El uso de las TDIC en la educación necesita tener el objetivo de ultrapasar las barreras de una clase tradicional, en la cual el profesor es visto como detentor del saber y el alumno como hoja blanca en la cual el conocimiento será impreso. La Profesora X estaría, por lo tanto, ante una oportunidad de rompimiento con el exclusivismo del saber almacenado en las páginas de los libros (Serres, 2013) y de las prácticas tradicionales de la recitación, lectura silenciosa y repetición oportuna. Sin embargo, con las TDIC y su apropiación pedagógica, "El saber se propaga en un espacio homogéneo descentrado, de movimiento libre. El salón de clases de antiguamente murió, aunque aún lo vemos tanto, aún que solo sepamos construir otros iguales [...]" (Serres, 2013, p. 49).

A pesar de reconocer el valor de la instrucción en un proceso de enseñanza, combatimos su exclusividad como recurso didáctico. Así, consideramos que la reconfiguración de la acción estudiantil está pautada en transformar el educando en sujeto (inter)activo en el proceso enseñanza-aprendizaje y el profesor en mediador del aprendizaje del alumno con las TDIC. O sea:

El profesor se torna un animador de la inteligencia colectiva de los grupos que están a su encargo. Su actividad será centrada en el acompañamiento y en la gestión de los aprendizajes: la incitación del cambio de los saberes, la mediación relacional y simbólica, el pilotaje personalizado de las rutas de aprendizaje etc. (Lévy, 1999, p. 171).

De ese modo, el alumno se configura como autor en el proceso de enseñanza-aprendizaje y su individualidad, cultura y realidad son respetadas. Delante de las prácticas realizadas con las tecnologías digitales, la Profesora X nos indicó su percepción acerca del inicio de una reconfiguración de la acción estudiantil, pues las actividades modificarán la postura de los alumnos, emergiendo la autoría en el ciberespacio. De esa manera, el uso de las TDIC en las aulas fomentó la superación de la enseñanza pautada en la transmisión de informaciones, posibilitando que los sujetos involucrados se movilizasen, moviera, dialogara e intercambiara informaciones (Serres, 2013) Apuntando a la construcción de sus aprendizajes. Esa es la reconfiguración del 
oficio del alumno, antes dicho receptor de contenidos y ejecutor de instrucciones, para un alumno más participativo y con noción de su lugar en el proceso de aprendizaje. Consecutivamente, esos encaminamientos acabarán por germinar un proceso de (re)empoderamiento pedagógico en la Profesora X, lo cual sintetizamos en la siguiente subsección.

\subsection{Potenciación de la práctica pedagógica con las TDIC}

El código "Potenciación de la práctica pedagógica con las TDIC" fue destinado para el registro de los desdoblamientos de nuestra investigaciónacción en el cotidiano pedagógico de la Profesora $\mathrm{X}$, indiciando modificaciones. Es importante resaltar que el contexto de este código estuvo relacionado a los dos códigos ya presentados: "Reconfiguración de la acción estudiantil" y "Recursos del ciberespacio/TDIC". Buscamos proporcionar a la Profesora X formación continua con el propósito de potencializar sus prácticas, pues "no se pode exigir cambio en el perfil de los profesionales de la educación" (Souza \& Schneider, 2016, p. 420) sin considerar el hecho de que sus formaciones iniciales aun ocurren bajo los moldes tradicionales.

Como fue visto anteriormente, identificamos en las contribuciones de la Profesora X el relato de que las actividades virtuales emprendidas con los alumnos fueran rentables. La profesora destacó su consciencia de que la ejecución del proyecto con las TDIC no cambió toda la realidad escolar, pero contribuyó para la expansión de sus acciones pedagógicas. Resaltó, también, el interés y la voluntad estudiantil en participar de las actividades, una vez que aquella práctica no fue evaluada (en el sentido de registrar nota): “[054...] no fue una actividad evaluada, no fue aquella cosa, vale punto, es para entregar tal fecha, entonces, así, ellos hicieron, porque ellos quisieron. [...]” (Profesora X).

Agregados, esos aspectos colaborarán para un inicio de reconfiguración del campo de acción estudiantil y para la potenciación de la práctica pedagógica con las TDIC. Al final, el planeamiento de nuestras intervenciones cerca de la profesora fue concebido en la "dirección [de] una instrucción centrada en el alumno, y no en el currículo, en dirección a las tareas colaborativas, y no tareas individuales, en dirección al aprendizaje activa, y no pasiva" (Sandholtz et al., 1997, p. 33). En otras palabras, la Profesora X se ha permitido trabajar con las TDIC de manera a "pensar, en vez de imitar" (Kohan, 2013, p. 71) los métodos utilizados en la práctica docente, resignificando su forma de enseñanza y los medios para la promoción del aprendizaje:

[091...] nosotros damos muchas clases, tu no dedicas mucho tiempo para hablar 'No, esa semana, yo voy a hacer de esa manera, de esa forma, con esa turma'. No, tú vas llevando, las clases todas iguales y eso va quedando tedioso, pero es cómodo para mí como profesora. Solo que allí llega un proyecto de ese es dice: 'Vamos para el laboratorio' (...). Entonces, eso ya me da una sacudida, no tiene forma, yo tuve que moverme un poco y eso fue muy bueno en ese sentido, tú descubre que puedes hacer poco diferente de su rutina (...) (Profesora X).

Al favorecer la expresión creativa, el diálogo y la interacción en el ciberespacio, las actividades realizadas permitieran a los alumnos que asuman una postura más activa en la construcción de sus conocimientos (Papert, 1985), rompiendo con la tradición que "raramente abre brechas para situarnos como sujetos de nuestro aprendizaje" (Kenski, 2006, p. 123). Obviamente, esa dinámica de renovación del campo de acción estudiantil no quedó desapercibida por la Profesora X, la cual pasó a ocupar la posición de mediadora de rutas de aprendizaje, minimizando la dicotomía entre educador y educando. En esa perspectiva de enseñanza activo y colaborativo, el profesor también aprende mientras enseña, emergiendo la inteligencia colectiva (Lévy, 1999) pautada en la comunicación -dentro y fuera del ciberespacioentre todos los integrantes del proceso. 
La aproximación docente-TDIC y la incorporación pedagógicamente planeada de esas tecnologías a las prácticas de enseñanza propiciarán a la Profesora X un proceso reflexivo, lo cual colaboró para un inicio de (re)significación de sus acciones. Por lo tanto, vale señalar que esos cambios en la rutina pedagógica no acontecieran de forma linear y sin tensiones. Contrariamente, el desplazamiento de la tradición pedagógica implica desafíos que descentralizan la gestión de la construcción del conocimiento y flexibilizan tiempo(s) y espacio(s) de operaciones (Panuci et al., 2016). Fue en esa perspectiva que la Profesora X, durante el proyecto, apenas transmitía informaciones, pero acompañaba e incentivaba la producción de los alumnos en el ciberespacio, planeando rutas de aprendizaje más interactivas y colaborativas.

\subsection{Evaluación del proyecto y perspec- tivas para nuevos trabajos con las TDIC}

El código "Evaluación del Proyecto y perspectivas para nuevos trabajos con las TDIC" fue destinado para el registro de las consideraciones de la Profesora $\mathrm{X}$ sobre nuestra investigación-acción con sus alumnos, apuntando a su validación. En un principio, buscamos comprender cómo la docente evaluó las actividades emprendidas junto a los alumnos. Ya el código "Perspectivas para nuevos trabajos con las TDIC" fue destinado para el registro de las manifestaciones de la profesora con respecto de eventuales trabajos futuros con las TDIC en sus prácticas.

En el análisis de los fragmentos discursivos de la Profesora X referentes a la evaluación de nuestra intervención, la profesora evidenció modificaciones en sus prácticas de enseñanza. La docente relató que el trabajo realizado la motivó a planear actividades didácticamente diferenciadas con los alumnos utilizando las TDIC. Buscamos posibilitar a la docente la percepción del potencial interactivo del ciberespacio, lo cual podría concebir a su proceso de enseñanza la posibilidad de agregar algo nuevo a su cotidiano (Rancière,
2002). En ese aspecto, la Profesora $X$ reforzó que la investigación-acción colaboró para la revisión de su práctica en el sentido de abrir nuevas miradas para tornar sus clases más dinámicas, situadas y significativas:

[054...] una otra ventaja también de ese proyecto fue ese, que rompió ese, ese mi recelo de salir con ellos del aula. Yo salí, todo ocurrió bien y, es eso, pienso yo que (...) enriqueció.

$[065 \ldots]$ esas pequeñas cosas traen diferencia, si, para el salón de clases, (...) porque el ambiente, el día a día en la escuela es muy árido, muy penoso, así, ¿porque es cansado, verdad? (...) esas cosas dan un aire mismo (...) (Profesora X).

Mediante la evaluación final positiva de nuestro proyecto, comprendemos que el planeamiento colaborativo y su implementación gradual y aclarada, unida al soporte pedagógico, pueden favorecer la adopción de nuevas perspectivas para los procesos educacionales mediados con TDIC. Entretanto, no se puede ignorar que la reforma de enseñanza depende de los profesores, de aquello que ellos piensan y hacen en su cotidiano pedagógico, "al final, son los profesores quienes determinan lo que acontece en el salón de clases y de qué formas las innovaciones son, o no, implementadas" (Sandholtz et al., 1997, p. 20).

Nuestra investigación-acción no tuvo como objetivo utilizar las TDIC para replicar la enseñanza pautada en la instrucción. La elección de esa metodología tuvo el propósito de aproximar las prácticas docentes de las TDIC de manera a instigar el potencial del alumno e incentivar la autoría e intercambios de conocimiento. Nuestra intención es la de explorar las funcionalidades de las tecnologías para instigar el potencial cognitivo/creativo de los alumnos y potencializar las acciones pedagógicas de la profesora.

La Profesora $\mathrm{X}$ nos relató que, aunque después de la realización de la investigaciónacción, los alumnos solicitarán nuevos trabajos utilizando las TDIC, sugiriendo una perspectiva para trabajos futuros: “[036...] probablemente, 
eso va a suceder, nosotros vamos hacer otras cosas. (...)" "[099...] vamos más veces, verdad? (...)" (Profesora X).

Creemos que el trabajo emprendido junto a la Profesora X, posibilitó una oportunidad de revisión y/o re significación de su campo de acción y el inicio de un proceso de apropiación pedagógica de las TDIC. Las intervenciones realizadas abrieron perspectivas para nuevos trabajos utilizando el ciberespacio y potencializando autoría, interacción, creación y dialogicidad (Freire, 2005).

\section{Consideraciones finales}

El presente trabajo pretendió contribuir y enriquecer las prácticas pedagógicas de una profesora de enseñanza básica, aproximándola a la cibercultura. Haciendo la aproximación entre docente-TDIC/ ciberespacio, buscamos identificar significados de la profesora sobre el proceso de integración de aquellas tecnologías a sus prácticas de enseñanza.

De las contribuciones de la profesora, identificamos - en su visión - la existencia de pocas Políticas Públicas Educacionales orientada para la inclusión de las tecnologías digitales en las escuelas. En ese sentido, constatamos en la escuela investigada el precario soporte de infraestructura y la inexistencia de apoyo pedagógico dirigida a la orientación de los docentes en actividades con las TDIC. Notamos que, al proponer las actividades con las tecnologías digitales, la Profesora X quedó recelosa en llevar los alumnos para el laboratorio de informática: tanto la profesora como los alumnos no estaban acostumbrados a trabajar de aquella manera. Eso nos sugirió que la propuesta de un trabajo efectivo con las tecnologías digitales y el desplazamiento para un espacio diferente del habitualmente frecuentado podría estar ocasionando un impacto cultural en la profesora. Más aun, la Profesora X comprendió la proposición y la asumió como una oportunidad de revisión de acciones y de formación personal, manteniéndose abierta al planeamiento y comprometida en su efectividad.
Con vivenciar la práctica con TDIC, la Profesora X evaluó positivamente la intervención considerando las actividades como significativas para sus alumnos. La docente tomó como base de su evaluación el hecho de que, aun después de la ejecución del proyecto, los alumnos continuaran a reivindicar nuevas formas de trabajo utilizando las TDIC/ciberespacio. Lo que pasó a estar en juego en la rutina pedagógica fueran las posibilidades de creación, interacción, publicación y comunicación en red. En su apreciación final, la docente nos dejó saber que nuestra investigación-acción y las actividades con las tecnologías digitales contribuyeran para la potenciación de sus acciones pedagógicas.

Consciente de que las acciones proyectadas y emprendidas en esta investigación científica constituyeran apenas una (micro)posibilidad de reflexión para el cambio del cotidiano pedagógico de la Profesora X y de sus alumnos, reiteramos la importancia de los ambientes de producción y socialización del ciberespacio al proceso de enseñanza-aprendizaje. Con todo, rechazamos la visión determinística de que las TDIC/ciberespacio, por sí solo, traerán cambios en la cultura escolar. El factor decisivo en esa aproximación de la escuela y de sus prácticas de la cibercultura recae en las percepciones de los efectos y ganancias pedagógicas por los profesores. Por lo tanto, es necesario que el profesor - por intermedio de la formación inicial y continua - pueda apropiarse de las TDIC de manera para reconfigurar su práctica en el contexto cibercultural. Acreditamos transcurrir de allí posibles transformaciones de comportamiento $y$ resignificaciones, revelando una dinámica continua que involucra readaptación de costumbres, valores, creencias, actitudes y prácticas pedagógicas.

Finalmente, nuestra incursión en campo y las sistematizaciones analíticas nos sugirieran que la revisión de creencias docentes - mediante la presencia y uso pedagógicamente esclarecido de las TDIC/ciberespacio - consolida una posibilidad de superación de la cultura pedagógica transmisora, pautada en recitales, copia, memorización y reproducción de informaciones. 


\section{Apoyo y agradecimientos}

A la Fundação de Amparo à Pesquisa de Minas Gerais (FAPEMIG), por la concesión de beca de Iniciación Científica para la ejecución de la investigación científica.

A la Pro-Rectoría de Pesquisa e Pósgraduación de la Universidad Federal de São João del-Rei (PROPE/UFSJ), que siempre ha sido solícita a nuestras demandas, atendiéndonos con prontitud y puntualidad.

\section{Notas}

1. De acuerdo con Internet World Stats (2018), América Latina posee populación estimada de 647604645 de habitantes, de los cuales 404269163 son usuarios de internet (62,42\%).

2. Registrase que la profesora colaboradora de este estudio firmó un término de consentimiento libre y aclarado, por el cual atestó su participación de manera voluntaria y consciente. La docente tuvo su nombre substituido a lo largo del texto en cumplimento al anonimato previsto en el documento.

3. Los usuarios activos son aquellos que efectuaran login en el Facebook durante los últimos 30 días.

\section{Referencias bibliográficas}

Ally, M., \& Prieto-Blázquez, J. (2014). What is the future of mobile learning in education? Mobile Learning Applications in Higher Education. Revista de Universidad y Sociedad del Conocimiento (RUSC), 11(1), 142-151. http://dx.doi.org/10.7238/rusc.v11i1.2033

Almeida, M. E. B. (2004). Inclusão Digital do Professor: formação e prática pedagógica. São Paulo: Articulação.

Bonilla, M. H. S. (2009). Inclusão digital nas escolas. In A. C. F. Pinheiro, \& M. Ananias (Orgs.), Educação, direitos humanos e inclusão social: histórias, memórias e políticas educacionais (183-200). João Pessoa, Brasil: Editora da UFPB.

Coelho, P. M. F., Costa, M. R. M., \& Mattar Neto, J. A. (2018). Saber Digital e suas Urgências: reflexões sobre imigrantes e nativos digitais. Educação \& Realidade, 43(3), 1077-1094. https://dx.doi.org/10.1590/2175-623674528
Bardin, L. (1977). Análise de conteúdo. Lisboa: Edições 70.

Brasil. (2008). Decreto no 6.424. Brasília, Brasil. Recuperado de https://goo.gl/vNdMk7.

Franco, M. L. P. B. (2008). Análise de Conteúdo. Brasília: Liber Livro Editora.

Freire, P. (2005). Pedagogia do oprimido. Rio de Janeiro: Editora Paz e Terra.

Hanauer, M., \& Abegg, I. (2017). Políticas públicas e programas de incentivo à integração de tecnologias no ensino. Jornal de Políticas Educacionais, 11(16), 1-18. http://dx.doi.org/10.5380/jpe.v11i0.53196

Kenski, V. M. (2006). Tecnologias e ensino presencial e a distância. Campinas, Brasil: Papirus.

Kohan, W. O. (2013). O mestre Inventor. Relatos de um viajante educador. Belo Horizonte: Editora Autêntica.

Lévy, P. (1999). Cibercultura. São Paulo: Editora 34.

Lima, M. R. (2015). Projeto UCA e Plano CEIBAL como possibilidades de reconfiguração da prática pedagógica com as Tecnologias Digitais de Informação e Comunicação. Tese de doutorado em Educação. Universidade Federal de Minas Gerais, Belo Horizonte, MG, Brasil. Recuperado de https://goo.gl/VA8PzV

Maldonado, M. E. (2018). El aula, espacio propicio para el fortalecimiento de competencias ciudadanas y tecnológicas. Sophia, 14(1), 39-50. https://dx.doi.org/10.18634/sophiaj.14v.1i.822

Medeiros, Z. A. (2011). Letramento digital em contextos de autoria na internet. Tese de doutorado em Educação, Universidade Federal de Minas Gerais, Belo Horizonte, MG, Brasil.

Moraes, D., \& Lima, C. (2018). O estudante e sua relação com as tecnologias digitais: Representações em sua aprendizagem. Revista Teias, 19(53), 299-313. https://doi.org/10.12957/teias.2018.33212

Papert, S. (1985). Logo: Computadores e Educação. São Paulo: Brasiliense.

Panuci, L. R., Bianchini, L. G. B., Souza, C. J, Silva, J. B., \& Munhoz, C. M. E. (2016). Interações, Celulares Smartphones e Processos de Ensino e Aprendizagem. Revista de Ensino, Educação e Ciências Humanas, 17(2), 105-111. http://dx.doi.org/10.17921/2447-8733.2016v17n2p105-111 Passarelli, B. (2017). Os desafios do contemporâneo hiperconectado. In B. Medeiros. Neto (org.), 
O cidadão contemporâneo frente às tecnologias da informação e comunicação (17-22). São Paulo: FAC Livros.

Pinto, Á. V. (2005). O conceito de Tecnologia. Rio de Janeiro: Contraponto.

Quintanilha, L. F. (2017). Inovação pedagógica universitária mediada pelo Facebook e YouTube: Uma experiência de ensinoaprendizagem direcionado à geraçãoZ. Educar em Revista, (65), 249-263. https://dx.doi.org/10.1590/0104-4060.50027

Rancière, J. (2002). O mestre ignorante: Cinco lições sobre a emancipação intelectual. Belo Horizonte: Editora Autêntica.

Sandholtz, J. H., Ringstaff, C., \& Dwyer, D. C. (1997). Ensinando com tecnologia: Criando salas de aula centradas nos alunos. Porto Alegre: Artes Médicas.

Santaella, L. (2013) Comunicação ubíqua: Repercussões na cultura e na educação. São Paulo: Editora Paulus.

Serres, M. (2013). Polegarzinha. Rio de Janeiro: Editora Bertrand do Brasil.
Silva, M. (2010). Formação de professores para docência online: Uma pesquisa interinstitucional. Anais do Encontro Nacional de Didática e Prática de Ensino, Belo Horizonte, Brasil, 15.

Souza, A. A. N., \& Schneider, H. N. (2016). Tecnologias digitais na formação inicial docente: Articulações e reflexões com uso de redes sociais. ETD - Educação Temática Digita, 18(2), 418-436. https://doi.org/10.20396/etd.v18i2.8640946

Teixeira, V. (2016). Tecnologia e políticas educacionais: Desafios e contribuições das tecnologias da informação e comunicação em escolas estaduais da cidade de Itaperuna. Texto Livre: Linguagem e Tecnologia, 9(1), 140-159. http://dx.doi.org/10.17851/1983-3652.9.1.140-159

Thiollent, M. (1996). Metodologia da Pesquisa-ação. São Paulo: Cortez Editora.

Valente, J. A. (2011). Um laptop para cada aluno: Promessas e resultados educacionais efetivos. In M. E. B. Almeida, \& M. E. B. B. Prado (Orgs.), O Computador Portátil na Escola (20-33). São Paulo: Avercamp. 


\title{
El impacto de la utilización de la modalidad B-Learning en la educación superior
}

\section{The impact of the use of the B-Learning modality in higher education}

\begin{abstract}
Dra. Estela Núñez-Barriopedro es profesora/investigadora de Comercialización e Investigación de Mercados de la Universidad de Alcalá (España) (estela.nunezb@uah.es) (http://orcid.org/0000-0002-22928147)
\end{abstract}

Dra. Ingrid Miguelina Monclúz es catedrática de la Universidad Autónoma de Santo Domingo (República Dominicana) (imoncluz@gmail.com) (http://orcid.org/ 0000-0001-5115-7268)

Dr. Rafael Ravina-Ripoll es profesor/investigador de Organización de Empresa de la Universidad de Cádiz (España) (rafael. ravina@uca.es) (http://orcid.org/0000-001-7007-3123)

Recibido: 2017-12-23 / Revisado: 2018-04-23 / Aceptado: 2018-05-08 / Publicado: 2019-01-01

\section{Resumen}

Los nuevos escenarios educativos plantean adaptar el proceso de enseñanza-aprendizaje al uso de las TIC -en especial la modalidad semi presencial o B-Learning-, el trabajo en colaboración, el desarrollo de competencias y de competencias comunicativas para satisfacer las necesidades y expectativas de los estudiantes, el mercado laboral y las dinámicas sociales imperantes. El principal objetivo de esta investigación es analizar los condicionantes del proceso de enseñanza-aprendizaje de la universidad latinoamericana para la adopción de los nuevos planteamientos educativos. El diseño de la investigación es mixto con triangulación recurrente DITRIAC. En la fase cuantitativa el método empleado es descriptivo-transversal, a través de cuestionario con Escala de Likert a 50 profesores, 402 estudiantes y 6 autoridades. En la fase cualitativa el método fue etnográfico. Se realizaron entrevistas semiestructuradas a 10 docentes, 38 estudiantes y dos autoridades, con análisis descriptivos e interpretativos. Entre las principales conclusiones se vislumbra la nece- sidad de fomentar el factor social del aprendizaje y darle mayor protagonismo al estudiante. Los recursos empleados son tradicionales y analógicos. Los docentes acusan cambios en su práctica docente, pero poco en la inclusión de las TIC. Asimismo, los tres aspectos que más le cuesta cambiar a los docentes en su paso de la modalidad presencial a la B-learning son: dejarle el protagonismo al estudiante, cambiar de la clase transmisiva al aprendizaje colaborativo, y de la evaluación sumativa a la formativa.

Descriptores: B-learning, proceso enseñanzaaprendizaje, educación superior, aprendizaje colaborativo, competencias comunicativas, evaluación.

\begin{abstract}
The new educational scenarios propose to adapt the teaching-learning process to the use of ICT, especially the semi-classroom or B-learning modality, the work in collaboration, the development of competences and communication skills to meet the needs and expectations of the students, the labor market and the prevailing
\end{abstract}

Forma sugerida de citar: Núñez-Barriopedro E., Monclúz I. M., \& Ravina-Ripoll R. (2019). El impacto de la utilización de la modalidad B-Learning en la educación superior. Alteridad, 14(1), 26-39. https://doi.org/10.17163/alt.v14n1.2019.02. 
social dynamics. The main objective of this research is to analyze the conditioning factors of the teaching-learning process of the Latin American university for the adoption of new educational approaches. The research design is mixed with recurrent triangulation DITRIAC. In the quantitative phase, the method used is descriptive-transversal, through questionnaire with Likert Scale to 50 teachers, 402 students and 6 authorities. In the qualitative phase the method was ethnographic. Semi-structured interviews were conducted with 10 teachers, 38 students and 2 authorities, with descriptive and interpretative analysis. Among the main conclusions is the need to promote the

\section{Introducción y Estado de la cuestión}

Las autoridades y organismos que regulan las instituciones de educación superior, las universidades, los propios actores del proceso de enseñanza-aprendizaje y la sociedad en general, consideran la oferta formativa universitaria mejorable, al percatarse que las necesidades y expectativas de los estudiantes, del mercado laboral y de la sociedad en general no se satisfacen adecuadamente. $\mathrm{Y}$ desde todos estos frentes se externan posibles soluciones (UNESCO, 1998; SEESCyT, 2008; UASD, 2013).

Como consecuencia, los paradigmas educativos en educación superior han sufrido en las últimas décadas grandes transformaciones (Iborra \& Izquierdo, 2010; Núñez \& Vilchez, 2017). Algunas de estas transformaciones provienen no solo de la psicología educativa (Woolfolk, 2006), sino también de las didácticas de las diferentes disciplinas. Pero la más trascendental, sin lugar a dudas, ha sido la irrupción de las TIC (Tecnologías de la Información y la Comunicación) en la educación; en especial el Internet, la Web 2.0 o Red Social con los correos electrónicos, foros, wikis, blogs, Twitter $\mathrm{y}$ ahora las plataformas educativas y la Web 3.0 (realidad virtual o realidad aumentada) (Barriopedro, Valiño \& Leguía, 2012; Núñez, Penelas \& Cuesta, 2014). social factor of learning and give greater prominence to the student. The resources used are traditional and analog. Teachers accuse changes in their teaching practice, but little in the inclusion of ICT. Likewise, the three aspects that are most difficult for teachers to change in their faceto-face modality modality are: leaving the protagonism to the student, changing from the transmissive class to collaborative learning, and from the summative evaluation to the formative one.

Keywords: B-learning, teaching-learning process, higher education, collaborative learning, communicative skills, evaluation.

En cuanto al área de Enseñanza de Lengua Española (ELE), se está considerando que el texto escrito y la normativa ya no bastan para enseñar Lengua Española por la creación de nuevas categorías del discurso, la modificación de la escritura y su combinación con otros tipos textuales (Cassany, 2012). Completa este panorama el que una de las finalidades de la asignatura Lengua Española es potenciar las competencias comunicativas de los estudiantes para su socialización y desarrollo cognoscitivo.

Como solución a lo antes expuesto, los expertos proponen implementar el B-learning en el nivel superior bajo el paradigma del enfoque por competencias, el desarrollo de competencias comunicativas y el empleo de métodos que fomenten el aprendizaje colaborativo, bajo los siguientes alegatos.

- El B-learning presenta en la sociedad digital muchas ventajas para la educación superior, entre ellas se puede poner a disposición de los alumnos un amplio volumen de información y contenidos fácilmente actualizables. Así como, flexibilizar la información, independientemente del espacio y el tiempo en el cual se encuentren el profesor y el estudiante. También, permite la deslocalización del conocimiento; facilita la autonomía del estudiante; propicia una formación just in time y just for me; entre otras (Cabero \& Román, 
2008). Según las tendencias educativas de los últimos años en educación superior, el aprendizaje semipresencial o B-learning (Blended Learning) es el más recomendado para el logro de las nuevas competencias (Llorente, 2009; Johnson, Becker, Estrada, \& Freeman, 2015).

- El aprendizaje colaborativo ayuda a los estudiantes a su desarrollo cognitivo y pensamiento crítico, desarrollo socioafectivo y equilibrio emocional, desarrollo de las destrezas sociales, democratización de las oportunidades del éxito académico, entre otras ventajas (Moruno, Sánchez \& Zariquiey, 2011).

- El aprendizaje por competencias proporciona mayor flexibilidad, más inclusividad al ser más individualizada, más objetividad en las evaluaciones, busca el desarrollo holístico de los educandos, fomenta el trabajo colaborativo y los aprendizajes son contextualizados, entre otras muchas ventajas (Zabala \& Arnau, 2014).

- La vida en sociedad conlleva comunicación; hoy día se escribe y lee más que nunca, y los géneros discursivos se amplían, así como los medios; pero también es cierto que se observa un progresivo cambio en las formas de comunicarse de los usuarios de la lengua. La educación formal debe asumir el compromiso de ajustarse a las necesidades comunicativas de los hablantes (Cassany, 2012; Lomas, Osoro \& Tusón, 2002).

\subsection{Nuevas retos, nuevos roles y nuevas asunciones}

Se reconoce que la excelencia de un sistema educativo no puede ser superior a la calidad de sus profesores, ya que los resultados obtenidos por los estudiantes dependen en gran medida de la capacidad del docente, y la mejoría del rendimiento académico se logra elevando la calidad de la instrucción (Tiana, 2013). La educación en el siglo XXI exige un cambio curricular que trae aparejado un cambio actitudinal y de compromiso del docente que es el agente catalizador de las reformas e innovaciones en las aulas. Porque las nuevas tendencias y corrientes educativas demandan la formación de ciudadanos críticos y transformadores de un mundo donde la ética y los valores primen, coexistiendo con las tecnologías y el cuidado del ambiente, en un clima democrático, igualitario y con un desarrollo holístico (De la Torre \& Barrios, 2000; Carbonell, 2015). Por tales razones, los docentes deben fomentar la autonomía de los estudiantes, organizar la cultura que pretenden enseñar, conocer y ejecutar estrategias de enseñanza que ayuden a los estudiantes a generar, gestionar y evaluar los conocimientos, unido al manejo de medios y recursos didácticos y de organización del entorno de aprendizaje adecuados a las circunstancias y características de todos y cada uno de los estudiantes (Jiménez Rodríguez, 2011; Brown \& Pickford, 2013). Para lograr los fines teleológicos, gnoseológicos y epistemológicos que impone el acto educativo, el docente debe actuar reflexivamente (Perrenoud, 2007), fundamentado en la reflexión e indagación conjunta entre docentes y estudiantes para dialogar, revisar sus concepciones, creencias, valores y supuestos en los que apoyan las clases (Margalef, Iborra, Pareja, Castro, Domínguez, García \& Giménez, 2007), aplicando la criticidad a todos los actos que realice ya sean en la clase, para la clase o por la clase, pues la educación no es un producto acabado (Durkheim, 1976).

Tras ese ejercicio reflexivo el docente debe proponer modelos de actuación que involucren el aprendizaje colaborativo, activo, reflexivo, autónomo y constructivista del alumno (Zabala \& Arnau, 2014). A su vez, Iborra e Izquierdo (2010), creen que para el éxito de este cambio se necesita un proceso de reacomodación, donde se enfatice la inclusión de elementos que incrementen la motivación, la creatividad, la innovación, la felicidad y la responsabilidad de los estudiantes en sus procesos de aprendizajes para el uso óptimo y eficaz de estrategias de enseñanza y 
aprendizaje (Galiano \& Ravina, 2017). Pero es más fácil decirlo que hacerlo, pues el problema es más conceptual que operativo, porque tiene que ver más con los cambios en la forma del docente pensar la enseñanza y el aprendizaje y su papel en ese cometido (Zabalza, 2011). Este cambio debe darse a lo interior de las universidades, "partir del análisis de las dinámicas culturales y los justificantes que entran en juego entre la estabilización del status quo y las fuerzas dialécticas, teniendo siempre presente sus inquietudes y necesidades, utilizando las herramientas que demanda el contexto" (Gairín, 2012, p. 39).

Emplear las TIC e implementar el B-learning en las instituciones de formación afecta la metodología, las estrategias didácticas, el acceso y distribución de los materiales, la estructura organizativa, y los roles tradicionales de docentes y estudiantes (Cabero \& Márquez, 1999). Por tales razones se propone el análisis de la realidad de los docentes de la universidad latinoamericana, en este caso, de la Universidad Autónoma de Santo Domingo (UASD), como forma de adecuar la oferta formativa a los estándares necesarios para el logro de clases en B-learning, como es la tendencia a nivel mundial.

\subsection{Características de la modalidad semipresencial}

La modalidad semipresencial posee características que le confieren su identidad propia y no ser una mera superposición o solapamiento de estrategias $y$ actividades inconexas en el aula y en la red. Entre esas características se encuentran (Llorente, 2009; Cabero \& Márquez, 1999) las siguientes:

- Confluencia o combinación de espacios y tiempos (presencial y no presencial).

- El escenario es una continuidad porque permite comunicación síncrona y asíncrona, en tiempo real y diferido, de acuerdo a las necesidades y posibilidades del usuario, y la naturaleza del tema (comunicación cara a cara en el aula, correo, chat, videoconferencias, wiki, blog, microblogging, etc.).

- Mezcla de ambiente físico (aula, pasillos, cafetería, parques, biblioteca) y soporte virtual (aula virtual y toda la Web 2.0 y 3.0).

- Mezcla de tecnologías y recursos analógicos y digitales (libros, revistas, PDF, animaciones, videoconferencias, etc.).

- Mezcla de enfoques y metodologías (conductismo, constructivismos, conectivismo, clase expositiva, trabajo colaborativo, ABP, por proyectos, etc.; análisis de los objetivos de aprendizaje que se pretenden, la teoría que explica mejor ese proceso de aprendizaje, y la tecnología que más se adecua a esa necesidad).

- Fomenta experiencias de aprendizaje, su apropiación y socialización (presenciales y en EVA).

- Permite plantear variadas formas de representaciones de la realidad en contextos diversificados.

- Facilita los procesos de construcción del conocimiento y la metacognición.

- La información relevante la presenta de forma dinámica y modular.

- Altamente interactivo, con el programa y otras personas (tutor-estudiante, estudiante-tutor, estudiante-estudiante).

- Fomenta el aprendizaje autónomo y la toma de decisiones.

- Fomenta el aprendizaje complejo, donde se aprende del error y se recompensa el acierto con retroalimentaciones positivas.

- Presenta reportes de los progresos de los estudiantes.

- Aprendizaje ubicuo por la facilidad que ofrecen los dispositivos móviles a las personas de capacitarse a cualquier hora y en cualquier lugar.

- Convergen en el mismo ambiente de aprendizaje tecnologías, redes y contenidos a disposición del estudiante en todo momento. 


\section{Material y métodos}

La complejidad del proceso de enseñanza-aprendizaje ha hecho que se aborde el tema de investigación bajo enfoques y perspectivas diferentes, pero complementarios. Por una parte, el enfoque cualitativo y por otra parte, el enfoque cuantitativo. Este último enfoque permite medir y ponderar opiniones, actitudes, actividades, estrategias empleadas, entre otros, de diferentes fuentes, herramientas, estamentos y enfoques, da una idea más acabada de la realidad objeto de investigación, un conocimiento más profundo y generalizable, pues los datos son "más ricos y variados" (Hernández Sampieri, Fernández Collado \& Baptista, 2008, p. 756). En la tabla 1, se expone la metodología empleada.

Tabla 1. Metodología empleada en la investigación

\begin{tabular}{|c|c|}
\hline \multicolumn{2}{|c|}{$\begin{array}{c}\text { Investigación mixta } \\
\text { Triangulación Recurrente DITRIAC (Cresswell, 1994) }\end{array}$} \\
\hline Fase cuantitativa & Fase cualitativa \\
\hline Método: descriptivo-transversal & Etnográfico, educativo, interpretativo. \\
\hline $\begin{array}{l}\text { Técnicas: Cuestionarios Escala de Likert } \\
\text { ( } 1=\text { negativo, } 3=\text { neutro, } 5=\text { positivo) }\end{array}$ & $\begin{array}{l}\text { Entrevistas semiestructuradas, análisis de fotografías, } \\
\text { impresiones investigadora }\end{array}$ \\
\hline $\begin{array}{l}\text { Análisis: Estadístico de frecuencias, desviación, regresión, } \\
\text { correlación y clúster K-media (SPSS 22.0) }\end{array}$ & $\begin{array}{l}\text { Descriptivo, analítico, interpretativo, categorización, ma- } \\
\text { trices, conceptualización (Atlas.ti 7.0) }\end{array}$ \\
\hline
\end{tabular}

Universo: 87 docentes, aprox. 5,655 estudiantes y siete autoridades

Población y muestra: 50 docentes, 402 estudiantes y seis autoridades

Seis docentes, 38 estudiantes y dos uncionarios

Ámbito geográfico: sede central de la Universidad Autónoma de Santo Domingo (UASD), en 35 edificios diseminados en el Gran Santo Domingo (República Dominicana). Feb.-junio 2015.

Validación: por expertos, prueba piloto, fiabilidad Alfa de Cronbach, Coeficiente de Spearman-Brown y dos mitades de Guttman.
Triangulación mixta: entre

métodos-teoría-estamentos-instrumentos.

Fuente: elaboración propia

La presente investigación se enmarca en el ámbito geográfico de la República Dominicana, concretamente en la Universidad Autónoma de Santo Domingo (UASD), como ejemplo a otros contextos en situaciones similares. Para el presente trabajo se seleccionó a la Universidad Autónoma de Santo Domingo (UASD), por ser la más antigua (fundada en 1538), la de mayor número de estudiantes (casi el 50\% de la matrícula universitaria), por ser estatal y de fácil acceso a los estudiantes con menos recursos.

Las asignaturas programadas por UASDVirtual en modalidad virtual y semipresencial fueron 71 asignaturas, distribuidas en: 23 en la Facultad de Ciencias; 13 en la Facultad de Ingeniería y Arquitectura; 8 en la Facultad de Ciencias Económicas y Sociales; 8 en la Facultad de Humanidades; 6 en la Facultad de Ciencias Jurídicas y Políticas; 5 en la Facultad de Ciencias de la Salud; 4 en la Facultad de Artes; 4 en la Facultad de Ciencias de la Educación. Se piensa aumentar gradualmente el número de asignaturas y secciones en modalidades virtual y semipresencial. La meta a mediano plazo es tener en línea dos asignaturas en modelo virtual por facultad; eso representaría 18 asignaturas con varios grupos o secciones cada una. La meta a largo plazo es que el $50 \%$ de las asignaturas se oferten en modalidad virtual a fin de descongestionar las aulas y aligerar la carga 
docente presencial. La oferta de asignaturas en estas modalidades aumenta de forma sostenible, pero no se verifica en la Escuela de Letras. Esta ausencia nos motivó a iniciar esta investigación, por ir contra la tendencia global en la modalidad semipresencial. Y cabe preguntarse si esta ausencia se debe a falta de personal calificado para desarrollar el proceso de enseñanza y aprendizaje en los Entornos Virtuales de Aprendizaje o a que se resta importancia al uso de las TIC con fines educativos.

Para validar el método mixto apelamos a respetar las características tanto del método cuantitativo como del método cualitativo (validez interna), adecuamos ambos métodos a las preguntas de investigación, al objetivo general y a los objetivos específicos de la investigación (validez externa), y explicamos las coincidencias y discrepancias en los resultados obtenidos con cada método (validez de los instrumentos) (Hernández Sampieri et al., 2008, p. 795). En cuanto a la fiabilidad de los cuestionarios empleados en la metodología cuantitativa recurrimos a comprobar según criterios estadísticos. Aplicamos las pruebas Alfa de Cronbach, Coeficiente de dos mitades de Guttman, Coeficiente de Spearman-Brown. Los resultados obtenidos fueron muy buenos, ya que el cuestionario de los estudiantes en el Alfa de Cronbach el valor fue de .949 y .925 lo que lo ubica como excelente, lo que demuestra una alta consistencia interna entre los ítems reflejando que miden un mismo constructo y que están altamente relacionados. Lo mismo se observa en la salida de SPSS del cuestionario de los docentes (.985 y .919). En cuanto a la correlación de Spearman-Brown las longitudes en el cuestionario de los estudiantes quedaron en .723 y el coeficiente de dos mitades de Guttman fue de .717; en el cuestionario de los docentes ambos valores fueron de .912 y .775 , respectivamente, lo que lo califica también como buena la correlación entre los ítems.

Según la Universidad Autónoma de Santo Domingo (UASD) existe un promedio de 65 estudiantes por sección de clase. Si tenemos 87 docentes y tomamos una sección de cada docente, con un promedio de 65 alumnos por sección, entonces el universo aproximado sería de 5655 estudiantes. De este universo se tomó una muestra aleatoria estratificada simple. Finalmente, la muestra obtenida fue de 50 docentes, 402 estudiantes y seis autoridades. se distribuye de la siguiente forma: 246 cursan el nivel 1 de LEB y 51 estudian LEB II (81,5\% y 16,9\% respectivamente), en relación al género el $54,6 \%$ pertenecen al género femenino y $45,4 \%$ al masculino.

Los objetivos principales de esta investigación son, primero, establecer los rasgos fundamentales definidores del proceso de enseñanzaaprendizaje en una institución de educación superior en la modalidad presencial y las variables críticas a considerar para, segundo, analizar cómo implementar el b-learning para mejorar las competencias comunicativas de los estudiantes a través del aprendizaje colaborativo en las dos vertientes de esta modalidad. La acción de migrar LEB de presencial a semipresencial en la Universidad Autónoma de Santo Domingo (UASD), debe cumplir ciertos requisitos que en esta investigación que procuramos determinar a través de dar respuesta a las hipótesis:

H1: Los docentes de educación superior del área de LEB se diferencian de modo significativo en la metodología que emplean en clases.

$\mathrm{H} 2$ : Los docentes consideran que se deben introducir cambios en el proceso de enseñanza-aprendizaje de LEB, en especial incluir las TIC, factor positivo para la implementación del B-learning.

H3: En los profesores del área de LEB se observan tendencias al cambio en su práctica docente.

Para demostrar la hipótesis H1 se realiza un clúster K-medias para determinar la homogeneidad de los grupos antes señalados y las diferencias intergrupales para determinar las metodologías y la cantidad de docentes que las practican. Se elige el análisis clúster K-medias 
porque todas las variables que agrupamos son cuantitativas y la distancia cuadrática euclídea simple es adecuada para determinar la similitud entre los objetos que buscamos comparar. Las preguntas empleadas en este clúster fueron las $7,8,9,10,13,21$ y 30 que miden las variables Planificación, Métodos y Modalidades de Enseñanza, Estrategias de Enseñanza, Recursos Utilizados, Competencias Perseguidas y Tipos de Evaluaciones, respectivamente. Las escalas de evaluación fueron $1=$ Nunca, $2=$ Casi nunca, $3=$ A veces sí, a veces no, $4=$ Casi siempre y $5=$ Siempre, excepto en la pregunta \# 8, de escala $1=$ No lo aplico, 2= Muy poco uso, $3=$ Poco uso, $4=$ Uso moderado y $5=$ Mucho uso.

Para la demostración de la $\mathrm{H} 2$ se comparan las medias de las preguntas 11 del cuestionario de los docentes y 28 del cuestionario de los funcionarios de UASDVirtual.

En la demostración de la $\mathrm{H} 3$ se cruzaron las preguntas 5 (Variación en la Práctica Docente) con la pregunta 6 (Causas Variación en la Práctica Docente), para determinar la correlación existente entre estas dos variables a través del método estadístico R de Pearson.

Seguidamente se detallan los constructos empleados con los correspondientes ítems.

Constructo 7- Al planificar la asignatura de Lengua Española Básica tomo en cuenta:

1. La misión y visión de la institución.

2. Los objetivos del programa y las unidades.

3. Las necesidades y particularidades de los estudiantes

4. Los requerimientos de la sociedad y del mercado laboral

5. La función tradicional de la asignatura de enseñar reglas y análisis gramatical

6. Las competencias que deben desarrollar mis estudiantes para ser, hacer y convivir en un mundo cambiante

7. Formular los objetivos como capacidades y valores

8. Proporcionar los contenidos correctos para el logro de los objetivos
9. La parte afectiva, emocional y motivacional de mis estudiantes

10. Tener altas expectativas de logro con relación a mis estudiantes

Otro constructo es el correspondiente a la variable 9- Las estrategias de enseñanza que empleo con mejores resultados para mis estudiantes son, con los siguientes ítems:

1. Objetivos

2. Ilustraciones

3. Preguntas intercaladas

4. Señalizaciones

5. Resúmenes

6. Organizadores previos

7. Analogías

8. Mapas y redes conceptuales

9. Organizadores textuales

10. Discusión guiada

11. Diagramas

12. Cuadros CQA

13. Cuadros sinópticos

14. Situaciones problemáticas

15. Análisis de casos

16. Simulaciones

17. Cuestionarios

La variable 10- Los recursos que utilizo para impartir Lengua Española Básica I y II son, con los siguientes ítems:

1. Libros de texto

2. Libros de consulta

3. Diccionarios

4. Obras literarias

5. Periódicos

6. Revistas

7. Internet

8. Problemas del contexto

9. Proyectores

10. Televisión

11. DVD

12. Plataforma virtual

13. Computadoras 
14. Pizarra interactiva

15. Pizarra y tiza

16. Wikis

17. Blogs

18. Foros

19. Redes sociales

En relación a la opinión de los docentes sobre las competencias que buscan desarrollar en sus estudiantes, 13- Por los ejercicios que pongo, el tipo de evaluación que empleo y el trato con mis estudiantes, busco desarrollar en ellos, con los siguientes ítems:

1. Capacidad de análisis y síntesis de textos y situaciones.

2. Capacidad para organizar y planificar sus clases.

3. Conocimientos básicos del mundo en que vive.

4. Conocimientos básicos de la profesión que estudia.

5. Su comunicación oral y escrita.

6. Habilidades básicas en el manejo de la computadora.

7. Habilidades para buscar y analizar las informaciones que encuentra.

8. Habilidades para la resolución de problemas.

9. Habilidades para la toma de decisiones.

10. Desarrollar su capacidad crítica y autocrítica.

11. Que aprenda a trabajar en equipo.

12. Incrementar sus habilidades interpersonales.

13. Capacitarle para trabajar en un equipo con personas de diferentes disciplinas.

14. Que aprecie la diversidad y multiculturalidad.

15. Que tenga compromiso ético.
Y la última variable latente es la 21- Para verificar el grado de aprovechamiento de mis cursos, aplico las siguientes evaluaciones a mis estudiantes, con los siguientes ítems:

1. Evaluación diagnóstica.

2. Evaluación formativa.

3. Evaluación sumativa.

4. Autoevaluación de los estudiantes.

5. Coevaluación entre los estudiantes.

\section{Análisis y resultados}

H1: Los docentes de educación superior del área de LEB se diferencian de modo significativo en la metodología que emplean en clases.

Al diseñar los diferentes ítems de los cuestionarios, se consideran cinco posibilidades de respuestas acordes a los cinco paradigmas educativos planteados en la parte teórica: 1) el paradigma de la enseñanza tradicional, que en el área de Lengua representa lo que se llama la gramática tradicional; 2) el paradigma conductista, de Skinner y Pavlov, el cual equiparamos con el estructuralismo saussureano y postsaussureano; 3) el paradigma cognitivista, que asimilamos en él a la gramática generativa de Noam Chomsky; 4) los diferentes estructuralismos, desde Piaget hasta Vygostky, abarcamos aquí la lingüística textual y la semiótica; y 5) el paradigma de las competencias, que lo representamos con los enfoques funcionales y comunicativos en la enseñanzaaprendizaje de lengua. En la Tabla 2 se observan los ítems donde más diferencias se dan entre los docentes en cuanto a sus metodologías.

Tabla 2. Clúster tipos de docentes por sus metodologías

\begin{tabular}{|c|c|c|c|c|c|c|c|}
\hline Tipología de & & fu & $\begin{array}{l}\text { sus op } \\
\text { Válid }\end{array}$ & es st & s $\mathbf{m}$ & ogías qu & lean \\
\hline \multirow{2}{*}{ Ítems } & \multicolumn{5}{|c|}{ Centros Clústeres Finales } & \multirow{2}{*}{$\begin{array}{c}\text { ANOVA } \\
F\end{array}$} & \multirow{2}{*}{$\begin{array}{c}45 \text { Gl. } \\
\text { Sig. }\end{array}$} \\
\hline & 1 & 2 & 3 & 4 & 5 & & \\
\hline $\begin{array}{l}\text { P. } 27 \text { Planificación } \\
\text { 1- NecPartEst }\end{array}$ & 5 & 5 & 5 & 3 & 5 & 21.099 & .000 \\
\hline 2- ReqSocMerLab & 4 & 5 & 3 & 4 & 1 & 11.069 & .000 \\
\hline
\end{tabular}




\begin{tabular}{|c|c|c|c|c|c|c|c|}
\hline 3- ComSerHacCon & 5 & 5 & 4 & 3 & 5 & 11.299 & .000 \\
\hline 4- FormObjCapVal & 5 & 5 & 4 & 3 & 1 & 29.411 & .000 \\
\hline 5- ParaAfeEmoMotEst & 4 & 5 & 4 & 4 & 1 & 21.516 & .000 \\
\hline 6- AltExpLogEst & 5 & 5 & 4 & 3 & 1 & 59.977 & .000 \\
\hline \multicolumn{8}{|c|}{ MODELO Y MÉTODO: } \\
\hline 1- EstCasos & 4 & 4 & 3 & 4 & 3 & 4.571 & .004 \\
\hline 2- AprOriProy & 4 & 4 & 3 & 3 & 1 & 6.071 & .001 \\
\hline 3- AprCoop & 3 & 5 & 4 & 3 & 4 & 9.453 & .000 \\
\hline 4- ClasPráct & 4 & 5 & 5 & 3 & 5 & 14.300 & .000 \\
\hline \multicolumn{8}{|c|}{ ESTRATEGIAS DE ENSEÑANZA: } \\
\hline 1- EstPregInterc & 2 & 4 & 4 & 3 & 3 & 6.639 & .000 \\
\hline 2- EstSeñaliz & 4 & 4 & 2 & 4 & 3 & 3.931 & .008 \\
\hline 3- EstResumen & 4 & 4 & 4 & 4 & 1 & 4.212 & .006 \\
\hline 4-EstOrgPrev & 4 & 4 & 3 & 4 & 3 & 3.956 & .008 \\
\hline 5- EstMapRedConc & 5 & 4 & 3 & 3 & 3 & 6.021 & .001 \\
\hline 6- EstOrgText & 5 & 5 & 4 & 3 & 1 & 5.663 & .001 \\
\hline 7- EstDiscGuia & 5 & 5 & 4 & 3 & 4 & 5.398 & .001 \\
\hline 8- EstCuadCQA & 4 & 3 & 2 & 3 & 1 & 5.398 & .001 \\
\hline 9- EstCuadSinóp & 4 & 4 & 3 & 3 & 2 & 4.529 & .004 \\
\hline \multicolumn{8}{|c|}{ RECURSOS EMPLEADOS } \\
\hline 1- UsoLibCons & 5 & 4 & 4 & 3 & 3 & 4.791 & .003 \\
\hline 2- UsoObrLit & 5 & 4 & 4 & 3 & 3 & 6.283 & .000 \\
\hline 3- UsoPeriod & 4 & 4 & 3 & 3 & 3 & 5.174 & .002 \\
\hline 4- UsoRevist & 4 & 4 & 3 & 3 & 1 & 5.802 & .001 \\
\hline 5- Usolnternet & 5 & 4 & 4 & 3 & 4 & 4.077 & .007 \\
\hline 6- UsoProyect & 5 & 4 & 4 & 4 & 1 & 8.031 & .000 \\
\hline 7- UsoProbCont & 4 & 3 & 3 & 3 & 1 & 3.220 & .021 \\
\hline 8- UsoTV & 4 & 2 & 2 & 2 & 2 & 4.993 & .002 \\
\hline 9- UsoDVD & 4 & 2 & 2 & 3 & 1 & 4.314 & .005 \\
\hline 10- UsoPlatVirt & 4 & 2 & 2 & 3 & 1 & 6.367 & .000 \\
\hline 11- UsoPizIntera & 4 & 2 & 2 & 3 & 1 & 3.420 & .016 \\
\hline 12- UsoWikis & 4 & 2 & 2 & 3 & 1 & 4.650 & .003 \\
\hline 13- Foros & 4 & 2 & 2 & 3 & 1 & 3.989 & .008 \\
\hline \multicolumn{8}{|c|}{ COMPETENCIAS A FOMENTAR: } \\
\hline 1- CapAnáSinTexSit & 4 & 5 & 4 & 3 & 4 & 5.088 & .002 \\
\hline 2- CapOrgPlanClas & 4 & 5 & 3 & 3 & 3 & 9.665 & .000 \\
\hline 3- ConocBásMund & 4 & 5 & 4 & 4 & 5 & 8.505 & .000 \\
\hline 4- ConBásProfEst & 4 & 5 & 4 & 3 & 5 & 11.540 & .000 \\
\hline 5- ComOralEsc & 4 & 5 & 5 & 4 & 5 & 6.941 & .000 \\
\hline 6- HabBuscAnallnf & 5 & 5 & 4 & 3 & 3 & 12.583 & .000 \\
\hline 7- HabResProb & 4 & 5 & 4 & 3 & 3 & 8.266 & .000 \\
\hline
\end{tabular}




\begin{tabular}{|c|c|c|c|c|c|c|c|}
\hline 8- HabTomaDec & 4 & 5 & 4 & 3 & 1 & 28.178 & .000 \\
\hline 9- DesCapCrítAutoc & 5 & 5 & 5 & 3 & 5 & 8.602 & .000 \\
\hline 10- AprenTrabEquip & 5 & 5 & 4 & 3 & 3 & 18.519 & .000 \\
\hline 11- IncrHablnterp & 4 & 5 & 4 & 3 & 1 & 35.264 & .000 \\
\hline 12- CapTraEquilnterd & 4 & 5 & 3 & 4 & 1 & 10.510 & .000 \\
\hline 13- ApreDivMulticult & 4 & 5 & 4 & 3 & 3 & 8.842 & .000 \\
\hline 14- CompÉtica & 5 & 5 & 5 & 3 & 4 & 26.166 & .000 \\
\hline \multicolumn{8}{|c|}{ SISTEMA DE EVALUACIÓN } \\
\hline 1- EvalDiagn & 3 & 5 & 4 & 3 & 4 & 7.567 & .001 \\
\hline 2- EvalFormat & 5 & 5 & 4 & 3 & 3 & 5.940 & .000 \\
\hline 3- EvalSumat & 4 & 5 & 5 & 4 & 1 & 17.844 & .000 \\
\hline 4- AutoEvalEst & 3 & 4 & 3 & 3 & 1 & 6.508 & .000 \\
\hline 5- CoevalEst & 4 & 4 & 3 & 3 & 1 & 4.884 & .002 \\
\hline Total Sumatoria Medias & 328 & 321 & 277 & 270 & 204 & & \\
\hline $\begin{array}{l}\text { Total de Número de Casos } \\
\text { en Cada Clúster }\end{array}$ & $\begin{array}{l}3 \\
6 \%\end{array}$ & $\begin{array}{l}33 \\
66 \%\end{array}$ & $\begin{array}{l}8 \\
16 \% \\
\end{array}$ & $\begin{array}{l}5 \\
10 \% \\
\end{array}$ & $\begin{array}{l}1 \\
2 \%\end{array}$ & & \\
\hline TIPOLOGÍAS & 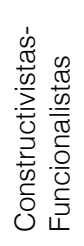 & 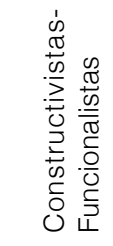 & 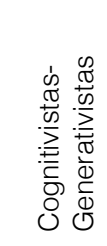 & 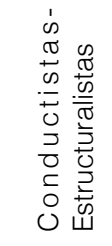 & 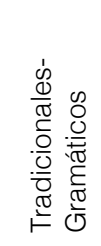 & & \\
\hline
\end{tabular}

\section{Fuente: elaboración propia}

Al realizar el clúster para agrupar a los docentes a partir de sus paradigmas educativos, encontramos que la mayor cantidad de ellos se ubican en el Grupo 2, profesores con perfil constructivista (33 sujetos, $68 \%$ del total), le siguen los profesores con tendencia cognitivista (Grupo 3 , con 8 individuos para el $16 \%$ de la muestra), luego continúan los docentes con tendencia conductista (Grupo 4, 5 docentes, un 10\% de los encuestados), en cuarto lugar están los profesores que emplean metodologías y modelos por competencias (Grupo 1, 3 profesores, para el 6\%); y en último lugar, con un $2 \%$, pues sólo un docente pertenece al Grupo 5, está el modelo de enseñanza tradicional, la tendencia a enseñar gramática.

H2: Los docentes consideran que se deben introducir cambios en $L E B$, en especial incluir las TIC, factor positivo para la implementación del $B$-learning respectivamente se analizaron la pregunta 11 del cuestionario aplicado a los docentes que mide la variable Opinión sobre Cambios en el Programa de la Asignatura, y la pregunta 28 del cuestionario aplicado a los funcionarios de UASDVirtual, que mide la variable Resistencia al Cambio de Paradigma en B-learning de los Docente. Según los análisis univariables, los cambios que los docentes marcaron como necesarios en el programa de LEB están, según las medias, en primer lugar, incluir más actividades con TIC (4.22), Cambiar en el uso de estrategias (3.96), Las competencias a lograr en los estudiantes (3.91), Los objetivos a lograr (3.88) y El sistema de evaluación (3.87). También obtuvieron media por encima de 3.5, cambiar: Los recursos, Los temas, El enfoque pedagógico y La parte metodológica. Asimismo, según UASDVirtual, el organismo encargado de ofertar las asignaturas en modalidad virtual y semipresencial, en la variable Problemas Para el Cambio al B-learning, los problemas más acuciantes son: Dejarle el protagonismo al estu- 
diante (4.67), Cambiar de la clase transmisiva al aprendizaje colaborativo (4.67), y Cambiar de la evaluación sumativa a la formativa (4.67).

H3 En los profesores de LEB se observan tendencias al cambio en su práctica docente se cruzaron las medias de la pregunta 5 (Variación en la Práctica Docente) con las medias de la pregunta 6 (Causas Variación en la Práctica Docente), para determinar la correlación existente entre estas dos variables a través del método estadístico $\mathrm{R}$ de Pearson. El análisis arrojó que existe una moderada relación positiva, casi fuerte, de una aceptación del 99\% entre la reflexión y el cambio metodológico (.675 con .000 de significancia); entre la reflexión y el cambio conceptual (.591 con .000 de significancia); entre la reflexión y el uso de materiales (.562 con significancia de .000); así como entre la reflexión y la forma de relacionarse con los estudiantes (.577 con significancia de .000) y la reflexión y la actualización a las nuevas corrientes pedagógicas (.487 con significancia de .000). En el uso de las TIC no se de una relación significativa en el cambio.

Tabla 3. Correlación cambios y causa de los cambios en los docentes

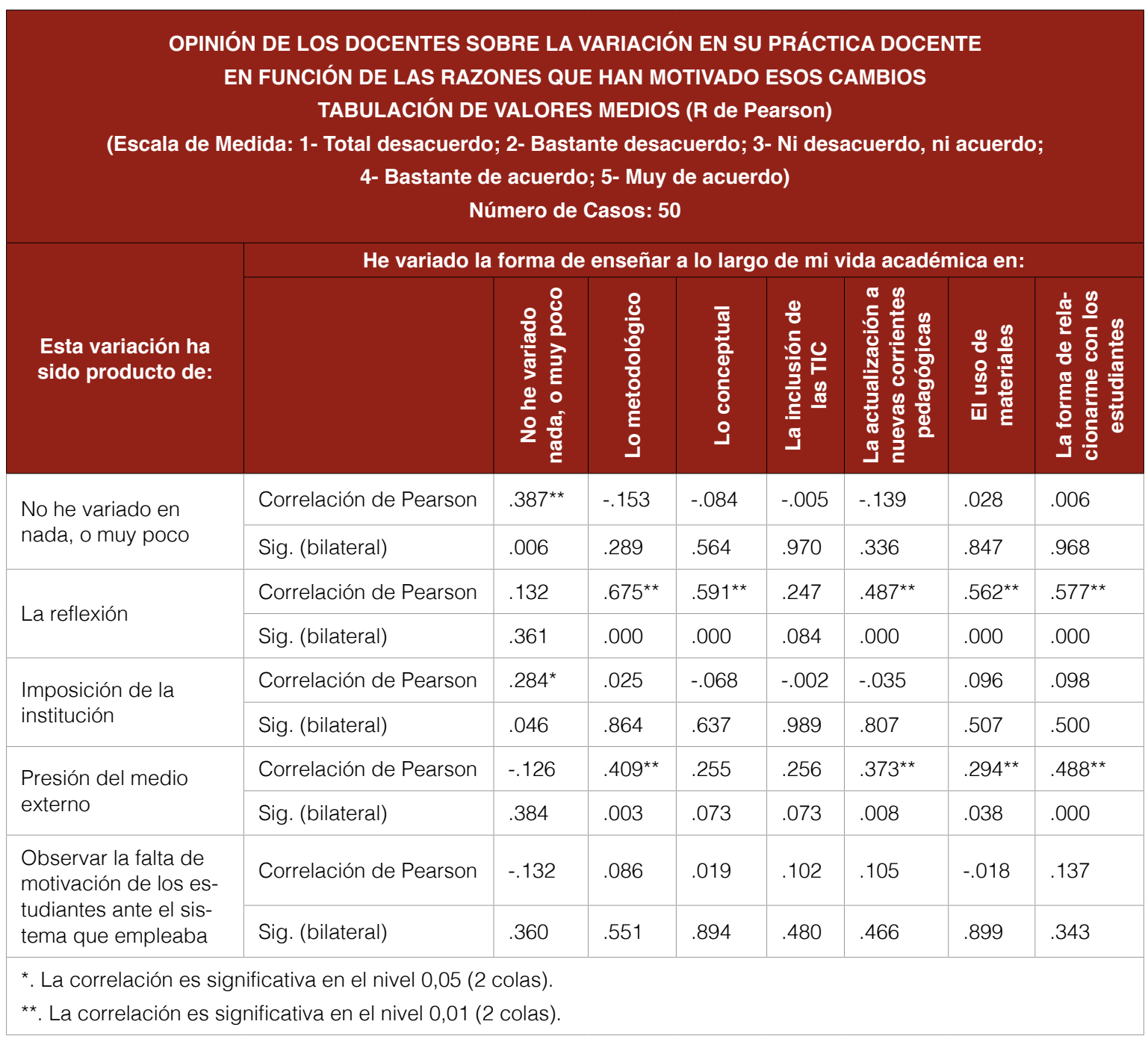




\section{Discusión y conclusiones}

La hipótesis $H 1$ Los docentes de LEB se diferencian de modo significativo en función de la metodología que emplean en clases, queda confirmada, pues se observa que existen cinco grupos bien diferenciados por sus prácticas pedagógicas: 1) Competencias-funcionalistas-complejos $(6 \%)$; 2) Constructivistas-funcionalistas $(66 \%)$; 3) Cognitivistas-generativistas (16\%); 4) Conductistas-estructuralistas (10\%); y 5) Tradicionales-gramáticos (2\%). Según se observa, el $72 \%$ de la muestra de docentes de LEB, la suma de los grupos formados por los constructivistas-funcionalistas y los que pertenecen al grupo competencias-funcionalistas-complejos, son docentes que su práctica educativa se enrumba por senderos donde el estudiante es el centro del proceso, se toma en cuenta su desarrollo en todos los aspectos, se considera el contexto, el aprendizaje desde diferentes ópticas y con variados métodos, modelos, estrategias y recursos. Los aspectos anteriores, corresponden a los puntos fuertes de la práctica de los docentes, y los puntos débiles son que todavía existen remanentes del aprendizaje tradicional y se debe incrementar más el uso de la tecnología, porque fue el renglón menos favorecido, es una materia pendiente. También hace falta mejorar en la participación que se da a los estudiantes en su evaluación, pues deben aumentarse la coevaluación y la autoevaluación. Estas conclusiones conducen a trazar estrategias institucionales para adecuar las ofertas formativas y guiar los rediseños curriculares a fin de que los profesores adquieran mayores competencias digitales, que es de lo que se adolece actualmente.

En esto se observa coincidencia con Gutiérrez (2011), quien encontró que los profesores emplean diferentes estrategias metodológicas, pero las menos conocidas y empleadas son las estrategias apropiadas para el trabajo en red. En este sentido, Monclúz \& Núñez (2014) encontraron que -en el mismo contexto educativo investigado-, los recursos más empleados son los libros de textos, la pizarra y tiza, los libros de consulta, y los menos empleados los wikis, blogs, foros, plataformas y software de aplicación; lo que Báez (2009), demostró se debe a la falta de alfabetización digital de los docentes.

Según la revisión de la literatura, la educación superior que propugnan los organismos internacionales, los ministerios de educación de las distintas naciones, los gobiernos y las instituciones particulares, debe ser adecuada a los requerimientos de la sociedad, el empleo y el desarrollo integral del individuo. Esto supone incluir el aprendizaje basado en competencias, colaborativo, centrado en el estudiante, métodos como el ABP, que incluya las TIC y con tendencia a la hibridación o semipresencialidad.

Se confirman las hipótesis H2: Los docentes consideran que se deben introducir cambios en LEB, en especial incluir las TIC, factor positivo para la implementación del B-learning y H3: En los profesores de LEB se observan tendencias al cambio en su práctica docente, porque los docentes de LEB están motivados al cambio, que de hecho lo asumen en varios renglones en su quehacer docente. También consideran necesario reformar el programa de la asignatura, privilegiando el empleo de las TIC por encima de cualquier otra reforma. Esto conlleva que la institución reconsidere la actualización de los programas de las asignaturas, ya que además de las opiniones sobre ello, las pruebas recogidas en UASDVirtual aconsejan trabajar los aspectos más neurálgicos del cambio de paradigma, que son la metodología, el sistema de evaluación y la implementación del aprendizaje colaborativo. Los resultados obtenidos son muy esperanzadores, pues la actitud de los docentes hacia el cambio puede calificarse de positiva con motivación intrínseca y extrínseca fruto, en gran parte, de la reflexión, la observación de sus prácticas y, en menor medida, de la presión del medio externo. 
Falta un largo trayecto, mucho trabajo y recursos, pero se están tomando las medidas. Finalmente, se recomienda planificar tomando en cuenta los lineamientos institucionales, las nuevas corrientes pedagógicas y tecnológicas, teniendo siempre como norte las necesidades del estudiante y del contexto socioeconómico donde desarrollará sus funciones vitales y laborales.

Entre las limitaciones del presente artículo se encuentra que ha sido desarrollado en una sola universidad de la República Dominicana, concretamente en la Universidad Autónoma de Santo Domingo (UASD), una de las instituciones de enseñanza superior de este país mejor posicionada en los rankings de excelencia académica de las universidades Latinoamérica. Bajo nuestro punto de vista, sería interesante que en el futuro este estudio se llevara a cabo en otras universidades con la finalidad de tener una fotografía nítida del papel que juega el aprendizaje B-Learning dentro del sistema educativo superior latinoamericano. De esta forma se podría determinar, entre otras cosas, si la implementación de esta pedagogía ha contribuido de forma activa y positiva en los objetivos establecidos a principio de curso por los diferentes programas que conforman las asignaturas de una titulación académica.

\section{Referencias bibliográficas}

Báez, E. (2009). La formación multimedia del profesorado universitario en el proceso de integración curricular de las TIC. Estudio de caso: Pontificia Universidad Católica Madre y Maestra, campus Santiago de los Caballeros (Tesis doctoral). España: Universidad de Salamanca.

Barriopedro, E. N., Valiño, P. C., \& Leguía, A. P. (2012). Experiencias de evaluación en e-learning en la UAH. Cómo sacarle el máximo partido a las plataformas virtuales. RELADA-Revista Electrónica de ADA-Madrid, 6(4), 282-290.

Brown, S., \& Pickford, R. (2013). Evaluación de habilidades y competencias en Educación. Madrid: Narcea Ediciones.
Cabero, J., \& Márquez, D. (Dirs.) (1999). La producción de materiales multimedia en la enseñanza universitaria. Sevilla: Editorial Kronos.

Cabero, J., \& Román, P. (2008). E-actividades. Un referente básico para la formación en Internet. Sevilla: Editorial MAD.

Carbonell, J. (2015). Pedagogías del siglo XXI. Alternativas para la innovación educativa. Barcelona: Ediciones Octaedro.

Cassany, D. (2012). En-línea. Leer y escribir en la red. Barcelona: Editorial Anagrama.

De La Torre, S., \& Barrios, O. (Eds.) (2000). Estrategias didácticas innovadoras. Barcelona: Octaedro.

Gairín, J. (2012). La transformación de la universidad. En De La Herrán, A., \& Paredes, J. (Coords.), Promover el cambio pedagógico en la universidad (25-39). Madrid: Ediciones Pirámide.

Gutiérrez, I. (2011). Competencias del profesorado universitario en relación al uso de las Tecnologías de la Información y Comunicación: Análisis de la situación en España y propuesta para un modelo de formación (Tesis doctoral). España: Universitat Rovira I Virgili.

Hernández Sampieri, R., Fernández Collado, C., \& Baptista, P. (2008). Metodología de la Investigación. México: McGraw-Hill.

Iborra, A., \& Izquierdo, M. (2010). ¿Cómo afrontar la evaluación del aprendizaje colaborativo? Una propuesta valorando el proceso, el contenido y el producto de la actividad grupal. Revista General de Información y Documentación, (20), 221-241.

Jiménez Rodríguez, M. A. (2011). Cómo diseñar y desarrollar el currículo por competencias. Guía práctica. Madrid: PPC, Editorial.

Johnson, L., Becker, S.A., Estrada, V., \& Freeman, A. (2015). NMC Horizon Report: 2015 Higher Education. Texas: Edition Austin.

Llorente, M. del C. (2009). Formación semipresencial apoyada en la Red (Blended Learning). Diseño de acciones para el aprendizaje. Sevilla: Editorial MAD.

Lomas, C., Osoro, A., \& Tusón, A. (2002, 1 de noviembre). Ciencias de lenguaje, competencia comunicativa y enseñanza de la lengua. Revista espacio Logopédico.com. Recuperado de https://goo.gl/qwaT8h

Margalef, L., Iborra, A., Pareja, N., Castro, B., Domínguez, S., García, I.,\& Giménez, S. 
(2007). Tejiendo redes de aprendizaje y reflexión: Una propuesta de innovación en la licenciatura de psicopedagogía. Revista Pulso, (30), 123-142.

Monclúz, I., \& Núñez Barriopedro, E. (2014). Training of teachers and students of higher education for an educational innovation using Information and Communication Technologies: A Latin-American study. En L. Gómez Chova, A. López Martínez y Candel Torres I. (Coords.), EDULEARN14 Proceedings (7536-7545). Valencia: IATED Academy.

Galiano-Coronil, A., \& Ravina-Ripoll, R. (2017). Universitarios felices, aulas creativas?: el uso de las redes sociales como herramienta de integración social en la ONG Down Jerez Aspanido. En A.R. Fernández Paradas y M. Fernández Paradas (Coords.), Didáctica de las ciencias sociales ante la necesidad de nuevas narraciones en el siglo XXI: Digitalidad, nuevas tecnologías y competencias documentales (225-240). Granada: Editorial Comares.

Moruno, P., Sánchez, M., \& Zariquiey, F. (2011). La cultura de la cooperación. El aprendizaje cooperativo como herramienta de diferenciación curricular. En J. C. Torrego (Coord.), Alumnos con altas capacidades y aprendizaje cooperativo (167-198). Madrid: Fundación SM.

Núñez, E., Penelas, A., \& Cuesta, P. (2014). El desarrollo de web 3.0 como innovación en la docencia. Caracciolos. Revista digital de investigación en docencia, Caracciolos, 2(1).

Núñez Barriopedro, E., \& Vílchez, E. M. (2017). Estrategias de trabajo colaborativo utilizando Twitter y wikispaces. Innovaciones aplicadas. Madrid: Editorial Académica Española.

Perrenoud, Ph. (2007). Desarrollar la práctica reflexiva en el oficio de enseñar. Barcelona: Editorial Graó.

Secretaría de Estado de Educación Superior, Ciencia y Tecnología (2008). Plan Decenal de Educación Superior (2008-2018). Una educación superior de calidad, para el país que soñamos los dominicanos. Recuperado de https://goo.gl/Qicrnt

Tiana, A. (2013). Los cambios recientes en la formación inicial del profesorado en España: Una reforma incompleta. Revista Española de Educación Comparada, (22), 39-58.

UNESCO (1998). Conferencia Mundial sobre la Educación Superior. La Educación Superior en el siglo XXI. Visión y Acción. París: Ediciones Unesco.

Universidad Autónoma de Santo Domingo (2013). Plan Estratégico 2012-2022, UASD. Santo Domingo: Editora Universitaria.

Woolfolk, A. (2006). Psicología Educativa. México: Pearson Educación.

Zabala, A., \& Arnau, L. (2014). Métodos para la enseñanza de las competencias. Barcelona: Graó.

Zabalza, M. A. (2011). Metodología docente. REDU. Revista de Docencia Universitaria. 9(3),75-98. https://doi.org/10.4995/redu.2011.6150 


\title{
Las TIC y Artes mediales: La nueva era digital en la escuela inclusiva
}

\section{ICTs and Media Arts: The new digital age in the inclusive school}

\begin{abstract}
Diego Bernaschina Cuadra es artista hipoacúsico, diseñador y docente (Chile)
\end{abstract} (diegobernaschina@gmail.com) (https://orcid.org/0000-0002-3317-8580)

Recibido: 2018-06-28 / Revisado: 2018-09-21 / Aceptado: 2018-11-22 / Publicado: 2019-01-01

\section{Resumen}

El presente artículo corresponde una experiencia educativa sobre el impacto de las prácticas pedagógicas de los medios digitales en el aula. En este objetivo principal es comprender la relación entre la asignatura complementaria (Educación Artística y Educación Tecnología) y la metodología interdisciplinaria. Así como una nueva metodología para la educación tecnológica en artes mediales. En este contexto de la escuela inclusiva, el rol de la innovación educativa adquiere gran importancia, sin embargo, para mejorar y fusionar con un modelo modernizado entre dupla docente, contenidos digitales y estudiantes inclusivos en el aula virtual. Como los resultados de las actividades realizadas en los distintos talleres de: Animación Stop Motion para la educación primaria, y Video Arte para la educación secundaria. En ambos talleres, esos que corresponden a la muestra del plan de asignatura complementaria en diferentes actividades artísticas-tecnológicas, dependiendo del nivel de escolaridad. Por tanto, un verdadero cambio educativo para toda la sociedad y la escuela inclusiva. Uno de los grandes retos de futuro en el quehacer educativo en el aula, que aporta para satisfacer las necesidades de nuevas oportunidades educativas tanto los profesionales como el liderazgo docente, compartiendo y promoviendo con el trabajo colaborativo hacia un nuevo método alternativo del aprendizaje estratégico y de la participación de los estudiantes dentro del aula virtual.

Descriptores: Artes mediales, tecnología digital, proceso de enseñanza, aprendizaje, TIC y educación escolar.

\begin{abstract}
The paper corresponds an educational experience about the impact of the pedagogical practices of digital media in the classroom. In this main objective is to understand the relation between the complementary subject (Art Education and Technology Education) and the interdisciplinary methodology. As well as a new methodology for technological education in media arts. In this context of the inclusive school, the role of educational innovation assumes great importance, however, in order to improve and merge with a modernized model between teaching duo, digital content and inclusive students in the virtual classroom. As the results of the activities carried out in the different workshops of: Stop Motion Animation for primary education, and Video Art
\end{abstract}

Forma sugerida de citar: Bernaschina Cuadra, D. (2019). Las TIC y Artes mediales: La nueva era digital en la escuela inclusiva. Alteridad, 14(1), 40-52. https://doi.org/10.17163/alt.v14n1.2019.03. 
for secondary education. In both workshops, those that correspond to the simple of the plan of complementary subject in different artistic-technological activities, depending on the level of schooling. Therefore, a true educational change for the whole of society and the inclusive school. One of the great challenges of the future in the educational task in the classroom, which contributes to satisfy

\section{Introducción}

La nueva propuesta para la integración de las TIC y el arte de los nuevos medios hacia la escuela inclusiva, el respeto y la atención a la diversidad en la educción escolar. Ahora piense en el futuro de la tecnología, la escuela, el arte y la inclusión. Así pues, es necesario mezclar la asignatura complementaria (Educación Artística y Educación Tecnología). En cierto modo será difícil llevar a cabo una tarea de enseñanza-aprendizaje en la escuela inclusiva. ¿Cuál es el motivo de enseñar una tarea compleja de las herramientas didácticas en las TIC a través de la educación artística? ¿Cómo se planifica adecuadamente el currículo interdisciplinario y la enseñanza basada en las TIC en el mundo de las artes? ¿Dónde viene la tecnología a través de artes mediales? ¿De qué se trata de la tecnología educativa en el arte y su diversidad en el aula virtual? ¿Cómo puedo lograr y enseñar sus usuarios como estudiantes en el nivel de aprendizaje estratégico? Para definir los dos tipos de artes mediales y escuela inclusiva.

\subsection{Breve definición de escuela inclusiva}

La escuela inclusiva es uno de los problemas que tropieza con mayores dificultades, principalmente las opuestas por la naturaleza humana. Sin embargo, los agentes de socialización corresponden la familia, la comunidad y la diversidad. En este sentido, como indica Mogollón y Falla (2014, p. 93) al hablar de lo que él denomina:

El movimiento de la inclusión ha surgido con fuerza en los últimos años para hacer frente a the needs of new educational opportunities both the professionals and the teaching leadership, sharing and promoting with collaborative work towards a new alternative method of strategic learning and the participation of students within the virtual classroom.

Keywords: Media Arts, Digital technology, Teaching process, Learning, ICT and Education.

los altos índices de exclusión, discriminación y desigualdad principalmente presentes en los sistemas educativos del mundo. Aunque se suele confundir con el concepto de integración, o ser considerados como sinónimos, la inclusión posee un foco más amplio en varios sentidos, considerándose un desafío para todo el sistema educativo, en especial para la educación especial.

Por el otro lado, no solo que la segregación de los estudiantes a través de un sistema educativo especial, sino más bien la existencia humana. Por tanto, las necesidades humanas se desarrollan y aumentan en la civilización, generalmente vinculados a las relaciones sociales para satisfacer sus resultados, sus particularidades e indicaciones especiales, tales como fisiológicas, terapéuticas, psicologías, intervenciones educativas, etc. Así como la discapacidad se enfrenta en diversas situaciones y obstáculos para obtener más seguridad y confianza en uno mismo. Habitualmente tienen dificultades para tomar ciertas decisiones que involucran los cambios en la personalidad y el comportamiento, dependiendo de las habilidades sociales que sean reconocidas por su entorno. En este sentido, la escuela inclusiva, que permita mejorar el grado de aceptación y el respeto a la diversidad cultural. Así como la migración y los pueblos originarios. Uno de los aspectos que debe tener un clima incluso para mejorar las relaciones sociales en el aula. Desde esta perspectiva resulta imprescindible reconocer la importancia de la educación como proceso que posibilita el derecho a la participación y el desarrollo integral (García-Yepes, 2017, p. 189). Esto también significa entender que toda (o alguna) escuela no ayuda a educar con distintos 
valores, costumbres, conocimientos diversos de la interculturalidad — por supuesto la multiculturalidad-, y del género a través del centro educativo. Asimismo, según García-Yepes (2017, pp. 189-190) que señala:

Desde esta perspectiva, impulsar el conocimiento y la comprensión de la diversidad cultural en el ámbito educativo permite mejorar los procesos de integración de los niños entre sí. En ese sentido, estas estrategias fortalecen la convivencia social ya que reconoce la inclusión como un proceso que depende de los niños[, las niñas, los jóvenes] y de las comunidades.

Así como el tratamiento inclusivo de la diversidad y del fortalecimiento institucional a nivel escolar, dependiendo de su nivel de aprendizaje y las necesidades de los estudiantes en el campo de la nueva generación del cambio social. En la noción de educación inclusiva subyace el ideal de fomentar y desarrollar la cohesión y el sentido de pertenencia, el ideal de crear comunidades de aprendizaje que compartan el respeto y aceptación de la diversidad (Amaya et al., 2010, p. 115).

Finalmente, bajo el término de la educación global de la "multiculturalidad", que consiste una cultura más homogénea como la tolerancia a través de la socialización distinta, y la práctica educativa en los distintos valores (culturas minoritarias, racismos, xenofobias, géneros, pueblos originarios, discapacidad, etc.) para promover la diversidad y la pluralidad educativa.

\subsection{Breve introducción de arte de los nuevos medios}

Para introducir brevemente sobre el arte de los nuevos medios -literalmente de artes mediales- corresponde una aproximación del lenguaje de los nuevos de comunicación a través de la imagen en la era digital. A partir de este apartado, aunque existen muchos tipos diferentes de arte de los nuevos medios: arte digital, arte electrónico, arte multimedia, arte interactivo y arte de la red, por supuesto, la filosofía de artes mediales o estética digital. Para definir este término:

El arte [de los nuevos medios en la era] digital es un arte perteneciente al multimedia, que trata datos provenientes del campo del sonido, del texto, de las imágenes fijas y también en movimiento. Lo que lo caracteriza no es, por lo tanto, la mezcla de los géneros (estilos) sino la creación y la constitución de un lenguaje propio. Lo que le interesa son las posibilidades expresivas propias de sus diferencias. Por ejemplo, una obra clásica de literatura grabada en un disco, queda como una obra clásica. Si lo digital es capaz de proyectar imágenes sobre bailarines, el arte digital solamente empieza cuando estas imágenes se vuelven componentes del cuerpo del bailarín o del actor. Este arte no consiste en complementar prácticas ya clásicas, sino en proponer situaciones expresivas y semióticas inéditas. Si puede ponerse al servicio de otros tipos de arte, tales utilizaciones no constituyen, por lo tanto, un arte digital. Del mismo modo que lo digital puede, a partir de ahora, complementar todos los aspectos de las actividades humanas, también puede ser un instrumento y un dominio artístico particular (Riboulet, 2013, p. 139).

Así, las nuevas tecnologías y en la relación del arte con los ordenadores, tanto artista, diseñador, animador y programador como teoría del cine, historia del arte y teoría literaria para contribuir un medio artístico (en la pintura, la fotografía, el cine, la televisión, la animación, el ciberespacio, el ordenador, el hipermedia, los videojuegos, la composición, la telepresencia, la videoconferencia, los sonidos, etc.). El arte siempre ha estado estrechamente ligado a la tecnología, y los nuevos medios centrados en diversos instrumentos creativos, con el fin de brindar por la llegada de Internet. Finalmente, todas las escuelas para la educación artística que les permitan evolucionarse y adaptarse a una nueva realidad social-tecnológica para los usuarios, especialmente a los estudiantes inclusivos en 
diferentes habilidades (inter)culturales y estratégicas de sus propios ordenadores/dispositivos.

\section{Nueva propuesta de metodología interdisciplinaria}

La metodología interdisciplinaria consiste en una propuesta innovadora para favorecer los distintos factores de la enseñanza $y$, del aprendizaje a través de las TIC y artes mediales. Esta propuesta metodológica va a depender del nivel de la escolaridad para poder desarrollar la creatividad y el aprendizaje centrado por parte de los estudiantes - tal como la alfabetización digital dirigida exclusivamente a los usuarios- en el aula virtual.

A partir de las iniciativas innovadoras en la enseñanza y el aprendizaje estratégico para la asignatura de educación artística y educación tecnológica. $\mathrm{Y}$ este apartado se dividen en dos partes: interacción pedagógica (o triángulo pedagógico), y nueva forma de enseñar de la asignatura interdisciplinaria.

\subsection{Interacción pedagógica (o triángulo pedagógico)}

Para introducir la propuesta de metodología interdisciplinaria que señala:

Partiendo del diseño de actividades bien planificadas, consideradas como estrategias de aprendizaje, que se componen de destreza + contenidos + método $y+$ ¿actitud?, hay que diseñar cómo aplicar tales estrategias en el aula para que el estudiante pueda desarrollar habilidades, actitudes y aprender contenidos. Normalmente, el profesor sabe qué hay que hacer, -puede saberlo en teoría-, pero hay una gran distancia entre la teoría y la practica; la gran cuestión es: ¿cómo hacer lo que hay que hacer? Entramos, así, en el dominio de los métodos de intervención educativa, o sea, en la metodología, y en las técnicas y estrategias metodológicas (Latorre y Seco del Pozo, 2013, p. 9).

La interacción pedagógica (o triángulo pedagógico) se relaciona con los tres ejes dialécticos (profesor-estudiante-contenidos) para intervenir en la toma de decisiones educativas, tanto la teoría como la práctica desde la perspectiva-estrategia metodológica. La comparación de dos modelos de interacción pedagógica de la metodología interdisciplinaria (Figura 1). Así como el modelo original de Latorre y Seco del Pozo (2013), se relaciona con los tres ejes actuales dentro del aula tradicional. Por otro lado, el modelo modernizado se actualiza en forma continua estos nuevos ejes. Este nuevo modelo se relaciona con los contenidos digitales para la asignatura complementaria de Artes Mediales, junto con una dupla docente (o acompañamiento docente) para trabajar de manera colaborativa y, combinar las dos áreas mencionadas, así como la educación artística y educación tecnología. La adquisición de esas habilidades estratégicas y creativas. Esto va a depender de la complejidad de los recursos didácticos-tecnológicos y atención a la diversidad para favorecer el aprendizaje de los estudiantes inclusivos. 
Figura 1. Comparación de modelos de interacción pedagógica (o triángulo pedagógico)

\author{
Modelo original \\ por Latorre y Seco del Pozo (2013)
}

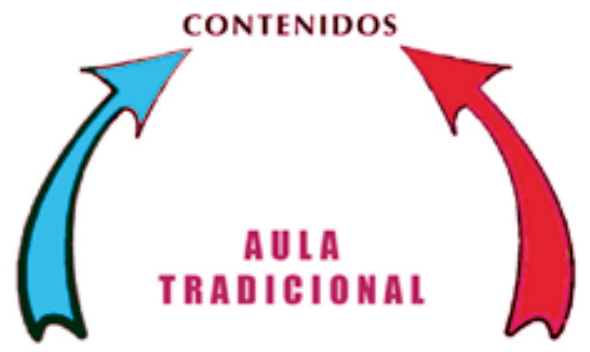

PROFESOR

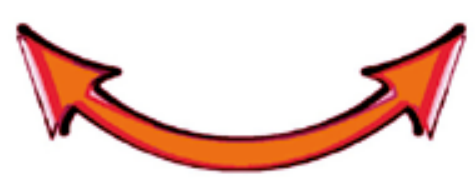

\section{Modelo modernizado por Bernaschina (2018)}

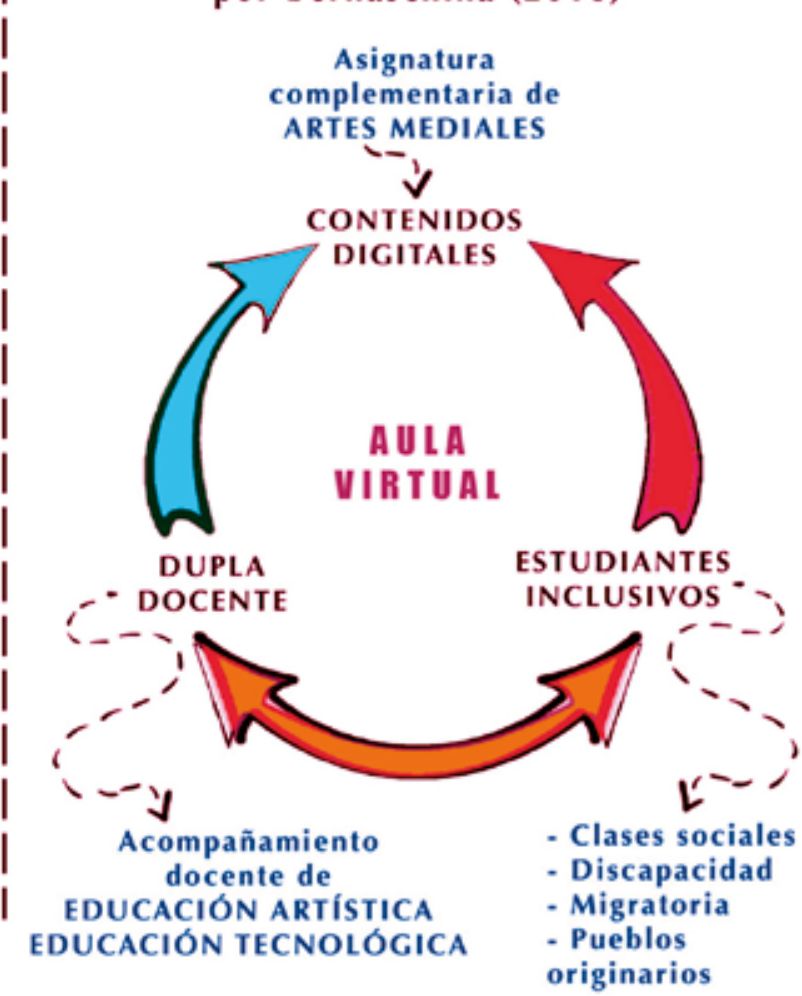

\section{Fuente: elaboración propia}

Asimismo, esta dimensión explica los contenidos digitales, en primer lugar, cada procedimiento de la tecnología educativa incorporándola con la materia de artes plásticas o artes gráficas. Y, en segundo lugar, cada estudiante obtiene un resultado favorable o ausencia de la motivación creativa. En este sentido, el nuevo reto de las TIC como el desarrollo y optimización de software educativo para el aprendizaje, donde se incluye la actividad conjunta a través del modelo modernizado dentro del aula virtual.

A continuación de los modelos a través de la metodología interdisciplinaria (Figura 2), se comparan con los tres ejes, dependiendo con los dos modelos relacionados con la enseñanza (eje profesor-contenidos), el aprendizaje (eje estudiante-contenidos) y la formación-aprendizaje (eje profesor-estudiante). Por tanto, el modelo original se mantiene en vigente. Sin embargo, la mayoría de los cambios de la metodología interdisciplinaria, a pesar de la diferencia del modelo modernizado se incluye con la enseñanza interdisciplinaria para la asignatura complementaria de educación tecnología-artística (eje dupla docente-contenidos digitales), a continuación, el aprendizaje estratégico (eje estudiantes inclusivos-contenidos digitales), y por último, las actividades de artes mediales (eje dupla docente-estudiantes). 
Figura 2. Comparación de los modelos de 3 ejes

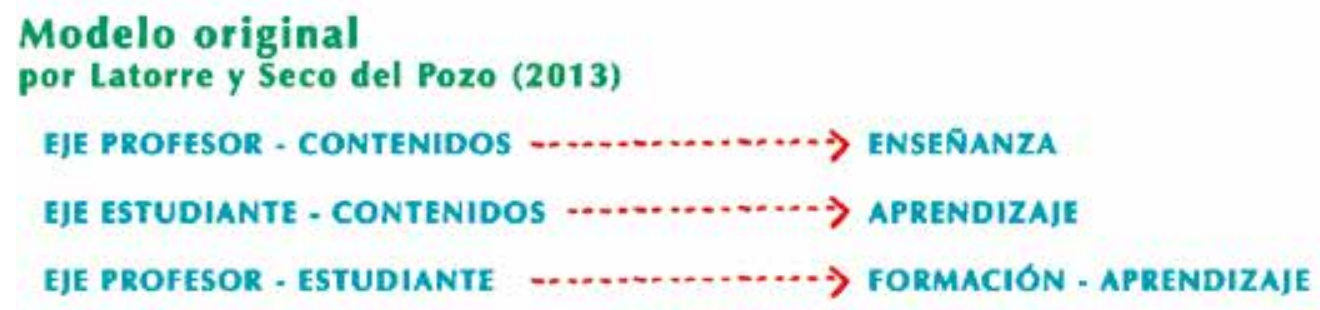

Fuente: elaboración propia

Para resumir ambos modelos: De acuerdo con las dos figuras, puede observarse, entonces, que la metodología interdisciplinaria no es siempre que los estudiantes tienen mayor confianza al sistema educativo tecnológico. Sin embargo, ese nuevo método pedagógico se considera un intercambiar con las ideas que nos favorecen el desarrollo de habilidades creativas y sus pensamientos independientes, con el fin de lograr la comprensión y el apoyo de la escuela inclusiva y de las ideas previas de los estudiantes a través de la TIC en Artes Mediales. Por lo tanto, podemos decir que las prácticas educativas inclusivas con TIC nos permiten incluir los programas softwares como el recurso didáctico tecnológico (ordenador, computador portátil, celular, tableta, cámara fotográfica, etc.), para garantizar una mayor actividad interdisciplinaria que permita ofrecer el funcionamiento del aprendizaje significativo (del psicólogo estadounidense, David Ausubel) y aprendizaje colaborativo (o la interacción educativa, más conocida de la ZDP -Zona de Desarrollo Próximo o proximal. ZDP es un concepto creado por el psicólogo ruso,
Lev Vygotsky - para resolver un problema de la creatividad, y compartir las relaciones sociales de usuarios (estudiantes inclusivos) a través de las TIC en artes mediales. Asimismo, nos demuestra que los estudiantes en distintos niveles de la escolaridad no estarían capacitados para trabajar con los medios digitales en área de artes mediales, sino también mejorar la enseñanza interdisciplinaria, tanto la educación artística como la educación tecnología, asumiéndose con la incorporación de las TIC a las asignaturas complementarias para crear un papel de estudiantes sobre las habilidades tecnológicas y sus aprendizajes flexibles sin importar la calidad de trabajo (Daniels, 2003; Latorre y Seco del Pozo, 2013; Torres, 2006; Vygotsky, 1995, 2009, 2013; Wertsch, 1988).

\subsection{Nueva forma de enseñar de la asig- natura interdisciplinaria}

Para evidenciar esta metodología interdisciplinaria de enseñanza y aprendizaje de las TIC y arte de los nuevos medios en la escuela inclusiva. Desde 
esta perspectiva de la metodología interdisciplinaria, se considera necesario ofrecer pautas para la Educación Primaria, especialmente dirigidos a los estudiantes en el contexto educativo de las nuevas tecnologías de los programas softwares de atención temprana. Para Aranda (2005), así como el programa de habilidades sociales-motrices es importante para estimular el conocimiento de sí mismo, y del entorno de una manera directa en el éxito o fracaso del aprendizaje y en el rendimiento escolar a través del uso de las TIC del arte. Es imposible de enseñar a los estudiantes más pequeños a través del desarrollo de las TIC.

Aunque, como ya se he explicado el modelo modernizado para crear los nuevos cambios en educación de las TIC en el arte. Para Latorre y Seco del Pozo (2013), que implica la metodología (o equivalente a un método), por tanto, corresponde un camino orientado hacia la meta. Hay otro término sobre el método de aprendizaje escolar. En este sentido, los autores que señalan:

El método de aprendizaje es el camino que sigue el estudiante para desarrollar habilidades más o menos generales, aprendiendo contenidos. Un método es una forma de hacer. Cada estudiante, con sus diferencias individuales, tiene un estilo peculiar de aprender, es decir, una manera concreta de recorrer el camino del aprendizaje (Latorre \& Seco del Pozo, 2013, p. 13).

Adicionalmente, para referirse el método de aprendizaje a través de las TIC:

El método de aprendizaje se concreta a través de técnicas metodológicas, en función de las habilidades que se quieren desarrollar al aplicarlo a un contenido determinado, de las características del estudiante, de su nivel de desarrollo psicológico, de los contenidos del área de que se trate, de la posible mediación del profesor, etc. Así, podemos decir, que técnica metodológica es la forma concreta de recorrer cada estudiante el camino elegido, en función de sus características, de los contenidos, de la mediación del profesor, etc. La técnica metodológica es elegida por el profesor en función de la realidad de los estudiantes y de los fines que persigue (Latorre \& Seco del Pozo, 2013, p. 13).

Por lo tanto, el método de aprendizaje consiste en la relación de los tres ejes de la metodología interdisciplinaria a través de un modelo modernizado:

Todo método de aprendizaje consta de: destreza sustantivada (el para qué) + el contenido (el qué) + el conector (por medio de, mediante, a través de, en...) + el cómo (el método propiamente tal) (Latorre \& Seco del Pozo, 2013, p. 13).

Así como una nueva forma de enseñar de la asignatura interdisciplinaria. Asimismo, en la medida a la incorporación de los nuevos medios en la educación inclusiva. Dentro del desarrollo de esta asignatura complementaria sobre las TIC y el arte de los nuevos medios, facilitándola con los medios tecnológicos en el nivel de aprendizaje estratégico para los estudiantes, dependiendo sus habilidades digitales. De ahí la importancia de lo que podríamos denominar como una educación para los nuevos medios [...] o una educación multimedia (Gutiérrez, 1997, p. 10). Estas actividades educativas están diseñadas para facilitar y guiar el paso de la materialidad de "interfaz gráfica de usuario" (Manovich, 2005). Este hecho obliga a reconsiderar el supuesto efecto transformador e innovador de las prácticas educativas escolares que, como ya hemos mencionado, se atribuye en ocasiones de forma automática a la incorporación de las TIC a la educación (Coll, Maur \& Onrubia, 2008, p. 83).

\section{Propuesta sobre el plan de asignatura complementaria}

Antes de empezar la teoría y el diseño curricular para la educación de artes mediales. Lo primero que hay que saber la definición de la estrategia metodológica sobre la interdisciplinariedad, y luego, una muestra de la planificación realizada de dos talleres para educación primaria y 
secundaria. Así como los principales resultados obtenidos a través del modelo modernizado. Sin embargo, para ejemplificar esta propuesta sobre el plan de asignatura complementaria. Para incluir un término fundamental:

La interdisciplinariedad es la cooperación entre dos o más disciplinas, sin la fragmentación propia de lo disciplinar, para abordar un tema, objeto o problemática mediante sus métodos específicos, de modo que se enriquezcan mutuamente y desarrollen conocimientos más complejos y profundos (CNCA, 2015, p. 17).

También existen aspectos curriculares sobre los contenidos digitales para ajustar colaborativamente las dos o más áreas del trabajo docente. Así como la dupla docente que trabaja en los distintos tratamientos de los temas transversales desde las TIC y el arte de los nuevos medios. Según Torres (2006), la interdisciplinariedad se permite una generación posterior sobre las propuestas curriculares, y por eliminar las barreras existentes entre la escuela y su entorno. Y por otro lado se busca reconocer en los proce- sos educativos, donde la tecnología es necesaria para el desarrollo integral.

A continuación, por ejemplo, la propuesta de contenidos digitales en distintos niveles de escolaridad (Tabla 1.1 y 1.2). En el primer paso, la planificación resulta prácticamente imposible establecer el vínculo con los programas educativos obligatorios por parte del Ministerio de Educación en cada país del origen. Por lo general, las herramientas tecnológicas van acompañadas las propuestas de la asignatura complementaria como tal la enseñanza interdisciplinaria más global y precisa. Al utilizarlas para la puesta del trabajo educativo en las TIC, y el desarrollo de actividades recreativas para todos los usuarios, especificándolo con la incorporación de herramientas, de recursos y de aplicaciones de softwares, que siempre el desarrollo de enseñanza-aprendizaje pueden utilizar sus propuestas sea independientemente para facilitar una diversidad (multi)cultural. Y el segundo paso, cada estudiante, realizando la práctica educativa como un proceso personalizado, ajustándola su problema y su necesidad para desarrollar la actividad tecnológicamente y artísticamente.

\section{Tabla 1.1. Propuesta de contenidos digitales en distintos niveles de escolaridad por Bernaschina (2018)}

\begin{tabular}{|c|c|c|}
\hline Nivel de escolaridad & Educación Primaria & Educación Secundaria \\
\hline Nombre del Taller & Animación Stop Motion & Video Arte \\
\hline Objetivos & $\begin{array}{l}\text { Objetivos generales: } \\
\text { Realizar un taller de animación stop motion } \\
\text { que potencie el desarrollo artístico-institu- } \\
\text { cional educativa. } \\
\text { Objetivos específicos: } \\
\text { - } \quad \text { Realizar un cortometraje de animación } \\
\text { - } \quad \text { An todas sus etapas. } \\
\text { - } \quad \text { Crear personajes, maquetas y escena- } \\
\text { - } \quad \text { rios de animación. } \\
\quad \text { Proyectar el trabajo realizado. }\end{array}$ & $\begin{array}{l}\text { Objetivos generales: } \\
\text { Realizar un taller de video arte que po- } \\
\text { tencie el desarrollo artístico- institucional } \\
\text { educativa. } \\
\text { Objetivos específicos: } \\
\text { - } \quad \text { Realizar un cortometraje de video arte } \\
\text { en trabajo individual / grupal. } \\
\text { - } \quad \text { Conocer las herramientas básicas } \\
\text { - } \quad \text { Elabo la edición de video. } \\
\text { - } \quad \text { Proyectar el trabajo realizado. }\end{array}$ \\
\hline
\end{tabular}




\begin{tabular}{|c|c|c|}
\hline Nivel de escolaridad & Educación Primaria & Educación Secundaria \\
\hline Nombre del Taller & Animación Stop Motion & Video Arte \\
\hline Contenidos & $\begin{array}{l}\text { - } \quad \text { Ejemplos y concepto de stop motion. } \\
\text { - } \quad \text { ca narración cinematográfica y acer- } \\
\text { - } \quad \text { Confección escenográfica y } \\
\text { ambientes. } \\
\text { - } \quad \text { Rodaje Stop Motion. } \\
\text { - Edición de video. }\end{array}$ & $\begin{array}{l}\text { - Introducción del programa para edi- } \\
\text { - } \quad \text { Ción de video. } \\
\text { - el programa de edición de video. } \\
\text { - } \quad \text { Prepara el trabajo individual/ grupal. } \\
\text { - Muestra previa del trabajo final. }\end{array}$ \\
\hline
\end{tabular}

Tabla 1.2. Propuesta de contenidos digitales en distintos niveles de escolaridad por Bernaschina (2018)

\begin{tabular}{|c|c|c|}
\hline $\begin{array}{c}\text { Nivel de } \\
\text { escolaridad }\end{array}$ & Educación Primaria & Educación Secundaria \\
\hline $\begin{array}{c}\text { Nombre del } \\
\text { Taller }\end{array}$ & Animación Stop Motion & Video Arte \\
\hline Metodologías & $\begin{array}{l}\text { - Todos los estudiantes practicarán sus capac } \\
\text { - } \quad \text { Componiendo sus propias historias para ser } \\
\text { - } \quad \text { Elaborar un plan simple de producción con } \\
\text { - } \quad \text { la obra. } \\
\text { - } \quad \text { Renfeccionar escenarios de acuerdo a las h confección de personajes utilizan } \\
\text { - } \quad \text { Ejecutar el proceso de rodaje, bajo la tutela } \\
\text { - } \quad \text { El docente titular/tallerista (dupla docente) y } \\
\text { - } \quad \text { la edición, trabajarán en el proceso de postr } \\
\text { Visualización de las obras realizadas. }\end{array}$ & $\begin{array}{l}\text { idades de creación, a través de la imaginación, } \\
\text { ejecutadas en sus trabajos. } \\
\text { ealizar. } \\
\text { os requerimientos básicos para la ejecución de } \\
\text { storias creadas. } \\
\text { do distintos materiales. } \\
\text { del profesor guía; los alumnos animarán sus his- } \\
\text { un grupo variable de estudiantes interesados en } \\
\text { roducción de las obras. }\end{array}$ \\
\hline Evaluación & $\begin{array}{l}\text { El taller se evaluará a partir de la calidad de las d } \\
\text { incluye la asistencia (y la justificación médica) de } \\
\text { tre y/o anual. Los resultados del taller serán exhib }\end{array}$ & $\begin{array}{l}\text { scusiones basadas en el trabajo desarrollado, e } \\
\text { os participantes con nota al libro en cada semes- } \\
\text { dos en el cierre semestral (o anual). }\end{array}$ \\
\hline $\begin{array}{l}\text { Recursos } \\
\text { didácticos }\end{array}$ & $\begin{array}{l}\text { Los programas softwares educativos recomenda- } \\
\text { dos en: } \\
\text { - } \quad \text { Adobe Photoshop (Animación GIF) } \\
\text { - } \quad \text { Windows Movie Maker } \\
\text { - } \quad \text { Otro programa similar de edición de video } \\
\quad \text { para niños y niñas. }\end{array}$ & $\begin{array}{l}\text { Los programas softwares educativos recomen- } \\
\text { dados en: } \\
\text { - } \quad \text { Adobe Photoshop } \\
\text { - } \quad \text { Adobe Premiere } \\
\text { - } \quad \text { Otro programa similar de edición de video } \\
\quad \text { para jóvenes. }\end{array}$ \\
\hline
\end{tabular}

En la mayoría de las ocasiones, sin embargo, los esfuerzos dirigidos a elaborar la planificación de usos de las TIC que tengan en cuenta tanto las características de las herramientas tecnológicas como las dimensiones de las prácticas educativas. Así como el motor del desarrollo social a través de los medios, es decir, las nuevas visiones de la realidad social en la escuela inclusiva (Coll, Maur \& Onrubia, 2008; Ruiz, 2015).

Por otro lado, se entiende que el uso de la planificación a través de las TIC (Tabla 2) para generar los tres tipos de técnicas y estrategias de aprendizaje de evaluación en distintos niveles de escolaridad. Por lo tanto, se refiere al plan de asig- 
natura complementaria que permite realizar en diferentes actividades a los usuarios, dependiendo en la nivelación de la escolaridad. Podemos crear y analizar que toda actividad escolar consta de los tres tipos de evaluación junto con las técnicas y las estrategias de aprendizaje.

Tabla 2. Los 3 tipos de técnicas y estrategias de aprendizaje de evaluación en distintos niveles de escolaridad por Bernaschina (2018)

\begin{tabular}{|c|c|c|}
\hline $\begin{array}{c}\text { Diagnóstica } \\
\text { (o técnicas informales) }\end{array}$ & $\begin{array}{c}\text { Formativa } \\
\text { (o técnicas semiformales) }\end{array}$ & $\begin{array}{c}\text { Sumativa } \\
\text { (o técnicas formales) }\end{array}$ \\
\hline $\begin{array}{l}\text { Diagnóstica que determina cono- } \\
\text { cimientos previos de los conteni- } \\
\text { dos digitales. }\end{array}$ & $\begin{array}{l}\text { Formativa que observa y analiza el pro- } \\
\text { ceso de aprendizaje estratégico. }\end{array}$ & $\begin{array}{l}\text { Sumativa que valora los resultados es- } \\
\text { perados de las TIC y artes mediales. }\end{array}$ \\
\hline \multicolumn{3}{|c|}{ Técnicas de evaluación } \\
\hline $\begin{array}{l}\text { - Observación de actividades } \\
\text { preparadas por los estudian- } \\
\text { tes inclusivos. } \\
\text { - Exploración a través de los } \\
\text { cuestionarios en el formulario } \\
\text { web de Google por la dupla } \\
\text { docente. } \\
\text { - Conversaciones y diálogos. }\end{array}$ & $\begin{array}{l}\text { - Ejercicios y prácticas con los pro- } \\
\text { gramas softwares, depende con el } \\
\text { uso de los contenidos digitales } \\
\text { para que los usuarios (estudiantes } \\
\text { inclusivos) realizan en la clase. } \\
\text { - Revisión de los trabajos y consultas } \\
\text { dentro y fuera de la clase; dentro } \\
\text { de la clase corresponde las activi- } \\
\text { dades en el aula virtual, y fuera de } \\
\text { la clase corresponde las consultas } \\
\text { a través del correo electrónicos } \\
\text { para los estudiantes inclusivos. }\end{array}$ & $\begin{array}{l}\text { - } \text { Reconocimiento de habilidades } \\
\text { estratégicas por cada usuario. } \\
\text { Exploración de herramientas bá- } \\
\text { sicas para mejorar y desarrollar } \\
\text { las prácticas por los usuarios. } \\
\text { Motivación y creatividad (o la } \\
\text { creatividad en el aprendizaje es- } \\
\text { colar) para el desarrollo de técni- } \\
\text { cas individuales / grupales. }\end{array}$ \\
\hline \multicolumn{3}{|c|}{ Estrategias de aprendizaje (o instrumentos de evaluación) } \\
\hline $\begin{array}{l}\text { Una práctica introductoria en la } \\
\text { asignatura complementaria para } \\
\text { crear un paso de conocimiento } \\
\text { previo de los contenidos digitales. }\end{array}$ & $\begin{array}{l}\text { Ejercicios y prácticas que realizan los } \\
\text { usuarios como parte de las actividades } \\
\text { de la asignatura complementaria de las } \\
\text { TIC y artes mediales. También al nivel } \\
\text { de aprendizaje estratégico para los es- } \\
\text { tudiantes inclusivos tanto los usuarios } \\
\text { como los trabajos individuales/grupales } \\
\text { en el aula virtual. Asimismo, la actividad } \\
\text { de aprendizaje estratégico se requiere } \\
\text { con mayor preparación hacia la práctica } \\
\text { de libertad y creatividad. }\end{array}$ & $\begin{array}{l}\text { Finalidad de los trabajos durante el } \\
\text { período escolar para elaborar sus re- } \\
\text { sultados sofisticados como conceptos } \\
\text { innovadores o nuevas experiencias } \\
\text { por parte de los estudiantes inclusivos. }\end{array}$ \\
\hline
\end{tabular}

En este punto, es importante destacar que, en la metodología interdisciplinaria se discute la construcción del conocimiento en arte para crear un espacio abierto y diálogo creativo, dependiendo de la temática sobre el intercambio y el aprendizaje cooperativo para la atención a la diversidad hacia las manifestaciones culturales contemporáneas y tecnológicas. Sin embargo, que favorezcan la interacción entre los distintos elementos a través de un modelo modernizado del proceso educativo -educación primaria y secundaria-, con el fin de la capacidad humana de aprender su entorno con el apoyo a la adquisición y desarrollo de procedimientos y, estrategias de aprendizaje (Coll, Maur \& Onrubia, 2008; Piccolotto, 2013; Ruiz, 2015).

\section{Conclusión}

Actualmente, en muchos casos al desconocimiento o mala aplicación de la metodología tradicional. Por ejemplo, el modelo original de Latorre y Seco del Pozo (2013) por la realización de las inactividades humanas, a partir de la 
ausencia de la creación de procesos, instrumentos, lenguajes y métodos, aportándolo con las dos asignaturas para intervenir las nuevas prácticas sobre atención a la diversidad.

Por tanto, la metodología interdisciplinaria se esfuerza con el avance de la tecnología educativa para simplificar con las dos herramientas en desarrollo de las TIC y el arte de los nuevos medios. Sin embargo, para el futuro de este nuevo modelo será modernizado los programas estructurados, dependiendo de las necesidades de sus potencialidades y alcances de la tecnología artística a fin de transformaciones sociales y sus propios intercambios en la comunicación inclusiva, es decir, incorporar las habilidades creativas, sociales, (inter)culturales y estratégicas de sus propios ordenadores/dispositivos.

Por ejemplo, a lo largo de la historia de las TIC ha ofrecido soluciones creativas para desarrollar, innovar y adquirir nuevas herramientas de expresión artística. No obstante, será difícil de responder con los objetos, casi cualquier persona podría distinguir los valores artísticos-culturales a través de la imaginación artística, la simbólica y la tradición de virtuosos maestros artistas como Miguel Ángel, Rafael o Leonardo Da Vinci; sus precursores movimientos de mayor impacto, como el dadaísmo, estridentismo o Pop Art, y; además, la llegada de la fotografía y el cine desde mediados del siglo XX como las artistas de Julia Margaret Cameron, Lewis Caroll, y otros. De ahí dio un gran paso al construir la tecnología educativa y la civilización artística, Así como a representar la naturaleza humana en el proceso creativo, tanto en el desarrollo de la personalidad y del sentido estético como en la actividad artística-tecnológica para establecer un diálogo enriquecedor con el entorno físico y social del individuo (Merodio de la Colina, 2001; Vygotsky, 2003; La tecnología y el arte: una combinación para labrar el futuro, 2012; Parejo, 2014).

En la actualidad existen varios fundamentos tecnológicos, sociales, artísticos y educativos para comprender la dimensión teórica y práctica de los nuevos caminos de la interculturalidad y la inclusión en el contexto educativo a través de la asignatura complementaria. Así, la discusión cultural contemporánea sobre la educación artística y las TIC, que suelen un papel central en la metodología interdisciplinaria para favorecer, y apreciar los valores estéticos en sus múltiples dimensiones en distintas obras, y esferas de la actividad humana y su relación con el mundo del lenguaje deseado, propio y autónomo en la vía experimentación con uso de los nuevos medios en la diversidad cultural. Será entonces, a través de la educación inclusiva, la que creará esos lazos de unión entre diversas culturas (Olhagaray Llanos, 2002; Fabelo Corzo, 2004; Solís, 2009; Muiños de Britos, 2011; Leiva, 2016; Tipa, 2018). La tecnología educativa puede dimensionarse bastante complejo los procedimientos artísticos dentro de las TIC sobre la asignatura de la educación artística:

No obstante, el tratamiento inclusivo de la diversidad reporta ventajas más allá de los propios alumnos y de la institución educativa, convirtiéndose en un elemento también importante en el desarrollo de una sociedad más justa, tolerante y respetuosa con la diversidad, sin olvidarnos de que la amplitud que tiene el término inclusión, enmarcado dentro del discurso de los derechos humanos, va mucho más lejos del ámbito educativo (González Fernández, Medina Domínguez, \& Domínguez Garrido, 2016, p. 135).

Así pues, para adaptar el modelo modernizado sobre la interacción pedagógica que será mejorado, especialmente en entornos inclusivos asociados al uso de las TIC en la escuela.

Para reflexionar sobre una nueva mirada a la formación pedagógica desde el uso de las TIC en Artes Mediales. Por tanto, necesitamos un verdadero cambio educativo para brindar la sociedad hacia la escuela inclusiva. Dada nuestra tradición en el campo de la educación artística a través de los nuevos medios, y por supuesto, las nuevas tecnologías multimedia. 


\section{Referencias bibliográficas}

Aranda, R. (2008). Atención temprana en educación infantil. Madrid: WK Educación.

Amaya et al. (2010). Educación y fomento de la cohesión social. En Boza, A. et al. (Coords.), Educación, investigación y desarrollo social (103-134). Madrid: Narcea.

CNCA (2015). Caja de herramientas para la educación artística: Cuaderno 3: Una educación artística en diálogo con otras disciplinas. (1 $1^{\mathrm{a}} \mathrm{ed}$.). Santiago: Consejo Nacional de la Cultura y las Artes, Chile.

Coll, C., Mauri, T., \& Onrubia, J. (2008). Capítulo III: La utilización de las tecnologías de la información y la comunicación en la educación: Del diseño tecno-pedagógico a las prácticas de uso. En C. Coll y C. Monereo (Eds.), Psicología de la educación virtual: aprender y enseñar con las tecnologías de la información y la comunicación (74-103). Madrid: Ediciones Morata.

Daniels, H. (2003). Vygotsky y la pedagogía. Barcelona: Paidós.

Fabelo Corzo, J. (2004). Aproximación teórica a la especificidad de los valores estéticos. Graffylia, 2(4), 17-25. Recuperado de https://goo.gl/puL9Rm

García-Yepes, K. (2017). Procesos de integración social de inmigrantes en escuelas de Huelva, España. Alteridad, 12(2), 188-200. https://doi.org/10.17163/alt.v12n2.2017.05

González Fernández, R., Medina Domínguez, M., \& Domínguez Garrido, M. (2016). Ventajas del tratamiento inclusivo de la diversidad: perspectivas de los principales agentes encargados de su desarrollo. Enseñanza \& Teaching: Revista Interuniversitaria de Didáctica, 34(2), 131-148. http://dx.doi.org/10.14201/et2016342131148

Gutiérrez, A. (1997). Educación Multimedia y Nuevas Tecnologías. Madrid: Ediciones de la Torre.

La tecnología y el arte: una combinación para labrar el futuro. (2012, 14 de octubre). BBC News. Recuperado de https://bbc.in/2oDbOd9

Latorre, M. \& Seco del Pozo, C. (2013). Metodología: Estrategias y técnicas metodológicas. Lima: Universidad Marcelino Champagnat. Recuperado de https://goo.gl/Sc4BcH
Leiva, J. (2016). Abriendo caminos de interculturalidad e inclusión en la escuela. Madrid: Dykinson.

Manovich, L. (2005). El lenguaje de los nuevos medios de comunicación: la imagen en la era digital. Barcelona: Paidós.

Merodio de la Colina, Ma . (2001). Procesos de creatividad en la expresión plástica para la educación primaria. En Oriol de Alarcón, N. (Ed.), La educación artística, clave para el desarrollo de la creatividad (135-154). Madrid: Ministerio de Educación, Cultura y Deporte.

Muiños de Britos, S. (2011). Capítulo I: La educación artística en la cultura contemporánea. En A. Giráldez, y L. Pimentel (Coords.), Educación artística, cultura y ciudadanía. De la teoría a la práctica (9-20). Madrid: OEI. Recuperado de https://bit.ly/2BusGLI

Olhagaray Llanos, N. (2002). Del video-arte al net-art. Santiago: LOM.

Parejo, D. (2014, 28 de julio). El impacto de la tecnología en el Arte [Blog]. Recuperado de https://goo.gl/DgbyS2

Piccolotto, D. (2013). Artes visuales y tecnología digital como instrumentos de innovación en la educación escolar. Revista Campus Virtuales, 2(2), 46-52.

Recuperado de https://goo.gl/1QmzVC

Rebollo, M. Á. (2006). Género e interculturalidad: educar para la igualdad. Madrid: La Muralla.

Riboulet, C. (2013). En el arte de los nuevos medios. Calle 14, 7(10), 136-143

https://doi.org/10.14483/udistrital.jour.c14.2013.1.a09

Ruiz, A. (2015). Capítulo I: Desarrollo tecnológico y uso educativo de las TIC: visión crítica de la modernidad. En R. Arauz et al., TIC en Educación (15-46). Madrid: Ediciones Díaz de Santos.

Solís, Ma. (2009). El profesorado, elemento mediador hacia la interculturalidad. En E. Soriano, R. Zapata, y A. González (Eds.), La formación para el desarrollo de una sociedad intercultural (2-8). Almería: Universidad Almería.

Tipa, J. (2018). ¿De qué me sirve la interculturalidad? Evaluación de la Universidad Intercultural de Chiapas por sus estudiantes. Alteridad, 13(1), 56-71. https://doi.org/10.17163/alt.v13n1.2018.04 
Torres, J. (2006). Globalización e interdisciplinariedad: el curriculum integrado ( $5^{\mathrm{a}}$ ed.). Madrid: Ediciones Morata.

Vygotsky, L. S. (1995). Pensamiento y Lenguaje: Teoría desarrollo cultural de las funciones psíquicas. Buenos Aires: Ediciones Fausto.

Vygotsky, L. S. (2003). La imaginación y el arte en la infancia (9a ed.). Madrid: Ediciones Akal.
Vygotsky, L. S. (2009). El desarrollo delo procesos psicológicos superiores ( $3^{\mathrm{a}}$ ed.). Barcelona: Crítica.

Vygotsky, L. S. (2013). Psicología del arte. Barcelona: Paidós.

Wertsch, J. (1988). Vygotsky y la formación social de la mente. Barcelona: Paidós. 


\section{Propuesta de diseño de instrumento para analizar vídeo-lecciones en MOOC}

\section{Proposal for design an instrument for video lectures analysis in MOOC}

Edna Manotas Salcedo es coordinadora de diseño de Material Educativo Digital de la Universidad del Norte (Colombia) (ednam@uninorte.edu.co) (https://orcid.org/0000-0002-4080-2740)

Dra. Amor Pérez-Rodríguez es docente e investigadora de la Universidad de Huelva (España) (amor.perez@dfesp.uhu.es) (https://orcid.org/0000-0001-8312-5412)

Dra. Paloma Contreras-Pulido es docente e Investigadora. Universidad de Huelva (España) (paloma.contreras@dedu.uhu.es) (https://orcid.org/0000-0002-6206-7820)

Recibido: 2018-06-29 / Revisado: 2018-10-07 / Aceptado: 2018-11-07 / Publicado: 2019-01-01

\section{Resumen}

El artículo presenta el proceso de construcción y validación de un instrumento para valorar la estructura de vídeo-lecciones de cursos masivos en línea, MOOC. El instrumento divide la vídeo-lección en momentos de la clase: inicio, desarrollo y cierre, para revisar de qué manera cada apartado aporta a la construcción de la narración. La justificación de este estudio se basa en la necesidad de generar propuestas para la producción de vídeos en cursos masivos, toda vez que algunos replican modelos tradicionales de transmisión de información. En la primera parte del texto, se explica el proceso de diseño y los soportes teóricos que enmarcan los bloques de preguntas, así como el resultado de la valoración de los expertos y pilotaje del instrumento y los resultados. Al final, el artículo ofrece perspectivas para el diseño de vídeo-lecciones y para contar con instrumentos que le permitan a los docentes y a los diseñadores instruccio- nales de cursos virtuales hacer una lista de chequeo de los principios de Storytelling y narrativa audiovisual que refuercen los discursos contenidos en las vídeo-lecciones. Se concluye con una propuesta de uso del instrumento para abrir nuevas líneas de investigación que apoyen la producción de vídeo-lecciones y con el planteamiento de ideas para usar elementos de televisión vía streaming como Netflix a las secuencias didácticas de cursos virtuales.

Descriptores: Vídeo-lecciones, análisis de vídeos, educación en línea, MOOC, diseño instruccional, video educativo

\begin{abstract}
This article carried out the process of construction and validation of an instrument to assess the structure of video lectures from MOOC. The tool is divided in the parts of the class: opening, core and closure
\end{abstract}

Forma sugerida de citar: Manotas Salcedo, E., Pérez-Rodríguez, A., \& Contreras-Pulido, P. (2019). Propuesta de diseño de instrumento para analizar vídeo-lecciones en MOOC. Alteridad, 14(1), 53-64. https://doi.org/10.17163/alt.v14n1.2019.04. 
for check how each part contribute to the narrative sequence. The aim of the study is based on the need to made proposals for the production of videos for massive on line courses because the trend is to replicate the traditional teaching models of information transfer. The design process and the theoretical supports that frame of the questions are explained, as well as the result of the assessment of the experts and the piloting of the instrument. In the end, the article offers perspectives for the design of video-lessons and to have instruments that allow teachers and instructional designers of virtual courses to make a checklist to the Storytelling tips and audiovisual narrative that reinforce the discourses con-

\section{Introducción y estado de la cuestión}

El diseño y uso de vídeo-lecciones se ha posicionado como el eje de las secuencias didácticas de los xMOOC, o cursos basados en contenidos (Raposo, Martínez \& Sarmiento, 2015). A la vídeo-lección se le define como una pieza audiovisual en la que se exponen unos contenidos temáticos y se le asemeja a una clase magistral (Ferrés, 1992; Marqués,1999). Para Biggs (2006) este tipo de clases tiene un importante potencial, sin embargo, "requiere de una concentración que reduce drásticamente su valor si no se realiza adecuadamente" (p. 129).

Si bien los primeros MOOC que aparecieron en el ámbito educativo fueron los que se centraban en conexiones, tienen como principio el conectivismo y la idea de que miles de personas interactúen con los contenidos de un curso (Downes, 2007; Siemens, 2005) los xMOOC son los que han proliferado en las plataformas como Udacity, Coursera, Future Learn, Miriada X, Canvas, Edx, entre otras. Cabe anotar que a la definición de los MOOC también se han sumado nuevas elaboraciones según tamaño de los grupos, herramientas y nivel de interacciones, como las planteadas por Clark (2013), quien define 8 tipos de MOOC: TransferMOOCs, MadeMOOCs, SynchMOOCs, AsynchMOOCs, AdaptiveMOOCs, GroupMOOCs, ConnectivistMOOCS, MiniMOOCSs. También tained in the video-lessons. The results of the analysis identified progress and limitations in the construction of the resources. Based on the findings, reflections are offered on how these resources could be improved. It concludes with a proposal to use the instrument to open new lines of research that support the video lessons production and to give ideas about how use resources of the television streaming like Netflix, in the pedagogical sequences in on- line courses.

Keywords: Video Lectures, Video Analysis, MOOC, Online Education, Instructional designer, educational videos.

recientemente se habla de (Small Private on Line Courses), que es muy similar a la definición que plantea Clark (2013) como Group MOOC.

De igual manera, se habla de otro tipo de tecnología asociada el uso de teléfonos móviles "MOOcast" que propone interconectar el contenido de los cursos MOOC a las comunicaciones a través del móvil. Con la tecnología screencast, un usuario puede enviar contenido desde un teléfono (YouTube o Netflix) en un televisor. Su función clave como facilitador para acceder a los contenidos de aprendizaje es probablemente la más importante (Tabuenca, Kalz \& Löhr, 2017). Osuna-Acedo, Marta-Lazo \& Frau-Meigs (2018) explican que ya podemos hablar de la era postMooc con aproximaciones como el sMOOC (Social Massive Open Online Course), llegando a lo que denominan $\mathrm{tMOOC}$, $\mathrm{t}$ de transferencia de conocimiento proponiendo tareas auténticas que permiten que este tipo de MOOC encaminados a la transformación pedagógica. En estos últimos casos se superan las propuestas de MOOC enfocados en contenidos para reelaborar los cursos centrados en trabajo colaborativo.

Para el estudio que aquí nos ocupa nos hemos centrado en la construcción de un instrumento para analizar vídeo-lecciones contenidas en xMOOC. En éstos, los estudiantes se relacionan de manera individual con los recursos que despliega la plataforma y realiza pruebas automatizadas (Clark, 2013). No se privilegia la interacción entre los participantes, sino con 
los recursos, por lo que es interesante analizar la vídeo-lección, ya que es el medio casi exclusivo de mediación en este tipo de cursos.

El aprendizaje a través de vídeo ha sido objeto de variadas reflexiones (Giannakos, Sampson, Kidzinski \& Pardo, 2016; Mohamed, Amine \& Schroeder, 2014; Van Der Sluis, Ginn, Van Der Zee \& 2016). El desarrollo de los MOOC ha hecho que este tipo de aprendizaje adquiera más relevancia, de manera que muchos estudios se preguntan en qué medida las vídeo-lecciones inciden en la innovación pedagógica en ambientes de aprendizaje mediados por tecnología o si por el contrario sólo replican un modelo transmisivo de enseñanza.

En la primera parte del artículo se explican las bases conceptuales alrededor del uso de vídeo en la construcción de MOOC, propuestas de líneas narrativas para su producción y las preguntas que plantea la revisión de literatura sobre el enfoque transmisionista de este tipo de cursos. Luego se explica la metodología de construcción y validación del instrumento por pares expertos y su posterior pilotaje. En las conclusiones se plantean nuevas líneas de trabajo a partir del uso de la herramienta para generar ideas que nos permitan producir vídeo-lecciones potentes y creativas.

Cabe anotar que el estudio se centró en vídeo-lecciones contenidas en xMOOC y no en otro tipo de cursos masivos, ya que se buscó observar qué pasa con la mediación audiovisual cuando el curso no tiene un diseño instruccional basado en conexiones o interacciones con sus pares, sino en la visualización de vídeos.

La construcción del instrumento, que aquí se presenta, hace parte de una tesis doctoral en Comunicación y Educación realizada, entre 2015 y 2018, en donde se analiza el contenido de un grupo de vídeo-lecciones de xMOOC de la plataforma Miriada X, resultados que se expondrán en artículos posteriores.

\subsection{El uso de videos en un MOOC}

Los tipos de vídeo-lección más usados en los xMOOC son los de tipo magistral con soporte en presentaciones power point (Atapattu \& Falkner, 2016; Guo, Kim \& Robin, 2014; Evans, Baker \& Dee, 2015). La variedad de vídeo-lecciones también se ha configurado a partir del tipo de tecnología que se usa para su producción o el lugar donde se realiza la grabación, y se clasifican en: talking head (busto parlante), las grabadas en el salón de clases, picture in picture (imágenes con voz en off), captura de una tablet (tipo Khan academy), animación con voz en off, chroma o green screen, entrevista y tutorial (Chauhan \& Goel, 2015; Hansch, Hillers, McConachie, Newman \& Schmidt, 2015).

La revisión de literatura en bases de datos especializadas ha permitido comprobar la predominancia de estudios centrados en la observación de prácticas de comportamiento de los usuarios frente a las vídeo-lecciones, tipo seguimiento de escaneo visual, análisis de los patrones de observación y permanencia según el número de repeticiones en el visionado de los vídeos. También se observa una tendencia a establecer características ideales para este tipo de piezas audiovisuales como duración, preferencias y recomendaciones de manejo visual. No obstante, son escasas las aportaciones relacionadas con la estructura narrativa de las vídeo-lecciones, al respecto, los estudios de Cortes (2015) ofrecen una lista de verificación para reconocer elementos de la Teoría de Carga Cognitiva en espacios multimedia. Con ello se explica en qué medida ciertos elementos multimedia favorecen el aprendizaje y se plantea un instrumento para el análisis de vídeo-lecciones desde el punto de vista de atributos multimedia. A diferencia de este estudio, el instrumento que se presenta en este artículo plantea el análisis en la forma en que se comunica la lección y la estructura narrativa audiovisual.

La producción de recursos audiovisuales para los MOOC debe enfocarse en un análisis de las posibilidades de la comunicación audiovisual aplicada a la elaboración de contenidos didácticos. Estos vídeos deberían diseñarse como piezas audiovisuales que puedan proporcionar experiencias de aprendizaje despertando emo- 
ciones (Gértrudix, Rajas \& Álvarez, 2017; Koumi, 2006). Al respecto se reconocen experiencias de producción de contenido para este tipo de cursos que incluyen videoconferencias simuladas, documentales que les llaman reflexivos, narraciones animadas y hasta el uso de fábulas chinas o relatos orientales para diseñar lo que se define como experiencias de aprendizaje que buscan contextualizar y vincular al estudiante como audiencia que se involucra en la narración (Morris, 2017).

Thomson, Bridgstock \& Willems (2014), por su parte, explican que la narrativa debe estar en un contexto, tener un propósito claro, contar una historia y ser corto y conciso. El vídeo debe estar alineado con una construcción de significados alrededor del objetivo de aprendizaje. El material también debe estar disponible para ser usado y reusado por la mayor cantidad de público posible.

\subsection{Aprendizaje vs Diseño instruccio- nal en un MOOC}

El aprendizaje en espacios masivos y el diseño instruccional adecuado para que éste suceda plantea muchas dudas acerca de su eficacia y calidad (Aguaded \& Medina-Salguero, 2015; Bartolomé \& Steffens, 2015; Zapata-Ros, 2015). En esta línea, Chiappe, Hine \& Martínez (2015) determinaron que el concepto de "masa" genera unas prácticas estandarizadas para el diseño de ambientes de aprendizaje que redunda en la producción de cursos con estructuras muy similares entre si, centrados en una línea de tiempo con vídeos y quices. Este tipo de arquitectura estándar puede deberse a estrategias inmediatas para responder a la gran demanda de estudiantes con bajos costos de producción audiovisual.

Los MOOC son cursos magistrales con un esquema de clase tradicional y la mayoría no representa una innovación en la manera en qué se organiza un curso virtual (Laaser \& Toloza, 2017; Leal, 2012). El conocimiento abierto entonces se encuentra atrapado en un esquema antiguo pero vendido en un escenario tecnológico que le permite exponerse como innovador.
Esto aumenta las posibilidades de masificación pero no las posibilidades de generar aprendizajes auténticos. Investigadores de diferentes partes del mundo centran su trabajo en demostrar que el cerebro no aprende a base de discursos (Fink, 2008; Torres, 2017). Así, se cuestiona la validez de la clase magistral como monólogo del profesor. Si logramos volcar el video a un lenguaje audiovisual lleno de posibilidades, el valor pedagógico de la vídeo-lección puede aumentar.

En estudios más recientes, Osuna-Acedo, Marta-Lazo y Frau- Meigs (2018) plantean el uso de conexiones a la narrativa de los cursos dentro de los Transfer-MOOC. "Los tMOOC se posicionan como una alternativa educativa disruptiva y como puntos de encuentro entre los participantes, a través de los cuales podemos acceder a la inteligencia distribuida y accesible" (p. 105) En este orden de ideas, Marta-Lazo, ValeroErrazu, Gabelas-Barroso (2018) también desarrollan análisis sobre el uso de Twitter en cursos MOOC como elemento clave en el aumento de la motivación y desarrollo del aprendizaje con los estudiantes. En este tipo de propuestas la vídeolección hace parte de un engranaje colaborativo y no es exclusivamente el core de los cursos.

Pese a los esfuerzos por mejorar la calidad de los vídeos, la producción en línea, estandarizada, limita estos diseños y no abre la posibilidad para nuevas experiencias narrativas. Esto demandaría más tiempo, aumentaría los costos y generaría un flujo de gestión de cursos que no responde a lógicas comerciales. Se necesita un modelo estándar de producción audiovisual para que pueda funcionar la producción masiva, sin embargo, pone sobre la mesa el reto de construir contenidos que den respuesta a un tipo de enseñanza mediada por TIC que responda a nuevos paradigmas de enseñanza.

\subsection{Nuevas narrativas para vídeo-lecciones}

La vídeo-lección puede considerarse como una sesión magistral en vídeo: por tanto, puede divi- 
dirse en los tres momentos clave de una clase: inicio, desarrollo y cierre. En esta estructura, el inicio debería estar marcado por elementos atrayentes que llamen la atención de la audiencia como el uso de preguntas y retos y la activación de conocimientos previos. Por tanto, los primeros minutos han de recurrir a elementos de narración potente que mantengan la motivación, enlazando los contenidos de clases anteriores con lo planteado en el nuevo segmento (Ambrose, Bridges, Di Pietro, Lovett, Norman \& Mayer, 2010; Lang, 2016). Para el desarrollo y cierre, el uso de metáforas, giros de humor, relación del contenido con sucesos de la vida real como se plantean en las charlas TED, son recursos con los que se persigue sembrar una idea en pocos minutos recurriendo a la calidad del discurso oral (Anderson, 2016). En este sentido, el orador debe limitarse a hablar de pocos conceptos, reducir su contenido e integrarlo en un contexto personal, y debe despertar la curiosidad del público con preguntas provocativas y atrayentes. Anderson (2016, p. 1) hace hincapié en que "los oradores a menudo olvidan que muchos de los términos y conceptos que usan son completamente desconocidos por su público. Las metáforas pueden jugar un papel crucial en el ensamblaje de las piezas, porque revelan la forma deseada del patrón, con base en una idea que quien escucha ya entiende".

La producción de vídeo-lecciones considerándolas como unidades narrativas que mantienen el potencial de una historia debería tener en cuenta aspectos clave como la fuerza del discurso del interlocutor y su riqueza para mantener la atención. Así, tiene que estructurarse de tal manera que permita conmover, emocionar, hacer reír y cautivar la atención. Bravo (1996) señala como elementos significativos en una vídeo-lección, el apoyo visual que esté centrado en demostraciones y la calidad del discurso.

Las herramientas de Storytelling pueden ayudar en esta mejora de elementos narrativos de las vídeo-lecciones (Díaz-Barriga \& Hernández 2010). El significado de éstas lo darán la voz y la creatividad del profesor (narrador) para crear y presentar una historia convincente, atractiva, seductora y concreta que estimule las emociones del estudiante que hace las veces de espectador (Edutren, 2017). Todos estos elementos son conceptos difíciles de adoptar en la academia porque se debe usar la economía verbal, la coherencia, la poca ambigüedad, la sensibilidad y la innovación en la producción televisiva para cursos y no todo el mundo tiene el talento de contar historias atractivas recurriendo a elementos como la diversión y/o metáforas audiovisuales con base en el entretenimiento aplicado a la educación (Pastor; 2010; Wakefield, 2009). Sin duda, uno de los principales retos es lograr mantener la atención y motivación para evitar la deserción de estudiantes, sin embargo. Cabe anotar que esta función no recae solamente en los vídeos, también implica la formación del equipo de docentes, no sólo producir los contenidos, sino también gestionar los cursos con gran cantidad de estudiantes (García, Rivera \& Ramírez, 2014).

\section{Material y métodos}

\subsection{Diseño del instrumento}

Dado el objeto del estudio, valorar la estructura de vídeo-lecciones de cursos masivos en línea y la necesidad de analizar esa estructura narrativa y el uso de recursos audiovisuales, se procedió a la elaboración de un instrumento que respondiera a los diferentes conceptos considerados y asumidos tras la revisión de literatura. Se diseñó un primer borrador de la herramienta y luego varias versiones. Finalmente, el instrumento quedó constituido por 25 ítems y cuatro grandes categorías:

- Inicio de la vídeo-lección y principios de engagement. Para ello se incluyen preguntas que hacen alusión a la manera en que el docente da inicio al video. Esto es, si plantea preguntas, si enuncia el objetivo, si contextualiza y da un marco general de los temas que se abordarán en la clase. 
- Desarrollo de la vídeo-lección y principios de secuencias narrativas. Aquí se hacen preguntas que tienen que ver con la manera en que el docente organiza la charla. Si utiliza ejemplos, giros de humor, anécdotas o si relaciona el contenido con problemas de la vida real.

- Cierre de la clase: Conclusiones. Las preguntas de este bloque se relacionan con aspectos relativos a la forma en cómo el profesor engloba todo el contenido de la video lección, cómo ayuda al estudiante a organizar el contenido enunciando las ideas principales vistas durante la charla, $y$ si se cuenta con resúmenes y enlace con la lección que continuará.

- Aspectos técnicos y de soporte narrativo audiovisual. Las cuestiones aquí se refieren a si la video-lección cuenta con cámara fija, efectos de imágenes, imágenes en movimiento y al rol de los gráficos para dar soporte al argumento del profesor durante la vídeo-lección.

El instrumento se ha conformado en una primera parte correspondiente a la caracterización general del curso en la que se plantean cuestiones para recabar la información relativa al nombre del curso, la Universidad, el objetivo de aprendizaje del curso y del módulo, número de módulos, título de la vídeo-lección, tiempo de duración estándar, si se puede conectar con redes sociales asociadas, la participación del estudiante en el contenido, el tipo de vídeo lección (Talking Head, Clases Grabadas en el Salón de clases, Picture in Picture, Power point con voz en off, Captura de una tablet (Khan Academy), Animación con voz en off, Chroma o Green Screen, Entrevista, Tutorial). Y la segunda parte se divide en tres subcategorías: inicio, desarrollo y cierre de la clase. Las tablas siguientes muestran los conceptos teóricos que enmarcan cada bloque de preguntas:

\section{Tabla 1. Cuestiones relacionadas con el desarrollo de la clase}

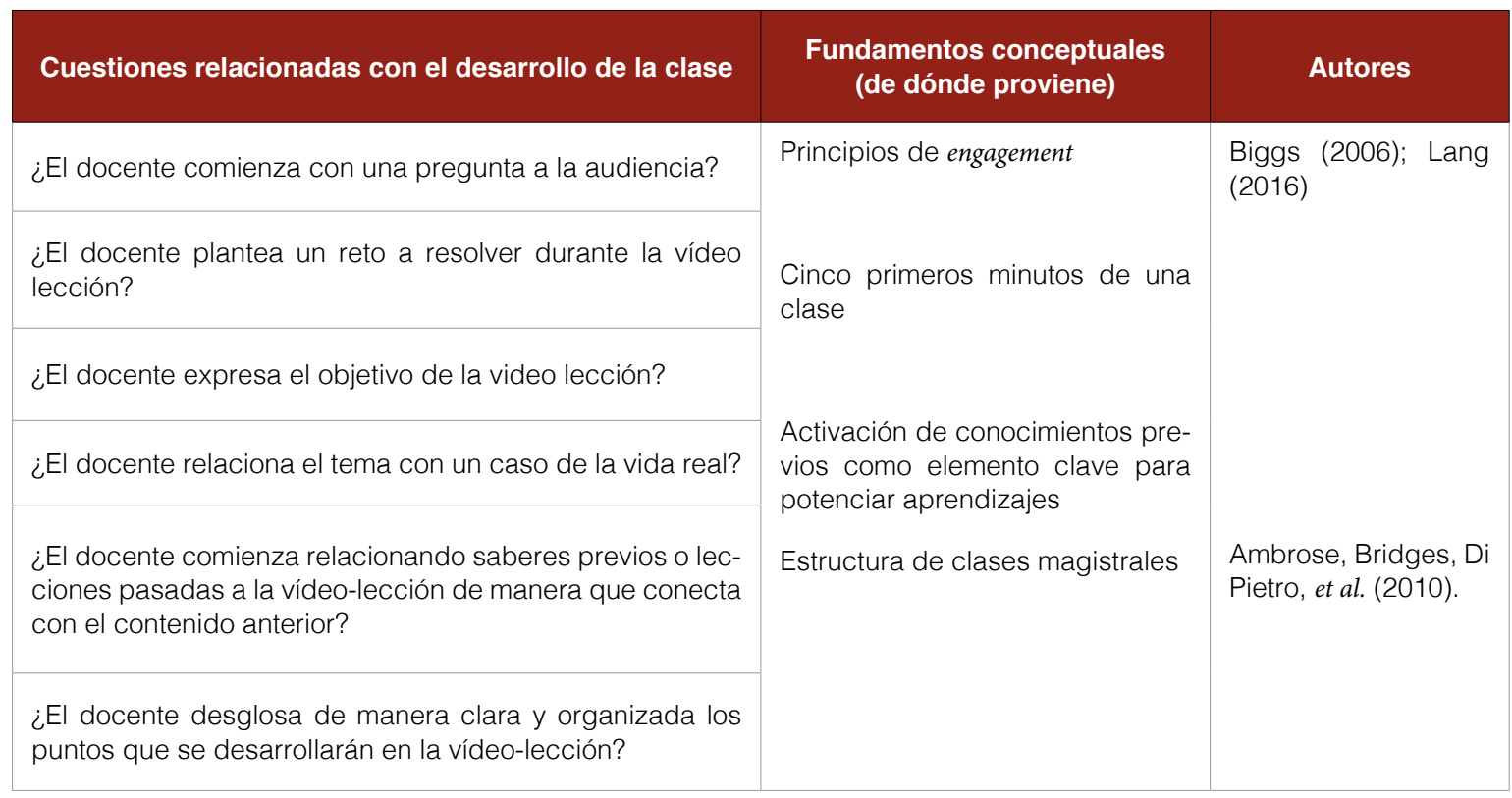

Fuente: elaboración propia. 
Tabla 2. Cuestiones relacionadas con el inicio de la clase

\begin{tabular}{|c|c|c|}
\hline $\begin{array}{l}\text { Cuestiones relacionadas con el } \\
\text { desarrollo de la clase }\end{array}$ & Fundamentos conceptuales & Autores \\
\hline $\begin{array}{l}\text { ¿Se evidencia una sucesión de contenidos o } \\
\text { temáticas? }\end{array}$ & \multirow{6}{*}{$\begin{array}{l}\text { Principios de aprendizaje } \\
\text { Aprendizaje significativo } \\
\text { Conexión del vídeo con emociones }\end{array}$} & \multirow{3}{*}{$\begin{array}{l}\text { Ambrose, Bridges, Di Pie- } \\
\text { tro, et al. (2010). } \\
\text { Díaz-Barriga y Hernández } \\
(2010) \text {. }\end{array}$} \\
\hline ¿El docente usa giros de humor? & & \\
\hline $\begin{array}{l}\text { ¿El docente utiliza anécdotas personales para rela- } \\
\text { cionar el tema de la vídeo-lección? }\end{array}$ & & \\
\hline ¿Existen cambios de ritmo en el vídeo? & & \\
\hline ¿Existen puntos de giro o hechos inesperados? & & Koumi (2006). \\
\hline ¿El docente pone ejemplos de lo que está hablando? & & \\
\hline
\end{tabular}

Fuente: elaboración propia.

Tabla 3. Cuestiones relacionadas con el cierre de la clase

\begin{tabular}{|c|c|c|}
\hline Cuestiones relacionadas con el cierre de la clase & Fundamentos conceptuales & Autores \\
\hline $\begin{array}{l}\text { ¿El docente establece conclusiones de acuerdo con } \\
\text { lo planteado en el inicio de la vídeo-lección? }\end{array}$ & \multirow{6}{*}{$\begin{array}{l}\text { Cinco últimos minutos de la clase } \\
\text { Principios de aprendizaje }\end{array}$} & \multirow{6}{*}{$\begin{array}{l}\text { Lang (2016) } \\
\text { Ambrose, Bridges, Di Pie- } \\
\text { tro, et al. (2010) }\end{array}$} \\
\hline $\begin{array}{l}\text { ¿El docente realiza resúmenes o síntesis de lo abor- } \\
\text { dado en la vídeo-lección a manera de compilado? }\end{array}$ & & \\
\hline $\begin{array}{l}\text { ¿El docente menciona los puntos que se verán en la } \\
\text { próxima lección? }\end{array}$ & & \\
\hline $\begin{array}{l}\text { ¿El docente establece conclusiones de acuerdo con } \\
\text { lo planteado en el inicio de la vídeo-lección? }\end{array}$ & & \\
\hline $\begin{array}{l}\text { ¿El docente realiza resúmenes o síntesis de lo abor- } \\
\text { dado en la vídeo-lección a manera de compilado? }\end{array}$ & & \\
\hline $\begin{array}{l}\text { ¿El docente menciona los puntos que se verán en la } \\
\text { próxima lección? }\end{array}$ & & \\
\hline
\end{tabular}

Fuente: elaboración propia. 


\section{Tabla 4. Cuestiones relacionadas con los aspectos técnicos}

\begin{tabular}{|c|c|c|}
\hline $\begin{array}{c}\text { Cuestiones relacionadas con aspectos } \\
\text { técnicos }\end{array}$ & $\begin{array}{l}\text { Fundamentos conceptuales (de } \\
\text { dónde proviene) }\end{array}$ & Autores \\
\hline $\begin{array}{l}\text { ¿Se evidencian cambios de plano en la cámara? } \\
\text { Esta vídeo-lección cuenta con ayudas visuales } \\
\text { dinámicas? (gráficos en movimiento, infografías } \\
\text { en movimiento) } \\
\text { ¿Las imágenes se relacionan con el contenido de } \\
\text { lo mencionado por el docente a lo largo de la ví- } \\
\text { deo lección? (cambian de acuerdo con lo que va } \\
\text { diciendo y le da soporte a su argumento) } \\
\text { ¿Se usa una gran variedad de imágenes para so- } \\
\text { portar los contenidos? } \\
\text { ¿La vídeo lección está apoyada en diapositivas } \\
\text { de power point? }\end{array}$ & $\begin{array}{l}\text { Narrativas digitales } \\
\text { Vídeo educativo y su valor } \\
\text { didáctico } \\
\text { Diseño y producción de cursos } \\
\text { MOOC } \\
\text { Diseño instruccional } \\
\text { Experiencias visuales y auditivas } \\
\text { en los vídeos educativos. } \\
\text { Teoría Cognitiva del Aprendizaje } \\
\text { Multimedia }\end{array}$ & $\begin{array}{l}\text { Díaz-Barriga y Hernández } \\
\text { (2010). } \\
\text { Area (2000). } \\
\text { Aguaded y Medina-Salguero } \\
\text { (2015). } \\
\text { Guo, Kim y Rubin (2014). } \\
\text { Koumi (2006); } \\
\text { Cortes (2015); }\end{array}$ \\
\hline
\end{tabular}

Fuente: elaboración propia.

Para la elaboración del cuestionario se utilizó la plataforma Question Pro, ya que esta brinda muchas facilidades para la gestión de la información para encuestas e instrumentos de esta naturaleza. El instrumento está disponible en el siguiente link: https://goo.gl/W39xvv

\subsection{Validación del instrumento}

La validez del instrumento se sometió a juicio de expertos, seleccionándose los pares por su trayectoria y publicaciones acerca del tema de los MOOC. De este modo, en la nómina de revisores está una doctora en Comunicación y Educación de la Universidad de Santiago de Compostela (exp.1) que ha trabajado en la producción de MOOC para la plataforma Miriada X, un docen- te e investigador de la Universidad Rey Juan Carlos (exp.2), y una doctora en Ciencias de la Información de la Universidad de Zaragoza con amplia trayectoria en temas de competencia mediática y MOOC (exp.3). Para el juicio de expertos se diseñó una guía de evaluación en donde se explicaban las variables de la investigación, objetivos y necesidades expresadas del instrumento.

\section{Análisis y resultados}

Los resultados finales obtenidos en la validación del cuestionario se recogen en la tabla 5, valorándose en un intervalo de 3 a 1 , en el que el 3 significa muy de acuerdo, 2 de acuerdo, y 1 totalmente en desacuerdo. 
Tabla 5. Media de resultados de la valoración de los expertos

\begin{tabular}{|l|l|l|l|l|l|}
\hline Experto & $\begin{array}{l}\text { Se compone de un } \\
\text { número razonable } \\
\text { de cuestiones }\end{array}$ & $\begin{array}{l}\text { La enunciación de } \\
\text { las preguntas es } \\
\text { clara }\end{array}$ & $\begin{array}{l}\text { Las cuestiones } \\
\text { permiten lograr } \\
\text { el objetivo que } \\
\text { pretende el } \\
\text { instrumento }\end{array}$ & $\begin{array}{l}\text { Las cuestiones son } \\
\text { significativas y de- } \\
\text { mandan informa- } \\
\text { ción relevante para } \\
\text { el tema a tratar }\end{array}$ & $\begin{array}{l}\text { El cuestionario } \\
\text { integra interrogan- } \\
\text { tes sobre todas } \\
\text { las dimensiones a } \\
\text { analizar }\end{array}$ \\
\hline 1 & 3 & 3 & 2 & 3 & 3 \\
\hline 2 & 2 & 3 & 2 & 2 & 2 \\
\hline 3 & 3 & 3 & 2 & 2 & 2 \\
\hline
\end{tabular}

Coeficiente de Proporción por Rangos

Fuente: elaboración propia

Se asume como criterio que un instrumento de recolección de datos con un Coeficiente de Proporción de Rango por encima de 0,75 es válido. Cuanto más se acerque al CPR a uno (1) más se garantiza la validez del contenido del instrumento (Ramírez, 2004). Como se puede observar, la valoración fue positiva por los expertos. Luego del juicio de expertos, se realizó un pilotaje del instrumento con un grupo de 10 vídeo-lecciones de la plataforma Miriada X, una de las plataformas más importantes para universidades de habla hispana. Hernández, Fernández y Baptista (2010) afirman que "en las muestras no probabilísticas, la elección de los elementos no depende de la probabilidad, sino de causas relacionadas con las características de la investigación o de quien hace la muestra" (pp. 189190). La validación y pilotaje del instrumento reflejó una alta consistencia interna en sus preguntas y cumple con sus objetivos.

\section{Discusión y conclusiones}

El instrumento propuesto se convierte en una herramienta para el análisis de vídeo-lecciones y permite hacer una lista de chequeo a diseñadores instruccionales y docentes sobre los componentes de este tipo de piezas ya que divide su caracterización en los momentos clave de una clase (inicio- desarrollo y cierre).
El discurso prevalece en este tipo de material, por lo que se hace necesario un desglose detallado de cómo se cuenta la clase y qué tipo de elementos narrativos incluye. Teniendo en cuenta que la fuerza de la producción recae en el Green Screen con soporte en el Power Point (Atapattu \& Falkner, 2016; Guo, Kim \& Robin, 2014; Evans, Baker \& Dee, 2015) el cuestionario permite analizar el tipo de gráficos que soportan la vídeo-lección, el tipo de expresiones y cómo se estructura de principio a fin. Korving, Hernández \& De Groot (2016) afirman que, las vídeo lecciones enriquecidas con imágenes, que dan sentido al discurso del profesor, cuentan con mayor chance de ser vistas. En este orden de ideas, en el cuestionario no sólo se pregunta por el tipo de gráfico, sino por el uso de éste para darle valor al discurso del profesor. Si da lo mismo descargar un podcast que ver el vídeo, los gráficos no están contribuyendo a la narración.

En este sentido, el instrumento permite proponer cuestionamientos sobre cómo despertar la curiosidad de los estudiantes a partir del uso de preguntas, sin incurrir en gastos exagerados de producción y orienta a los docentes sobre nuevas propuestas para estructurar los guiones de cada clase. Todo esto desde un enfoque interdisciplinar para brindar mayor variedad a las investigaciones sobre el tema (Veletsianos \& Shepherdson, 2015. 
La primera parte del instrumento plantea cuestiones sobre cómo comenzar una vídeolección, Lang (2016) lo define como la capacidad que tiene el profesor de usar los cinco primeros minutos de su clase para captar la atención de sus estudiantes. Se hace referencias a recursos cómo preguntas, conexiones con la clase anterior, resolver un misterio, plantear una secuencia. Conectar explícitamente con el nuevo material al conocimiento previo del propio curso no es automático, necesitamos ayudar a los estudiantes resaltando estas conexiones (Ambrose, Bridges, Di Pietro et al., 2010) En cuanto al desarrollo y cierre de la vídeo-lección, el instrumento plantea el uso de recursos como giros de humor y relacionar el contenido del curso con situaciones de la vida real. El manejo de las emociones y herramientas de Storytelling agregarán valor a la producción de la vídeo-lección (Díaz-Barriga \& Hernández, 2010; Koumi, 2006).

Para Laaser \& Toloza (2017) el uso actual del video en plataformas LMS es realmente deficiente en términos de explotar sus características como medio de comunicación. "Conceptos tales como xMOOC y Flipped classroom no son un paso adelante, sino un paso atrás en el desarrollo de vídeo educativo" (Laaser \& Toloza, 2017, p. 5). Este tipo de estudios evidencia la necesidad de estructurar diseños instruccionales de vídeo-lecciones que demuestren un equilibrio entre la calidad del contenido y la manera en cómo se cuenta.

Dentro de los aspectos a resaltar por los expertos estuvo el incluir dentro del instrumento propuesto, cuestiones que indagaran por el uso de redes sociales en las vídeo-lecciones (MartaLazo, Valero-Errazu \& Gabelas-Barroso, 2018). Estos ítems se incluyeron en la versión final del cuestionario. Los expertos también valoraron el uso de preguntas dicotómicas ya que se facilita el diligenciamiento de la herramienta.

Se espera, en estudios posteriores, publicar los resultados del uso del instrumento con la muestra total de vídeo-lecciones, extender el rango de análisis y delimitar más información sobre modelos de producción que incluyen pro- puestas asociadas al edu-entretenimiento. Este uso plantea el convertir los cursos en series tipo Netflix y que respondan a lógicas de consumo de vídeo vía streaming. Se espera aplicar esta propuesta en cursos completos y analizar su efecto en la construcción de ambientes de aprendizaje en línea.

La expectativa es que el instrumento pueda ser un primer aporte en estas transformaciones y que esté disponible, a mediano plazo, a investigadores, docentes, administradores de plataforma y diseñadores instruccionales para hacer listas de verificación de los mínimos de producción y estructuración del discurso en este tipo de piezas audiovisuales y lograr cambios en su estructura narrativa.

\section{Referencias bibliográficas}

Aguaded, I., \& Medina-Salguero, R. (2015). Criterios de calidad para la valoración y gestión de MOOC. RIED. Revista Iberoamericana de Educación a Distancia, 18(2), 119-143. Recuperado de https://bit.ly/2teQte0

Ambrose, S., Bridges, M., Di Pietro, M., Lovett, M., Norman, M., \& Mayer, R. (2010). How Learning Works. 7 research-based principles for smart teaching. Estados Unidos: JosseyBass.

Anderson, C. (2016). Charlas Ted. España: Gestión 2000.

Atapattu, T., \& Falkner, K. (Abril de 2016). A framework for topic generation and labeling from MOOC discussions. En Proceedings of the Third ACM Conference on Learning Scale, 201-204.

Bartolomé, A., \& Steffens, K. (2015). ¿¿Son los MOOC una alternativa de aprendizaje? Comunicar 44, 91-99. http://dx.doi.org/10.3916/C44-2015-10

Bravo, L. (1996). ¿Qué es el vídeo educativo? Comunicar, 6, 100-105. Recuperado de https://bit.ly/2H8AbY0

Biggs, J. (2006). Calidad del Aprendizaje Universitario. España: Narcea.

Clark, D. (4 de Abril de 2013). MOOCs: taxonomy of 8 types of MOOC. [Mensaje en un blog]. Recuperado de https://goo.gl/UGb84y 
Cortes, D. (2015). Videos educativos en los Cursos Masivos, Abiertos y en Línea (MOOC). Una propuesta de análisis desde la Teoría Cognitiva del Aprendizaje Multimedia. Tesis de postgrado. México: Universidad de Guadalajara.

Chauhan, J., \& Goel, A. (2015). An Analysis of Video Lecture in MOOC.ICT in Education, Research and Industrial Applications: Integration, Harmonization and Knowledge Transfer, 35. Recuperado de https://goo.gl/hFVwjA

Chiappe, A., Hine, N., \& Martínez, J. (2015). Literatura y práctica: una revisión crítica acerca de los MOOC. Comunicar, 44, 09-18.

https://doi.org/https://doi.org/10.3916/C44-2015-01

Díaz-Barriga, F., \& Hernández, G. (2010). Estrategias docentes para un aprendizaje significativo, una interpretación constructivista. México: McGraw Hill.

Downes, S. (Febrero 3 de 2007). What connectivisme is? [Mensaje en un blog]. Recuperado de https://bit.ly/2JdgXql

Edutren (febrero de 2017). Storytelling. Edutren. Recuperado de https://bit.ly/2JkqAmg

Evans, B., Baker, R., \& Dee, T. (2016). Persistence Patterns in Massive Open Online Courses (MOOCs). The Journal of Higher Education, 87(2) 206-242.

https://doi.org/10.1080/00221546.2016.11777400

Fink, D. (2008). Una guía auto-dirigida al diseño de cursos para el Aprendizaje Significativo. Estados Unidos: Jossey-Bass.

García, A., Rivera, N., \& Ramírez, M.S. (2014). MOOC: principales problemáticas que enfrenta un equipo de Team Teaching. Memorias del Encuentro Internacional de Educación a Distancia, 3(3) Recuperado de https://bit.ly/2JLIEWr

Gértrudix, M., Rajas, M., \& Álvarez, S. (2017). Metodología de producción para el desarrollo de contenidos audiovisuales y multimedia para MOOC. RIED. Revista Iberoamericana de Educación a Distancia, 20(1), 183-203. https://doi.org/10.5944/ried.20.1.16691

Giannakos, M., Sampson, D., Kidzinski, L., \& Pardo, A. (2016). Enhancing Video-Based Learning Experience through Smart Environments and Analytics,SE@VBL@1 (6). Recuperado de https://bit.ly/2lnrdxT

Guo, P., Kim, J., \& Rubin, R. (marzo 4 de 2014). How video production affects student enga- gement: an empirical study of MOOC videos. Conferencia llevada a cabo en ACM conference on Learning. Estados Unidos. http://dx.doi.org/10.1145/2556325.2566239

Hansch, A., Hillers, L., McConachie, K., Newman, C., \& Schmidt, J. (2015). Video and Online Learning: Critical Reflections and Findings from the Field. HIIG Discussion Paper Series, 2, 6-31. http://dx.doi.org/10.2139/ssrn. 2577882

Koumi, J. (2006). Designing video and multimedia for open and flexible learning. Designing Video and Multimedia for Open and Flexible Learning, 1, 1-237. http://dx.doi.org/10.4324/9780203966280.

Laaser, W., \& Toloza, E. (2017). The Changing Role of the Educational Video in Higher Distance Education. The International Review of Research in Open And Distributed Learning, 18(2). http://dx.doi.org/10.19173/irrodl.v18i2.3067

Lang, J. (2016). Small Changes in Teaching: The First 5 Minutes of Class. [Mensaje en un blog]. Recuperado de https://bit.ly/2tSosau

Leal, D. (24 de febrero 2014). ¿MOOC o no MOOC? [Mensaje en un blog].

Recuperado de https://bit.ly/2I7E7cb

Marta-Lazo, C., Valero-Errazu., D., \& Gabelas Barroso, J. A. (2018). Uso de Twitter en los MOOC: Nuevas formas de interacción juvenil y su influencia en el aprendizaje. Revista Latina de Comunicación Social, 73, 1333-1352.

http://dx.doi.org/10.4324/9780203966280.10.4185/RLCS-2018-1309. Marqués, P. (1999). Los vídeos educativos: tipología, funciones y orientaciones para su uso. Recuperado de https://goo.gl/JaF9n5

Mohamed, F., Amine, C. \& Schroeder, U. (2014). The State of Video-Based Learning: A Review and Future Perspectives. International Journal on Advances in Life Sciences, 6(3-4), 122-135. Recuperado de https://goo.gl/SWRP1m

Osuna-Acedo, S., Marta-Lazo, C. \& Frau-Meigs, D. (2018). From sMOOC to tMOOC, learning towards professional transference. ECO European Project. [De sMOOC a tMOOC, el aprendizaje hacia la transferencia profesional: El proyecto europeo ECO]. Comunicar, $55,105-114$. https://doi.org/10.3916/C55-2018-10

Raposo, M., Martínez, E., \& Sarmiento, J. (2015).Un estudio sobre los componentes pedagógicos 
de los cursos online masivos. Comunicar, 44, 27-35. https://doi.org/10.3916/C44-2015-03

Ramírez, T. (2004). Cómo hacer un Proyecto de Investigación. Venezuela: Panapo.

Siemens, G. (2005). Connectivism: A learning theory for the digital age. International Journal of Instructional Technology and Distance Learning, 2(1), 3-10.

Recuperado de https://bit.ly/1YMDmrf

Tabuenca, B., Kalz, M., \& Löhr, A. (2017). MoocCast: Evaluating Mobile Screencast for Online Courses. Universal Access in the Information Society. ISSN 1615-5297. https://doi.org/10.1007/s10209-017-0528-x.

Torres, A. (6 de febrero de 2017). Los últimos minutos de la clase magistral. [Mensaje en un blog]. Recuperado de https://bit.ly/2jSrhXS
Van Der Sluis, F., Ginn, J., \& Van Der Zee, T. (Abril de 2016). Explaining student behavior at scale: the influence of video complexity on student dwelling time. En Proceedings of the $3 d$ 2016 ACM Conference on Learning at Scale. Edinburgo, Reino Unido.

Veletsianos, G., \& Shepherdson, P. (2015). Who studies MOOCs? Interdisciplinarity in MOOC research and its changes over time. The International Review of Research in Open and Distributed Learning, 16(3). http://dx.doi.org/10.19173/irrodl.v16i3.2202 Zapata-Ros, M. (2015). Calidad en enseñanza abierta online universitaria: del aula virtual al MOOC. Campus Virtuales, 4(2), 86-107. Recuperado de https://bit.ly/2tnX0Co 


\section{Adolescentes gays en la era digital: orientaciones para la educación}

\section{Gay teenagers in the digital age: orientations for educators}

Dr. Lander Calvelhe Panizo es profesor asociado de la Universidad Pública de Navarra (España) (lander.calvelhe@unavarra.es) (https://orcid.org/0000-0003-2178-0686)

Recibido: 2018-07-23 / Revisado: 2018-09-25 / Aceptado: 2018-11-07 / Publicado: 2019-01-01

\section{Resumen}

Internet ofrece múltiples oportunidades de acceso a información e interacciones con distintas personas de manera rápida y fácil. Este artículo presenta los resultados de una investigación sobre los procesos de auto-identificación y socialización como gays de doce jóvenes entre los 14 y los 19 años en dicha era digital. En él se analizan experiencias y prácticas a partir de sus testimonios en los que aparece la necesidad de conexión con sus iguales, y al mismo tiempo, el miedo subyacente a la homofobia. En coherencia, Internet es percibido como un lugar de esperanza y también de incertidumbre, y por lo tanto, es utilizado con cautela desde el anonimato. También se evidencia cómo este tipo de prácticas en Internet son más comunes durante un periodo de confusión sobre las consecuencias de su homosexualidad, y es así que decaen una vez su socialización como gays en la vida real está más extendida. La metodología de esta investigación se basa en el análisis del contenido de entrevistas individuales y en profundidad de la muestra elaborada durante dos años, al mismo tiempo que bebe de las aportaciones de la investigación narrativa por su interés por el relato y la anécdota como aproximaciones a la experiencia vivida. Finaliza proponiendo una serie de orientaciones educativas basadas en los resultados del estudio a la vez que las pone en relación con diferentes materiales y reflexiones de otros autores.

Descriptores: Adolescencia, identidad, homosexuales, entrevista, internet, análisis de contenido.

\begin{abstract}
Internet offers multiple opportunities to access quickly and easily to information and interactions with other people. This article presents the results of a research on the processes of self-identification and socialization as gay of a group of twelve teenagers between 14 and 19 y. o. in this digital age. Here their experiences and practices are analysed based on their testimonies in which we find the need for connection with their peers, and at the same time, the fear of homophobic bullying. In coherence, Internet is perceived as a place of hope and also of uncertainty, hence it is used with caution and anonymity. Moreover, there are evidences on how these Internet practices are more common during a period of confusion about the consequences of their homosexuality, and also on how their decline once the teenagers' socializations as gay in real life are more widespread. The methodology of this research is based on the analysis of the content of the individual in-depth interviews of a sample elaborated during two years, while taking into account the
\end{abstract}

Forma sugerida de citar: Calvelhe Panizo, L. (2019). Adolescentes gays en la era digital: orientaciones para la educación. Alteridad, 14(1), 65-75. https://doi.org/10.17163/alt.v14n1.2019.05 
contributions of the narrative research and its interest on storytelling and the anecdote as approximations to lived experience. The article ends proposing educational implications based on the results of the study,

\section{Introducción}

Las investigaciones españolas cuyo objeto de estudio son las experiencias de adolescentes que se identifican como lesbianas, gays, transexuales y bisexuales (LGTB) son tan recientes como escasas (Generelo, Pichardo \& Galofré, 2008; Coll-Planas, Bustamante \& Missé, 2009) en comparación, por ejemplo, con EEUU y Australia que cuentan con más de 30 años de tradición (Savin-Williams, 2009; Robinson et al., 2014). Esta carencia contrasta con dos fenómenos: (i) la considerable visibilidad de la figura del adolescente gay en los medios de comunicación desde finales de los años 90, especialmente en las series de televisión (Al salir de clase, Física o Química y Aída, como producciones españolas; o Glee, Misfits, Shameless, norteamericanas, pero emitidas también en español). Y (ii), con el interés por la educación en la diversidad afectivo-sexual y de género (DASyG) desarrollado desde inicios de los años 2000 en el mismo país, coincidiendo con la aprobación de la Ley Orgánica de Educación del 2006, la primera en la historia de España en nombrar este tipo de diversidad (Real Decreto 1631/2006). Este interés se ha materializado en la publicación de numerosas guías y materiales educativos (Generelo \& Moreno Cabrera, 2007; Platero \& Gómez, 2007), además de monográficos en revistas especializadas (Ferriols, 2011; Huerta, 2014). Ante tal contraste, el presente artículo viene a compartir parte de los resultados de una investigación financiada por el Ministerio de Ciencia e Innovación. Su primer objetivo es ofrecer el análisis de una serie de prácticas y experiencias en el ámbito de Internet, descritas por doce adolescentes de entre los 14 y los 19 años en torno a su auto-identificación y socialización como gays. Al mismo tiempo, el segundo and putting them in relation with other authors' materials and reflections.

Keywords: Adolescence, identity, homosexuality, interviews, Internet, content analysis.

objetivo es señalar una serie de orientaciones educativas que nacen a partir de tales resultados.

Respecto a las cuestiones teóricas que enmarcan este artículo procede desarrollar varios conceptos clave y sus relaciones entre sí. Siguiendo el trabajo de Foucault (2008) y de D’Emilio (1994), la homosexualidad y su correlato gay pueden entenderse como fenómenos históricos resultantes del desarrollo de lo conocido como sociedad del bienestar. Según Weeks (2003), la identidad gay es una ficción necesaria, producto de la necesidad de encontrar confort y comunidad; al mismo tiempo que Butler (2010) la vincula con la necesidad de devenir sujetos inteligibles en sociedades que otorgan un gran poder a las cuestiones de género, sexo y sexualidad. Estas cuestiones estarían reguladas por el miedo a encarnar lo abyecto, es decir, a ser el objeto de la injuria inter/trans/homófoba (CollPlanas, 2010). De ahí la importancia de los roles de género, no sólo entre hombres y mujeres, también en las relaciones endogrupales, en este caso entre los propios homosexuales.

Desde esta perspectiva, la identidad gay es entendida como una identidad cultural (Hall, 2005), y por tanto, en constante negociación y proceso de aprendizaje. Ya el trabajo de Troiden (1989) aporta evidencias sobre cómo, previamente a la auto-identificación y socialización gay, toda persona debe conocer la existencia de dicha identidad y de sus características principales, para así poder evaluar si las comparte o se asemeja más que difiere. A su vez, dicha persona debe saber que existen otras que, anterior y/o coetáneamente, encarnan dicha identidad gay. En este sentido, Troiden presenta un proceso de aprendizaje identitario a través de diferentes estadios y conceptos de los cuales destacamos: (i) las fases de confusión y la de aceptación, ya a que suponen el punto de inflexión de dicho proceso; 
y (ii), el concepto de "disembodied affiliation", la afiliación a la homosexualidad sin haber conocido en persona a alguien abiertamente gay, en este caso debido al entorno que nos ocupa, Internet.

Según recogen varios estudios, los jóvenes aprenden qué significa es ser gay en ámbitos como el escolar (Epstein \& Johnson, 2000; Renold, 2005), en los medios de comunicación (Riggle, Ellis \& Crawford, 1996; Bond-Raacke et al., 2007; Gomillion \& Giuliano, 2011), y más recientemente en Internet (Laukkanen, 2007; Alexander \& Losh, 2010; de Abreu, 2017). En el artículo de Szulc \& Dhoest (2013) se profundiza y actualiza la idea ya presentada por Hillier et al. (1998) sobre cómo la red es un lugar de aprendizaje/ensayo para lesbianas, gays y bisexuales (LGB). También se concluye que el uso de Internet en relación a la identidad sexual es significativamente mayor antes y alrededor de las primeras socializaciones o salidas del armario. Concretamente se incrementan tanto las visitas a páginas webs consideradas LGB como las búsquedas de contacto con otras personas LGB, al mismo tiempo que se inicia el consumo de pornografía. Todo ello generalmente desde el anonimato y con el objetivo de romper lo que Kielwasser \& Wolf (1992) denominan como la "pluralistic ignorance", el desconocimiento de que existen otras personas con su misma atracción sexual.

Revisando estos estudios, en el trasfondo de todos ellos aparece lo que Barnhurst nombra como "the queer paradox of technology", es decir, la convivencia de esperanza y peligro que genera Internet entre los adolescentes gays (2007, p. 13). En el caso de los trabajos realizados por Laukkanen (2007) y Alexander \& Losh (2010), ambos concluyen que Internet está lejos de ofrecer una "sexual/gender liberation", ya que los usos de la red están mediados por tres cuestiones capitales:

- Las características de los propios espacios web, por ejemplo si se trata de una red social dirigida específicamente a gays o no.

- Los "readings" que las personas online realizan de las representaciones/comunicaciones de resto. Es decir, el factor de las audiencias, las posibles audiencias y el manejo de las mismas (Boyd, 2014).

- Y por último lo que Lipton (2008) denomina como "queer reading practices", lecturas entre líneas realizadas en clave homosexual.

\section{Metodología}

Este artículo forma parte de una investigación cualitativa que intenta dar cuenta de un fenómeno $y$, al mismo tiempo, interpretarlo desde el sentido que sus protagonistas le otorgan (Denzin \& Lincoln, 2000). Para ello, se realizaron doce entrevistas semi-estructuradas e individuales siguiendo un guión temático de preguntas abiertas (Heath et al., 2009) a chicos de entre los 14 y los 19 años que se auto-identificaron como gays. Varias investigaciones en torno a este tipo de adolescentes han reflexionado y evidenciado la importancia de la selección, organización y comunicación con los participantes y, muy especialmente, las dificultades de acceder a ellos (Savin-Williams, 2009; Generelo, Pichardo \& Galofré, 2008; Kielwasser \& Wolf, 1992).

En consecuencia, la presente investigación también cuidó de tales aspectos, tanto fue así que la configuración de su muestra supuso el trabajo de dos años en espacios físicos (centros juveniles municipales, espacios asociativos e institutos de secundaria) y virtuales, llegando a crear un blog y una cuenta en la red social Tuenti. Durante el curso 2011-2012 dicho perfil llegó a contar con más de 300 amistades $y$, a través de él, unos 30 jóvenes recibieron la invitación de participar en la investigación aunque tan sólo uno de ellos la aceptó. Fue mediante aquel primer colaborador que se inició un efecto mariposa al que el resto fue encadenándose. Así, la muestra de la investigación fue laboriosamente formada debido a sus características minoritarias, y finalmente consta de doce adolescentes con diferentes trayectorias: distintos tipos de centros educativos (públicos, concertados y privados, tanto católicos como no), y diferentes lugares y tipos de familia (un joven de Centroamérica, otro de Europa del 
éste, otro de familia numerosa y dos de familias monoparentales), dando así una concentrada representatividad.

Durante el año 2013 se llevaron a cabo las entrevistas con una duración media de una hora y media cada una. Siguiendo las reflexiones de Martino \& Pallotta-Chiarolli (2003) sobre la importancia de la localización, se les propuso a los participantes que eligieran un lugar a su gusto y un momento del día, teniendo en cuenta la duración estimada. También se les informó de la necesidad de que el sitio no fuera muy ruidoso, ya que la conversación iba a ser grabada, asegurándoles que nadie más que el responsable de la investigación tendría acceso a los audios. En general los jóvenes no sugirieron ningún lugar y se les invitó a aprovechar una de las salas de reuniones de la universidad, y la mayoría aceptaron. Al inicio de cada encuentro se les preguntaba si querían saber algo más sobre la investigación, se les recordaba la confidencialidad y la posibilidad de usar pseudónimos mientras que se mantendrían los datos de edad, país de procedencia y ciudad de residencia.

Es necesario recordar que la entrevista es un método de larga tradición en la investigación sobre experiencias personales y procesos de significación (Anderson \& Jack, 1991; Kvale, 2007). Como Kvale señala, las entrevistas son eventos en los que la persona entrevistada y la investigadora colaboran en el entendimiento mutuo, $y$ por lo tanto se parte de la voluntad de escuchar, comprender y compartir. En esta línea también es necesario indicar que la presente investigación bebe a partes iguales de: (i) la investigación narrativa (Clandinin \& Connelly, 2000), por poner en valor la anécdota y el relato como elementos que nos aproximan a las experiencias (Van Manen, 2003), y (ii) del análisis temático, por su cualidad organizativa para el estudio del contenido (Braun \& Clarke, 2006; Ryan \& Bernard, 2000).

Así, tras la transcripción detallada de las entrevistas y la validación por parte de cada colaborador, el trabajo prosiguió cribando todo el material en búsqueda de extractos que pudieran ser agrupados bajo diferentes epígrafes. Estas agru- paciones fueron perfilándose durante un intenso proceso guiado por las preguntas de la investigación e informado por su marco teórico. Como explican Wetherell \& Potter (1996), el primer paso fue seleccionar un subgrupo manejable de datos entre los cientos de páginas, seguido de repetidas relecturas en búsqueda de patrones y organizaciones recurrentes cada vez más específicas.

Es muy importante finalizar este apartado enfatizando que el objetivo final de esta investigación es aprender de las experiencias de los jóvenes entrevistados con respeto y honestidad. Al igual que Coll-Planas, Bustamante \& Missé (2009), el presente artículo entiende y atiende a los malestares de sus colaboradores, pero no cae en posibles victimizaciones. Igualmente, siguiendo a Heath et al. (2009), aquí se da cuenta sus resiliencias y éxitos, pero no se pretende sobredimensionarlos como héroes impostados.

\section{Resultados}

En una primera aproximación a las entrevistas se hace evidente que la mayoría de los colaboradores recurrió a Internet en búsqueda de contenidos e interacciones relacionadas con la homosexualidad y, como se desarrolla a continuación, aquellas experiencias tuvieron un papel relevante en sus procesos de auto-identificación y socialización como gays. Al mismo tiempo, tales experiencias estuvieron marcadas por lo conocido como "the queer paradox of technology" (Barnhurst, 2007), es decir, por lo esperanzador/ liberador y lo limitado/peligroso de Internet, y se dieron especialmente en las fases antes señaladas: entre la confusión sobre su orientación sexual y la aceptación de la misma.

\subsection{Sobre las experiencias esperan- zadoras: "Anonymous Cyber Gay Affiliations" en el espacio de segu- ridad virtual}

La mayoría de los adolescentes entrevistados dijeron haber buscado en Internet testimonios de 
otros chicos, datos en forma de imágenes y textos que les informasen de la existencia de adolescentes gays, tanto en su localidad como en otros lugares. Su objetivo principal era romper con los sentimientos de soledad y aislamiento causados por una "pluralistic ignorance" (Kielwasser \& Wolf, 1992), es decir, por el desconocimiento de iguales en la vida offline. La mayoría lo hicieron desde perfiles anónimos en redes sociales, chats y foros, por lo que nos encontramos ante lo que en esta investigación se denomina como "Anonymous Cyber Gay Affiliations", a raíz del trabajo de Troiden (1989):

[E]stuve hablando con un chico durante mucho tiempo. [F]ue uno de mis apoyos para salir del armario. [L]o conocí en un foro [donde] la gente contaba sus historias, había temas de juegos, temas de libros, de películas, de un montón de cosas... [Pero yo] sobre todo [miraba] las historias de salir del armario, que era lo que más me preocupaba en ese momento... (Mario, 18 años).

$[\mathrm{M}] \mathrm{e}$ hice un Tuenti falso y también un Messenger donde tenía gente que no conocía, otros chicos gays que me suponía... Bueno, pues era para tenerlos sin más. A mí me gusta ver sus fotos, sólo para eso, no para hablar. $[\mathrm{M}]$ e gusta cotillear, enterarme. [...]. No era para ligar, no he salido con gente ni nada, era para enterarme y ver si había gente aquí o no. (Alain, 16 años).

Pues a comienzos del verano pasado, finales de $2^{\circ}$ [de la ESO] empecé a buscar información. $[\mathrm{P}]$ use "blogs adolescente gay", o "adolescente gay"... [...]. Yo quería saber de gente. Ya sé que no soy el único pero me encuentro un poco solo (Marco, 14 años).

En estos procesos de afiliaciones indirectas, un buen número de adolescentes dieron muestras de evaluar los datos que obtenían de sus posibles iguales, especialmente de sus fotografías. Según indicaron, querían comprobar la veracidad de los perfiles, si pertenecían realmente otros chicos gays, y su ubicación:
[En el perfil falso de un chico que sabía que era gay] podía ver sus amistades con otros perfiles y tenía un montón de chicos y supuse que eran de homosexuales que los había conocido. Así fue que comencé a ver que había más gente aquí, que no era yo sólo (Nicolás, 18 años).

Tampoco visité [el foro/chat] mucho [...]. Yo leía que ponían y miraba sus fotos para ver si eran reales, porque eso hay que tenerlo en cuenta (Eneko, 17 años).

Al mismo tiempo Internet no fue sólo una fuente de información, sino un lugar de prácticas previas, y/o paralelas, a una socialización gay offline (Hillier et al. 1998), lo que evidencia que tampoco hay una única salida del armario, sino diversos "degress of outness" (Harry, 1993). De hecho, varios adolescentes describieron Internet como un espacio de seguridad, lo que en algunos casos se acentuaba al contrastar con el peligro o la incerteza que sentían en sus centros escolares y familias:

[E]ste foro lo veía como que tú entrabas y te encontrabas con amigos y ya está. Podías decir cualquier cosa que nadie te iba... En todo lo que leía creo que nunca me encontré una falta de respeto, parecía que estaba bastante controlado por los moderadores (Mario, 18 años).

$\mathrm{Al}$ principio era súper adicto $[\mathrm{y}]$ estuve bastante enganchado [a Tuenti]. Hablaba en chat [con mucha gente] y les contaba mi historia y me decían que no me preocupara, que era algo normal [ser gay]. Así le contaba mi historia a gente desconocida, pero a las personas que conocía no me atrevía a contarles. [...] Al no conocerles me daba confianza, no sé. Como estaban lejos, si no me aceptaban sólo tenía que borrarles (Jesús, 17 años)

Por lo tanto, si estos usos de Internet estaban relacionados con la necesidad de conocer a iguales y de socializarse como gays de forma anónima en espacios de seguridad, tiene sentido que muchos dejaran de realizar este tipo de prácticas al ir desarrollando sus vidas fuera del armario 
en el mundo offline, como también observaron Szulc y Dhoest (2014):

[S]e veía la gente tan maja, ¿cómo no te ibas a no conectar si no tenías nada que hacer? Y así... Ahora ya no me conecto tanto la verdad... (Mario, 18 años).

[A]hora ya no le doy tanta importancia [al Tuenti]. Ahora en Zaragoza todo mi grupo de amigos, que confío mucho en ellos, pues sí nos tenemos mucha confianza ya. (Jesús, 17 años).

Antes de acabar este sub-apartado es importante regresar puntualmente a la llamada "pluralistic ignorance" (Kielwasser \& Wolf, 1992), en tanto que motor de las búsquedas e interacciones en Internet. Leyendo atentamente los testimonios de los colaboradores encontramos que ese desconocimiento de posibles iguales en la vida offline no era totalmente cierto. $Y$ es que, de la misma manera que afirmaban desear conocer a otros jóvenes gays, también confesaban su rechazo a aproximarse e interactuar con aquellos chicos que se decían, o de quienes se decía, que eran gays en sus centros educativos:

Contaban de un chico de no sé qué curso, pero a mí me daba mucho miedo hablar de eso, me ponía muy nervioso y tomaba la opción de callarme para no meter la pata [y] que me descubrieran (Jesús, 17 años).

Ahora sólo conozco a uno, y no lo conozco, sino que es [...] el amigo de mi mejor amiga y un día en el pasillo este chico se lo dijo a una profesora "Oye Inés, soy gay". [Y] no sé [si quiero hablar con él] parece majo, pero no sé... No lo conozco de nada (Alain, 16 años).

Ante esta contradicción se puede interpretar que el motivo fundamental por el que los colaboradores no desarrollaron afiliaciones directas, y utilizaron Internet y el anonimato para interactuar con sus iguales, fue el miedo a la injuria/estigma inter/trans/homófoba. En otras palabras, no fue únicamente la ignorancia de la existencia de iguales, sino el temor a las consecuencias de que en el mundo offline se les asociase con chicos con potencial de ser injuriados/ estigmatizados y, por lo tanto, serlo ellos mismos.

\subsection{Sobre los límites y peligros: El miedo a la salida forzada del armario y des- confianza endogrupal en Internet}

Como se desarrolla a continuación, los principales peligros que emergieron y regularon las prácticas en Internet de los adolescentes entrevistados fueron los temores sobre:

- La posibilidad de que diferentes círculos sociales, on y offline, se encontraran accidentalmente (Boyd, 2014), y tal colapso les sacase del armario sin su control.

- La posibilidad de que entre las audiencias invisibles con las que interactuaban en Internet, se encontrasen con la figura del homosexual pervertido, aquella que todavía relaciona la homosexualidad con la patología (Foucault, 2008).

En primer lugar, la mayoría de los adolescentes nos informó de prácticas en Internet cuyo principal objetivo era mantener en secreto sus actividades vinculadas a la homosexualidad, sobre todo cuanto más jóvenes eran y más oculta tenían su homosexualidad:

Tengo dos [perfiles de Tuenti, un real y otra falso] y los uso depende del caso (Óscar, 18 años).

$[\mathrm{H}]$ ay un canal dedicado a este tema [de la homosexualidad en Youtube]. [...]. No [lo comparto porque] en Tuenti tengo demasiada gente del instituto; lo puse en GooglePlus y en Twitter (Gael, 15 años).

Tales prácticas y experiencias en Internet formaron parte del aprendizaje del manejo de su propia auto-identificación y socialización como gays. Según sus testimonios, muchos sabían que sus vidas online podían informar a quienes las 
observasen, y/o a quienes interactuaban con ellos, de su orientación. Es decir, habían desarrollado la consciencia de que sus búsquedas y usos en Internet eran extensiones de su auto-identificación como gays, y por lo tanto precisaban de un manejo estratégico debido a su potencial de injuria/estigma (Orne, 2011). Es más, a pesar del cuidado puesto, algunos contaron anécdotas en las que informaciones o prácticas en Internet en torno a la homosexualidad fueron detectadas por sus familiares, lo que les sacó del armario de manera indirecta e involuntaria:

[M]i padre alguna vez me comentó que se me había olvidado borrar el historial de Internet. [...] Creía que no lo miraba y me pilló por sorpresa, de hecho no sabía que se podía mirar el historial. Y bueno, hizo algún comentario como de "tenemos que hablar" y siempre sonaban como muy fatales (Nicolás, 18 años).

[B]orro el historial... Bueno ahora, en casa de mi padre sí y, de hecho, me dejé un día el correo abierto y mi padre descubrió los mensajes de [la asociación LGTB]. Pues no dije nada, cerré mi correo y la cosa se quedó ahí (Marco, 14 años).

En segundo lugar, para muchos de los entrevistados el cuidado de sí mismos en Internet no sólo tenía que ver con ocultar información a familiares y amistades, sino también con las complejas relaciones endrogrupales entre gays, principalmente debido al histórico y patológico vinculo de la homosexualidad con las teorías de la degeneración (Foucault, 2008):

[N] unca llegué a hablar con nadie [en el chat], esas cosas no me gustan [p]orque hablaban casi todo de guarradas (Eneko, 17 años).

[M]e metí en Google y busqué "Chat gay" y ya está. Probé varios y hasta que di con uno que para mí era estupendo [y] estuve hablando con gente que me ayudó y me sirvió de apoyo. Bueno, con un chico sólo, porque los demás iban para ver si follaban (Iñigo, 16 años).
[M]e parece demasiado arriesgado. Si no tienes seguridad de que los perfiles son reales o de que no te quieran gastar una broma... Si tienes confianza, no sé, pero yo no confío mucho (Marco, 14 años).

Se cierra este apartado subrayando que Internet ha destacado como escenario y medio fundamental de la auto-identificación y socialización como gays de los entrevistados al ofrecerles un espacio virtual de aprendizaje sobre sí mismos y el mundo. Aunque lejos de ser un espacio de seguridad real, la red les posibilitó valiosas afiliaciones y prácticas anónimas en las que aprendieron a gestionar la propia identidad gay y su temido potencial de injuria.

\section{Discusión y conclusión: Orientaciones para la educación}

Teniendo en cuenta los resultado de la investigación, la pregunta a discutir desde el ámbito educativo podría formularse de la siguiente manera: "Sí el desconocimiento de sus iguales, y el miedo a ser tratados de forma injuriosa, llevó a los adolescentes entrevistados a realizar ciertas prácticas en Internet durante su auto-identificación y primeras socializaciones como gays, ¿cómo podría el profesorado ayudar para que tales procesos se desarrollasen sin dicho desconocimiento y miedo?"

En primer lugar, antes de adentrarnos a responder, cabe destacar cómo:

En poco menos de quince años hemos pasado de la ausencia total de materiales específicos [sobre la diversidad afectivo-sexual y de género (DASyG)] a contar, no sólo con materiales dirigidos al alumnado de todos los tramos educativos, sino con textos para la formación del profesorado y de las familias (Platero, 2013, p. 185).

Ciertamente nunca antes en la historia de la educación española ha habido tanto interés en este tipo de diversidad y, por lo tanto, nunca antes el profesorado había tenido tan a mano 
materiales que facilitaran tanto terminología como experiencias docentes. En la actualidad contamos con numerosas guías (Generelo \& Moreno Cabrera, 2007; Platero \& Gómez, 2007; STEILAS, 2015; Xente Gai Astur, 2002), compilaciones (Generelo \& Pichardo, 2006; Simonis, 2005; Sánchez Sáinz, 2009,2010 ) y publicaciones monográficas (Ferriols, 2011; Huerta, 2014) que ofrecen amplios recursos para dar a conocer la DASyG, principalmente confiando en que su reconocimiento e historia conlleve su respeto social y dignificación.

Hay que destacar favorablemente cómo este tipo de trabajos optan por la accesibilidad, la claridad y la síntesis, pero al mismo tiempo hay que incidir en que, en términos generales, obvian cuestiones sobre la perspectiva y el posicionamiento epistemológico, es decir, sobre las características de los conocimientos que difunden. De ahí que hayan aparecido voces alternativas desde perspectivas críticas que promueven sofisticadas formas de análisis sobre los conceptos de sexo, género y educación (Britzman, 2002; Berná, Cascone \& Platero, 2012; Planellas \& Pié, 2012); en este caso, confiando que tales análisis conlleven una deconstrucción de los antiguos patrones.

En segundo lugar, basándonos en los resultados de esta investigación, hay que señalar que la necesidad de afiliación con sus iguales y el miedo a ser tratados de manera injuriosa, presentan una dimensión diferente a: (i) el conocimiento de la DASyG por medio de clasificaciones sobre la sexualidad, el sexo y el género; (ii) al estudio de personajes históricos y relevantes LGTB; y (iii) al análisis crítico de estas cuestiones. Por lo tanto, quizá de manera complementaria a las propuestas anteriores, aquí nos aventuramos a presentar tres aspectos que de manera indirecta pueden acompañar en los procesos identificación de los adolescentes, en concreto a los gays, pero no exclusivamente:

\section{Favoreciendo la construcción de una red social analógica}

Invitamos al profesorado a promover la interacción entre todo el alumnado dentro de los mismos centros educativos, creando espacios de seguridad y uniendo lo educativo y lo lúdico. Esta cuestión puede desarrollarse a través de proyectos en los que colabore y conviva alumnado de diferentes edades, e incluso de diferentes centros de un mismo barrio o municipio. El objetivo es fomentar una red social analógica en la que el alumnado pueda conocerse entre sí y crear redes de aprendizaje, amistad y ayuda mutua que no den lugar a la sensación de aislamiento, desconocimiento y desconfianza entre iguales de cualquier diversidad. Por ejemplo, este tipo de experiencias han sido ampliamente desarrolladas en las "comunidades de aprendizaje" (Elboj et al., 2005) debido a su compromiso con la transformación social y el aprendizaje dialógico más allá de las aulas y las tapias de las escuelas.

\section{Fomentando "experiencias vivas" para ser individual y colectivamente}

Volviendo a los testimonios de los entrevistados, encontramos pensamientos recurrentes de carácter negativo que, junto a los intentos de manejar y controlar sus prácticas en Internet (para así no ser descubiertos pero a su vez descubrir a sus iguales), nos llevan a considerar oportuno y sensible animar al profesorado a que favorezca experiencias en las que el desarrollo de capacidades intelectuales, como el análisis y la proyección de conceptos, pasen a un segundo plano. Cabe recordar las palabras de Stoll, Fink \& Earl (2004) invitándonos a ampliar el paradigma cartesiano, "pienso, luego existo", hacia el "aprender a conocer, a hacer, a convivir y a ser". De manera similar a Planellas \& Pié (2012), aunque sin la preocupación por subvertir, también proponemos fomentar "experiencias vivas" para ser individual y grupalmente. Como escribe Greene:

[E]n toda visión social defendible, la felicidad es tan importante como la claridad y el consenso, o, como otros han dicho, el amor es tan importante como la lógica. [...] Obviamente, no estoy diciendo que baste simplemente con danzar y reír. Lo que sí digo es que me parece importante 
dejar que se libere la energía que permite un contacto familiar con todo y con todos [...] [y así] sentar las bases para la convivencia dentro de la comunidad (Greene, 2005, pp. 102-103).

\section{Usando las artes a favor de la eman- cipación de todo el alumnado}

Existen varias experiencias que han puesto en relación las prácticas artísticas con el desarrollo de resiliencia entre jóvenes LGTB, (Boyd Acuff, 2011; Shelton, 2008), pero el hecho de que se llevaran a cabo únicamente con este colectivo juvenil, limita el alcance de lo que aquí se promueve. Mientras que proyectos como Respira (Varanda, 2012) y Five Days to Dance (Andreu \& Moles, 2014), que sí tuvieron lugar en la educación formal, y por tanto, con grupos heterogéneos, conectan mejor con la anterior cita de Greene. De esta manera lo ilustra el testimonio de una de las profesoras participantes en Five Days to Dance:

Me emocionó mucho ver a dos alumnos que en realidad son el agua y el aceite. Están en el mismo aula (sic) y no interactúan para nada, y verles teniendo que hacer equipo, cogiéndose de las manos para sujetar a otro compañero que se dejaba caer hacia atrás, me pareció precioso. [De hecho] confío en que [tras] este proyecto, pues, por una vez ya se relajen, se suelten y disfruten un poco porque se nota mucha tensión [en el aula]. [...] Creo que es una oportunidad, no sólo para quienes han sufrido las risas de los compañeros de clase, sino incluso para los que no se han portado bien. [...] Va a ser igualmente difícil para todos [dejar] esos roles que han tomado, y que se expresen, y compartan, y vean que somos iguales, distintos pero iguales. [...] Tengo la esperanza que este proyecto sea un empezar, un empezar a trabajar otras cosas que no sean sólo con la mente (Andreu \& Moles, 2014).

Finaliza el presente artículo con la misma esperanza. Como profesionales de la educación podemos trabajar de manera holística, ayudando a diluir los miedos y desconfianzas que están limitando a numerosos jóvenes, no sólo gays, que les llevan a buscar en Internet lo que no conocen, y no se atreven a conocer, en sus vidas offline más allá de lo digital.

\section{Apoyos}

Investigación subvencionada por el Ministerio de Ciencia e Innovación en relación con el proyecto "Jóvenes productores de cultura visual: competencias y saberes artísticos en educación secundaria", con referencia EDU2009-13712, concedido en el año 2010.

\section{Referencias bibliográficas}

Alexander, J., \& Losh, E. (2010). "A youtube of one's own?" "Coming out" Videos as rhetorical action. En C. Pullen y M. Cooper (Eds.), LGBT Identity and On-line New Media (23-36). New York/London: Routledge. Recuperado de https://bit.ly/2LiC0ZD

Anderson, K., \& Jack, D.C. (1991.) Learning to listen: Interview techniques and analyses. En S.B. Gluck y D. Patai (Eds.), Women's Words: The Feminist Practice of Oral History (11-25). New York: Routledge.

Andreu, J., \& Moles, R. (Dirs/Prods.) (2014). Five Days to Dance. España/Alemania: SUICAfilm \& REC grabateka estudioa.

Barnhurst, K. G. (2007). Visibility as paradox: Representation and silmultaneous contrast. En K. G. Barnhurst (Ed.), Media/Queered. Visibility and its Discontets (1-22). New York: Peter Lang.

Berná, D., Cascone, M., \& Platero, R. (L.) (2012). ¿Qué puede aportar una mirada queer a la educación? Un estado de la cuestión sobre los estudios sobre la LGTBfobia y educación en el Estado español. The Scientifc journal of Humanistic Studies,6(4). Recuperado de https://bit.ly/2mzMbKm

Bond-Raacke, J., Cady, E., Schlegel, R., Harris, R., \& Firebaugh, L. (2007). Remembering gay/ lesbian media characters: Can Ellen and Will improve attitudes toward homosexuals? Journal of Homosexuality, 53(3), 19-34. 
Boyd, D. (2014). It's complicated. The social lives of networked teens. New Haven/ London: Yale University Press.

Boyd Acuff, J. (2011). Looking through the kaleidoscope: prims of self and LGTBQ youth identity. Visual Culture \& Gender, 6. Recuperado de https://bit.ly/2LC2e8u

Butler, J. (2010)[1997]. Mecanismos Psíquicos del Poder. Teorías sobre la sujeción. Madrid: Cátedra.

Braun, V., \& Clarke, V. (2006). Using Thematic Analysis in Psychology. Qualitative Research in Psychology, 3(2), 77-101.

Britzman, D. (2002) [1998]. La pedagogía transgresora y sus extrañas técnicas. En R. Mérida Jiménez, (Ed.) (2002), Sexualidades transgresoras. Una antología de estudios queer (197229). Barcelona: Icaria.

Clandinin, D. J., \& Connelly, F. M. (2000). Composing research texts. En D. J. Clandinin y F. M. Connelly (Eds.), Narrative Inquiry. Experience and Story in Qualitative Research (139-168). San Francisco: Jossey-Bass Publishers.

Coll-Planas, G. (2010). La voluntad y el deseo. La construcción social del género y la sexualidad: el caso de lesbianas, gays y trans. Barcelona/ Madrid: Editoral Egales.

Coll-Planas, G., Bustamante, G., \& Missé, M. (2009). Transitant per les fronteres del gènere. Estratègies, trajectories $i$ aportacions de joves trans, lesbianes i gais. Barcelona: Generalitat de Catalunya, Departament d'Acció Social i Ciudadania. Secretaria de Joventut. Recuperado de https://bit.ly/2O9MmbK

De Abreu, C. (2017). Géneros y sexualidades no heteronormativas en las redes sociales: Sexualidades desobedientes en internet. Publicia.

D'Emilio, J. (1994) [1983]. 'Capitalism and Gay Identity'. En H. Abelove et al. (Eds.), The Lesbian and Gay Studies Reader (22-26). USA: Routledge.

Elboj, C., Puigdellívol, I., Soler, M., \& Valls, R. (2002). Comunidades de Aprendizaje. Transformar la educación. Barcelona: Graó.

Denzin, N. K., \& Lincoln, Y.S. (Eds.) (1999). Handbook of qualitative research. London: Sage.

Epstein, D., \& Johnson, R. (2000)[1998]. Sexualidades $e$ institución escolar. Madrid/A Coruña: Ediciones Morata/Fundación Paideia Galiza.
Ferriols, M. J. (Ed.) (2011). La diversidad afectivosexual [Monográfico]. Cuadernos de pedagogía, 414.

Foucault, M. (2008)[1976]. Historia de la sexualidad I. La voluntad de saber. Madrid: Siglo: XXI.

Generelo, J., \& Moreno Cabrera, O. (2007). Diferentes formas de amar. Guía para educar en la diversidad afectivo-sexual. Madrid: Federación Regional de Enseñanza de Madrid de CCOO.

Generelo, J., \& Pichardo, J. I. (Coord.) (2006). Homofobia en el sistema educativo. Madrid: COGAM.

Generelo, J., Pichardo, J. I., \& Galofré, G. (Eds.) (2008). Adolescencia y sexualidades minoritarias. Voces desde la exclusión. Alcalá la Real: Ed. Alcalá.

Gomillion, S., \& Giuliano, T. (2011). The influence of media role models on gay, lesbian, and bisexual identity. Journal of Homosexuality, 58(3), 330354. DOI: 10.1080/00918369.2011.546729. Recuperado de https://bit.ly/2NFAMEu

Greene, M. (2005). Liberar la imaginación. Ensayos sobre educación, arte y cambio social. Barcelona: Editorial Graó.

Hall, S. (2005)[1996). 'Who needs 'identity'?'. En S. Hall y P. Du Gay (Eds.), Questions of Cultural Identity (1-17). UK: Sage Publications Inc.

Harry, J. (1993). Being out: A general model. Journal of Homosexuality, 26(1), 25-37.

Heath, S., Brooks, R., Cleaver, E., \& Ireland, E. (2009). Researching young people's lives. GB: SAGE Publications Ltd.

Hillier, L., Dempsey, D., Harrison, L., Beale; L., Matthews, L., \& Rosenthal, D. (1998). Writing themselves in: A national report on the sexuality, health and well-being of same-sex attracted young people. Carlton: National Centre in HIV Social Research, La Trobe University. Recuperado de https://bit.ly/2uJwsNg

Huerta, R. (Ed.) (2014). Arte y diversidad sexual [Tema del mes]. Cuadernos de pedagogía, 449.

Kielwasser, A. P., \& Wolf, M. A. (1992). Mainstrean televisión, adolescent homosexuality and significant silence. Critical Studies of Mass Communication, 9, 350-373.

Kvale, S. (2007). Doing Interviews. London: SAGE Publications.

Laukkanen, M. (2007). 'Young Queer Online: the limits and possibilities of Non-heterosexual 
self- representation in Online Conversation' En K. O'riordan y D. J. Phillips (Ed.), Queer online: Media Technology \& Sexuality (8199). New York: Peter Lang.

Lipton, M. (2008). 'Queer readings of popular culture. Searching [to] out the subtext'. En S. Driver (Ed.), Queer Youth Cultures (116-180). New York: State University of New York.

Martino, W., \& Pallota-Chiarolli, M. (2003). So what's a boy? Addressing issues of masculinity in education. Maidenhead: Open University Press.

Orne, J. (2011). 'You will always have to "out" yourself: Reconsidering coming out through strategic outness. Sexualities, 14, 681-703. http://doi.org/10.1177/1363460711420462 Recuperado de https://bit.ly/2mzMWDc

Planella, J., \& Pié, A. (2012). Pedagoqueer: resistencias y subversiones educativas. Educación XXI, 15(1), 265-283.

Platero, R. (L.), \& Gómez, E. (2007). Herramientas para combatir el bullying homofóbico. Madrid: Talasa

Platero, R. (L.) (2013). Entre el tabú y los estudios pioneros: Educación, LGTB fobia y bullying homofóbico. En M. Jiménez y F. J. Del Pozo (Eds.), Propuestas didácticas de educación para la igualdad (185-205). Granada: Natívola.

Real Decreto 1631/2006, de 29 de diciembre. Viernes 5 de enero del 2007, Boletín Oficial del Estado (BOE), no 5. Madrid: España.

Renold, E. (2005). Girls, Boys and Junior sexualities: Exploring Childrens' Gender and Sexual Relations in the Primary School. London: Routledge Palmer.

Riggle, E., Ellis, A., \& Crawford, A. (1996). The impact of "media contact" on attitudes toward gay men. Journal of Homosexuality, 31(3), 55-69.

Robinson, K. H., Basel, P., Denson, N., Ovenden, G., \& Davies, C. (Eds.) (2014). Growing up queer: Issues facing young Australians who are gender variant and sexuality. Melbourne: Young and Well Cooperative Research Centre.

Ryan, G. W., \& Bernard, H. R. (2000). Data management and analysis methods. En N. K. Denzin y Y. S. Lincoln, (Eds.), Handbook of Qualitative Research (769-802). London: Sage Publications.
Sánchez Sáinz, M. (Coord.) (2009). Cómo educar en la diversidad afectivo-sexual en los centros escolares. Orientaciones prácticas para la ESO. Madrid: La Catarata.

Sánchez Sáinz, M. (Coord.) (2010). Cómo educar en la diversidad afectiva, sexual y personal en Educación Infantil. Orientaciones practicas. Madrid: La Catarata.

Savin-Williams, R. (2009)[2005]. La nueva adolescencia homosexual. Madrid/Coruña: Ediciones Morata, S. L. y Fundación Paideia Galiza.

Shelton, J. (2008). Redefining realities through selfrepresentational performance. En S. Driver (Ed.), Queer Youth Cultures (69-86). New York: State University of New York.

Simonis, A. (Comp.) (2005). Educar en la diversidad. Barcelona: Editorial Laertes.

STEILAS (2015). Guía para trabajar la diversidad afectivo-sexual y de género. Recuperado de https://bit.ly/2LL4S8L

Stoll, L., Fink, D., \& Earl, L. (2004). Sobre el aprender y el tiempo que requiere, implicaciones para la escuela. Barcelona: Octaedro.

Szulc, L., \& Dhoest, A. (2013). 'The Internet and sexual identity formation: Comparing Internet use before and after coming out'. Communications, 38(4), 347-365.

Troiden, R. (1989). The formation of homosexual identities. Journal of Homosexuality, 17(1-2), 43-74.

Van Manen, M. (2003). Investigación educativa y experiencia vivida. Barcelona: Idea Books.

Varanda, P. (2012). Dançar é crescer. Aldara Bizarro e o projecto Respira. Portugal: Caleidoscópio Recuperado de https://bit.ly/2LGiWAl

Weeks, J. (2003). 'Necessary Ficctions: Sexual Identities and the Politics of Diversity'. En J.Weeks et al. (Eds.), Sexualities and Sociesty: A Reader (112-132). USA: Polity Press \& Blackwell Publishing Ltd.

Wetherell, M., \& Potter, J. (1996). El análisis del discurso y la identificación de los repertorios interpretativos. En A. J. Gordo López y J. L. Linaza (Eds.), Psicologías, discursos y poder. Madrid: Visor.

Xente Gai Astur (2002). Guía didáctica: El respeto a la diferencia por orientación sexual. Homosexualidad y lesbianismo en el aula. Recuperado de https://goo.gl/nfKGd8 



\section{ALTERIDAD}

enero-junio 2019

Vol. 14, No. 1, 77

\section{Sección Miscelánea}

(Miscellaneous Section)

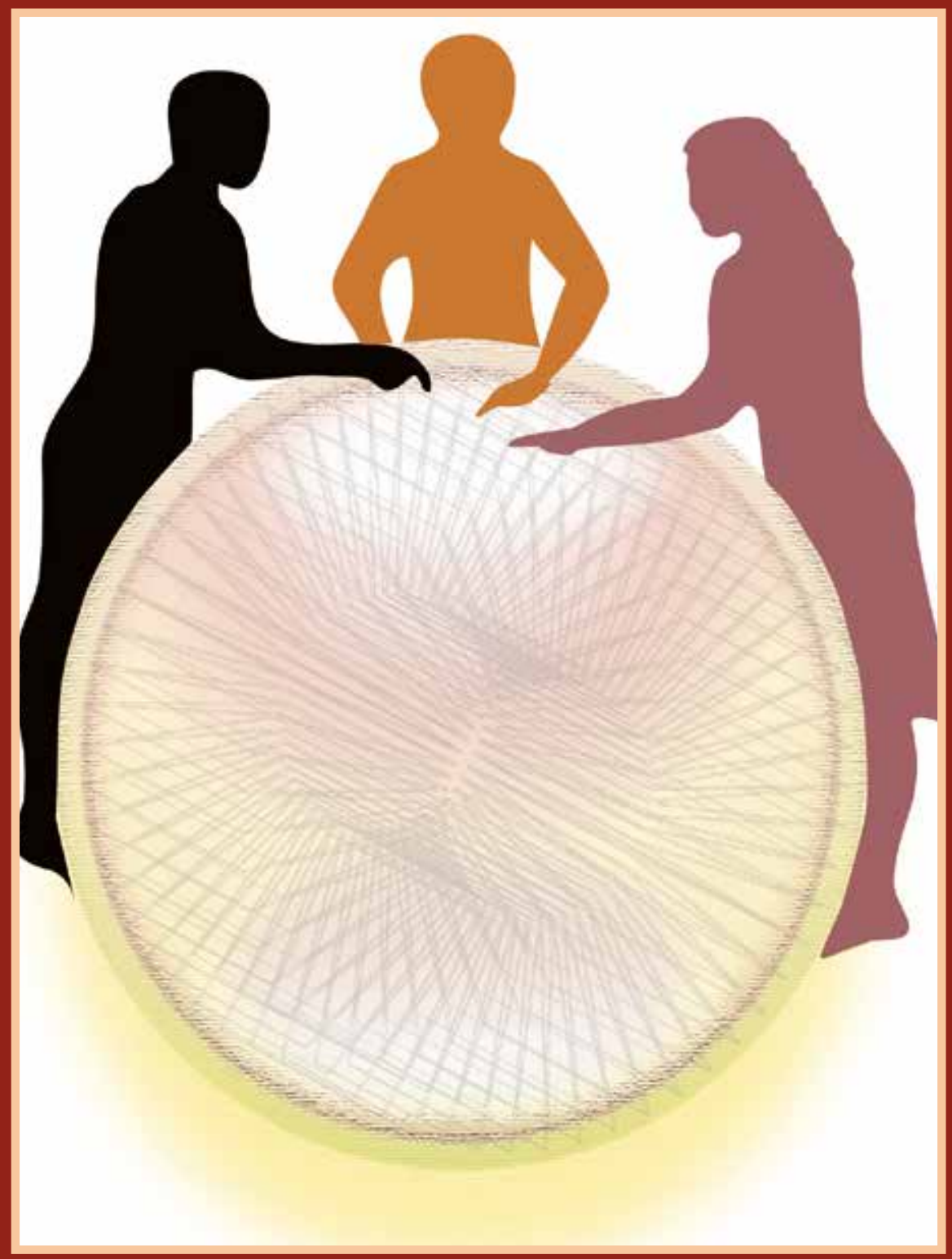

Aprendizaje en red, ilustración digital, 17 cm x 12 cm 


\title{
Necesidades formativas de docentes de Educación Intercultural Tsáchila
}

\section{Training needs of teachers of Intercultural Education Tsáchila}

\begin{abstract}
Jacqueline Marilú Aguavil Arévalo es docente de la Unidad Educativa Intercultural Madre Laura (Ecuador) (jmaguavila@pucesd.edu.ec) (https://orcid.org/0000-0002-3362-9484)
\end{abstract}

Ramiro Andrés Andino Jaramillo es docente de la Unidad Educativa Vivian Luzuriaga Vásquez (Ecuador) (raandinoj@gmail.com) ( https://orcid.org/0000-0001-8547-8780)

Recibido: 2017-05-05 / Revisado: 2018-04-02 / Aceptado: 2018-05-07 / Publicado: 2019-01-01

\section{Resumen}

El presente estudio pretende analizar las necesidades formativas y los procesos de capacitación en los que están inmersos los docentes que laboran en las Unidades Educativas Interculturales Bilingües: Madre Laura, Tsáchila, Tomás Rivadeneira, Conadu, Abraham Calazacón, Enrique Terán, Patricio Romero Barberis. Estas instituciones se encuentran ubicadas en comunidades de la etnia Tsáchila en la provincia de Santo de los Tsáchilas, Ecuador. La propuesta metodológica del estudio se basó en un diseño no experimental apoyado en la investigación cualitativa y cuantitativa para determinar las falencias formativas de los docentes interculturales bilingües y, cómo esto afecta en los procesos educativos y la ejecución de los lineamientos de Modelo del Sistema de Educación Intercultural Bilingüe (MOSEIB). La muestra estuvo formada por 19 docentes tsáchilas y 10 docentes mestizos. Las técnicas de recolección y análisis de datos fueron la encuesta y el análisis estadístico. Los resultados de la investigación muestran que los docentes de instituciones interculturales bilingües presentan necesidades formativas y de capacitación que están afectando el proceso educativo y la correcta aplicación del MOSEIB. En la discusión y conclusiones se explica y argumenta la importancia de la formación inicial y continua del docente, además se enfatiza la necesidad de fortalecer las competencias docentes con base a la investigación y propuestas educativas ajustadas a las necesidades de cada contexto educativo y, a partir de ello, fortalecer la Educación Intercultural Bilingüe en el Ecuador.

Descriptores: Educación, educación intercultural, cultura, docente, formación, formación profesional.

\begin{abstract}
The current study helps to analyze the training needs and training processes in which the teachers who work in the Bilingual Intercultural Education schools are immersed: Madre Laura, Tsáchila, Tomás Rivadeneira, Conadu, Abraham Calazacón, Enrique Terán, Patricio Romero Barberis. These institutions are located in communities of the Tsáchila ethnic group in Santo Domingo de los Tsáchilas Province, Ecuador. The methodological proposal of the study was based on a non-experimental
\end{abstract}

Forma sugerida de citar: Aguavil Arévalo, J. M., \& Andino Jaramillo, R. A. (2019). Necesidades formativas de docentes de Educación Intercultural Tsáchila. Alteridad, 14(1), 74-83. https://doi.org/10.17163/alt.v14n1.2019.06 
design based on qualitative and quantitative research to determine the training short comings of bilingual intercultural teachers and how this affects the educational processes and the execution of the Education System Model Guidelines Intercultural Bilingual (MOSEIB). The sample consisted of 19Tsáchilas teachers and 10 mestizo teachers. The data collection and techniques analysis were the survey and the statistical analysis. The results of the research show that teachers of bilingual intercultural institutions present training and training needs that are affect-

\section{Introducción}

La interculturalidad de forma general concierne a la relación sinérgica entre culturas, que pueden tener aspectos comunes o distintos entre sí. Los elementos característicos de cada cultura se ve reflejado en los individuos que la conforman, pero no significa que exista diferencia entre una cultura y otra, sino que está intrínsecamente relacionado a los rasgos sociales, cognitivos, culturales, históricos de cada persona. Al ser humano no se lo distingue o caracteriza solamente por rasgos genéticos, esto supone la importancia del bagaje cultural que se transmite de generación en generación, permitiendo la interrelación entre seres humanos $y$, por supuesto de forma general el diálogo intercultural.

La relación entre culturas y el diálogo que debe suponer la interacción cultural es un elemento transcendental en la educación porque según Rodríguez \& Fernández (2017) las escuelas no solo educan a un individuo sino a toda una comunidad. Esto representa rasgos culturales similares, pero no iguales, que permiten la socialización entre agentes de la comunidad escolar, además fomenta la mejora de la convivencia dentro de los centros educativos y prepondera la mejora de la educación sobre la base de la interculturalidad y la inclusión social de los individuos de una comunidad en cada ambiente escolar.

La educación fundamentada con base en la interculturalidad desarrolla estructuras sociales y posibilita la adquisición de herramientas culturales que permiten la interacción entre indi- ing the educational process and the correct application of MOSEIB. In the discussion and conclusions, the importance of the teacher's initial and continuing education is explained and argued. In addition, emphasis is placed on the need to strengthen teaching competencies based on research and educational proposal adjusted to the needs of each educational context. From this, strengthen Intercultural Bilingual Education in Ecuador.

Keywords: Education, intercultural education, culture, teacher, training, vocational training.

viduos de una cultura con otras. Daniels (2016) considera que las estructuras sociales y culturales son fundamentales dentro del contexto escolar y con más énfasis en la educación de cada estudiante en las aulas de clase. Esta afirmación permite aclarar que la interculturalidad dentro de la educación es una mediadora entre el estudiante, los docentes, la familia y la comunidad; los cuales no pueden mantenerse aislados, sino que deben interrelacionarse para continuar la transmisión social y cultural, por medio de la educación y la convivencia dentro de las aulas de clase.

Sobre la base de las perspectivas acerca de la interculturalidad y su importancia en la educación, se puede enfatizar que la interculturalidad potencia la relación entre culturas dentro de la sociedad, además favorece la continuidad y la perpetuidad del diálogo sin que ninguna cultura renuncie a su identidad original (López \& Pérez, 2013). La diversidad cultural es una fuente principal de desarrollo integral del ser humano y la sociedad, en todo ámbito y dimensión posible; por esta razón la educación intercultural es un reto para las escuelas, colegios y universidades.

El intercambio cultural entre estudiantes docentes, administrativos, padres de familia y la comunidad educativa es parte de la formación y educación en las instituciones educativas, porque según López \& Pérez (2013) la tarea pedagógica de los centros educativos es elaborar una propuesta educativa que se oriente a la transmisión de elementos culturales y valores que permitan la cohesión social y el diálogo intercultural. Es necesario, que la educación intercultural proponga el 
diálogo bidireccional entre los agentes de la comunidad educativa para alcanzar un nivel óptimo de formación y educación para los estudiantes.

Los centros educativos deben valorar la educación intercultural como una manera eficaz para el desarrollo de competencias y la superación personal de cada estudiante (Tomé \& Manzano, 2016), por lo tanto, la formación de los docentes interculturales debe resaltar y construir una praxis comprometida con el diálogo, la diversidad cultural, la inclusión, la búsqueda de valores y la transmisión de elementos culturales de generación en generación (López \& Pérez, 2013). Por medio de la educación intercultural se puede enaltecer y profundizar la identidad cultural de cada individuo y comunidad, sin perder $\mathrm{u}$ olvidar rasgos fundamentales al momento de cohesionar cada cultura.

El docente intercultural asume un papel principal como mediador, gestor y promotor del diálogo intercultural y la enseñanza de derechos colectivos que permitan la comprensión y valoración de cada cultura a la que pertenecen los estudiantes en el aula de clases (Walsh \& García, 2002). La educación intercultural considera el desarrollo del conocimiento, valores y actitudes que los docentes fomentan en las aulas de clases, es parte del desarrollo de competencias sociales y culturales que cada estudiante debería adquirir como parte de su formación y educación a lo largo de la vida, tanto dentro como fuera de la institución educativa.

Los fundamentos descritos sobre la importancia del docente como gestor de la educación intercultural, forman parte del proceso social que experimentan las comunidades al reunir los elementos propios y ajenos provenientes de cada cultura. De acuerdo a Walsh \& García (2002), el docente intercultural debe promover formas de interacción social y cultural sobre la base de valores y el respeto entre seres humanos, considerando que cada cultura aporta un bagaje extenso de rasgos que se unifican al conglomerado social y generan una mega cultura que acoge la historia, los cambios sociales, el desarrollo y la cohesión cultural del ser humano, sin separación o discriminación alguna, ya que cada individuo es una representación extensa de la transmisión cultural que se repite una y otra vez de generación en generación.

Situándose en la importancia de la educación intercultural, en el Ecuador se propuso el Modelo de Educación Intercultural Bilingüe (MOSEIB) desde el 2014, iniciando su implementación en la región Sierra y posteriormente pasó a ser aplicado desde el 2015 en todas las instituciones educativas interculturales bilingües del sistema educativo ecuatoriano. Este modelo propone que la educación es un proceso integral y se debe convertir en un modo de vida armónico del ser humano consigo mismo y con los demás para recuperar la educación ancestral, la familia y la comunidad como elementos fundamentales en la formación de cada persona, además debe ser una contribución al reconocimiento y valoración del conocimiento de cada cultura para el progreso de la humanidad (Ministerio de Educación del Ecuador, 2014).

Desde los pilares del MOSEIB la formación del docente debe reunir ciertas características, expuestas por Moreno (2015), como son: habilidades sociales y comunicativas, praxis orientada a procesos, trabajo comunitario, conocimiento en estrategias y recursos didácticos y formación en educación intercultural e inclusiva. Las características antes señaladas por el autor son troncales en la formación de un docente intercultural bilingüe, porque reúnen competencias esenciales para encaminar adecuadamente procesos formativos, $y$ sobre todo, para fomentar la convivencia pacífica en la comunidad escolar, para poner en practica valores humanos y para valorar cada uno de los rasgos culturales que tiene cada estudiante, orientándose a la práctica del diálogo como un eje rector en el aprendizaje y el desarrollo integral de cada uno.

De acuerdo a las características que un docente intercultural debe desarrollar, en la realidad educativa de las instituciones interculturales bilingües cercanas a comunidades de la 
nacionalidad Tsáchila es necesario que haya una constante actualización de estrategias y modelos de gestión pedagógica para acoplarse a las nuevas formas de enseñar y aprender, además de priorizar el desarrollo integral y formación intercultural de los estudiantes tsáchilas y mestizos que conviven en una misma aula. De acuerdo a Lalangui, Ramón \& Espinoza (2017), el docente que recibe una formación inicial para dirigir y gestionar un proceso educativo, constituye en el inicio de su continuo proceso de formación docente, ya que la praxis educativa y el trabajo continúo dentro del aula de clases permite que los docentes desarrollen competencias en el ejercicio del quehacer educativo.

La formación continua del docente intercultural bilingüe puede ser un índice positivo en el desempeño profesional en pedagogía, didáctica, metodología, currículo, inclusión educativa y educación intercultural. El proceso de formación inicial y continua en la carrera docente puede revertir algunos problemas en la educación de forma general, pero también incide positivamente en la inclusión, la interculturalidad, el diálogo, la resolución pacífica de conflictos y el fomento de una cultura de paz. En este sentido, el desempeño exitoso de los docentes interculturales podría ser el resultado de modelos y estrategias adecuadas a las necesidades del contexto educativo de la institución y correspondería a procesos de enseñanza y aprendizaje innovadores y orientados hacia la calidad educativa (Álvarez, 2014).

Desde las perspectivas antes escritas, Ungerfeld \& Morón (2016), explican que los docentes deben poseer un mínimo de conocimientos específicos, habilidades intelectuales y técnicas, además de un desarrollo de actitudes y comportamientos sociales que permitan comprender las necesidades de los estudiantes y determinar las etapas de desarrollo que progresivamente deben alcanzar los estudiantes que tengan una necesidad educativa especial o, por el contrario, establecer un proceso continuo e inclusivo que responda las necesidades de cada estudiante, considerando expresamente la diversidad como un eje troncal en la formación humana y educativa de cada uno.

La formación docente en la actualidad se encuentra orientada a nuevas prácticas educativas, que son enfocadas al desarrollo del docente como un medio para responder a las urgentes necesidades de los estudiantes y la comunidad educativa. De este modo, López \& Pérez (2013), expresan que la educación intercultural se vincula a la actualidad y realidad del contexto escolar; esto requiere un tratamiento formativo en los docentes que laboran en instituciones interculturales bilingües, porque la interculturalidad es una competencia que primero se desarrolla en el docente para que luego sea trasladada a cada aula de clase, ya que la cosmovisión de la etnia Tsáchila es un valor agregado durante la ejecución de experiencias de aprendizaje en las que intervienen el docente y los estudiantes. La estrecha relación entre formación docente e interculturalidad se construye sobre la práctica educativa, por lo tanto, requiere un análisis de los diversos contextos socioculturales a los que pertenecen los estudiantes y que, los docentes interculturales bilingües deben acoplarse y proponer las mejores estrategias para formar y responder a las necesidades de los estudiantes y en general de la comunidad educativa cohesionada con los rasgos culturales de la etnia Tsáchila.

Con base a las problemáticas descritas sobre las necesidades formativas de los docentes interculturales, además de las discrepancias entre la realidad y el hecho educativo de la aplicación de modelos de educación intercultural bilingüe, el proceso de investigación se situó en el contexto de unidades educativas tsáchilas ubicas en las comunidades: El Búa, Peripa, Otongo Mapalí, Chigüilpe, Cóngoma, Los Naranjos, El Poste. Los tsáchilas se encuentran asentados en la provincia Santo Domingo de los Tsáchilas, son una etnia endémica de la provincia y representan un legado cultural y ancestral reconocido en todo el Ecuador. En este sentido, el estudio se enfoca en analizar las necesidades formativas y los procesos de capacitación en 
los que están inmersos los docentes que laboran en las Unidades Educativas: Madre Laura, Tsáchila, Tomás Rivadeneira, Conadu, Abraham Calazacón, Enrique Terán, Patricio Romero Barberis. Los resultados y conclusiones expuestos en este estudio, serán útiles para replantar los procesos de Educación Intercultural Bilingüe, que hasta cierto punto parecen tener incongruencias entre la teoría y la práctica.

En definitiva, los antecedentes teóricos descritos abren una brecha de análisis sobre las situaciones procedimentales y formativas de los docentes interculturales bilingües. Este trabajo investigativo no constituye una crítica para estos docentes, sino un análisis del proceso de formación en los que estuvieron inmersos y la capacitación que han recibido sobre educación intercultural bilingüe contextualizada con la cosmovisión tsáchila. A pesar de los esfuerzos que puedan realizar estos docentes en el quehacer educativo, posiblemente también sean mitigados por aspectos sociales o económicos ajenos al estudio realizado, que ahondan la realidad de la educación intercultural bilingüe ofertada en instituciones educativas asentadas en comunidades tsáchilas.

\section{Material y métodos}

La metodología de trabajo aplicada en la investigación considera un diseño no experimental para analizar la situación formativa de los docentes interculturales que conforman el estudio; sin manipulación de variables ni asignaciones al azar de sujetos. En este sentido, se propone un proceso descriptivo y diagnóstico de las características formativas de los docentes y, cómo estas influyen en el contexto de la educación intercultural bilingüe de las instituciones educativas en las que laboran. La propuesta de trabajo se sistematiza mediante la investigación cuantitativa y cualitativa para analizar las necesidades en la formación de los docentes de educación intercultural bilingüe que imparten clases en instituciones educativas ubicadas en las comunas de la nacionalidad tsáchila en la ciudad de Santo Domingo. Con base a la metodología propuesta, el estudio se realizó mediante la descripción y fundamentación de las necesidades identificadas en los docentes considerados para el estudio.

La muestra de docentes que formaron parte del estudio fue de tipo intencional, porque se la determinó sin aplicar métodos aleatorios debido a que los sujetos fueron claramente identificados como docentes interculturales bilingües por la denominación de las instituciones educativas y no representaban un número extenso para el proceso de recogida de datos. Del total de 29 docentes que imparten clases desde inicial hasta décimo año de Educación General Básica, 19 docentes son de nacionalidad tsáchila y 10 docentes son de etnia mestiza.

Para la recopilación de datos se aplicó una encuesta con preguntas relacionadas a la formación inicial docente y a la capacitación sobre educación intercultural recibida recientemente. Los datos permitieron determinar las necesidades que tienen estos docentes dentro del contexto de instituciones educativas interculturales bilingües en la ciudad de Santo Domingo. Con base a los datos obtenidos, fue necesario la aplicación del análisis estadístico para sistematizar e interpretar la información condensada de las encuestas, además se aplicó un análisis bibliográfico para situar y contextualizar mediante fundamentos teóricos las necesidades de los docentes con respecto a la ejecución y conocimiento del Modelo de Educación Intercultural Bilingüe (MOSEIB), vigente en el sistema nacional de educación en el Ecuador hasta la actualidad. De acuerdo a las perspectivas propuestas en el estudio, se pudo realizar un análisis de las posibles complicaciones y dificultades que se producen en los docentes al momento de aplicar los lineamientos de la educación intercultural en el aula de clases. 


\section{Análisis y resultados}

Tabla 1. Nivel académico de docentes interculturales bilingües

\begin{tabular}{|l|l|}
\hline Bachillerato & $34,48 \%$ \\
\hline Título de tercer nivel & $58,62 \%$ \\
\hline Título de cuarto nivel & $6,90 \%$ \\
\hline Total & $\mathbf{1 0 0} \%$ \\
\hline
\end{tabular}

Fuente: Elaboración propia, datos obtenidos de la encuesta a docentes de Unidades Interculturales Bilingües Tsáchilas.

Sobre la base de los resultados obtenidos, se observa que el $34,48 \%$ de los docentes que laboran en unidades educativas interculturales bilingües tiene formación de bachiller, a diferencia del 58,62\% de docentes con título de tercer nivel. En contraste con los porcentajes antes descritos, solo el 6,90\% de los docentes interculturales bilingües poseen un título de cuarto nivel (ver tabla 1). Los resultados observados en la tabla, muestran que más de la mitad de los docentes encuestados poseen un título de tercer nivel, pero también se observa que hay un porcentaje relevante de docentes con formación bachiller, que en cierto modo puede afectar la implementación de procesos educativos y formativos en las instituciones interculturales bilingües. En efecto, el desequilibrio en cuanto a la formación académica de los docentes encuestados, explica el bajo porcentaje de docentes con estudios de cuarto nivel, evidenciando la necesidad de implementar un proceso integral de formación docente, dirigido especialmente a los docentes con titulación de bachiller para incrementar y mejorar la calidad educativa dentro de instituciones interculturales bilingüe ubicadas en comunidades de la etnia tsáchila.

Posiblemente, la representatividad de docentes bachilleres tenga relación con el contexto rural en el que se ubican las instituciones interculturales bilingües, pero también tiene una posible relación con el dominio del tsa'fiki que es la lengua autóctona de los tsáchilas y que los docentes mestizos probablemente no dominen para poder impartir clases en la lengua materna tsáchila. Este factor comunicativo puede que incremente la presencia de docentes bachilleres pero que hablen tsa'fiki y español, sumado al poco incentivo de las autoridades educativas por formación de tercer nivel o capacitación con base al MOSEIB implique un estancamiento o conformismo de estos docentes por como imparten sus clases.

Tabla 2. Formación docente y capacitación en Educación Intercultural Bilingüe

\begin{tabular}{|l|l|}
\hline Formación en Educación Intercultural Bilingüe & $86,21 \%$ \\
\hline Capacitación docente en Educación Intercultural Bilingüe & $93,10 \%$ \\
\hline Capacitación recibida en los últimos 6 meses & $37,93 \%$ \\
\hline Capacitación recibida en los últimos 2 años & $17,24 \%$ \\
\hline Conocimiento del Modelo del Sistema de Educación Intercultural Bilingüe (MOSEIB) & $37,93 \%$ \\
\hline
\end{tabular}

Fuente: Elaboración propia, datos obtenidos de la encuesta a docentes de Unidades Interculturales Bilingües Tsáchilas. 
De acuerdo a los resultados, el $86,21 \%$ de los docentes tienen formación en educación intercultural bilingüe, además el 93,10\% de los docentes se han capacitado en este tipo de educación. En cuanto a la frecuencia en la que los docentes encuestados reciben capacitaciones, el $37,93 \%$ señala que se ha capacitado en los últimos 6 meses, del mismo modo, el 17,24\% de los docentes se ha capacitado en los últimos 2 años (Ver tabla 2). A diferencia de los resultados favorables, con respecto a la formación en educación intercultural bilingüe y procesos de capacitación recibidos, resulta contradictorio que solo el 37,93\% de los docentes conozcan sobre el Modelo del Sistema de Educación Intercultural Bilingüe (ver tabla 2).

Con base a los resultados de la tabla 1 , se determina una relación sustancial con los resultados de la tabla 2, ya que existe una necesidad de formación académica de docentes interculturales bilingües, porque al parecer está afectando la aplicación del MOSEIB, que es el eje troncal de la educación intercultural en unidades educativas ubicadas en comunidades de la etnia Tsáchila. Esta duda sobre el quehacer educativo de los docentes interculturales bilingües no puede generalizarse para todo el Ecuador porque en cada contexto educativo se observan variantes. Por los datos obtenidos, parece ser que los docentes tienen una percepción errónea sobre educación intercultural bilingüe o no es lo sufrientemente sólida, ya que la aplicación del MOSEIB parte del conocimiento de sus lineamientos y sobre todo implica un proceso de capacitación continua para establecer procesos educativos acoplados a la cosmovisión tsáchila. Enseñar con la lengua materna no implica una educación intercultural, es una parte importe importante, pero se requiere de un cambio de percepción en estos docentes sobre cómo educar interculturalmente a estudiantes tsáchilas y de otras étnicas.

\section{Discusión y conclusiones}

A partir de los resultados, se evidencia que existe una cantidad significativa de docentes con titu- lación de bachiller, a diferencia de los docentes que tienen formación pedagógica y titulación de tercer y cuarto nivel. La premisa anterior muestra una primera aproximación a las necesidades formativas de los docentes que laboran en instituciones educativas interculturales ubicadas en comunidades de la etnia Tsáchila; en este sentido, lo que está ocurriendo con estos docentes es posiblemente el estancamiento en cuanto al avance en materia de formación y actualización de conocimientos y calidad en el desempeño profesional de docentes que laboran en instituciones interculturales bilingües asentadas en comunas de las nacionalidad Tsáchila. De acuerdo a De los Saltos \& Abreu (2013), la formación continua en la carrera docente permite en primer lugar, titular a los docentes y en segundo lugar, garantizar el desarrollo profesional y reunir las competencias que permitan el ejercicio del hecho docente en el contexto educativo; sin embargo, esto no se está evidenciando en el contexto escolar y profesional de los docentes que laboran en instituciones interculturales bilingües, por lo tanto, se está afectando el desarrollo profesional y a su vez, esto posiblemente sea un punto de quiebre en el proceso de enseñanza y aprendizaje que se establece en cada aula de las instituciones interculturales de la etnia tsáchila.

Las necesidades formativas de los docentes que laboran en instituciones interculturales pueden influenciar contrariamente en las valoraciones y orientación de la formación y carrera docente, ya que los docentes que poseen título de bachiller parecen no querer continuar con un proceso de profesionalización docente, o por el contrario, estos docentes no han sido considerados o llamados en los procesos de formación continua y profesionalización docente ofertados por universidades con el aval y auspicio del Ministerio de Educación del Ecuador. Inciarte, Camacho \& Casillas (2017) mencionan que las prácticas que se orientan al desarrollo de la carrera docente parten de la intervención reflexiva de los actores del hecho educativo, por lo tanto, las necesidades formativas de los docentes 
que laboran en instituciones interculturales de la etnia tsáchila, son resultado compartido de la poca iniciativa de formación en los docentes y el inadecuado proceso de inserción a procesos de capacitación y formación docente que ofertan los organismo de control y gestión de la educación en el Ecuador.

La formación docente es y seguirá siendo un punto de reflexión, incertidumbres y conflictos en todo sistema educativo; es más, en algunos casos se desestima la importancia de la formación y carrera docente para el logro de los propósitos educativos y sociales de las reformas educativas. De acuerdo a la investigación realizada por Lozano (2016), la mayoría de docentes que fueron encuestados en su estudio no tenía un proyecto de mejora profesional, ya que no se sentían preparados para un reto intelectual o porque el medio social y/o económico no lo permitía. Dado el caso del estudio antes mencionado, al parecer, los docentes interculturales bilingües también carecen de un proyecto de profesionalización docente, además posiblemente tengan las mismas necesidades formativas y dificultades en el acceso a capacitaciones que les permitan mejorar el quehacer educativo y alcanzar nuevos logros profesionales en sus respectivos contextos escolares.

Los docentes que laboran en instituciones interculturales de la etnia Tsáchila requieren de procesos de formación continua en educación intercultural de forma general y específicamente la que se contextualiza con la cosmovisión y cultura de la etnia Tsáchila; por lo tanto, parece ser que la necesidad de profesionalización de docentes con título de bachiller está acompañada de la necesidad de formación continua en educación intercultural en todos los docentes partícipes del estudio; de esta manera, es necesario enaltecer la formación docente como un aspecto troncal en la educación pero sin desestimar el cúmulo de experiencia y praxis que tiene cada docente, ya que Pegalajar (2014) considera que el desarrollo profesional es más que formación; es el producto del desarrollo pedagógico, la experiencia, el conocimiento, la comprensión, las emociones y los sentimientos individuales de cada docente como aspectos influyentes sobre los procesos educativos.

Posiblemente esta problemática esté afectando el proceso de enseñanza y aprendizaje que se desarrolla en las clases, ya que si los docentes interculturales bilingües no poseen un perfil mínimo de formación podrían estar improvisando, proponiendo actividades inadecuada o malinterpretando el proceso formativo y educativo en los que está inmersos los estudiantes. Iglesias (2014) menciona que es necesario educar para la formación humana con una visión comunitaria y promover el cambio social mediante la participación y propuesta de proyectos educativos inclusivos para el desarrollo de competencias interculturales, sin embargo los docentes participantes del estudio no poseen un perfil de capacitación en educación intercultural y la mayoría aún no ha iniciado un proceso de formación docente que le permita mejorar el desequilibrio de la educación regular con respecto a la educación intercultural.

El posible estancamiento de la educación intercultural contextualizada con la etnia Tsáchila no se produce de forma aislada, porque esto tiene relación con el sistema educativo, la formación docente, el acceso a la educación, la innovación y las propuestas curriculares; y en el caso de la formación docente parece ser que no está siendo tomada en cuenta como un aspecto transformador de la educación. En este sentido, Vizcarra, Tirado \& Triviño (2016) mencionan que las transformaciones educativas deben estar acompañadas de capacitación y profesionalización de los docentes para alcanzar las metas y compromisos que se establezcan en la propuesta educativa y, de este modo, pensar en transformar y mejorar la educación intercultural sin la debida capacitación y formación docente sería una total incongruencia entre la legislación educativa y la realidad del contexto escolar.

A partir de las explicaciones anteriores sobre las inconsistencias con respecto a la formación como aspecto transformador de la educación, 
Villagómez (2017) alerta que se debe tener una mirada crítica a la experiencia educativa que tienen los docentes, ya que su formación debe ser paralela a su experiencia dentro de procesos educativos para comprender los requerimiento educativos, didácticos, pedagógicos, sociales y procedimentales de los agentes que conforman la comunidad educativa, además de fomentar prácticas sociales de tolerancia, diálogo, atención a la diversidad y la generación de espacios que facilitan la interculturalidad y el pensamiento complejo.

La importancia de formar al profesorado que labora en instituciones interculturales bilingües tsáchilas es y seguirá siendo un aspecto fundamental en la mejora de la educación y la diversificación del sistema educativo, por esta razón, Andino (2018) menciona que la capacitación y formación docente desde cualquier perspectiva o punto de análisis es un aspecto positivo en la mejora de los procesos educativos, ya que la carrera docente es un proceso inacabado que se debe adecuar a los cambios del sistema educativo o de las actualizaciones del quehacer educativo. Es trascendental la mejora de la educación intercultural, pero con capacitación y formación de docentes interculturales bilingües, porque de no ser así, se seguiría alimentando las lagunas y vacíos procedimentales en instituciones educativas ubicadas en comunidades tsáchilas.

El abordaje superficial de la formación docente y la consideración de la capacitación con un elemento secundario en los procesos de perfeccionamiento docente provoca de cierto modo una limitada concepción de la complejidad de la carrera docente. Situándose en el análisis de la formación docente en educación intercultural Tipa (2017) menciona que esta debe tener una vinculación con la investigación, pero además plantea las siguientes cuestiones para una adecuada formación docente intercultural: (a) Acceso de jóvenes de etnias a la educación superior, (b) mayor acceso geográfico de universidades, (c) integración de los conocimientos ancestrales con los conocimientos profesionales, (d) valorización del idioma y cosmovisión de las etnias, (e) desarrollo y fortalecimiento docente en Educación Intercultural y (f) promoción e integración de docentes a etnias y comunidades.

Las explicaciones expuestas sobre las inconsistencias de la formación docente en educación intercultural se complementan con lo que parece ser una inadecuada o baja frecuencia de capacitación en interculturalidad, diversidad, cosmovisión étnica como parte de la formación de los estudiantes. La razón del estudio de la interculturalidad y diversidad se sustenta en la importancia de que las personas sepan convivir con sus diferencias culturales y étnicas, pero también la cosmovisión forma parte la transversalidad de la clase, ya que la transmisión cultural desde los ancestros, representa la cotidianidad de las personas de generación en generación.

La solución ante las falencias en la capacitación de docentes interculturales bilingües no es aislada porque la capacitación no es el único medio para proponer un sistema educativo intercultural. La respuesta a esta necesidad la explica Fabara (2016), el cual propone a la investigación docente como parte de la mejora de la calidad de la educación. De este modo, el emprendimiento de proyectos de investigación es un aliciente para la mejora de los procesos educativos, además los docentes que investigan pueden ser los que fortalecen las competencias de sus equipos de trabajo (Castro \& Castillo, 2016). Con base a lo explicado, hacer referencia a la formación docente es hablar sobre la preparación de los docentes para la producción de conocimiento, además de la competencia para proponer propuestas investigativas que permitan la resolución de problemas en el aula de clases (Faria, Reis \& Peralta, 2016).

En definitiva, la formación de docentes interculturales bilingües, tiene estrecha relación entre la capacitación que estos reciben y la competencia investigativa que cada uno adquiere durante su formación inicial y que es llevada a la práctica en el quehacer educativo; por lo tanto, Paz (2017) resalta que es vital para la educación el fortalecimiento de competencias que motiven tanto a docentes como estudiantes el desarrollo 
intelectual, ya que la transformación del propio sistema educativo depende de las propuestas coherentes que radican en el cuestionamiento y solución de prácticas que por un lado pueden no ser efectivas y por otro no están siendo ejecutadas correctamente (Díez Gutiérrez, 2013) $y$, a partir de ello se puede proponer cambios sustanciales en los procesos educativos que como es el caso de la educación intercultural para etnia Tsáchila, sigue siendo una quimera dentro de las propuestas educativas del país.

\section{Referencias bibliográficas}

Álvarez, J. (2014). Formación docente para el desempeño exitoso. Revista ARJÉ, 6(15), 121-129. Recuperado de https://goo.gl/iJn8Co

Andino, R. (2018). Capacitación docente: Pilar para la identificación y gestión de la violencia escolar. Alteridad, 13(1), 108-119. https://doi. org/10.17163/alt.v13n1.2018.08

Castro, P., \& Castillo, S. (2016). La evaluación de la formación en comportamiento innovador. Alteridad, 11(1), 66-77. https://doi. org/10.17163/alt.v11n1.2016.05

Daniels, H. (2016). El aprendizaje en culturas de interacción social. Revista de Investigación Educativa, 34(2), 315-328. http://dx.doi.org/10.6018/rie.34.2.252801

De los Saltos, S., \& Abreu, C. (2013). La certificación docente: otro eslabón para una carrera docente renovada. Ciencia y Sociedad, 38(3), 443-461. Recuperado de https://goo.gl/jeCsrK

Díez Gutiérrez, E. (2013). El decrecimiento en la formación del profesorado. Revista Interuniversitaria de Formación del Profesorado, 27 (3), 207-219. Recuperado de https://goo.gl/Romsbd

Fabara, E. (2016). La formación y el ejercicio de la docencia universitaria en Ecuador. Desafíos. Alteridad, 11(2), 171-181. https://doi. org/10.17163/alt.v11n2.2016.03

Faria, A., Reis, P., \& Peralta, H. (2016). La formación de profesores: ¿formación continua o formación postgraduada? Perspectivas de profesores y de líderes de las escuelas. Revista Electrónica Interuniversitaria de Formación del Profesorado, 19(2), 289-297. Recuperado de https://goo.gl/D3Y439

Iglesias, E. (2014). La formación en interculturalidad en la educación en el tiempo libre: necesidades y estrategias desde una perspectiva de competencias interculturales. Revista Electrónica Interuniversitaria de Formación del Profesorado, 17(2), 167-182.

http://dx.doi.org/10.6018/reifop.17.2.197511

Inciarte, A., Camacho, H., \& Casillas, D. (2017). Sistematización de experiencias formativas en competencias docentes investigativas. Opción, 33(82), 322-343. Recuperado de https://goo.gl/c7LpSz

Lalangui, J., Ramón, M., \& Espinoza, E. (2017). Formación continua en la formación docente. Revista Conrado, 13(58), 30-35. Recuperado de https://goo.gl/aWdVNj

López, E., \& Pérez, E. (2013). Formación permanente del profesorado y práctica docente intercultural: contenidos actitudinales y complementariedad competencial. Espiral. Cuadernos del Profesorado, 6(12), 32-42. Recuperado de https://goo.gl/MTzBwH

Lozano, I. (2016). Las trayectorias formativas de los formadores de docentes en México. Actualidades investigativas en Educación, 16(1), 1-25. https://doi.org/10.15517/aie. v16i1.22671

Ministerio de Educación del Ecuador (2014). El Modelo del Sistema de Educación Intercultural Bilingüe. Recuperado de https:// goo.gl/Frzhgn

Moreno, A. (2015). Enfoques en la formación docente. RA XIMHAI, 11(4), 511-518. Recuperado de https://goo.gl/tplcid

Paz, A. (2017). Análisis de la formación en comunicación intercultural. Revista Científica de estudios sobre interculturalidad, 3(1), 53-85. https://goo.gl/o4ykjP

Pegalajar, M. (2014). Importancia de la actividad formativa del docente en centros de Educación Especial. Revista Electrónica Interuniversitaria de Formación del Profesorado, 17(1), 177-192. http://dx.doi.org/10.6018/reifop.17.1.181731

Rodríguez, A., \& Fernández, A. (2017). Adultos que conforman menores en una escuela de colores. Actitudes de progenitores y profesores ante la diversidad cultural. Revista 
de Investigación Educativa, 35(2), 465-482. http://dx.doi.org/10.6018/rie.35.2.256371

Tipa, J. (2017). ¿De qué me sirve la interculturalidad? Evaluación de la Universidad Intercultural de Chiapas por sus estudiantes. Alteridad, 13(1), 56-71. https://doi.org/10.17163/alt. v13n1.2018.04

Tomé, M., \& Manzano, B. (2016). La Educación inclusiva intercultural en Latinoamérica. Análisis legislativo. Educación Inclusiva, 9(2), 1-17. Recuperado de https://goo.gl/6b1YYP

Ungerfeld, R., \& Morón, S. (2016). La investigación en la formación docente. Ideas para el debate. Intercambio, 3(2), 54-66. Recuperado de https://goo.gl/AqG6op
Villagómez, M. (2017). “Otras Pedagogías": La experiencia de la Carrera de Educación Intercultural Bilingüe-UPS. Alteridad, 13(1), 30-41. https://doi.org/10.17163/alt. v13n1.2018.02

Vizcarra, J., Tirado, M., \& Triviño, B. (2016). La especialización docente por campos formativos en la educación básica mexicana. Una necesidad para concretar el modelo curricular. RA XIMHAI, 12(6), 177-185. Recuperado de https://goo.gl/xjUfvr

Walsh, C., \& García, J. (2002). El pensar del emergente movimiento afro ecuatoriano: Reflexiones (des) de un proceso. Recuperado de https:// goo.gl/MVbMwc 


\title{
Educación, cuerpo y alteridad. Encuentros cara a cara para la formación del otro
}

\section{Education, body and alterity Meetings face to face for the formation of the other}

\begin{abstract}
Jhon Fredy Orrego Noreña es Docente-Investigador de la Maestría en Educación y Desarrollo Humano del Centro de Estudios Avanzados en Niñez y Juventud de la Universidad de Manizales y CINDE (Colombia) (jforrego@cinde.org.co) (https://orcid.org/0000-0002-4914-5636)
\end{abstract}

Diego Armando Jaramillo Ocampo es profesor de la Maestría en Pedagogía de la Universidad Católica de Manizales (Colombia) (djaramillo@ucm.edu.co) (https://orcid.org/0000-0002-3949-7697)

Recibido: 2018-04-15 / Revisado: 2018-11-05 / Aceptado: 2018-11-08 / Publicado: 2019-01-01

\section{Resumen}

No es posible pensar, reflexionar, hacer y/o transformar la educación al margen de la relación con el Otro; no se puede asumir la educación sin la pretensión de "formar" al Otro o por lo menos, intentarlo, como si tal cosa fuese posible. La educación, al igual que una práctica de transmisión de conocimiento (es también transmisión de cultura, lenguajes, modos y formas de ser y de estar, de nombrar y ser nombrado), pero, sobre todo, es un escenario de encuentro con el Otro, el cual dependerá de la concepción de sujeto y de mundo que se tenga, el desarrollo de una apuesta formativa. Este encuentro implica una transformación, ruptura, excedencia del sujeto de una ontología que encadena al sujeto a un utilitarismo cruel, para ir más allá, a un escenario en el que el sujeto ya no se encuentra solo a sí-mismo, sino que se encuentra con Otro, radicalmente diferente de él. Allí, es posible una educación que supere la preminencia del conocimiento y parta de una relación con el Otro. Dicha perspectiva, abordada desde las propuestas de los Filósofo Emmanuel Levinas y Joan Carles Mèlich, puede transitar por una educación moral centrada en el conocimiento, reglas y valores socialmente aceptados hasta una educación ética puesta sobre las necesidades formativas de los sujetos que responden responsablemente al y del Otro.

Descriptores: Educación, alteridad, ética, responsabilidad, acogimiento y cuerpo.

\footnotetext{
Abstract

Cannot possible think, do and / or transform education out of the relationship with the Other; you cannot assume education without the pretense of "form"
}

Forma sugerida de citar: Orrego Noreña, J. F., \& Jaramillo Ocampo, D. A. (2019). Educación, cuerpo y alteridad. Encuentros cara a cara para la formación del otro. Alteridad, 14(1), 89-97. https://doi.org/10.17163/alt.v14n1.2019.07 
the Other or at least try, as if such a thing were possible. Education, as a practical transmission of knowledge (also transmission of culture, languages, ways and ways of being and living, to appoint and be appointed), but above all, is a scene of encounter with the Other, which depend on the conception of the subject and the world you have, the development of a training bet. This encounter implies a transformation, rupture, leave of the subject of an ontology that chains the subject to a cruel utilitarianism, to go further, to a scenario in which the subject no longer finds himself alone, but finds himself with Other, radically differ-

\section{Introducción}

Durante el proceso de formación emergen gran cantidad de preguntas, interrogantes que van de un lado para el otro, de aquí para allá, cuestionamientos que transitan por las clases, los seminarios; incertidumbres que se sacuden en los pasillos y las cafeterías de las instituciones educativas y dudas que traspasan las diferentes clases y asignaturas que hacen presencia en el proceso formativo. Para el campo de la educación, estas preguntas están dirigidas en general sobre ¿Qué es la pedagogía? ¿Cuáles son las corrientes en las que se enfocan sus propuestas? ¿Cuáles son los modelos más apropiados para atender las múltiples realidades de nuestro país? ¿Qué papel juega la didáctica en la organización de los ambientes educativos? ¿Cuáles son los saberes más pertinentes y en qué lugar del proceso de formación se pueden ubicar? ¿Cómo transformar la realidad educativa? Entre tantas otras.

Todas estas preguntas que permiten proponer los diferentes encuentros en el campo de la educación no alcanzan a abarcar (o por lo menos no de manera explícita), otras cuestiones de igual o mayor importancia en la comprensión y transformación de la educación, como por ejemplo: ¿Qué es la educación? ¿Cuáles son sus trazos y horizontes de formación en el otro o con el Otro'? ¿Es posible pensarla al margen del sujeto? ¿Cuáles son las relaciones que se construyen en el marco de su práctica? ¿Debe la educación formar o, más bien, posibilitar la formación del Otro? ¿Quién ent from him. There, an education that exceeds the preeminence of knowledge and starts from a relationship with the Other is possible. This perspective, addressed from the proposals of the philosopher Emmanuel Levinas and Joan Carles Mèlich, can pass through a moral education based on knowledge, rules and socially accepted to a putting on the training needs of individuals who respond responsibly to education and other ethical values.

Keywords: Education, alterity, ethics, responsibility, fostering, body.

es el Otro de la educación? ¿Cómo se asume la existencia del Otro en los procesos de formación? ¿Hacia dónde se enfoca la relación que se establece con el Otro? ¿Cuáles son las condiciones de posibilidad para que la educabilidad aparezca y el Otro sea un sujeto educable? ¿Existe alguna diferencia entre hablar del otro o hablar con el Otro en educación²?; estas y muchas otras preguntas deberían dirigir permanentemente la labor educativa, orientar sus reflexiones, dinamizar sus procesos de cambio y transformación social de las personas y de las instituciones (Murcia, 2012).

Estos asuntos emergen permanentemente en el marco de escenarios contemporáneos, escenarios impregnados tanto de hegemonías y poderes como de resistencias y rupturas, en los cuales se exige cada vez más la re-significación de la educación, de la escuela, del conocimiento y de los saberes que por ella transitan en busca de superar escenarios tradicionales que han reducido al sujeto educable a un ser "cansado (...) una sociedad que se caracteriza por la desaparición de la otredad y la extrañeza" (Chul Han, 2012, p. 8 ), una sociedad que ve en el otro, en su ser, en su cuerpo, la diferencia que separa bien sea para excluir y rechazar o para incluir y normalizar, como si este no tuviese algo que enseñar, algo que decir, algo que mostrar, algo que contar, algo para dar.

Estas sociedades "cansadas" y "agotadas" por la velocidad del mundo "moderno", cada vez encierran más a las personas en su mismidad, es decir, cada vez se interacciona y se está más 
informado con el mundo al tiempo que se deja de conversar, compartir y conocer con los otros, pues la racionalidad moderna asume la cantidad y el ruido como opción de comunicación con los otros; sin embargo, se hace necesario una salida del terreno del ser que implique pensar y ser de otro modo (Lévinas, 1987), una pausa, un silencio, una paz que permita mirar y escuchar al Otro sin prejuicio y que le dé al sujeto una distancia en la que la alteridad radical no quede subsumida en los poderes del yo. Esto podría impedir "que el otro se cosifique como un objeto, como un 'ello'..." (Chul Han, 2014, p. 13).

Todo un desafío emerge en estos tiempos de premura y ocupación, este cansancio, esta cosificación y esta negación del Otro no se han limitado a la vigilancia y el control sobre las prácticas que podemos o no realizar, aprender e incluso pensar; se ha legitimado también en y sobre el cuerpo toda una estructura de dominación y encierro del cuerpo como totalidad (Lévinas, 1977, 2012).

Sin embargo, el cuerpo escapa cualquier intento o pretensión de captura y clasificación. Desde esta perspectiva, el ser humano que se muestra o que se "da" en su condición frágil y vulnerable lo hace desde su condición finita, tal como lo plantea Mèlich (2010b), para quien:

Los seres humanos somos corpóreos. Nuestra condición no es 'corporal' sino 'corpórea'. La corporeidad provoca una fractura, una grieta en nuestra identidad. Somos corpóreos porque no empezamos de cero, porque nacemos en un universo simbólico, en una gramática, y, al mismo tiempo, no estamos ubicados del todo, terminados del todo, constituidos del todo. Somos seres por hacer o haciéndonos (p. 37).

Esta ubicación de la condición de humanidad desde el cuerpo y en el cuerpo, lleva a pensar que los procesos de relación y encuentro son mucho más que asistir pasivamente a recibir una clase de manera tradicional y rutinaria, implican la constitución de la subjetividad por la irrup- ción del Otro, del cuerpo "que es el Otro", de su humanidad en la relación educativa.

Precisamente, la educación y la escuela tal como se conciben hoy en día, se han convertido en tiempos y espacios para adoctrinar, donde el único actor "activo" es un conocimiento impuesto que ha excluido los sujetos y los ha dejado en sus márgenes, y es justo allí fuera de la escuela donde otras formas de educación han emergido, acogiendo al ser humano, procurando su humanidad, otorgando reconocimiento a su condición sintiente, corpórea, dando un lugar transformador para sí mismo y para el contexto que lo rodea.

Es por ello, que pensar la relación entre educación, cuerpo y alteridad cobra valor, pues la educación debe recuperar su lugar como escenario de encuentro entre sujetos, encuentros que ocurren en un ser humano existente (Lévinas, 2006), de carne y hueso, finito, provisional, contingente (Mèlich, 2002, 2010a, 2010b) que también está ávido de saber, de experiencias que le permitan formarse a sí mismo en principio y desde allí aportar a la formación del Otro y de los otros; la educación y la escuela entonces deben volver la "mirada" y despertar su capacidad de "escucha" sobre su responsabilidad ética y política con la sociedad.

En estas consideraciones, desde una perspectiva ética, el proceso educativo se teje desde cuestionamientos tales como: ¿cómo se forma el ser humano? ¿cómo se aproxima al Otro en tanto Otro? y ¿qué relaciones se establecen con él en los múltiples espacios de encuentro que se constituyen como educativos?

En este sentido, abordar una apuesta por una educación desde/para/en y con la alteridad, podría asumirse como una redundancia pues todo proceso educativo siempre ha de estar dirigido hacia la formación del Otro, un Otro que demanda la presencia y la voz de un interlocutor, otro con el "quien" explorar el mundo (incluso el mundo del saber y el conocimiento) para con él reconstruirlo permanentemente; Otro que es corporeidad para sí 
y para el Otro, que mediante ella transita día a día en los escenarios de la vida humana.

\section{Desde el sujeto a la alteridad}

La alteridad, no es una condición que se dé per-se o se pueda definir, es precisamente lo indefinible en el ser humano, ${ }^{3}$ lo que no se puede enmarcar bajo ninguna categoría o nombrar de alguna manera, la alteridad es lo inefable en el sujeto y escapa a cualquier marco de referencia social y/o cultural.

De esta manera, si bien la alteridad es lo innombrable en el Otro, esta sólo puede emerger en la relación con él, esto implica que alguien (sea yo, o sea el Otro) se desprende de sus escudos, del mundo o la gramática ${ }^{4}$ la cual lo define o lo está definiendo, asumirse curioso y contemplativo frente a lo extraño, frente al rostro del Otro que se presenta como epifanía es lo que hace posible que la respuesta sea hospitalaria y fraterna, una respuesta cálida para acogerlo y hacerse responsable de él, de su singularidad antes que él mismo me exija cualquier responsabilidad (una responsabilidad sin justificación alguna y sin ningún porqués).

De igual manera, llegar hasta el Otro, hasta el infinito, ${ }^{6}$ es un camino arduo que implica una transformación del sí-mismo, una liberación de sí para poder trascender al Otro, librar una lucha constante con nuestra identidad, desprotegernos, distanciarnos de los marcos morales para ir en busca de lo ético, abrirnos a lo que aún no es y no sabemos si será.

Esta liberación parte de asumirnos, en primera instancia, como seres encadenados al mundo, encadenados a la existencia, encerrados en una consciencia tan particular que nos aísla de los demás, aun cuando compartimos un mundo con ellos, incluso estos, los otros, son vistos como "objetos" puestos allí, junto a mí, pero que no me afectan directamente, sino que desde la definición de sus características busco controlar, nombrar, clasificar, tematizar, ello para distinguir otros "objetos" en el mundo y saber cómo relacionarme y dirigirme hacia ellos.
La relación con ese mundo y los objetos es una relación moral, es una gramática ${ }^{7}$ del mundo, en la cual encontramos todo los insumos para dirigirnos a él de manera predeterminada. En esta relación, las respuestas ante todas las preguntas ya están dadas, ya se han definido por quienes creen tener la "razón" o la "verdad", por aquellos que legitiman su poder y su crueldad tanto en lo que dicen como en lo que hacen, lo cual hace que todo deje de ser extraño y novedoso para ser "normal", en ese instante todo se ha "naturalizado" y nada sorprende, pero tampoco, nadie interrumpe.

La gramática, es el escudo ante la paranoia producida por la diferencia, ante lo incontrolable, ante lo efímero; la gramática es así la normalización del mundo, para sentirnos seguros creyendo que "todo está bajo control" tan sólo por ser capaz de nombrarlo dentro de nuestros marcos referenciales.

Así, el Otro es otro, en tanto objeto a la consciencia, es otro representado, dibujado, clasificado y limitado a mi gama de posibilidades de nombrar sus características, éste sujeto pierde así su particularidad y se vincula, incluye ${ }^{8}$ si se quiere, a un todo. Allí, nos encontramos con una cara, con ciertas características (ojos, boca, nariz, colores, formas) que requieren ser nombradas, pero que no dan cuenta de lo que en realidad es ese otro frente a mí, o sea, se convierte en un otro distante de mí y no próximo. ${ }^{9}$

No obstante, en el ser humano se genera un malestar ante las categorías en las cuales ha sido enmarcado, pues su nombre, ser alto o bajito, lindo, feo, blanco, negro, mestizo, hombre, mujer, niño, joven o adulto, etc., no logran dar cuenta de lo que en realidad él siente que es, pero que de igual manera, no encuentra en sus marcos de referencia formas de nombrarse, no encuentra en lo que se le ha impuesto como "ser". Este malestar Lévinas (2011) lo denomina como "náusea", como esa presión que se siente en el interior, desde el encierro en el cual ha sido puesto y que ya no basta para contenerlo, generando así una "necesidad ${ }^{10}$ de evasión", necesidad de salir de 
ese molde que le ha sido impuesto, ir más allá del sí-mismo para ser-Otro, para dar testimonio de sí a través de su propio lenguaje.

Este estrés genera rupturas en el sujeto, en sus formas de ver y dirigirse hacia el mundo que lo rodea, se moviliza, se desestabiliza, se sacude para agrietarse y poder "excederse", lograr salir de sí mismo, adentrarse en la oscuridad, alejarse de la luz que le ha marcado el rumbo y caminar en la incertidumbre hacia lo imprevisto en busca de nuevos horizontes, caminar sin rumbo fijo.

Esta excedencia se da a través de un lenguaje propio, de una forma particular de decirse, de dar testimonio de sí encontrando sus propias palabras, descubriendo otras; otro lenguaje que fluye hacia el exterior en busca del Otro-ser excedido también de sí mismo, en busca de la alteridad. Pero este lenguaje propio, demanda del Otro su presencia para ser escuchado, para ser contemplado, para que lo encuentre y lo acoja, por eso ir hacia el Otro es excederse, esto requiere del deseo por él o ella -pero no un deseo como necesidad de algo que nos falta y podemos obtener, sino- como deseo de lo inalcanzable, deseo de un horizonte que nos convoca pero que no podemos alcanzar.

Dicho así, el Otro, la humanidad, el infinito (para Lévinas), es quien nos llama y exige nuestra atención, escucha, contemplación; su rostro trasciende las características nombrables de la cara y se presenta como lenguaje, como epifanía, presenta su dolor, su pasión, su emoción, su demanda, su alegría y su sufrimiento.

Este encuentro con el Otro (entre otros) que se presenta cada quien desde sus lenguajes, implica escucha atenta, contemplación, responsabilidad (compasión diría Mèlich, 2010b) por el otro, responder a su demanda, incluso en ausencia de un llamado explícito. Apenas acá, luego de las rupturas con uno mismo logramos encontrarlo al aproximarnos a él sin abarcarlo, sin controlarlo ni clasificarlo, justo acá asistimos, frente al rostro del Otro, a su epifanía, al encuentro ético, a la relación educativa que responde responsablemente por el Otro.

\section{De la educación moral al encuentro ético}

Plantea Joan-Carles Mèlich que toda educación es moral, en tanto la educación es el proceso a través del cual heredamos la cultura, las normas, las leyes, los comportamientos, incluso, las formas de pensar y hasta de sentir. En este sentido, la educación es una educación gramatical, pues aprendemos a nombrar, clasificar, incluir y excluir todo lo que nos rodea, incluso a los otros. Una educación moral, no tiene como preocupación central al sujeto, sino al conocimiento, toda vez que el primero es también conocimiento, es un cúmulo de características de las cuales podemos dar cuenta a partir de marcos referenciales heredados social y culturalmente. Desde este punto de vista, educar al ser humano implica llenarlo de conocimientos ${ }^{11}$ desde los cuales dar cuenta de todo a su alrededor, es enseñarle a protegerse de la incertidumbre, es decir, enseña a no ponerse frente al Otro sino a espaldas de él y esperar que los marcos morales predeterminados de la sociedad lo incluyan o lo excluyan y desde allí, desde la periferia, actuar en favor o en contra de él.

La educación vista desde este punto de vista, se ha convertido en un escenario de transmisión de conocimientos, con la plena pretensión de que adquiera lo necesario para poder ser miembro de la sociedad, para poderse incorporar y responder en la misma medida que esta le impone; de lo contrario será excluido, rechazado, visto como un extraño, recluido, confinado al olvido, a la esquina más profunda del salón.

El problema de la educación con cada generación, es precisamente quedarse allí, lo cual sucede porque quienes enseñan son de otras generaciones ya encadenadas a sus marcos referenciales, a sus marcos morales, la voluntad ya ha sido domada y desde allí se imponen al Otro, quieren adoctrinarle, mientras el Otro busca su emancipación, su apertura, se resiste a ser encadenado de la misma manera que sus maestros a ser convertido en uno más. 
Por ello, para que la educación trascienda se requiere que el mismo maestro se evada de sí mismo, de sus encuadres morales, se desestabilice, que rompa con sus propias cadenas para excederse, para descubrir nuevos lenguajes, para ir en busca del Otro por compasión y no esperar que él busque mi piedad (Mèlich, 2014, 2010b).

A partir de allí, la educación deja de ser transmisionista y el conocimiento ya no es el centro de todo acto educativo, se transforma, muda hacia una educación como excedencia, una educación que descubre lenguajes, formas de expresiones, saberes excepcionales, da cabida a la duda, a la incertidumbre y no encuentra una única respuesta cual verdad absoluta, sino respuestas múltiples desde donde cada sujeto, a partir de sus propias perspectivas, aporta a la construcción de nuevos saberes.

Una educación ética encuentra en el otro posibilidades, no imposición de esquemas de referencia, se abre a la epifanía del rostro del Otro, se presenta contemplativo ante él para aprender de él; así los roles entre maestro y estudiante se diluyen y ambos son maestros y aprendices, ambos tienen algo que compartir, algo que donar al Otro, algo que dar al Otro. ${ }^{12}$

Así, la educación logra en cabeza de sus actores, trascender, ir más allá, generar un escenario de contingencia para el acontecimiento ético (Bárcena y Mèlich, 2000, 2014) en el cual, cada quien es responsable del Otro, donde ninguno está en mejor posición que el Otro; por el contrario, donde todos nos construimos en la relación con el Otro y con el conocimiento. Desde este punto de vista, se transita de una educación moral, de dominación, de control y adoctrinamiento, a una educación ética, de contingencia, de incertidumbre, donde la duda es curiosidad no desconfianza y la interpelación no es irrespeto sino escucha, eso que para Han (2017) significa:

Escuchar no es un acto pasivo. Se caracteriza por una actividad peculiar. Primero tengo que dar la bienvenida al otro, es decir, tengo que afirmar al otro en su alteridad. Luego atiendo a lo que dice. Escuchar es un prestar, un dar, un don. Es lo único que le ayuda al otro a hablar. No sigue pasivamente el discurso del otro. En cierto sentido, la escucha antecede al habla. Escuchar es lo único que hace que el otro hable. Yo ya escucho antes de que el otro hable, o escucho para que el otro hable. La escucha invita al otro a hablar, liberándolo para su alteridad (pp. 117-118).

Así mismo, responsabilidad por el Otro, por su palabra. La educación entonces, se podría entender como escenario ético, de encuentro en procura de propiciar la formación del Otro. Formación que se presenta en el cara-a-cara, en la escucha atenta a lo que el Otro quiere decir y que se le ha negado a toda costa. Se asiste, a una educación que supera el adoctrinamiento y se presenta como diálogo, apertura y encuentro.

\section{Sobre la condición de humanidad: la corporeidad 13 como nicho de la existencia propia y compartida}

Esta perspectiva ética parte de asumir cómo se han expresado las relaciones existentes entre el ser humano finito y corpóreo con la presencia/ ausencia del otro y la respuesta otorgada desde lo educativo, o sea, una respuesta que nunca lo es completamente porque al frente se encuentra el Otro, es decir, a partir de los procesos de encuentro y aparición del otro ante el sí mismo, aparición que ocurre con la llegada del cuerpo, ese que es corporeidad da paso al acontecimiento, a las transformaciones, a las posibilidades de llegar a ser, en términos del mismo Mèlich (2010a, p. 11)

El cuerpo es, mientras que la corporeidad llega a ser y, a la vez, llega a ser otra de lo que es, llega a ser distinta, llega a ser contra lo que es... y, también, nunca es del todo, porque un ser corpóreo remite a un escenario abierto, siempre móvil, un escenario que no puede eludir el pasado, el recuerdo de lo que ha sido, de lo que le han hecho, la herencia recibida, la gramática en la 
que ha sido educado y, al mismo tiempo, remite a un porvenir, no solamente a un futuro más o menos previsible, programable o planificable, sino a un porvenir que siempre está por venir, que siempre está abierto a los acontecimientos que rompen cualquier proyecto, cualquier identidad, cualquier fijación.

Eso que somos como corporeidad y que llegamos a ser, es lo que con la ayuda de la educación nos vamos haciendo, nos vamos transformando y vamos transitando por nuestra propia existencia sin quedarnos en ella, sin detenernos en nuestro propio cuerpo, sino lanzándonos hacia el Otro, arrojándonos más allá del ser, incluso de-otro-modo-que-ser (Lévinas, 1987).

El ser humano es corpóreo, es decir, un ser de carne y hueso, un ser que habita un lugar en el mundo desde su existencia y al mismo tiempo es habitado por múltiples dimensiones que reposan sobre su existir corpóreo como posibilidad, el lenguaje, el pensamiento, la sensibilidad, las funciones biológicas y orgánicas así como las construidas socialmente tienen razón de ser en la corporeidad, esa que nos hace ser humanos. Este escenario de corporeidad constituido por lo visible y por lo invisible, por lo inmanente y lo quiasmático o por la unión del alma y el cuerpo (Merleau-Ponty, 1993, 2006) son los que posibilitan la existencia humana propia, particular, singular y complementariamente compartida con los otros y con el mundo.

Esta condición de existencia en la corporeidad y desde la corporeidad nos hace asumir una posición en la que el ser humano es un ser encarnado, un ser que no sólo tiene carne o cuerpo, sino que es carne y es más que cuerpo (corporeidad); en términos de Henry (2001).

Los seres encarnados son seres sufrientes, atravesados por el deseo y el temor, que sienten toda la serie de impresiones vinculadas a la carne por cuanto que, constitutivas de su sustancia una sustancia impresional por tanto-, comienzan $y$ acaban con lo que ella experimentan ( $p .11$ )

Eso que nos atraviesa como humanos, que nos toca y nos trastoca va rompiendo poco a poco lo que creíamos ser, saber o conocer, va mostrando nuestra frágil y vulnerable condición expuesta siempre a lo imprevisto, a lo que viene de lejos y de afuera, a lo que se escapa de nuestro control y que se convierte en condición de posibilidad para entrar en relación y encuentro con el Otro y con lo otro, esas tenues certezas de lo que uno es o cree haber sido van desbordándose hacia lo nuevo y lo desconocido, hacia el Otro.

Podría decirse entonces que la corporeidad encarnada es más que la objetividad del cuerpo cosa o cosificado, es un cuerpo que toca y es tocado, que desea y es deseado, un cuerpo como corporeidad sintiente con gestos llenos de significados (Vanegas, 2001), una corporeidad que se construye socialmente (Le Bretón, 2000) en el marco de las relaciones que se tejen con los demás, con los prójimos más cercanos, incluso con los extraños y los extranjeros.

Justamente, el reconocimiento del Otro de sí mismo como lo plantea Mèlich (2010a), o sea, del cuerpo como corporeidad, implica una respuesta adecuada o inadecuada a la solicitud del Otro, respuestas que son constantes en los procesos de formación y que en ocasiones limitan, rechazan o invisibilizan la existencia del otro en la Escuela, en las instituciones sociales construidas y que construyen la humanidad; sin embargo, una respuesta ética (al menos desde la perspectiva Lévinasiana) fundará su expresión en la escucha, en el lenguaje, en la obediencia al mandato del rostro del Otro (Lévinas, 2001a) y a la posibilidad de elegir responsablemente como permitir que el Otro siga siendo, como acompañar su proceso de llegar a ser, como llegar a ser juntos, entre nosotros (Lévinas, 2001b) manteniendo una distancia próxima, una relación cercana sin absorber la existencia del otro, sin eliminarla sutilmente en la homogeneidad ni abruptamente en la total heterogeneidad.

El cuerpo como corporeidad no nace, sino que se hace, no está previsto, programado o determinado, sino que es puro inacabamiento, incertidumbre, vértigo, es apertura del hombre al mundo, es riesgo atravesado por el encuentro y la 
aparición de los otros en la propia existencia, es la sensibilidad que irrumpe e interpela la propia calma, es el gozo de sentirse vivo, afectación que viene de afuera a increpar la propia piel, petición de otro que yace expuesto y manda, ordena, clama, llama preocupación, atención y recibimiento. Con razón insistió Unamuno (1913): "Ni lo humano ni la humanidad, ni el adjetivo simple, ni el sustantivado, sino el sustantivo concreto: el hombre. El hombre de carne y hueso, el que nace, sufre y muere -sobre todo muere-, el que come y bebe y juega y duerme y piensa $y$ quiere, el hombre que se ve y a quien se oye, el hermano, el verdadero hermano" (p. 3); si, el hermano, quien no tiene su propio cuerpo, sino que sufre y vive y muere en su cuerpo.

\section{Notas}

1 Se hace necesario precisar la diferencia entre "otro" y "Otro"; el "otro" es otro objetualizado, cosificado y anclado a una gramática (Mèlich, 2014) que lo clasifica y lo categoriza desconociendo así su radical alteridad. Por su parte el "Otro" es lo absolutamente otro, es aquel que rompe todo mis esquemas y que me altera en mi propia esencia, es quien nunca podré llegar a ser y, parafraseando a Lévinas (2009, p. 133) exige de mí responsabilidad sin que él se haga responsable de mí.

2 En un artículo que lleva este nombre, se expresan las diferencias considerables entre hablar del otro y hablar con el otro, la primera referida a una forma de definir y tematizar al otro y la segunda, como posibilidad para que surja la relacionalidad y el encuentro. Ver: Jaramillo y Orozco (2015) y Jaramillo y Murcia (2014).

3 Mèlich (2014) prefiere utilizar el término "ser finito".

4 Mèlich (2014) en su obra Lógica de la crueldad, desarrolla el concepto de gramática para plantear que vivimos una realidad moral en la que todo está controlado, predeterminado, donde todo ya ha sido nombrado y cuenta con un significado.

5 Sobre este asunto, Zielinski (2011) muestra con suficiente elocuencia el planteamiento de Lévinas acerca de la responsabilidad, esa que es sin porqué, sin contrato, sin reciprocidad.

6 Para Lévinas, el "Infinito" es la humanidad en el Otro, que demanda una respuesta ética de mí, lo que implica una respuesta no predeterminada, no de libreto ni de manual como la da la moral, sino una respuesta contingente ante la contingencia de la aparición, presencia e irrupción del Otro.

7 Para Lévinas es el conocimiento como ya se había mencionado; en cambio es más conveniente emplear el término gramática de Mèlich, mucho más cercano al mundo propiamente.

8 Desde esta perspectiva se desarrolla una amplia crítica a las políticas y apuestas por la inclusión, pues incluir al Otro, es normalizarlo, es hacerlo otro más. Por tanto, diría Mèlich que la inclusión en tanto gramática moral incluye también la exclusión de aquellos que no cumplen los requisitos necesarios para ser incluidos o clasificados; este es uno de tantos ejemplos de lo que él denomina lógica de la crueldad.

9 Dice Viveros y Vergara (2014) que la distancia con el otro está asociada a la otredad, mientras que la proximidad y la cercanía dan cuenta de la alteridad.

10 Necesidad, no como ausencia de algo que nos falte sino, como desbordamiento por exceso de algo. Ver por ejemplo Domínguez (2005) y Leibovici (2012)

11 Al mejor estilo de la "educación bancaria" ya denunciada por Freire (2005) en su Pedagogía del Oprimido.

12 Lévinas (1977, p. 263) plantea que esta entrega “... consiste, para el uno, en dar el mundo, su posesión, al otro...". Así mismo, Skliar (2007a, 2007b y 2011 ; y en colaboración con Larrosa (2009) insiste en una educación que es del Otro, que se da con el Otro y es para el Otro.

13 La corporeidad tiene sus raíces en la fenomenología, principalmente en los desarrollos de la fenomenología de la percepción de Merleau-Ponty (1993) y se asocia estrechamente con lo expuesto por Duch y Mèlich en escenarios de la corporeidad (2012); en estos textos, así como en otras referencias tratadas en este documento, se sostiene la condición humana desde sus dimensiones sintientes, vivientes y por supuesto, corpóreas.

\section{Referencias bibliográficas}

Bárcena, F., \& Mèlich, J-C. (2000). La educación como acontecimiento ético. Barcelona: Ediciones Paidós.

Bárcena, F., \& Mèlich, J-C. (2014). La educación como acontecimiento ético: Natalidad, narración y hospitalidad. Buenos Aires: Miño y Dávila editores. Segunda edición revisada y aumentada.

Domínguez, J. E. (2005). El concepto de excedencia en las obras de Emmanuel Lévinas anteriores a totalidad e infinito 1934 a 1954. México: Universidad Autónoma de México. Recuperado de https://bit.ly/2DRWFPT

Duch, L., \& Mèlich, J.C. (2012). Escenarios de la corporeidad. Antropología de la vida cotidiana 2. Madrid: Editorial Trotta.

Freire, P. (2005). Pedagogía del Oprimido. México: Siglo XXI Editores S.A. de C.V. Trad. Jorge Mellado.

Han, B-Ch. (2012). La sociedad del cansancio. Barcelona: Herder Editorial.

Han, B-Ch. (2014). La agonía del Eros. Barcelona: Herder Editorial. 
Han, B-Ch. (2017). La expulsión de lo distinto. Barcelona: Herder Editorial.

Henry, M. (2001). Encarnación, una filosofía de la carne. Salamanca: Ediciones Sígueme.

Jaramillo, D. A., \& Orozco, M. (2015). ¿Hablar del otro o hablar con el otro en educación? Revista Latinoamericana de Estudios Educativos, 11(2), 47-68.

Jaramillo Ocampo, D. \& Murcia Peña, N. (2014). Hacia una pedagogía del encuentro: apuestas por la relación cuerpo-alteridad en educación. Revista de Investigaciones UCM, 14(24), 142-149.

Le Bretón, D. (2000). El cuerpo y la educación. Revista Complutense de Educación, 11(2), 35-42.

Leibovici, M. (2012). Claustrofobia de sí y necesidad de excedencia. La "Patética del Liberalismo" según Emmanuel Lévinas. Santiago de Chile: Revista de la Academia, 17, 21-31.

Lévinas, E. (1977). Totalidad e infinito, ensayo sobre la exterioridad. Salamanca: Ediciones Sígueme.

Lévinas, E. (1987). De otro modo que ser o más allá de la esencia. Salamanca: Ediciones Sígueme.

Lévinas, E. (2001a). La realidad y su sombra. Libertad $y$ mandato. Madrid: Editorial Trotta. S.A. Traducción de Antonio Domínguez Leiva.

Lévinas, E. (2001b). Entre nosotros, ensayos para pensar en otro. Valencia: Editorial Pre-textos.

Lévinas, E. (2006). De la existencia al existente. Madrid: Arena Libros. Traducción de Patricio Peñalver.

Lévinas, E. (2009). Humanismo del Otro hombre. Madrid: Siglo XXI editores.

Lévinas, E. (2011). De la evasión. Madrid: Arena Libros. Segunda Edición. Trad. Isidro Herrera.

Lévinas, E. (2012). Totalidad e infinito. Ensayo sobre la exterioridad. Salamanca: Ediciones Sígueme, 2da Edición. Traducción de Miguel GarcíaBaró.

Mèlich, J. C. (2010a). El otro de sí mismo. Por una ética desde el cuerpo. Barcelona: Editorial UOC.
Mèlich, J. C. (2010b). Ética de la compasión. Barcelona: Herder Editorial.

Mèlich, J. C. (2014). Lógica de la crueldad. Barcelona: Herder.

Merleau- Ponty, M. (1993). Fenomenología de la percepción. Barcelona: Editorial Planeta.

Merleau- Ponty, M. (2006). La unión del alma y el cuerpo, Malebranche, Biran y Bergson. Madrid: Ediciones Encuentro.

Murcia, P. N. (2012). La escuela como imaginario social. Apuntes para una escuela dinámica. Magistro 6(12), 53-70. Universidad Santo Tomás.

Skliar, C. (2007a). La educación (que es) del otro: argumentos y desiertos de argumentos pedagógicos, 1 ed. Buenos Aires: Ediciones Novedades Educativas.

Skliar, C. (2007b). ¿Y si el otro no estuviera ahí? notas para una pedagogía (improbable) de la diferencia. Buenos Aires: Miño y Dávila.

Skliar, C. (2011). Lo dicho, lo escrito, lo ignorado. Escritos mínimos entre educación, filosofía $y$ literatura. Buenos Aires: Miño y Dávila Editores.

Skliar, C., \& Larrosa, J. (2009). Experiencia y alteridad en educación, 1 edición. Rosario: Homo Sapiens Ediciones.

Unamuno, M. (1913). Del sentimiento trágico de la vida. Salamanca: El Adivinario.

Vanegas, J. H. (2001). El cuerpo a la luz de la fenomenología. Manizales: Artes gráficas Tizán y Universidad Autónoma de Manizales.

Viveros, E.F., \& Vergara, C.E. (2014). Aproximación a la noción de encuentro en Emmanuel Lévinas. Revista Virtual Universidad Católica del Norte, 41, 61-69, febrero-abril. Fundación universitaria Católica del Norte, Medellín. Recuperado de https://goo.gl/qN232j

Zielinski, A. (2011). Lévinas: la responsabilidad es sin porqué. Bogotá: Universidad Externado de Colombia. Traducida por Alberto Supelano. 


\section{Desarrollo de un equipo docente en la coordinación del profesorado en el ámbito universitario}

\section{Development of a teaching team in the coordination of the teaching staff in the university environment} Dr. Miguel Ángel Sánchez Jiménez es investigador del Departamento de Marketing y Comunicación
de la Universidad de Cádiz (España) (miguelangel.sanchez@uca.es) (http://orcid.org/0000-0002-4271-3522)

Dra. Araceli Galiano Coronil es investigadora del Departamento de Marketing y Comunicación de la Universidad de Cádiz (España) (araceli.galiano@uca.es) (http://orcid.org/0000-0003-2270-0924)

Recibido: 2018-04-12 / Revisado: 2018-11-08 / Aceptado: 2018-11-28 / Publicado: 2019-01-01

\section{Resumen}

La coordinación en la docencia universitaria se ha establecido como uno de los elementos relevantes para el buen desempeño de la docencia y el buen desarrollo profesional y organizativo. Ante la identificación de la baja satisfacción de los alumnos del Grado de Marketing e Investigación de Mercados de la Universidad de Cádiz con la coordinación docente se plantea la creación de un equipo docente formado por profesores de dicho título con el objetivo de crear procedimientos comunes para conseguir una mejor comunicación del profesorado del Título y resolver así los inconvenientes derivados de la falta de coordinación generando una mayor satisfacción del alumnado. De esta manera se creó y desarrolló el equipo docente estableciéndose reuniones periódicas durante el curso académico 2016/2017 y proponiendo una serie de actividades que ayudasen a conseguir una mayor y mejor coordinación docente. Una vez realizadas las actividades se analizaron los resultados conseguidos durante el curso 2016/2017, comprobándose una mayor satisfacción por parte del alumnado y el profesorado del título. Por lo tanto, la experiencia fue realmente positiva, no obstante, es conveniente que el desarrollo y el estudio dicho equipo docente se siga realizando para los posteriores cursos académicos para corroborar así la eficacia de su implantación.

Descriptores: Coordinación, docencia, equipo, profesorado, universidad, alumnado.

\begin{abstract}
The teaching coordination in the university field has been established as one of the main elements for the good performance of teaching and good professional and organizational development. Before the identification of the low satisfaction of the students
\end{abstract}

Forma sugerida de citar: Sánchez Jiménez, M. Á., \& Galiano Coronil, A. (2019). Desarrollo de un equipo docente en la coordinación del profesorado en el ámbito universitario. Alteridad, 14(1), 98-108. https://doi.org/10.17163/alt.v14n1.2019.08 
of the Marketing and Market Research Degree of the University of Cádiz with the teaching coordination, the creation of a teaching team made up of professors of said degree is proposed with the aim of creating common procedures to achieve better communication of the Title faculty and to solve the problems derived from the lack of coordination, generating greater student satisfaction. In this way, the teaching team was created and developed, establishing regular meetings throughout the 2016/2017 academic year and proposing a series of decisions or activities that would help to

\section{Introducción}

Para Martínez y Yus (2015), los máximos responsables de las instituciones educativas deben diseñar modelos pedagógicos que alimente en el interior de las aulas una didáctica orientada a estimular la autonomía, el trabajo en equipo y la creatividad de los alumnos. Para ello se hace preciso cultivar la cooperación entre los diferentes profesores que forman parte activa del proceso de aprendizaje de los futuros titulados universitarios. Teniendo presente que actualmente existe una gran reticencia de los educadores de las instituciones de enseñanza superior en emprender proyectos de innovación docente orientados a promover labores de coordinación entre las distintas asignaturas que conforman el corpus académico de sus estudiantes (Soldevilla et al., 2012).

La documentación consultada para el desarrollo de esta producción científica pone de manifiesto, por un lado, el vínculo positivo que hay en el mundo universitario entre las acciones de colaboración que llevan a cabo los docentes que comparten una determinada asignatura con los resultados académicos y el bienestar subjetivo de sus estudiantes (Moreno, 2006; Lavié, 2009). Y por otro, el papel fundamental que juega en la puesta en marcha de un modelo de aprendizaje de tipo cooperativo que exista una excelente coordinación entre los diferentes profesores que conforman su ecosistema educativo (Santos et al., 2009).

Desde esta perspectiva, un conjunto de profesores de la facultad de ciencias sociales y la achieve greater and better teacher coordination. Once the activities were carried out, the results achieved during the 2016/2017 academic year were analyzed, demonstrating greater satisfaction both in the students and in the teaching staff of the degree, therefore the experience was really positive, however it is convenient that the development and This teaching team will continue studying for the subsequent academic courses to corroborate the effectiveness of its implementation. Keywords: Coordination, teaching, team, faculty, university, students.

comunicación de la Universidad de Cádiz se plantearon la creación de un equipo docente con el propósito de incentivar su coordinación tomando como base los dos siguientes objetivos. El primero, fomentar la satisfacción del profesorado con su coordinación docente, y la segunda, mejorar la satisfacción del alumnado con la coordinación del profesorado. En este artículo se especifican las actividades y decisiones llevadas a cabo por el equipo docente, así como el método de evaluación que se ha tenido en cuenta en cada uno de los dos objetivos para conocer si se han alcanzado.

\section{Justificación del estudio}

Cada curso académico la unidad de calidad de la Universidad de Cádiz para asegurar que la organización de la enseñanza funcione de manera eficiente realiza una serie de estudios a los grupos de interés de las titulaciones, entre las que destacan los profesores y los alumnos. Una vez analizados los resultados se identificó una baja satisfacción del alumnado con la coordinación docente del profesorado del Título de Marketing e Investigación de Mercados. Ante este hecho se planteó mejorar dicha coordinación docente en el Título mediante la creación de un equipo docente formado por los profesores coordinadores de las asignaturas pertenecientes al área de Comercialización e Investigación de Mercados que se imparten el grado de Marketing e Investigación de Mercado. Dicha área guarda una relación totalmente afín con el Grado de 
Marketing e investigación de Mercados, teniendo actualmente el $38 \%$ de la docencia en créditos para dicho Grado, contando con 15 asignaturas repartidas por curso de la siguiente manera:

$1^{\circ}$ Curso: Introducción al Marketing.

20 Curso: Dirección de Marketing, comportamiento del consumidor y marketing no lucrativo.

3o Curso: Producto y Precio, marketing sectorial, investigación de mercados I y II, distribución comercial I y II y comunicación comercial I y II.

$4^{\text {o }}$ Curso: Fuerza de ventas, introducción al e-marketing, fundamentos de marketing internacional.

Por lo tanto, se puede asegurar que dichas asignaturas tienen una grandísima importancia en el desarrollo del propio Título y en enriquecer el bienestar subjetivo tanto de los educadores como de sus educadores, indispensable para que el Título siga mejorando y pueda seguir adelante. El Título después de su inicio en el curso 2010/2011 se ha consolidado, siendo ya son dos las promociones de alumnos que han acabado la carrera. Por lo tanto, una vez que el Título se ha afianzado se estima idóneo hacer un análisis de las asignaturas más importantes del mismo por parte de los coordinadores y como podrían mejorarse algunos aspectos de las mismas.

De este modo se ha considerado indispensable la creación del citado equipo docente en el que formarán parte voluntariamente los siete profesores coordinadores de asignaturas del área que pertenezcan al Grado de Marketing e Investigación de Mercados y que servirá para mejorar la coordinación docente entre el profesorado y facilitar el trabajo en grupo de los mismos. La finalidad es que los coordinadores se puedan complementar y ayudar los unos a los otros en las distintas asignaturas, aportando ideas en común y facilitando así el trabajo. De esta manera es posible mejorar el contenido de las asignaturas y que el alumno quede más satisfecho en las distintas encuestas de satisfacción.
Tanto desde el departamento de Marketing y Comunicación como desde el equipo decanal de la Facultad de Ciencias Sociales de la Comunicación se da interés a la realización de nuevas acciones y mejoras en el Título, comprometiéndose así con la mejora continua en la docencia.

Además, la mención de equipo docente también se hace en la propia memoria del Grado, que especifica lo siguiente:

Los distintos profesores que impartan docencia en un mismo módulo, materia o asignatura formarán un Equipo Docente y mantendrán una coordinación permanente sobre el desarrollo de las actividades formativas y los objetivos alcanzados. Esta coordinación se hará tanto dentro de una misma asignatura, si tuviera más de un profesor, como entre las distintas asignaturas de una materia, y para las distintas materias de un módulo. Los Equipos Docentes de las distintas asignaturas actualizarán anualmente su Guía Docente atendiendo a los objetivos establecidos en esta Memoria y a los procedimientos contemplados en el Sistema de Garantía de Calidad. Con carácter anual, de manera ordinaria, y en cualquier momento en el caso de que se produzcan desviaciones respecto de la planificación realizada, los miembros de cada Equipo Docente están obligados a facilitar al Coordinador de la Titulación y a las Direcciones de los Departamentos implicados la siguiente información:

- Contenidos previstos no impartidos.

- Grado de consecución de las capacidades y objetivos previstos.

- Principales dificultades encontradas.

- Herramientas y sistema de evaluación seguido.

- Situaciones particulares relevantes.

- Resultados académicos obtenidos.

El Coordinador de la Titulación pondrá dicha información en conocimiento de otros Equipos Docentes que pudieran verse implicados para que adapten sus propuestas docentes respecto de 
lo planificado, si fuera el caso. Los departamentos deberán enviar con carácter anual un informe a la Comisión de Garantía de la Calidad del Centro (o Subcomisión del Título en su caso) en la que se indiquen las medidas que se tomaron para adaptarse a las disfunciones aparecidas y garantizar la coordinación entre las materias del Título bajo su responsabilidad.

\section{Estado de la cuestión}

Como se ha dejado entrever en las páginas anteriores, actualmente hay una extensa producción bibliográfica que revela la ausencia en los planes curriculares de las universidades españolas de acciones didácticas de coordinación entre los docentes en el desempeño de sus clases magistrales. Para Cazorla et al. (2010), las puestas en marcha de esta actividad pedagógica permitirían tres cosas fundamentalmente. La primera diseñar un temario que se pueda dar en su integridad sin estrés por la falta de tiempo. La segunda enriquecer las competencias transversales y las habilidades sociales de los educadores, y la última, poder desarrollar atractivas prácticas docente de naturaleza interdisciplinar siempre que no afecte a las fechas de los exámenes, cuyo cronograma se aprueba a principio del curso académico por los decanos. Con relación a esta última cuestión, señalar que hay una vasta cantidad de autores que muestran la necesidad de establecer en las instituciones de enseñanza superior españolas una educación que gravite en torno a la didáctica colaborativa y constructiva. Tal hecho viene justificado por múltiples factores, entre ellos cabe destacar una didáctica que cultive de forma significativa no solo la aparición de grupo docentes, sino también la creación de comunidades de aprendizaje o de conocimiento de tipo formativa o virtual (Armengol, 2009; Meirinhos y Osorio, 2009; Bozu \& Muñoz, 2009; Elboj et al., 2002; Rué \& Lodeiro, 2010; Martínez, et al., 2007; Imbernón, 2012). En líneas con estas investigaciones, Soldevilla et al. (2012) y Torrego \& Ruiz (2011) revelan que las universidades para adaptarse a las nuevas necesidades del mercado laboral deben promover o establecer normativamente la coordinación docente como una innovadora y eficaz herramienta de calidad de excelencia educativa en la era digital. Para ello, es preciso que se rijan bajo los principios rectores de la planificación formativa, los contactos informales y la comunicación diaria entre iguales, con la finalidad de ir poco a poco amortiguando el comportamiento individualista de muchos educadores a la hora de impartir las clases magistrales (Zabalza, 2000).

Al hilo de lo comentado, conviene advertir la existencia de dos niveles de coordinación docente. Uno de tipo vertical (es el que se produce a lo largo del desarrollo de una determinada carrera universitaria), y otra de tipo horizontal (esta se origina en el mismo curso o grupo). Para Martínez \& Yus (2015) la coordinación docente de carácter vertical facilita el establecimiento de los horarios, las prácticas, los exámenes, etc., existente en las diferentes facultades que poseen las universidades. Esto precisa a nivel horizontal de una alta comunicación y participación de los profesores adscrito a una misma asignatura. Tal hecho ayudará a los máximos responsables de la Ordenación Académica no solo en poder armonizar de forma consensuada ambos niveles de organización jerárquica, sino también en constituirse en un factor clave en la implementación de nuevos proyectos de innovación docente que tenga como finalidad incentivar modelos de aprendizaje de tipo colaborativo que esté en sintonía con el tópico principal del presente trabajo (Torrego \& Ruiz, 2011). En este sentido, Parra et al. (2011) demuestra que si las universidades quieren conseguir este determinado objetivo precisan de una cultura educativa cimentada, por un lado, en la corresponsabilidad proactiva y compartida de sus profesores, y por otro, en la generación en el interior de las aulas de un ambiente positivo que estimule el pensamiento disruptivo, el trabajo en equipo, el amor por adquirir conocimientos... (Senge, 1992; 
Hernández, 2011; Lieberman, 1995; Hargreaves, 1996; Martínez et al., 2013).

\section{Metodología}

Una vez establecido la justificación del estudio y vista la importancia y las implicaciones de la coordinación docente en el ámbito universitario, se especifica a continuación la creación, el desarrollo y la evaluación del equipo docente.

El equipo docente se materializó con una reunión a principio del curso 2016/2017, en septiembre antes de que comenzaran las clases. En dicha reunión cada profesor aportó las propuestas o ideas sobre las asignaturas de marketing en el curso 2016/2017 que consideró oportuno, referido más concretamente a los siguientes temas:

- Evaluación.

- Exigencia de evaluación.

- Asignaturas con varios profesores.

- Comportamiento o disciplina del alumnado.

- Parte práctica de la asignatura (trabajos en grupo).
- Actividades.

- Actividades complementarias entre asignaturas.

- (Otro tema que el profesor pueda proponer).

Dichas propuestas tuvieron que ser concretas, realizables y no excesivamente complejas, que ayudasen a un mejor desempeño docente tanto del profesorado como del alumnado. Además, no se pudo realizar nada que fuera en contra de lo especificado en la normativa de las asignaturas. De esta manera, y bajo consenso, se llevaron a cabo las propuestas. Posteriormente, el equipo docente siguió reuniéndose periódicamente y comunicándose entre ellos a través de medios electrónicos.

Después del primer curso académico con la aplicación del equipo docente se pudieron especificar los resultados obtenidos a través de las actividades y decisiones llevadas a cabo y la evaluación delos objetivos deseados para conocer si se han alcanzado. En las siguientes dos fichas se especifican los objetivos a alcanzar con el equipo docente y el método empleado para su evaluación.

Objetivo $n^{\circ} 1$

Mejorar la satisfacción del profesorado con su coordinación docente

\begin{tabular}{|l|l|l|l|}
\hline Descripción del objetivo: & $\begin{array}{l}\text { Comprobar si la creación del equipo docente ha propiciado por parte del profesorado una mejora en la } \\
\text { satisfacción con su coordinación docente. }\end{array}$ \\
\hline Método de evaluación: & $\begin{array}{l}\text { Se ha desarrollado un enfoque cualitativo mediante la realización de entrevistas personales a los } 7 \text { pro- } \\
\text { fesores implicados en el equipo docente para conocer su opinión y satisfacción sobre la coordinación } \\
\text { docente. }\end{array}$ \\
\hline Fecha de la evaluación: & Julio 2017 & $\begin{array}{l}\text { Fecha de medida del } \\
\text { indicador: }\end{array}$ & Julio 2017 \\
\hline
\end{tabular}

Objetivo $n^{\circ} 2$

Descripción del objetivo:

Método de evaluación:

Método de evaluación:

Fecha de la evaluación:
Mejorar la satisfacción del alumnado con la coordinación del profesorado

Comprobar si se ha producido una mejora en la satisfacción del alumnado con la coordinación del profesorado.

Se ha tomado en cuenta la encuesta de satisfacción del alumnado con la coordinación del profesorado que realiza todos los cursos académicos el sistema de garantía y calidad de la Universidad de Cádiz.

\begin{tabular}{l|l|l} 
Septiembre 2017 & $\begin{array}{l}\text { Fecha de medida del } \\
\text { indicador: }\end{array}$ & Septiembre 2017
\end{tabular}


Para la evaluación del objetivo 1 se ha seguido un enfoque cualitativo basado en un análisis de contenido sobre las entrevistas realizadas a los siete miembros del equipo docente. Un estudio adquiere el enfoque cualitativo cuando se quiere comprender y profundizar los fenómenos, explorándolos desde la perspectiva de los participantes en un ambiente natural y en relación con el contexto (Hernández et al., 2010). Así, la investigación cualitativa posibilita la comprensión de una realidad concreta a través del análisis de las perspectivas de los representantes de una realidad, en este caso, los miembros del equipo docente.

Para la recopilación de la información se ha utilizado una entrevista no estructurada con el propósito de obtener información relevante que contribuyan a evaluar el objetivo. La entrevista no estructurada no sigue un guion preestablecido y su secuencia, así como su formulación, puede variar en función del sujeto entrevistado (Vargas, 2012). De esta forma, el entrevistador realiza una pregunta abierta y el entrevistado tiene libertad de profundizar en el tema. La pregunta realizada en este caso fue: “ ¿Cuál ha sido su satisfacción con el equipo docente para la mejora de la coordinación entre el profesorado?"

Una vez obtenidas las respuestas de los siete profesores implicados en el equipo docente se realizó un proceso de categorización para la identificación de temas a través de patrones comunes de los términos más utilizados en las respuestas. En este estudio se realiza una categorización inductiva, ya que las categorías se obtienen una vez se ha recogido la información, a través de los datos en base al examen de los patrones y recurrencias presente en ellos (Chaves, 2005). Por último, se analizan las categorías obtenidas para conocer así la opinión del profesorado sobre su satisfacción del equipo docente.

Para la evaluación del objetivo 2 se ha tenido en cuenta la encuesta de satisfacción al alumnado sobre la coordinación del profesorado que realiza cada curso académico el sistema de garantía y calidad de la Universidad de Cádiz y se comparó con los datos habidos en años anteriores (Manual del sistema de garantía y calidad de la Universidad de Cádiz, 2018).

\section{Resultados obtenidos}

Una vez creado y desarrollado el equipo docente durante un curso académico se especifican los resultados obtenidos a través de las actividades y decisiones llevadas a cabo y la evaluación de los dos objetivos.

\subsection{Actividades y decisiones llevadas a cabo}

Se ha celebrado periódicamente reuniones del equipo docente para tratar distintos temas para mejorar la coordinación entre el profesorado y ayudar a un mejor desempeño docente tanto de los educadores como de los estudiantes. Para ello se han realizado tres reuniones presenciales y se ha mantenido una comunicación continúa vía correo electrónico entre el profesorado implicado.

Las actividades y decisiones que se han tomado en las reuniones respecto a la mejora de la coordinación docente del profesorado han sido las siguientes:

Coordinación entre el profesorado dentro de una misma asignatura: Se sigue considerando esencial en aquellas asignaturas que esté impartida por varios profesores que haya una buena coordinación entre los mismos, trabajando en común y dejando claro cuáles son los objetivos de la asignatura y qué se va a realizar en la misma, evitando así que el alumno perciba incongruencias o diferencias sustanciales entre lo impartido por cada profesor.

En este sentido se aconseja una reunión antes de que comience la asignatura, además de un calendario de la asignatura sobre lo que se prevé que se va a impartir cada día. (en el mismo correo se adjuntará un modelo de calendario para que cada coordinador lo rellene de su asignatura). 
También se adjunta un modelo para que los docentes de los grupos prácticos comenten que prácticas van a realizar y lo compartan con el profesor de teoría.

Exámenes parciales: Se debate sobre la idoneidad de que existan exámenes parciales en las asignaturas de marketing. Se llega a la conclusión que el examen parcial puede ser buena para el alumnado y aunque es autoridad del coordinador de asignatura establecer qué tipo de exámenes parciales se realiza en su asignatura, cada profesor comenta que tipo de examen parcial considera más idóneo, abriéndose la posibilidad de que en lugar de realizar dos exámenes parciales se realice solo uno al final de la asignatura y que el alumno pueda quedar exento del examen final. Todo ello mientras no contradiga la ficha 1B de la asignatura y la modificación de dicha ficha si se diera el caso.

Cambio de grupos prácticos: Los cambios de alumnos en los grupos prácticos es decisión del coordinador de la asignatura, pudiendo optar este por el criterio que considere oportuno. Lo que todos los presentes están de acuerdo es que no se puede permitir a los alumnos cambios de grupo sin control para evitar que haya un desfase sustancial entre el número de alumnos de un grupo y otro. Desde la coordinación del grado se dieron las instrucciones básicas sobre división de grupos prácticos y cambios de grupo, hecho que se puede verificar de forma nítida en el acta de la reunión de coordinación del grado.

Conferencias: Todos los presentes están de acuerdo en la idoneidad de traer a conferenciantes de interés para el grado, por lo tanto, se decidió que todo aquel que conozca a algún profesional del sector que pueda ser interesante contacte con el coordinador del grado para poder formar una conferencia. Sobre este tema se está trabajando actualmente para traer a exalumnos que estén trabajando para contar sus experiencias a los alumnos, así como a profesionales del sector.

Comportamiento del alumnado en clase: Se abre un debate sobre la idoneidad de unas pautas comunes entre el profesorado para tratar el com- portamiento del alumnado en clase. Por lo tanto, se especifica que lo ideal que todos los profesores mantengamos al menos unas pautas básicas de comportamiento que no varíen mucho entre asignaturas. Se adjunta en el correo un archivo en PowerPoint para que el profesor pueda colgarlo en el Campus Virtual y comunicárselo al alumno el primer día de clase.

Para comprobar si se ha cumplido el objetivo de mejora de la coordinación del profesorado se ha realizado una entrevista a los 6 profesores que han intervenido más activamente en el equipo docente.

En estas entrevistas se pidió opinión a los profesores sobre qué ha aportado el equipo docente como ayuda a la coordinación entre el profesorado, las conclusiones son las siguientes:

- Era necesario una mejor comunicación entre el profesorado.

- Era necesario llevar a cabo acciones comunes dentro del área de comercialización e investigación de mercados dentro del grado de marketing.

- Es idóneo que se celebren al menos dos reuniones de coordinación cada curso, una al principio y otra al final del mismo.

- Después de las propuestas debe haber un control para comprobar la efectividad y cumplimiento de las mismas.

Solapamiento de contenido: Hay que evitar por parte del profesorado el solapamiento de contenido respecto a otra asignatura, tanto en la parte teórica como en la parte práctica. Las fichas de las asignaturas con el temario están disponibles para todo el profesorado, si alguno considera oportuno impartir algún contenido específico que case con otra asignatura se recomienda que se lo comunique al profesor de esa asignatura para que tenga conocimiento.

Actualización de contenido de asignaturas $y$ contenido en marketing digital: Se aconseja también que para cada asignatura se actualice el contenido que el profesor considere oportuno 
para adaptarlo a las nuevas oportunidades del marketing que van surgiendo, entre ellas destaca el marketing digital en la que el profesorado tendrá que tener en cuenta a la hora de actualizar el contenido de la asignatura.

Práctica para las asignaturas de $3^{\circ}$ curso del grado: Se mantiene la idea de llevar a cabo para las asignaturas de $3^{\circ}$ curso una parte práctica que esté relacionada con cada una de estas asignaturas. En concreto se tratan de las asignaturas Producto y Precio, Distribución Comercial I y Comunicación Comercial I, se toma como base la realización de una feria de alimentos. Se enviará en el mismo correo del acta la propuesta genérica que se hizo en este curso 2015/2016 para que se tenga en cuenta para el próximo curso.

Para comprobar si se ha cumplido el objetivo de mejora de la coordinación del profesorado se ha hecho una encuesta y una entrevista a los 6 profesores que han intervenido más activamente en el equipo docente.

Para comprobar si se ha cumplido el objetivo de mejora de la coordinación del profesorado se ha tenido una cita con los 6 profesores que han intervenido más activamente en el equipo docente para obtener información.

De esta manera se preguntaba al profesorado si la participación en el equipo docente le ha sido útil para mejorar y resolver problemas en la docencia y si veían oportuno seguir realizándola en el futuro.

El resultado fue positivo y, en general, se resaltaba la importancia de tomar decisiones comunes en la docencia para evitar duplicaciones, mejorar el contenido de la asignatura y complementar ejercicios prácticos entre asignaturas.

\subsection{Evaluación del objetivo $\mathrm{n}^{\circ} 1$}

A continuación, tal como se ha especificado previamente en la metodología, se analizan las respuestas de los siete profesores para conocer así su satisfacción sobre el desarrollo del equipo docente para la coordinación del profesorado. En las respuestas se han identificado un total de
5 categorías: Experiencia con el equipo docente, actividades realizadas, logros conseguidos, comunicación entre el equipo docente y las perspectivas de futuro.

Sobre la experiencia con el equipo docente en general los profesores la han considerado muy positiva, destacando que se debería haber realizado con anterioridad y se han sentido realmente cómodos trabajando conjuntamente con sus compañeros, incluso mejor de lo esperado en un principio cuando se propuso la creación del equipo.

Sobre los logros del equipo docente el profesorado ha destacado una mejora en la motivación y el compromiso, pudiendo poner en práctica sus ideas y conocimientos con los demás compañeros y comprobando que la situación de coordinación entre ellos iba generando mayor facilidad y mejora en la docencia. Algunos profesores también han destacado la importancia del equipo en la propuesta de decisiones y en la resolución de problemas, pudiendo compartir sus experiencias con los compañeros y planteando así propuestas y soluciones conjuntas y comunes. Por último, algunos profesores también valoraron positivamente un contacto y comunicación más activa entre los profesores.

Sobre las actividades realizadas por el equipo docente la mayoría del profesorado han destacado la propuesta de pautas comunes sobre el comportamiento del alumnado en clase, ya que era un problema que se venía dando desde hace años en las aulas y que se ha podido mejorar ostensiblemente con la propuesta de pautas comunes de comportamiento entre el profesorado implicado. Las otras dos actividades más nombradas han sido la mejora de la coordinación del profesorado dentro de una misma asignatura y la propuesta de evitar el solapamiento de contenidos entre las diferentes asignaturas.

Sobre la comunicación ha habido una mayor discrepancia entre el profesorado. Tal como se ha comentado previamente para la comunicación y el contacto del equipo docente se han realizado tres reuniones presenciales junto a la reali- 
zada a través del correo electrónico. Para algunos profesores la comunicación ha sido la adecuada para el desarrollo y el bueno funcionamiento del equipo. Otros en cambio consideran la necesidad de más reuniones presenciales para resolver problemas que van surgiendo a lo largo del curso. Por último, otros sin embargo consideran que son demasiadas reuniones y que bastaría con solo una reunión al comienzo de curso y que el resto puede utilizarse los medios electrónicos o reuniones puntuales con algún miembro del equipo.

Por último, sobre las perspectivas de futuro las respuestas han sido muy alentadoras ya que los siete profesores implicados han especificado su compromiso de seguir perteneciendo y participando en el equipo docente para posteriores cursos. Además de esto, se han propuesto hablar positivamente sobre la necesidad de formación de equipos docentes con otros profesores de otras áreas.

Tomando como base las respuestas y opiniones emitidas por los educadores miembros del equipo docente se puede afirmar que la creación y el desarrollo del equipo docente ha propiciado una mayor satisfacción del profesorado con su coordinación, siendo el único punto a desarrollar la forma y periodicidad de la comunicación entre el equipo.

\subsection{Evaluación del objetivo $\mathrm{n}^{\circ} 2$}

También se ha considerado pertinente comprobar si bajo el prisma de los estudiantes se ha percibido una mejora de la coordinación entre el profesorado.

La valoración del alumnado con la coordinación del profesorado se puede comprobar a través del gestor documental del sistema de garantía y calidad de la Universidad de Cádiz, concretamente en el Procedimiento (P08) "Procedimiento para la evaluación de la satisfacción de los grupos de interés". Los datos de dicha valoración del alumnado de la coordinación del profesorado era el indicador más bajo que contaba la titulación con un 2,08 sobre 5 para el curso 2015/2016.
En el nuevo curso 2016/2017 hemos comprobado que la valoración de la coordinación del profesorado por parte del alumnado es de 2,38 sobre 5, 0,3 puntos porcentuales más que en el pasado curso. Dicha valoración es alentadora, pero es recomendable que siga comprobándose a lo largo de futuros cursos a medida que el equipo docente se vaya afianzando.

\section{Conclusiones}

Actualmente si las universidades españolas quieren cultivar una enseñanza de calidad $y$ de excelencia tienen que incorporar en sus planes curriculares la coordinación docente. Esta innovadora herramienta didáctica constituye un instrumento muy importante no solo para estimular las relaciones personales y el trabajo en equipo en los profesores, sino también para impulsar el aprendizaje cooperativo de los estudiantes, y por ende, su futura inserción en el mercado laboral. Para conseguir este objetivo se precisan fundamentalmente de dos cosas. La primera, establecer normativamente elementos que fomente la coordinación de los educadores en el desarrollo de su desempeño académico, y la segunda diseñar un modelo didáctico de tipo colaborativo que enriquezca el bienestar subjetivo de los docentes a través del contenido de las asignaturas y el fomento del uso de las nuevas tecnologías (TIC).

Respecto al caso que ocupa este estudio se puede corroborar que la experiencia con el equipo docente ha sido realmente positiva. A través de los procedimientos establecidos para su desarrollo ha permitido a los profesores una mayor y mejor coordinación entre los mismos, pudiendo complementarse y ayudarse los unos a los otros en las distintas asignaturas, aportando ideas en común y facilitando así el trabajo. De esta manera se han podido establecer una mejor coordinación entre los profesores de una misma asignatura, establecer criterios comunes en base a los exámenes parciales, cambios de grupos prácticos, realización de conferencias y com- 
portamiento del alumnado en clase. También el equipo docente ha permitido un mejor desempeño docente del profesorado evitando así el solapamiento de contenido en las distintas asignaturas, actualización del contenido de las mismas y estableciendo actividades prácticas comunes entre las asignaturas. Además de las mejoras desde el enfoque del profesorado, el equipo docente también ha permitido que el alumnado haya percibido una mejor coordinación docente del profesorado y un mejor desempeño en la docencia de las diferentes asignaturas implicadas. El único apartado donde ha habido más discrepancias entre el profesorado y el que debe ser tenido en cuenta en el futuro para su desarrollo es sobre el contacto y la comunicación entre el equipo docente, ya que algunos profesores consideran escazas las tres reuniones presenciales llevadas a cabo en el equipo durante el curso, mientras otros lo consideran excesivas, prefiriendo un mayor contacto online o en situaciones puntuales.

De esta manera, puede destacarse que la formación del equipo docente ha aumentado la satisfacción en la coordinación en los educadores y en los futuros graduados. No obstante, cabe destacar que el equipo docente es de escasa creación, desempeñando la labor durante algo más de un curso académico. Aunque las primeras valoraciones son positivas queda pendiente examinar cómo evoluciona a lo largo del tiempo y comprobar si se siguen alcanzando resultados positivos, tanto desde el punto de vista del profesorado como del alumnado.

\section{Referencias bibliográficas}

Armengol, C. et al. (2009). La coordinación académica en la Universidad. Estrategias para una educación de calidad. REIFOP, 12(2), 121-144. Recuperado de https://goo.gl/C1XfrJ

Bozu, Z., \& Muñoz, F. I. (2009). Creando comunidades de práctica y conocimiento en la Universidad: una experiencia de trabajo entre las universidades de lengua catalana. RUSC. Universities and Knowledge Society Journal, 6(1).
Cazorla, D., Macià, M., Puerta, J. M., Serrano, R., \& Rojo, T. (2010). Plan de coordinación docente en el Grado de Ingeniería Informática. En XVI Jornadas de Enseñanza Universitaria de la Informática. Universidade de Santiago de Compostela. Escola Técnica Superior d'Enxeñaría, 138-144.

Chaves, C. R. (2005). La categorización un aspecto crucial en la investigación cualitativa. InvestigiumIRE, 6(1), 113-118.

Elboj, C., Puigdellívol, I., Soler, M., \& Valls, R. (2002). Comunidades de aprendizaje. Transformar la educación. Barcelona: Graó.

Hargreaves, A. (1996). Profesorado, cultura y postmodernidad (Cambian los tiempos, cambia el profesorado). Madrid: Morata.

Hernández Sampieri, R., Fernández Collado, C., \& Baptista Lucio, M. D. (2010). Metodología de la investigación. México DF.

Imbernón, F. (2012). La formación permanente a través de las redes. De las comunidades de práctica formativa a las redes de profesorado. Revista Digital Educativa Wadi-red, 2(3).

Lavié Martínez, J. M. (2009). El trabajo colaborativo del profesorado. Sevilla: Comunicación Social Ediciones y Publicaciones.

Lieberman, A. (1995). The work of restructuring School: building from the ground up. New York: Teachers College Press.

Martínez, M. J. B., Yus, M. Á. M., \& Currás, M. P. (2013). Coordinación docente e interdisciplinariedad: análisis de su contribución a la adquisición de competencias docentes y discentes. REDU. Revista de Docencia Universitaria, 11(2), 443-462.

Martínez, M. J., \& Yus, M. Á. M. (2015). La coordinación docente en la universidad: retos y problemas a partir de Bolonia. Profesorado. Revista de Currículum y Formación de Profesorado, 19(2), 319-332.

Martínez, M., Prieto, A.T., Rincón, Y., \& Carbonell, D. (2007). Aprendizaje en las comunidades de conocimiento desde una perspectiva organizacional: una aproximación teórica. ORBIS Revista Científica Ciencias Humanas, 3, 007, 46-64.

Meirinhos, M., \& Osorio, A. (2009). Las comunidades virtuales de aprendizaje: el papel central de la 
colaboración. Pixel-Bit. Revista de Medios y Educación, 35, 45-60.

Moreno Olivos, T. (2006). La colaboración y la colegialidad docente en la universidad: del discurso a la realidad. Perfiles Educativos, 112, 98-130.

Parra Costa, C. J., Periago Bayonas, P. M., García Baño, R., Sánchez, M., Francisco, J., Peñalver Martínez, M. J., \& Doménech Asensi, G. (2011). Estrategias de coordinación horizontal $y$ vertical en los planes de estudios adaptados al EEES (1815-1824). Congreso Internacional de Innovación Docente, Cartagena. Cartagena: Universidad Politécnica de Cartagena.

Rué, J., \& Lodeiro, L. (2010). Equipos docentes y nuevas identidades académicas. Madrid: Narcea.

Santos Rego, M. A., Lorenzo Modelo, M.M., \& Priegue Caamaño, D. (2009). Aprendizaje cooperativo: prácticapedagógica para el desarrollo escolar y cultural. Magis, Revista Internacional de Investigación en Educación, 2, 289-303.
Senge, P. (1992). La Quinta Disciplina. Barcelona: Granica, S. A. Sánchez Santamaría.

Soldevilla, M. F. G., García Cabrera, M., Llorent García, V. J., \& García, Á. O. (2012). La coordinación docente universitaria desde la percepción del alumnado. Revista de Docencia Universitaria, 10(2).

Torrego Egido, L., \& Ruiz Esteban, C. (2011). La coordinación docente en la implantación de los Títulos de Grado. Revista electrónica interuniversitaria de formación del profesorado, 14(4).

Vargas, I. (2012). La entrevista en la investigación cualitativa: nuevas tendencias y retos. Revista Calidad en la Educación Superior, 3(1), 119139.

Zabalza, M. (2000). El papel de los departamentos universitarios en la mejora de la calidad de la docencia. Revista Interuniversitaria de Formación del Profesorado, 38, 47-66. 


\section{La escuela zapatista: educar para autonomía y la emancipación}

\section{The zapatista school: educating for autonomy and emancipation}

Dr. César Silva Montes es profesor e investigador de la Universidad Autónoma de Ciudad Juárez (México) (cesilva@uacj.mx) (http://orcid.org/0000-0003-0531-2911)

Recibido: 2018-03-31 / Revisado: 2018-11-05 / Aceptado: 2018-11-20 / Publicado: 2019-01-01

\section{Resumen}

En el presente artículo se expone el desarrollo de la escuela del movimiento zapatista que construye su propuesta educativa desde la comunidad, basados en la sabiduría ancestral para ligarla con el pensamiento contemporáneo. El fin de la educación zapatista es formar generaciones en la práctica de la autonomía y autogobierno para conservar su dignidad indígena. La experiencia no es un modelo ni cabe en otras corrientes pedagógicas. Aunque original, en su base pueden distinguirse las ideas de Paulo Freire de alfabetizar para leer el mundo y transformarlo. En este sentido, la escuela zapatista es anticapitalista y no se rige por las normas del mercado que expide títulos para cambiarse por dinero; no es mercancía pues nadie paga por aprender y a nadie cobra por enseñar; tampoco es un aparato de Estado, porque cada pueblo determina los contenidos curriculares para usar el conocimiento y desarrollar la colectivización del campo, impulsar cooperativas y las tiendas comunales. A diferencia de la tendencia global de escuelas que promueven la mentalidad emprendedora, del mérito y de autoempleo, en la educación zapatista se aspira a que los jóvenes sirvan a su pueblo, sean solidarios y que los conocimientos no impliquen la jerarqui- zación social. La vivencia en una comunidad zapatista y las entrevistas con promotores de educación, permiten entender que la escuela zapatista sigue en construcción y debe evitar la burocratización y la homogeneización propias del capitalismo.

Descriptores: Escuela, zapatismo, educación, comunidad, autonomía, emancipación.

\begin{abstract}
The present article exposes the development of the school of the Zapatista movement, which builds its educational proposal from the community, based on ancestral wisdom to link it with contemporary thought. The aim of the Zapatista education is to train generations in the practice of autonomy and self-government in order to preserve its indigenous dignity. This experience is not a model, nor does it fit into other pedagogical movements. Although it is original, Paulo Freire's ideas can be distinguished such as his alphabetize to understand the world and transform it. In this sense, the Zapatista school is anti-capitalist and is not governed by the rules of the market that grants titles to students to earn for money; it is not merchandise because nobody pays to learn and nobody charges for teaching; it is not
\end{abstract}

Forma sugerida de citar: Silva Montes, C. (2019). La escuela zapatista: educar para autonomía y la emancipación. Alteridad, 14(1), 109-121. https://doi.org/10.17163/alt.v14n1.2019.09 
part of the State either, because each town determines the curricular contents to use the knowledge and develop the collectivization of the field, promote cooperatives and the communal stores. Unlike the globalization trend of schools that promote the entrepreneurial mentality, merit and self-employment; Zapatista education aspires that young people serve their people, be supportive and that knowledge does not imply social

\section{Introducción}

En este artículo se presenta un acercamiento a la experiencia educativa zapatista. En principio, se establece que la senda hasta el 2018, no corresponde a la lógica de ligar la educación con los objetivos del Gobierno. Es un intento por superar los postulados de Louis Althusser (2003) que observa a la escuela como un aparato ideológico para reproducir los valores de los grupos en el poder. Una evidencia es la inexistencia de unicidad en el currículo y métodos de enseñanza de cada comunidad. La enseñanza busca un aprendizaje más autónomo, activo, creativo y liberador; en el cual importa más la dignidad que la comercialización de los títulos profesionales. Los criterios de calidad y evaluación relacionados con la eficiencia y el control de la productividad industrial no existen en su escuela. No es una educación para promover la ideología emprendedora e individualista del capital humano como solución a todos los problemas. Al contrario, es una propuesta construida desde las comunidades para emanciparse del capitalismo y, según el zapatismo, de sus cuatro ruedas: explotación, despojo, represión y desprecio.

El análisis surgió desde la convivencia en una comunidad de Acteal con la asistencia a la escuelita zapatista, de la revista Rebeldía, de algunos comunicados del Subcomandante Marcos y de textos de investigación y análisis sobre la práctica educativa zapatista. En la estructura del texto se presentan los fundamentos de la formación zapatista y una discusión sobre la escuela capitalista actual. Enseguida se pretende caracterizar el sentido de la enseñanza zapatista, que incluye un hierarchy. The experience in a Zapatista community and the interviews with promoters of education, allow us to understand that the Zapatista school is still under construction and must avoid the bureaucratization and homogenization proper to capitalism.

Keywords: School, zapatismo, education, community, autonomy, emancipation.

breve recorrido histórico de la educación popular en América Latina. Enseguida se detalla la experiencia de la escuela zapatista que diseña su currículo y contenidos desde cada comunidad. Cierra el artículo con las reflexiones de su propuesta y algunas de sus dificultades. Se destacan sus rasgos de una educación pública como un derecho, que no es una mercancía y se orienta por los anhelos de autonomía del movimiento zapatista.

\section{La escuela zapatista en el contexto de la globalización}

La educación zapatista surgió después de su movimiento armado y del establecimiento de 38 municipios autónomos en 1994, como un hecho político para formar en la población la conciencia para el autogobierno, la diferencia, la equidad de género, el cuidado de sus territorios, la independencia económica y la autosuficiencia alimentaria. En la Tercera Declaración de la Selva Lacandona el Ejército Zapatista de Liberación Nacional (EZLN, 1995) convocó a un Movimiento de Liberación Nacional para diseñar una nueva Constitución y un gobierno de transición, y evitar la venta del ejido a particulares. Demandó un programa económico en favor del colectivo obrero y del campesinado, principales productores de riqueza, y por la autonomía de los pueblos indígenas que reconozca su organización social, cultural y política. Desde su aparición, en la Primera Declaración de la Selva Lacandona (EZLN, 1994) el zapatismo expresó su renuncia a la toma del poder, a ser vanguardia, a cobrar por gobernar, y expresaron que desa- 
parecerían cuando se eliminen las causas de su insurrección.

Para entender la práctica de la escuela zapatista, conviene distanciarse de la retórica que considera a la escolarización como instrumento para desarrollo material y social de los países, sobre todo desde los sesenta del siglo XX. En 2018 a la escuela que certifica para el mundo del trabajo se le ostenta como un fetiche para la solución de todas las problemáticas. Ante la ausencia de evidencias empíricas de que educación es igual a progreso económico y humano, renace la idea de Ivan Illich (1989) de desescolarizar el mundo. En México cada nuevo gobierno implanta reformas educativas y poco cambia. No falta el comentario jocoso de que la recurrencia de tales reformas muestra su inutilidad (Tyack \& Cuban, 2001). Por ejemplo, la modificación en la ley sobre condiciones laborales para el magisterio en 2012 se justifica porque supone que mejorará el trabajo docente y del funcionamiento de la escuela para lograr calidad educativa, y así resolver los conflictos generadas en la sociedad, todavía, llamada capitalista.

En el siglo XXI, en medio de los cantos alegres del éxito de la globalización, persiste el despojo y la explotación de la naturaleza; el lucro es el eje de la economía y no para el servicio de las familias, las trasnacionales controlan a los países y los presidentes se vuelven gerentes; la desigualdad de la repartición del ingreso se acentúa; la biotecnología y la informática aumentan el desempleo (Silva, 2018). ¿Cómo resolverlo? Dirá la retórica oficial: "formando capital humano de alta calidad en las escuelas". Se cree que la escuela con materias como orientación vocacional, educación sexual o vial, podrá solucionar la desvinculación perfil de egreso-trabajo, los accidentes carreteros o las enfermedades venéreas. Sin faltar la promoción de valores universales afines al capital, sintetizado en el perfil de sujetos emprendedores y capaces de autoemplearse. Estrategia adecuada en el contexto de recorte de puestos de trabajo en los sectores privados y gubernamentales, más el incremento de las polí- ticas de subcontratación laboral que disminuye prestaciones, sólo queda la alternativa de laborar por cuenta propia.

Así lo postula el Gobierno mexicano en el Programa Sectorial de Educación 2013-2018, Estrategia 1. Democratizar la Productividad:

5. Promover y fomentar la vocación emprendedora (...) como una opción profesional (...) buscando sinergias (...) de formación de capital humano (...) 15. Fortalecer el sistema nacional de competencias laborales (...) (certificando) iniciativas productivas, educativas, laborales y de capacitación (pp. 52-53).

El discurso hegemónico en las escuelas mexicanas renueva la noción de aparato ideológico de Althusser (2003), porque la escuela reproduce los intereses del Estado. ¿Acaso el currículo en competencias no corresponde a las demandas del empresariado globalizado? La calidad en educación, ¿se mide con los parámetros de la producción o con los criterios cualitativos no mensurables de la cotidianidad del aula? ¿O la evaluación al profesorado escapa de los indicadores de eficiencia y productividad propios de la industria que manufactura a destajo? ¿O el predominio del modelo de enseñanza centrada en el estudiante, poco novedosa si se compara con la escuela nueva?

Pero no todo está perdido. Existe una pedagogía crítica que ubica el problema de la educación en lo político, no en lo técnico. Después de analizar la ideología que subyace en los procesos de enseñanza, entienden a las escuelas como espacios de resistencia y generación de proyectos comunitarios alternativos al poder del Estado (Giroux, 1992; Apple, 1997). Postulan que la renovación de la enseñanza no puede separarse del replanteamiento social, con base en las ideas de Freire se intenta una educación crítica y emancipadora, porque la dominación no es total. Y el profesorado debe ser un intelectual transformador (Giroux, 1997). El análisis institucional aporta la noción de autogestión pedagógica que significa la renuncia del profesorado a transmitir 
mensajes en el aula y aspira a que el estudiantado decida los métodos de aprendizaje (Lapassade, 1977). Por último, el concepto de resistencia en la escuela, espacio de contradicción y de conflicto, imagina que pueden generarse prácticas culturales alternativas y/o de oposición a la hegemonía.

Las antípodas permiten preguntarse si alguna vez la educación sirvió a la sociedad. En la historia de México aparece el ideal de la revolución de 1910 de impulsar un desarrollo nacional soberano e incluyente. En el México rural, el profesorado de entonces difundió conocimientos agrícolas prácticos según la región y se intentaba resolver los problemas de la comunidad (Vaughan, 1997). También se enseñaba curtiduría, canciones populares, educación física y danza. La imagen de aquellos profesores era de profesionales, honestos y comprometidos con una educación nacional heredera del principio: la tierra es de quien la trabaja. No obstante, las misiones culturales impulsadas por José Vasconcelos que bajo la noción de civilización para integrar al sector indígena, se trató de despojar a los pueblos originarios de su identidad.

Saltando a los sesenta, en el mundo hubo experiencias como la del Instituto Experimental de Oslo que cuestionaron la lógica de la escuela burocrática y plantearon: asistencia no obligatoria a las clases y no al pase de lista; programa y métodos de enseñanza discutido entre alumnado y docentes; libertad de enseñanza. La propuesta surgió de estudiantes de secundaria reprobados que decidieron fundar una escuela no tradicional. La enseñanza sería libre y sin la opresión de los reglamentos, buscando formar personas autónomas y democráticas (Jörgensen, 1997). Así de sencilla sería la aspiración de una educación opuesta a la lógica de reproducir el pensamiento único y de obediencia a las reglas, porque la escuela sola no puede modificar los males sociales. En otras palabras, sin reforma social no hay reforma educativa; o viceversa.

Para cerrar la sección, desde 1875 Marx escribió que la educación no es igual para todas las clases sociales. Ironizó la factibilidad de obligar a la burguesía a estudiar en la modesta escuela pública, la única accesible al proletariado y al campesinado. Para Marx (1986) el Estado no debería encargarse de la educación popular, más allá de la entrega de recursos y normar las condiciones del personal docente, sino que el pueblo debe educar al Estado. Pareciera que tales deliberaciones las entendieron las y los zapatistas.

\section{Los intentos por definir la educación zapatista}

Una de las propuestas para caracterizar la enseñanza zapatista es ligarla con la educación popular y el pensamiento de Paulo Freire, cuando plantea la alfabetización para conocer el mundo, nombrarlo, para que la gente aprenda a decir su palabra e intente transformarlo. Es una educación para el pueblo en busca de la emancipación de cualquier tutela, subordinación, dependencia o servidumbre. No es el pueblo en abstracto, se refiere a las personas que viven en la marginación social, política y económica. Para Freire (1997) "la rebeldía es un punto de partida indispensable" (p. 77) contra la injusticia. En el caso indígena, para salir de la opresión, la discriminación, incluso el racismo, que han padecido en México. Por esto, sin ambigüedades, la educación zapatista aspira a una escuela con una pedagogía política para la paz, la formación ciudadana en aras de construir el poder comunitario, el autogobierno y una educación no mercantil. Lograrlo, implica que los contenidos y las didácticas surjan de la gente para formarse con, por y en la comunidad.

En América Latina la educación popular tiene una larga tradición. Según Gómez \& Puiggrós (1986) las prácticas pedagógicas nacionalistas y populares en el continente, existen, cuando menos, desde 1935. En su recuento señalan que Lázaro Cárdenas en México promovió esta educación. En 1946 en Guatemala se instituyeron las Misiones Culturales Ambulantes para llegar a toda la nación. Se difundió el culto a los símbolos y valores patrios, el conocimiento de la Constitución y el sentido de la revolución. 
Además, se promovió la higiene, la prevención y cura de enfermedades, nociones sobre embarazo y parto, las técnicas agrícolas y la rotación de cultivos. Se ocuparon de impulsar el deporte, la música, el cine, el teatro. Aunque no tuvieron el efecto esperado, las Misiones se conformaron con un equipo multidisciplinario (en boga actualmente, como si fuera una novedad): un maestro, un estudiante de medicina del último año, un perito agrícola, un oficial del ejército y una intérprete indígena.

En el recorrido, Gómez y Puiggrós (1986) destacan las experiencias de Bolivia (1938 y 1954), Colombia (1947), El Salvador (1974), Cuba (1960) y Nicaragua (1980). Afirman que en 1961 se elaboró el discurso de la pedagogía de la liberación; y de 1976 a 1983 la escuela fue un espacio de lucha contra las dictaduras. Se resaltan las críticas a la enseñanza que conforma personas obedientes, individualistas, la ideología capitalista y la dependencia científica, tecnológica, cultural y económica de Latinoamérica. La alternativa se genera desde la comunidad y la sociedad marginada, por una educación gratuita, por la defensa de la cultura y la igualdad de la mujer. El énfasis de la educación popular fue lo étnico y lo indígena como en los países andinos. Las fuentes que conforman esta corriente, entre otras, son la teología de la liberación, la investigación-acción y la comunicación popular, según Gómez y Puiggrós.

En este contexto, para Torres (2012) la escuela zapatista, que se autonombra de educación verdadera, retoma los postulados de Freire sobre humanización, la liberación de los opresores, la naturaleza política de la enseñanza y su perspectiva de transformar las estructuras de poder. Es una educación para la praxis, con heterogeneidad lingüística y cultural, con una pedagogía crítica y radical. En consecuencia, la educación zapatista es de participación colectiva, reivindica el ser indígena, establece lazos de solidaridad y de responsabilidad compartida en sus pueblos. El currículo escolar se diseña desde la comunidad y en congruencia con las deman- das zapatistas de la rebelión de 1994, recogen el conocimiento oral de los ancianos y las ancianas. Los promotores y promotoras de educación preparan el material didáctico de los cuentos, guías y libros, en colaboración con asesores externos.

Otra caracterización de la escuela zapatista es de Baronnet (2010, 2011a, 2015), quien la concibe con autonomía indígena, relaciones horizontales en la educación, la democratización de la gestión escolar, una enseñanza contextualizada afín a las identidades sociales, étnicas y políticas de los pueblos. Son escuelas en resistencia y emancipadoras de acuerdo con un proyecto político-regional en cada municipio autónomo, basada en principios pedagógicos de la praxis y el sentido común. No existe un modelo de enseñanza de programas de estudio, sino en construcción constante. Baronnet coincide con Muñoz (2004) en que los encargados de la educación en talleres integran las demandas de conocimiento en grupos de reflexión y análisis en las comunidades que son ratificadas por las asambleas y las autoridades del municipio. De ahí la denominación de educación verdadera, porque se desarrolla en contra de los valores y conductas colonialistas. Se trata de rescatar la memoria histórica tradicional de los pueblos y la cultura con la participación de las familias. Esto permite que la escuela zapatista no sea la instancia principal de socialización política, porque en la cotidianidad los niños y las niñas participan en actos públicos, asambleas y movilización social. Por último, para Baronnet (2011a) la ideología educativa se integra con el pensamiento de izquierda como el Che Guevara y Friere; y en la docencia siguen algunas prácticas pedagógicas activas de Celestin Freinet.

No es interés expresar un modelo de la educación zapatista con este breve recuento. Sin embargo, se detectan principios políticos y filosóficos como la educación popular, la idea emancipadora de Freire, el currículo delineado desde cada comunidad, la educación como un asunto de las familias, la escuela, las autoridades y el EZLN. La relación en el aula es horizontal, no autoritaria y activa. Es una formación teórica- 
práctica pues combina la escuela con el trabajo en la comunidad; es una educación no mercantil, porque no se paga por enseñar ni por aprender; tampoco se venden títulos para intercambiarse en el mercado de trabajo.

\section{La experiencia educativa zapatista}

Desde las voces de Doroteo, Abraham, Artemio y Gerónimo integrantes de las JBG y de la administración de los pueblos, se establece que el sistema Educativo Autónomo Zapatista de Liberación Nacional (SERAZLN) inició en 1997 en La Realidad, en el Municipio Autónomo Rebelde Zapatista Libertad de los Pueblos Mayas (EZLN, s.f.a). Desde antes de 1994 entendieron que la educación oficial y sus métodos no eran compatibles con sus afanes de autonomía, pues se trataba de instituir una educación del, para y por el pueblo. Para empezar, no había receta ni recursos. Tampoco estaban conformes con el trabajo del profesorado enviado por el gobierno. En San Juan de la Libertad optaron por organizar una secundaria con personas que estudiaron la secundaria o la preparatoria, y hasta alguna maestra. El fin fue aprovechar que con las niñas y los niños egresados de la primaria se formarían los nuevos educadores y educadoras. Entonces el grupo Escuelas para Chipas apoyó la construcción de aulas y desembocó en las Escuelas Secundarias Rebeldes Autónomas Zapatistas (ESRAZ).

Después de reflexionar, decidieron que las matemáticas, la lectura y la escritura no se podían cambiar por su alcance universal. Pero en historia si modificaron los temas. Incluyeron la trayectoria del EZLN y de otros movimientos sociales. Luego se preguntó a los padres y madres de los pueblos qué necesitaba aprender la niñez zapatista en cada comunidad. Otros cambios de contenido y nombre se realizaron en español y ciencias naturales. Se renombraron lenguas $\mathrm{y}$ vida y medio ambiente, respectivamente. Se agregó "integración" a diversos tópicos que no abarcaran las asignaturas, como las 13 deman- das de su levantamiento. También la noción de materia se sustituyó por área. En el municipio de Ricardo Flores Magón elaboraron el "documento de educación verdadera”, entendida como rescatar los conocimientos y saberes del pueblo, conocer su historia. Con el apoyo de la sociedad civil de compatriotas e internacionalistas, se elaboraron los planes y programas de estudio y los materiales didácticos. Enseguida se plantearon cómo comprobar el aprendizaje del niño o la niña. Acordaron que en la escuela autónoma eran prescindibles las boletas de calificación y los certificados de estudio. Asimismo, descartaron los exámenes porque el aprendizaje se verificaría en el desarrollo de su trabajo en un cargo.

Otro desafío para la educación autónoma fue la formación de promotores y promotoras de educación, que fue posible con la colaboración del grupo Semillitas del Sol, de la Ciudad de México. La capacitación dura seis meses, se aplica una evaluación y si alguien no muestra el conocimiento pleno del área, estudian dos meses más. Luego se creó el Centro de Formación compañero Manuel. Se les llamó promotores porque no asistieron a la escuela normal a estudiar para impartir clases. Con la creación de las Juntas de Buen Gobierno (JBG) ${ }^{1}$ en agosto de 2003, se consolidó la estructura del SERAZLN y aumentó la construcción de escuelas. En primaria se enseña en tres niveles y aprenden a leer y escribir. En el municipio Che Guevara los estudiantes y las estudiantes salieron de sus comunidades y vivieron un periodo de estudio más intenso.

Para el zapatismo la autonomía de la escuela empieza con la independencia económica, ideológica y del personal docente del gobierno mexicano. La construcción de su sistema educativo en lo pedagógico y material deriva de la solidaridad de los pueblos del mundo. El fin y sentido de la escuela zapatista no es la capacitación para el trabajo, sino comprender su historia, su cultura y de su cosmovisión. El anhelo consiste en formar profesionistas indígenas y no indígenas para ayudar a sus comunidades, encaminados a fortalecer la construcción de su 
autonomía política, económica, social y cultural. En síntesis: "Podemos educar con los alumnos y alumnas -que nos educan- para poder educarnos de quienes somos para la vida y así construir a esos muchos mundos que soñamos todos y todas" (SERAZLN, s. f., parr. 2). Las escuelas reciben apoyo económico y las administran y vigilan las autoridades de los pueblos.

Los contenidos de la educación zapatista se diseñan con base en los propósitos que generaron su rebelión: salud, techo, tierra, trabajo, alimentación, educación, independencia, democracia, libertad, justicia, cultura, información y paz (EZLN, 1994). El equivalente del currículum de la educación zapatista se completa con el conocimiento cotidiano de sus comunidades y la propuesta de cada uno de los temas necesarios para que aprendieran sus hijos e hijas. En las clases se estudia la realidad del país, las maneras de convivencia y la lengua de los pueblos. Como en el SERAZLN se respetan las diferencias, las áreas de conocimiento varían según la comunidad y se dividen en: lenguas, matemáticas, ciencias naturales, ciencias sociales, humanismo y producción, que abarca el cuidado del medio ambiente, con la misma cantidad de horas de estudio a la semana. En secundaria se examinan el desarrollo de sus pueblos y de los acontecimientos globales.

En La Garrucha, en la selva tzeltal, en 2008 se renovó la dinámica educativa al constituirse la escuela Semillita del Sol, organizada en tres niveles. Inician enseñando a los niños y las niñas a escribir y dibujar, pasando por comprender las demandas del movimiento zapatista, hasta analizar comunicados, denuncias, organización de su gobierno, los motivos de su lucha y el logro de su autonomía. Se incluye el conocimiento de la sustentabilidad del territorio. Un tema transversal, como es común en los currículos actuales, es la agroecología porque es una preocupación en las comunidades.

El lema de las escuelas zapatistas: "Que haya una educación real y que sea para todos", bajo el principio de formar al educando con la conciencia colectiva, didácticas de aprendizaje grupales y no directiva. Es un ideal de aprender en la libertad, orientado a que cada niño y niña alcance el conocimiento en colaboración con los promotores y promotoras, en un ambiente sin maltratos. Si la educación zapatista es parte de su resistencia y la difusión de su filosofía zapatista, por tanto, se pretende que el alumnado reflexione "(...) sobre la lucha, pues el objetivo principal que nos planteamos es que (...) tengan una visión diferente de la vida. Que no hagan una vida individualista" (Muñoz, 2004, p. 10). $\mathrm{Al}$ egresar se les pide a las jóvenes y los jóvenes que apoyen las tareas de agroecología, en los centros de comercialización, en las farmacias o alfabetizando. El interés formativo de la escuela se enfoca a servir al pueblo, no para trabajar en favor del capitalismo; tampoco para diferenciar entre quien sabe más y eludir la jerarquización propia de la educación capitalista.

Un avance de la escuela zapatista es la asistencia de las niñas a educarse y combatir la marginación. En los certificados de la ESRAZ viene la leyenda: "Por lo que nuestro Sistema Educativo le reconoce su esfuerzo, sus aportes a la lucha de resistencia y le invita a compartir con nuestros pueblos, lo que el pueblo le ha dado (...) ¡Por una educación liberadora, (...) científica y popular! Me pongo al servicio de mi pueblo" (Marcos, 2003, parr. 21). Hay dos evaluaciones: A (área aprobada) y ANA (área no aprobada). La escuela es gratuita y los comités de educación procuran que cada estudiante cuente con un cuaderno y un lapicero.

Para una educación no diferenciadora no se necesitan calificaciones, exámenes ni certificaciones. Lo importante es que la juventud zapatista aplique en su vida cotidiana y comunitaria sus aprendizajes, sus capacidades para leer y escribir. Por supuesto, distintas a las competencias surgidas de la industria que en las escuelas modelan el perfil de egreso para la producción toyotista (Silva, 2016). Por cierto, competencias decidas desde Europa a través del proyecto Tunning, distantes de los saberes y contenidos decididos desde la comunidad congruentes con 
su comprensión de la realidad. Las competencias lectoras y de escritura son útiles para que las mujeres desarrollen sus tareas en las JBG. Para gobernar no se requieren títulos ni grados académicos. Innecesarios para llevar la contabilidad de los gastos de la JBG o en la formación de las parteras, yerberas y hueseras. También les sirve a las mujeres cuando trabajan de coordinadoras de zona o capacitadoras de educación.

\section{Los hombres y las mujeres que hacen posible la enseñanza no mercantilista}

Para sustentar que la educación zapatista no es objeto de comercio, se exponen los comentarios de mi entrevista con dos promotores y una promotora de educación de Oventik. Además, las conversaciones con una familia de Acteal durante mi asistencia a la escuelita zapatista en enero de 2014. El EZLN convocó a convivir con sus bases de apoyo en sus comunidades para conocer a través de sus enseñanzas su pensamiento y su libertad, los aciertos, errores, problemas y soluciones, los avances y los obstáculos de su autonomía (Moisés, 2013). También el EZLN elaboró "cuadernos de texto" para los asistentes estudiáramos cómo han construido su autogobierno, la participación de las mujeres en la política, sus avances en la salud y educación. Las familias nos proveyeron de habitación y alimentos. Compartimos sus actividades productivas, reuniones políticas y platicamos de su resistencia.

Así, la asamblea comunitaria elige a quienes educan en la escuela zapatista y serán cesados según el criterio del comité de vigilancia. Los llaman promotores y promotoras de educación, porque no se formaron en alguna normal oficial, sino con las personas con capacidades docentes de sus pueblos. La aceptación para enseñar es voluntaria y es parte de un compromiso de educar para la liberación y la lucha. No recibe plazas y deberá trabajar en la milpa, porque se compromete a trabajar para el sostenimiento de la escuela (Baronnet, 2011b). Ser promotor o promotora de educación no es una vía para alcanzar solvencia económica, ni privilegios en la comunidad. Como afirma Johnny, promotor de educación: “(...) Nosotros trabajamos por conciencia nada más y la conciencia es la que ganamos... no cobramos nada, pues es libre" (Hijar, 2008, p. 147).

La manutención de los promotores y las promotoras se basa en que la comunidad los ayuda con alimentos, ropa o trabajan en las parcelas de sus familiares durante las vacaciones, en la elaboración de artesanías o la crianza avícola. Por tanto, educar implica la dedicación para divulgar el proyecto político, social y económico zapatista que busca la autonomía y el autogobierno. En suma, no se trabaja por la remuneración económica capitalista. Como señalaron Marx y Engels (1985), la burguesía con el dinero enterró la dignidad personal convirtiendo en asalariados al médico, al jurista, al poeta, al sacerdote, al hombre de ciencia.

En la ESRAZ los promotores y las promotoras coordinan la escuela en colectivo y de manera rotativa, ellos y ellas deciden las actividades escolares con base en el consenso, entre otras, cómo trabajar. Gracias a su autonomía determinan las cuestiones pedagógicas y administrativas. Una forma de enseñanza es a través de las preguntas generadoras, tomadas de Freire, y del cuestionamiento sobre la realidad surgen temas a desarrollar en el aula. En grupo el estudiantado delibera cómo responder a las preguntas para aprender, apoyados en la revisión de documentos, en la observación de su entorno o desarrollando experimentos.

En su perspectiva global, el Centro de Español y Lenguas Mayas Rebelde Autónomo Zapatista (CELMRAZ), acoge a personas que deseen aprender el tzotzil y el español. Sin altas colegiatura ni limitar la oferta de idiomas al inglés como lengua franca. Como una actitud solidaria, sólo se pagan tres días de salario mínimo del país donde residen y trabajan, más 150 pesos para la alimentación. Además, otorgan, comidas y el hospedaje, porque el principio de 
CELMRAZ es: "No hacemos de la lengua una mercancía más" (s.f., parr. 2).

\section{La organización de las clases y la formación para la autonomía política}

Respecto a las clases, la pedagogía zapatista establece las actividades de acuerdo con estudiantes y promotores, los horarios son flexibles y no se restringe a un espacio físico. Las sesiones buscan la construcción colectiva y la animación de actividades. En consecuencia, se exhiben videos de la lucha zapatista; se visitan los espacios en donde se desarrollan proyectos económicos; se promueve la convivencia y la alegría con canciones, bailes y debates; se invita a labores voluntarias en la biblioteca o en la siembra. Se impulsa la conversación y la reflexión en colectivo.

El fin es lograr la autonomía que implica para el zapatismo, como lo sintetizan Adamovsky et al. (2011), la forma de hacer política con independencia de la clase política y sus partidos, rechazando el autoritarismo y las relaciones de dominio de la vida cotidiana; la diversidad que cuestiona la hegemonía de cualquier tipo; a favor de la autogestión y la autodeterminación; y la emancipación del capital. Se resisten a dejar ser pueblos indígenas y buscan dejar ser colonias de los finqueros. En su forma de gobierno las comunidades indígenas zapatistas se guían por el mandar-obedeciendo. El pueblo manda y las autoridades obedecen, no se paga por gobernar y los puestos son rotativos y elegidos por las asambleas. López (2011) condensa la exigencia de autonomía del movimiento indígena: demandan derechos colectivos para sus pueblos; la transformación del Estado; reclaman sus territorios y la propiedad de sus recursos naturales; el reconocimiento de sus formas de gobierno y la administración de justicia propia; el respeto a su cultura.

En síntesis, el zapatismo se propone educar para la liberación a partir de las vivencias de las comunidades. La estructura de las escuelas en niveles, no implican la división rigurosa por edad. Esto permite una convivencia en las aulas de estudiantes de diferentes edades y refuerza el principio de Freire de que nadie educa a nadie y nadie se educa solo. La educación zapatista pretende que los jóvenes y las jóvenes de las comunidades se identifiquen con su historia pasada y presente indígena, aceptar la diferencia entre las personas y preservar su lengua. Se trata de educar para formar en la autonomía una nueva forma de hacer política, la democracia directa y rechazar que la tierra es un artículo para venderse al mejor postor.

\section{Reflexiones sobre la escuela zapatista}

La educación zapatista cumple con tres conceptos ausentes en la globalización de mercado: 1) es pública, porque se diseña desde los pueblos y es un derecho; 2) es libre, pues no depende del Estado ni de las trasnacionales del dinero o de la cultura para diseñar su currículo, ni certifican al estudiantado para ser un expediente más en los archivos de la burocracia escolar; 3) es gratuita, nadie paga por asistir a la escuela, ni nadie cobra por enseñar, así la educación no es una mercancía. No corresponde al capitalismo académico que en resumen significa: realizar actividades en las universidades y la planta académica para responder a la economía basada en el conocimiento, y quienes investigan deben conseguir financiamiento para sus estudios, en general, conforme a las ciencias y disciplinas afines al mercado. Así, las humanidades se vuelven ciencias innecesarias para la competitividad, la productividad y el crecimiento económico. El conocimiento es un bien para comercializarse y generar ganancia, como con las patentes (Maldonado, 2016).

Un aporte de la escuela zapatista es que no sigue la linealidad de los grados para ejercer una profesión. En la lógica de la jerarquía social y los méritos, para ser médico o docente, se necesita cursar estudios en escuelas especializadas. En el territorio zapatista, se forman yerberas, hueseras y parteras para atender la salud de los habitantes. 
Para educar, se capacitan a promotores y promotoras, sin importar los grados académicos. El único requisito es que sepan leer y escribir, más la lengua de la comunidad y el español. La jerarquía se anula con la negación de la diferenciación, y la meritocracia se sustituye por la voluntad.

La educación zapatista no la viven las comunidades como un fetiche para curar todos los males sociales. A diferencia del discurso en boga de cualquier gobierno neoliberal que centra en la educación de calidad (lo que esto signifique) la solución a sus problemas, en la experiencia zapatista es una parte de la resistencia política, económica, cultural e ideológica. La educación autónoma se enlaza con el autogobierno, la autogestión de los proyectos de producción colectivos, el fortalecimiento de la identidad y la creación de sus medios de difusión. En medio de carencias materiales avanzan en los procesos de emancipación ideológica y de consolidación de su democracia desde abajo. Para esto no son indispensables las computadoras, los cañones y las presentaciones en Power Point. Tampoco las mesas redondas en las aulas, de moda por el constructivismo de Piaget, ni las paredes bien pintadas, porque su problema es político, no de infraestructura.

El desarrollo de la escuela zapatista continúa porque es una demanda de su levantamiento incluida en los acuerdos de San Andrés. Éstos firmados en 1996 con una comisión de negociación con el gobierno federal para solucionar el conflicto armado, pero que no fue avalado por el expresidente Ernesto Zedillo. En consecuencia, no se legisló el derecho de las comunidades indígenas de implantar una educación de acuerdo con su cultura y cosmovisión. Por otra parte, se creó la Ley de Concordia y Pacificación en noviembre de 1996 para garantizar el tránsito por el país de integrantes del EZLN, mientras lo hicieran desarmados y sin convocar a la violencia.

En este marco, el EZLN organizó su educación en dirección contraria a los planes del Estado mexicano. Como se citó en el Plan Sectorial de educación 2013-2018, la educación oficial aspira a formar sujetos con mentalidad empresarial.
Además, en 2017 difundió un modelo educativo para la educación básica que incluye al bachillerato. Se privilegia el uso de las tecnologías de la información y comunicación en el aula; también el aprendizaje a lo largo de la vida para reciclar la fuerza de trabajo según las exigencias de la esfera de la producción. En el modelo aludido los contenidos relevantes se refieren a: la educación financiera, la programación, la robótica y habilidades para emprender (Secretaría de Educación Pública 2017, p. 76). Como si no hubiera un contexto de especulación financiera, la sustitución del trabajo humano por la robótica y la automatización, más el aumento del empleo precario, el gobierno reproduce los contenidos sugeridos por los organismos financieros internacionales. La educación continúa viéndose desde un enfoque instrumental al servicio de la producción y el empleo (Silva, 2016). No obstante, el presidente electo, Andrés Manuel López Obrador, manifestó su oposición a la educación neoliberal. Se comprometió a mejorar las condiciones laborales del magisterio, aumentar la matrícula en educación superior y las becas en el bachillerato. Pero en el contexto de los gobernantes no existe la educación autónoma ni emancipadora, sino solo el supuesto desarrollo nacional.

Por tanto, la escuela zapatista no sigue la senda de convertirse en un aparato de Estado, porque la crean, recrean y conducen los integrantes de la comunidad. No propaga un discurso de dominación ni de obediencia del poder político o económico. Es su proceso no desean imponer, sino convencer. El nexo educación-producción no se orienta a forjar mano de obra asalariada, sino al desarrollo de la colectivización del campo, la constitución de cooperativas y tiendas comunales. En sus necesidades, estudiantes y promotores trabajan en la milpa para cosechar alimentos de autoconsumo. Así colaboran para la manutención en las secundarias que son albergues.

Es conveniente retomar el sentido del artículo: la educación zapatista como un movimiento de resistencia a las políticas educativas excluyentes de la globalización neoliberal. Es el intento de la construcción de una escuela anti- 
sistémica, porque no responde a la lógica de los rankings, la eficiencia terminal y la vinculación con el empleo. Sin certificaciones ni calificaciones se forma para servir a la comunidad, no a los empleadores. En este sentido, las dificultades de la escuela zapatista se concentran en la infraestructura y los recursos para mantenerlas, no tanto en su filosofía educativa y sus fines autonómicos. Sin embargo, las y los promotores de educación han afrontado las burlas del profesorado oficial que se infiltra en las zonas zapatistas y los acusa de no saber enseñar. El efecto es la renuncia de promotoras y promotores a su encargo (EZLN, s.f.b). También enfrentan la pérdida de la lengua materna porque las escuelas oficiales promueven el idioma inglés. Para contrarrestar esta situación se refuerza la enseñanza del tojolabal, tzetal o tzotzil. O la inequidad de las mujeres como responsables del impulso a la educación. Baronnet (2011b) registra que los promotores reconocen su falta de formación pedagógica $y$, en ocasiones, usan métodos de alfabetización ineficaces y tediosos, pero también son críticos de su práctica. En la ranchería Emiliano Zapata un promotor se quiere retirar porque necesita más apoyo y participación colectiva para realizar su labor. Otro problema es el incumplimiento de personas de la comunidad para aportar la ayuda en alimentos y leña; y aunque si hay colaboración del pueblo para trabajar la milpa, no siempre alcanza, en consecuencia, algunos promotores no pueden combinar la docencia y el cultivo agrícola.

En suma, el anhelo educativo del movimiento zapatista es una experiencia que se renueva para no institucionalizarse. De la escuela capitalista y occidental cambiaron radicalmente los contenidos, la idea de ser humano y sociedad. Aunque aplican exámenes de opción múltiple para conocer los aprendizajes, no se califica y no reproducen la lógica de la diferenciación y las recompensas, como las becas. Hasta el momento, tampoco hay una certificación oficial y demuestra que la educación no es tarea exclusiva de instituciones especializadas. Se avizora que se respeta la autonomía del estudiante. Ojalá que su escuela no se convierta en rígida, burocrática ni normalizada como la experiencia heredada de la modernidad.

Por el momento, en la escuela zapatista se enseña a contracorriente del pensamiento hegemónico global. Pareciera que se educa para lo inexistente. Por ejemplo, que para transformar la sociedad no es indispensable tomar el poder formal del Estado. O construir un gobierno sin políticos profesionales, con cargos rotativos y sin cobrar por ejercerlos, buscando erradicar la división entre quienes mandan y quienes obedecen para alcanzar procesos autogestivos (Castellanos, 2008). O la renuncia a toda vanguardia para que en la vida cotidiana la comunidad defina su identidad, viva el mandato y la democracia desde abajo, forjando el autogobierno bajo el principio de "mandar obedeciendo" y el ser colectivo. ¿Cómo enseñar ¡Para todos todo, nada para nosotros! (EZLN, 1995, parr. 18) en un mundo egoísta y utilitarista? A esto aspira la educación zapatista.

\section{Notas}

1 Es una forma de gobierno en las comunidades bajo el principio de mandar obedeciendo. El pueblo decide y los representantes realizan las acciones del pueblo; no se paga por gobernar, ni se reciben privilegios, los cargos son rotativos y colectivos. Siempre hay una mujer como representante en la JBG.

\section{Referencias bibliográficas}

Adamovsky, E. et al. (2011). Problemas de la política autónoma: pensando el pasaje de lo social a lo político. En E. Adamovsky et al. (Eds.), Pensar las autonomías. Alternativas de emancipación al capital y el Estado (209237). Distrito Federal, México: Bajo Tierra Ediciones-Sísifo Ediciones.

Althusser, L. (2003). Ideología y aparatos ideológicos del Estado. Freud y Lacan. Buenos Aires: Ediciones Nueva Visión.

Apple, M. (1997). Teoría crítica y educación. Buenos Aires: Miño y Dávila Editores. 
Baronnet, B. (julio, 2010). Zapatismo y educación autónoma: de la rebelión a la dignidad indígena. Sociedade e Cultura, 13(3), 247-258.

Baronnet, B. (abril, 2011a). Autonomía educativa zapatista: hacia una pedagogía de la liberación india en Chiapas. Em Aberto, Brasília, 24(85), 127-144.

Baronnet, B. (2011b). Entre el cargo comunitario y el compromiso zapatista. Los promotores de educación autónoma en la zona Selva Tseltal. En B. Baronnet, M. Mora \& R. StahlerSholk, (Eds.), Luchas "muy otras": Zapatismo $y$ autonomía en las comunidades indígenas de Chiapas (195-235). Distrito Federal, México: UAM-CIESAS-UACH.

Baronnet, B. (enero, 2015). Derecho a la educación y autonomía Zapatista en Chiapas, México. Convergencia 22(67) Recuperado de https:// goo.gl/x6z9bz

Castellanos, L. (2008). Corte de Caja. Entrevista con el Subcomandante Marcos. Distrito Federal, México: Endira-Bola de Cristal.

Centro de Español y Lenguas Mayas Rebelde Autónomo Zapatista (s.f.). Recuperado de https://goo.gl/bM8TpW

Ejército Zapatista de Liberación Nacional (1994). Primera Declaración de la Selva Lacandona. Recuperado de https://goo.gl/ZN5LbQ

Ejército Zapatista de Liberación Nacional (1995). Tercera Declaración de la Selva Lacandona. Recuperado de https://goo.gl/X4GQXF

Ejército Zapatista de Liberación Nacional (s.f. a). Gobierno Autónomo II. Cuaderno de texto de primer grado del curso de "La libertad según 1@s Zapatistas”, s. p.i.

Ejército Zapatista de Liberación Nacional (s.f. b). Resistencia Autónoma. Cuaderno de texto de primer grado del curso de "La libertad según 1@s Zapatistas", s. p.i.

Feire, P. (1997). Pedagogía de la autonomía. Distrito Federal, México: Siglo XXI Editores.

Giroux, H. (1992). Teoría y resistencia en educación, una pedagogía para la oposición (2a ed.). Distrito Federal, México: Siglo XXI EditoresCISE.

Giroux, H. (1997). Los profesores como intelectuales. Hacia una pedagogía crítica del aprendizaje. Barcelona: Páideos-M.E.C.
Gómez, M., \& Puiggrós, A. (1986). La Educación Popular en América latina 2. Distrito Federal, México: Ediciones Caballito-SEP.

Hijar, C. (2008). Autonomía Zapatista. Otro mundo es posible. México, Distrito Federal: AMV.

Illich, I. (1989). Un mundo sin escuelas. México, Distrito Federal: Nueva Imagen.

Jörgensen, M. (1997). Una escuela para la democracia. El instituto experimental de Oslo. Madrid: Laertes.

Lapassade, G. (1977). Autogestión pedagógica. Madrid: Gedisa.

López, F. (2011). Las autonomías indígenas en América Latina. En E. Adamovsky et al. (Eds.), Pensar las autonomías. Alternativas de emancipación al capital y el Estado (67102). Distrito Federal, México: Bajo Tierra Ediciones-Sísifo Ediciones.

Maldonado, C. E. (2016). El capitalismo académico: las universidades como entidades del mercado y mercadeo. Crítica $\mathrm{Cl}, 20$. Recuperado de https://goo.gl/xCAyg5

Marcos, S. (2003). Chiapas: la treceava estela. Quinta parte: una historia. Recuperado de https:// goo.gl/CpNXXE

Marx, C. (1986). Crítica del Programa de Gotha. Moscú: Editorial Progreso.

Marx, C., \& Engels, F. (1985). Manifiesto del Partido Comunista. Moscú: Editorial Progreso.

Moisés, S. (2013). Fechas y otras cosas para la escuelita zapatista. Recuperado de https://goo.gl/ plgGQe

Muñoz, G. (septiembre, 2004). Los caracoles: reconstruyendo la nación. Rebeldía 2(23), 3-24.

Revelli, M. (noviembre, 2004). La nueva palabra zapatista. Rebeldía, 2(25), 33-41.

Secretaría de Educación Pública (2013). Programa Sectorial de Educación 2013-2018. Distrito Federal, México: SEP.

Secretaría de Educación Pública (2017). Modelo Educativo para la educación obligatoria. Educar para la libertad y creatividad. Versión PDF.

Silva, C. (2016). Currículo basado en competencias en el bachillerato mexicano: El enfoque unidimensional hacia el mercado. Ciudad Juárez: UACJ. 
Silva, C. (2018). Perfil de egreso y empleo en el contexto del avance tecnológico. Revista Pedagogía y Saberes, (48), 83-96.

Torres, I. (2012). La nueva educación zapatista: Formación de una identidad diferenciada en los niños de las comunidades autónomas zapatistas. Revista Divergencia, 1(2), 135-160.

Tyack, D., \& Cuban, L. (2001). En busca de la utopía.

Un siglo de reformas de las escuelas públicas
( $2^{\text {a }}$ ed.). Distrito Federal, México: Fondo de Cultura Económica.

Vaughan, M. K. (1997). El cambio ideológico en la política educativa de la SEP: Programas y libros de texto, 1921-1940. En Susana Quintanilla (Ed.), Escuela y sociedad en el periodo Cardenista (76-108). Distrito Federal, México: FCE. 


\title{
Estrategia de reflexión para enseñanza de proyectos de construcción en Ingeniería Civil
}

\section{Reflection strategy for teaching construction projects in Civil Engineering}

\begin{abstract}
Albeiro Bejarano Castellanos es Arquitecto de Jaramillo Mora S.A. Cali (Colombia) (albeca34@hotmail.com) (https://orcid.org/0000-0003-3903-3099)
\end{abstract}

Dra. María Fernanda Serrano Guzmán es profesora titular de la Pontificia Universidad Javeriana Cali (Colombia), (maria.serrano@javerianacali.edu.co) (https://orcid.org/0000-0002-7366-6597)

Dr. Diego Darío Pérez Ruiz es profesor titular de la Pontificia Universidad Javeriana Cali (Colombia), ddperez@javerianacali.edu.co) (https://orcid.org/0000-0002-9656-2803)

Recibido: 2018-05-20 / Revisado: 2018-11-20 / Aceptado: 2018-11-15 / Publicado: 2019-01-01

\section{Resumen}

La competitividad de los programas educativos de las universidades exige que los contenidos de los programas académicos se ajusten de manera que puedan responder a las problemáticas del entorno. Por esta razón, en lo concerniente al perfil del desempeño ocupacional del ingeniero civil, en lo particular, resulta útil que el estudiante identifique prácticas y procesos administrativos que propendan por la reducción de costos y tiempos en las obras. En este artículo se presenta una propuesta de estrategias didácticas centradas en la reflexión alrededor de conceptos relacionados con administración de proyectos de construcción empleando reingeniería y la filosofía de construcción sin pérdidas (Lean) en diferentes actividades. Para ello, se parte de información recolecta- da en proyectos de construcción de vivienda en donde se evaluaron las mejores prácticas para la disminución de desperdicios. Se conjuga los conocimientos técnicos con herramientas centradas en la reflexión para afianzar conceptos de administración de recursos, tanto humanos como financieros, mediante herramientas que emplean pensamiento crítico, solución de problemas, compromiso social, trabajo en equipo y habilidades comunicativas las cuales, en conjunto, contribuyen de manera transversal a fortalecer aspectos éticos y de la responsabilidad social del ejercicio de la ingeniería. Se concluye del estudio que la reflexión es una herramienta útil del proceso de enseñanza-aprendizaje, ya que prepara al futuro profesional a resolver problemáticas de su entorno.

Forma sugerida de citar: Serrano Guzmán, M. F., Pérez Ruiz, D. D., \& Bejarano Castellanos, A. (2019). Estrategia de reflexión para enseñanza de proyectos de construcción en Ingeniería Civil. Alteridad, 14(1), 122-137. https://doi. org/10.17163/alt.v14n1.2019.10 
Descriptores: Aprendizaje, construcción, organización, competencias, trabajo de campo, vida profesional.

\begin{abstract}
The competitiveness of the educational programs on the universities requires an adjustment on the content of academic programs so that they can respond to the problems of their surroundings. For this reason, in regards to the profile of a civil engineer's occupational performance, particularly, it is useful for the student to identify administrative practices and processes that tend to reduce costs and time over the different works. In this work, it is presented a proposal of didactic strategies focused on the inside thought around concepts related to the administration of construction projects using reengineering and construction
\end{abstract}

\section{Introducción}

El currículum de Ingeniería Civil en las universidades incluye en la oferta académica cursos que en su contenido abordan temas relacionados con administración de obras, proyectos de construcción y procesos constructivos, entre otros, con los cuales se pretende aportar destrezas al futuro profesional para desempeñarse en el sector de la construcción. Comúnmente en el aula de clase, ambiente en donde confluyen diferentes aprendices con experiencias y preconceptos diversos (Ucol-Ganiron Jr. \& Alaboodi, 2013), se emplean diversas estrategias educativas que permiten la formación de un pensamiento crítico y reflexivo para profesionales (Arratia Figueroa, 2008) orientados al logro del bien común y hacia una sociedad más justa y democrática (Palomer, Humeres, Sánchez, González, \& Contreras, 2013). Usualmente, durante el desempeño ocupacional, el ingeniero debe emplear sus conocimientos para resolver problemas relacionados con procesos constructivos.

Por lo anterior, resulta imperativo el desarrollo de estrategias didácticas basadas en la reflexión sobre habilidades transversales que debe adquirir o desarrollar el estudiante sobre el compromiso social, pensamiento crítico, resolu- philosophy without losses (lean) concepts in different activities. For this, we started with information collected in housing construction projects, in which the best practices for waste reduction were evaluated. The applicability of technical knowledge is combined with tools focused on reflection to strengthen concepts of resource management, both human and financial, using tools that use critical thinking, problem solving, social commitment, teamwork and communication skills, which, all together, contribute to strengthen ethical aspects and social responsibility of the engineering practice. It is concluded from the study that inside though is a useful tool of the teaching-learning process, since it prepares the future professional to solve the problems surrounding it.

Keywords: Learning, construction, arrangement, skills development, fieldwork, working life.

ción de problemas y habilidades comunicativas de manera que el estudiante enfrente preconcepciones o prejuicios y al mismo tiempo se anticipe ante posibles imprevistos (Montalva, Ponce, y Llorca, 2017; Erren, 2008) que se pueden presentar durante la formulación o la ejecución de un proyecto, todo esto bajo la premisa que un buen profesional no solo es aquel que maneja el conocimiento teórico o técnico sino el que demuestra sus competencias para aplicar problemas del medio con este conocimiento (Sávio, D., Cândido Moraes, \& Motta Barreto, 2017).

Esta nueva forma de enseñanza es característica en la actualidad y responde a la adaptación permanente a los procesos de cambio del entorno (Luengo, Luzón, \& Torres, 2008), es una propuesta de formación efectiva dentro de los procesos de formación profesional, que incluye la adquisición de conocimientos con aproximación de realidades (González, Mieres, Denegri, \& Sepúlveda, 2014).

Conceptos tales como reingeniería y construcción sin pérdidas son ampliamente empleados en los proyectos de construcción. Si bien es cierto la reingeniería ha sido considerada una moda administrativa que nació hacia los 90 en Estados Unidos como estrategia para la documentación de información y que entró en desuso 
entre 1997 y 2007 debido a los desaciertos a nivel organizacional (Vergara-Schmalbach, Fontalvo, \& Morelos, 2013, p. 224), en los últimos años ha tomado vigencia por cuanto, justamente, se apoya en las lecciones aprendidas para el desarrollo de proyectos. En esencia, la reingeniería busca la revisión fundamental y el rediseño radical de los procesos productivos para alcanzar mejoras en rendimiento (Bustos, 2005, p. 3). Por lo anterior, desde la premisa de buscar la competitividad en las empresas constructoras, el reconocimiento de los aciertos y desaciertos del pasado puede ayudar a mejorar el proceso productivo en una obra.

En cuanto a la filosofía Lean, lo que se pretende es que se logre incremento de productividad, reducción de costos, mayor flexibilidad, mayor valor agregado al producto final y un incremento de resultados empleando un flujo de caja razonable con los materiales necesarios para aportar un producto de calidad (Raposo \& Cardoso Viera Machado, 2013), eliminando la superproducción, tiempos de espera y transportes innecesarios (Giroto \& Rodrigues, 2013). Según esto, Lean se centra en la materia prima, el producto, el proceso, el mercado y la forma de administrar (Flamarion, Petter, \& Valle Antunes Jr., 2008), todos estos conceptos relacionados estrechamente con el producto final de una obra civil.

Con el fin de responder a los nuevos retos derivados de la sociedad del conocimiento (Luengo, Luzón, y Torres, 2008) se desarrolla esta propuesta de actividades didácticas que tiene como objetivo afianzar conceptos relacionados con la administración de proyectos, fundamentando el ejercicio en estrategias de reflexión alrededor de reingeniería enfocada hacia la mejora en equipos y herramientas de construcción y Lean aplicado para el análisis de desperdicios en la actividad de mampostería, conceptos gerenciales que pueden influenciar en la calidad del producto a ser entregado en una obra. Aunque el planteamiento metodológico se centra en Administración de Obras, su aplicabilidad se extiende a los cursos de Métodos Constructivos y Proyectos de construcción. Además, si bien es cierto este planteamiento se centra en aplicaciones pedagógicas para Ingeniería Civil y Arquitectura, la estructura metodológica que la fundamenta puede orientarse hacia otras profesiones.

El enfoque de reflexión sobre diferentes etapas de procesos constructivos pretende que el futuro profesional analice aspectos significativos de estos conceptos y encuentre aplicación en su ámbito laboral (Arratia, 2008) proyectando su desempeño ocupacional en espacios en donde deba emplear sus conocimientos y habilidades en situaciones reales en la vida cotidiana (Iglesias \& Beltrán, 2012), pero también pueda desarrollar valores y actitudes (Palomer et al., 2013).

\section{Metodología}

Las estrategias de reflexión planteadas combinan las actividades curriculares y extracurriculares y los contenidos del curso Proyectos de Construcción e incorporan cuestionamientos que ubican al futuro profesional en su desempeño ocupacional con posturas ante diferentes situaciones. El diseño de las actividades se orientó para dar respuesta a las dificultades encontradas en la enseñanza de ciertos temas en este curso en tres cohortes (semestres consecutivos).

\section{Las estrategias pedagógicas de reflexión como apoyo a las pruebas del estado en Colombia}

Para el Consejo Nacional de Acreditación en Colombia el concepto de calidad en la educación superior está asociada al cumplimiento de características que posee la institución educativa y en virtud de las cuales se ofrece un servicio educativo en calidad óptima (Ministerio de Educación Nacional, 1998). El planteamiento de las estrategias pedagógicas basadas en reflexión que se presenta ha sido diseñado buscando que 
los futuros profesionales efectivamente adquieran los estándares de calidad requeridos en función de unas competencias de desempeño esperadas. Dichas competencias son evaluadas en los Exámenes de Estado de la Educación Superior en Colombia, hoy conocidos como Pruebas Saber Pro (Ministerio de Educación Nacional, 2010), exámenes que son de carácter obligatorio desde el 2009 (Ministerio de Educación Nacional, 2018).

En el taller de resultados que realizó el Ministerio de Educación Nacional se presentaron los resultados de estas pruebas que justamente contienen preguntas encaminadas a evaluar competencias generales y específicas empleando estrategias de pensamiento crítico, comunicación escrita, responsabilidad social entre otras modalidades (Ministerio de Educación Nacional, 2017). $\mathrm{Si}$ bien es cierto, las estrategias tradicionales pueden seguir siendo empleadas, la realidad es que estas no cumplen las expectativas que la educación del siglo XXI requiere (Sávio et al., 2017).

Lo anterior ratifica la necesidad de generar al interior del aula acciones pedagógicas que le permita al futuro profesional desarrollar buena capacidad comunicativa para relacionarse con el otro en un ambiente organizacional sano (Erren, 2008) y productivo (Bermúdez \& González, 2011) (Serrano Guzmán et al., 2017) que respete los aportes del otro y que aprenda a trabajar en equipo para alcanzar las metas (Ibarra \& Rodríguez, 2011); igualmente, que haga uso de su autonomía intelectual para entender su contexto (Vélez, 2012) (Serrano Guzmán et al., 2017) y responda de manera responsable en la formulación de soluciones técnicas que respeten los deberes solidarios de ciudad (Muñoz, 2011).

Las estrategias pedagógicas propuestas se han implementado en el curso de Proyectos de Construcción en el programa de Ingeniería Civil de la Pontificia Universidad Javeriana Cali y se encaminan hacia conceptos de construcción sin pérdida y reingeniería cuya apropiación le aporta al futuro egresado destrezas para el desempeño ocupacional en las obras en las que tenga opor- tunidad de trabajar. Sin embargo, la propuesta presentada puede ser implementada en diferentes programas educativos a nivel de pregrado y a nivel graduado en otras disciplinas.

\section{Resultados}

La reflexión ofrece un puente entre la teoría y la práctica bajo el entendido que "una onza de experiencia es mejor que una tonelada de teoría" (Bringle \& Hatcher, 1999). Las estrategias de reflexión fueron diseñadas para el curso Proyectos de Construcción partiendo de los lineamientos proporcionados en el Diplomado Aprendizaje+Servicio de la Pontificia Universidad Católica de Chile. Estas estrategias de reflexión permiten evaluar el aprendizaje de conceptos, desarrollar competencias/habilidades transversales como también actitudes y valores (Montalva, Ponce, \& Llorca, 2017), considerando competencias de pensamiento crítico, solución de problemas, compromiso social, trabajo en equipo y habilidades comunicativas. Justamente, si el futuro profesional desarrolla estas estrategias se podrá ofrecer a la industria y al medio laboral profesionales creativos y con espíritu de liderazgo (Serrano Guzmán et al., 2017; Shin et al., 2013: Oehrtman et al., 2010) cualidades y aptitudes que les permitirá defender sus posturas de manera crítica e interpretativa (Good \& McIntyre, 2015) en el marco de un ambiente ético (Vellurattil et al., 2014) y de responsabilidad social (Pérez de Maldonado, Bustamante, \& Maldonado, 2009). En el caso particular del curso Proyectos de Construcción, cada actividad se diseña considerando que debe permitir continuidad, estar relacionada con la temática abordada, constituirse en un reto para el estudiante y contextualizada a la realidad del grupo que la aborda (Montalva, Ponce, \& Llorca, 2017). Las partes fundamentales de la estrategia de reflexión incluyen el objetivo del curso, el objetivo que se pretende alcanzar con la actividad, recursos necesarios, duración, descripción de la actividad y anexos si es el caso. Estas estrategias están en consonancia con la estructuración de actividades en 
la metodología Aprendizaje+Servicio (Jouannet, Salas, \& Contreras, 2013) en donde, en algunos casos, intervienen socios comunitarios o beneficiarios. Se debe destacar también que estrategias de reflexión similares han sido planteadas en los cursos de Diseño I de pregrado y de Transporte de Contaminantes a nivel de posgrado. A continuación, se presentan las estrategias propuestas.

\subsection{Propuesta de reflexión en pensa- miento crítico}

Objetivo del curso: Identificar los conceptos contemporáneos de administración, organización y definición de un proyecto de construcción.

Objetivo de la estrategia de reflexión: Identificar situaciones del ejercicio ocupacional del ingeniero civil apoyadas en la costumbre y la implicación social que esto tiene en el desarrollo de una comunidad

Recursos: Lectura, computador, lápiz y papel

Modalidad de trabajo: individual y grupal

Duración: 30 min

Descripción: Los medios de comunicación constantemente informan sobre las repercusiones negativas para las comunidades ante la no ejecución de obras de infraestructura requeridas para la satisfacción de las necesidades básicas con el consecuente desmejoramiento de la calidad de vida de los habitantes.

Con esta actividad se identifican criterios personales para cambiar esta dinámica en el mundo. Se solicita a los alumnos que en $5 \mathrm{~min}$ lean el fragmento extractado de (Vega, 2015) "La leyenda del anillo de Giges", con el contenido que a continuación se transcribe textualmente:

Giges era un un pastor al servicio del rey de Lidia.... Un día, después de una tempestad y un terremoto, se agrietó la tierra, abriéndose un abismo en el lugar donde pastaba el rebaño de Giges. Asombrado, desciende en la grieta $y$ entre otras maravillas encuentra un caballo de bronce hueco con pequeñas aberturas. En el interior del mismo, había un cadáver de un hombre de gran tamaño que no llevaba sobre sí más que un anillo de oro en un dedo. Giges, tomó el anillo y se fue. Giges descubre que el anillo le confiere el poder de la invisibilidad y ante el beneficio de este, consigue que lo nombren pastor responsable de ir a rendir cuentas al rey. Después de mucho reflexionar, urdió un siniestro plan: ir al palacio, seducir a la reina, matar al rey y hacerse con el trono. Usando el privilegio de su anillo consigue materializar su plan, convirtiéndose en rey, pero no un rey cualquiera, uno tirano....Podría haber utilizado el anillo para descubrir por ejemplo a los criminales, para hacer una sociedad más justa, pero decide que es más interesante medrar adquiriendo riqueza y poder. Platón explica de esta manera la tiranía y corrupción de los dirigentes, al sentirse superiores, con poder e impunes y, cuestiona sobre 'que habríamos hecho cada uno de nosotros si hubiésemos encontrado el mágico anillo, distinguiendo entre expresar una opinión si se nos pregunta y ser dueños realmente del poder del anillo' (Vega, 2015).

En el libro II de la República se encuentra el conocido mito del anillo de Giges el cual muestra la noción de la injusticia humana y permite identificar el resurgimiento enérgico de la justicia (Higuera, 2016). La historia del anillo de Giges revela que portar el anillo le confiere confianza y libertad al pastor, con las cuales se transforma y le permiten hacer parte de un grupo social diferente (Higuera, 2016).

A continuación, se solicita que lean fragmentos tomados textualmente del escrito "El ser humano, la corrupción y la política" de Gerardo Berthin Siles en el volumen 5 de la revista Ciencia y Cultura (Berthin,1999) y que trata el tema de ética en política.

...[...]en política existe una ética diferente de la ética. Y se comprueba que con el pasar del tiempo el progreso en términos económicos y en otros términos ha resultado ser más importante que el desarrollo espiritual del ser humano, demostrando que existe una gran brecha entre lo que el hombre desea ser y lo que es en realidad, habría pues dos espacios, el del 
poder y el del no poder siendo el primero, el ámbito de lo político, el lugar donde el hombre miente, engaña, distorsiona, traiciona, de este modo se justificarían las guerras, por ejemplo. Para finalizar nos dice que el éxito político se mide si se puede mantener, incrementar o demostrar poder sobre otros, mientras que el éxito moral se mide si se puede demostrar en relación con los otros, que estos son objetivos en sí mismos (Berthin, 1999, p.1).

Luego, el docente orienta al grupo diciendo que se abre un espacio de discusión para que en plenaria los estudiantes respondan a las preguntas: 1) qué opina Ud. de la actitud de Giges? 2) en qué situaciones los ingenieros civiles pueden comportarse como Giges? 3) qué coincidencias pueden darse entre la actitud de Giges y la de aquellos que tienen el "anillo" de los fondos del Estado y son los encargados de administrar los fondos de los municipios en cada país? 4) de qué forma se puede ser partícipe activo en política manteniéndose en el marco de la ética y la moral? En esto, se destinan 20 minutos. Los resultados de la participación de los estudiantes se van registrando en el tablero.

Reflexión para el cierre de la actividad: Se finaliza haciendo énfasis en que la costumbre de "una vida de corrupción" debe desarraigarse del ejercicio ocupacional del ingeniero civil.

Evidencias de aplicación de esta estrategia de reflexión en otros cursos: el pensamiento crítico es una actividad reflexiva orientada a la acción (Zelaieta \& Camino Ortiz de Barrón, 2018) y puede aplicarse en diferentes ámbitos ya que permite analizar problemas de toda índole (France, de la Garza, Slade, Lafortune, Pallascio, \& Mongeau, 2003).

Este tipo ejercicios se han implementado en el curso Diseño I prerrequisito del curso Diseño II (Serrano et al., 2018), conducentes a grado a nivel de pregrado en Ingeniería Civil y en cursos de posgrado a nivel de maestría de Transporte de Contaminantes. En todo momento, para el desarrollo de esta actividad se busca un ambiente adecuado en el que los participantes puedan exponer sus argumentos generando una práctica comprometida con la transformación y para la mejora social (Zelaieta \& Camino Ortiz de Barrón, 2018).

\subsection{Propuesta de reflexión sobre com- petencia habilidades comunicativas}

Objetivos: Desarrollar habilidad de comunicación escrita; afianzar estrategias para la elaboración de resúmenes.

Recursos: Artículo de la web, computador con Word o procesador de texto.

Modalidad: Grupal, mínimo 2 y máximo 3 participantes.

Duración: 20 a 30 minutos.

Descripción: Teniendo en cuenta que el individuo emplea diferentes procesos y conocimientos de diversos tipos lingüísticos- sociolingüísticos para comunicarse, se deben fomentar estrategias para el fortalecimiento del manejo discursivo (Viera, 2010). En lo particular, en el curso de Proyectos de Construcción, el docente puede apoyarse en la construcción de definiciones como el concepto de la filosofía Lean aplicada a proyectos de construcción. Se procede a organizar los grupos de trabajo y se hace la siguiente invitación: "en un diálogo entre Uds. comenten lo que conocen acerca de Lean Manufacturing y en función de lo que conozcan, elaboren un párrafo que tenga entre 30 y 35 palabras". Se conceden 10 minutos.

Posteriormente, se solicita que cada grupo lea la definición que estructuró y se selecciona, por votación, la mejor definición. Como lo recomienda el Centro de Desarrollo Docente de la Pontificia Universidad Católica de Chile en la ventana Actividades de Reflexión $\mathrm{A}+\mathrm{S}$ : "ningún grupo puede votar por su propia definición" (Centro de Desarrollo Docente, 2017a). En esta actividad se destinan 5 minutos.

Una vez seleccionada la mejor definición, se solicita al grupo que se proceda a leer la cita textual del siguiente párrafo del artículo "El ingeniero industrial impactando el medio ambiente" 
de Ángela Patricia Anaya y Mario Fernando Acosta en la Revista Educación en Ingeniería (Anaya \& Acosta, 2010):

[...]Lean tiene como fundamentos el identificar las actividades de valor, entender el flujo de productos, servicios e información a través de la cadena de valor y entre los eslabones de la cadena de suministros, y, por último, la caracterización del desperdicio en las actividades de la empresa. [...] ]en las áreas de producción y manufactura los desperdicios son fácilmente identificables, mientras que, en el caso de información, el desperdicio es menos visible. La información es la que permite medir el desarrollo de las actividades para comparar con los estándares esperados o las metas fijadas y luego entonces entender si el funcionamiento del área, proceso o industria es el adecuado (Anaya \& Acosta, 2010, p. 182).

Y, que continúen con la lectura de la definición de Lean tomada y adaptada de (Raposo Rosa \& Cardoso Viera Machado, 2013):

Lean es una aproximación multidimensional que se extiende a grupos para gran variedad de prácticas administrativas que incluyen justo a tiempo, sistema de calidad, trabajo en equipo, producción por departamentos y administración de insumos en un sistema integrado. Cuando se logra la sinergia entre estos factores se logra alta calidad con bajos desperdicios (Raposo \& Cardoso Viera, 2013, p. 887).

Posteriormente, se indica al grupo que procedan a complementar la definición que se seleccionó con la definición aportada por Anaya \& Acosta (2010) y de Raposo \& Cardoso Viera (2013) y que, finalmente, escriban un párrafo que contenga por lo menos dos oraciones que resuman lo que podría ser la definición de la
Filosofía Lean aplicada a la construcción. Se solicita además que la nueva definición no exceda 60 palabras y que como mínimo tenga 55.

Reflexión para el cierre de la actividad: Se finaliza el ejercicio invitando a los participantes que señalen las dificultades encontradas para elaborar la definición.

Evidencias de aplicación de esta estrategia de reflexión en otros cursos: Esta actividad se adelantó con estudiantes del curso Diseño I, empleando el concepto de vivienda de interés social rural. El ejercicio permitió incluir en la definición de vivienda el concepto de sostenibilidad el cual no estaba inicialmente considerado.

\subsection{Propuesta de reflexión sobre com- petencia solución de problemas}

Objetivos: Identificar causas de desperdicios en actividad de mampostería; plantear alternativas para el aumento de la productividad en mampostería.

Recursos: Visita de campo y lectura de manuales para el diligenciamiento de proyectos con la Matriz General Ajustada (MGA) del Departamento Nacional de Planeación.

Modalidad: Grupal, entre 2 y 3 integrantes.

Duración: 40 minutos.

Descripción: Esta actividad se realiza luego de la visita de campo. El docente orienta a los estudiantes sobre la importancia de la observación para identificación de factores que afectan el rendimiento en la actividad de mampostería. En la visita de campo, el grupo de trabajo debe registrar las causas de la pérdida de materiales y de tiempo en la actividad de mampostería en una empresa constructora. Se elabora el árbol de causas y efectos en una infografía similar a la Figura 1. 


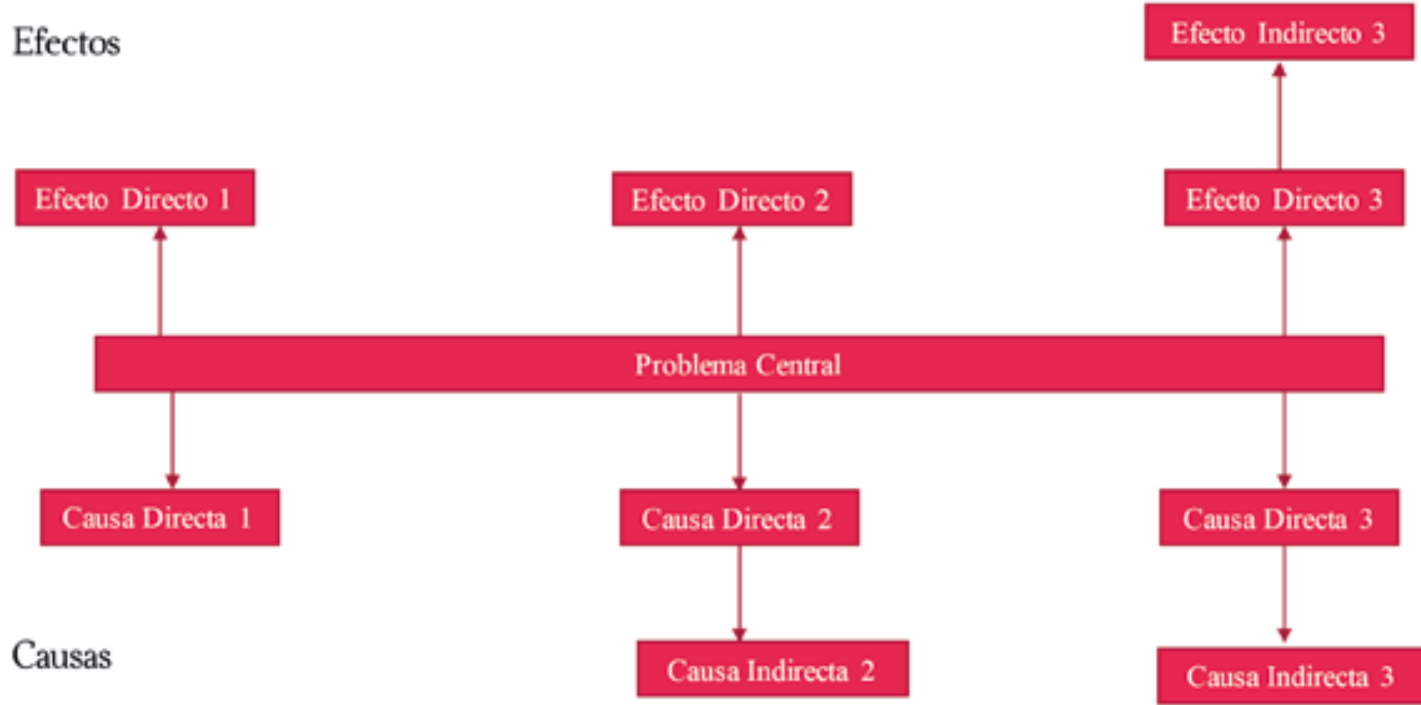

Fuente: Autores con información adaptada de Subdirección Territorial y de Inversiones Públicas del Departamento Nacional de Planeación, 2013.

Se espera que el estudiante genere un Figura 2. El tiempo destinado para esta actividad árbol de problemas similar al indicado en la son $15 \mathrm{~min}$.

Figura 2. Árbol de problemas identificados durante la visita

Efectos

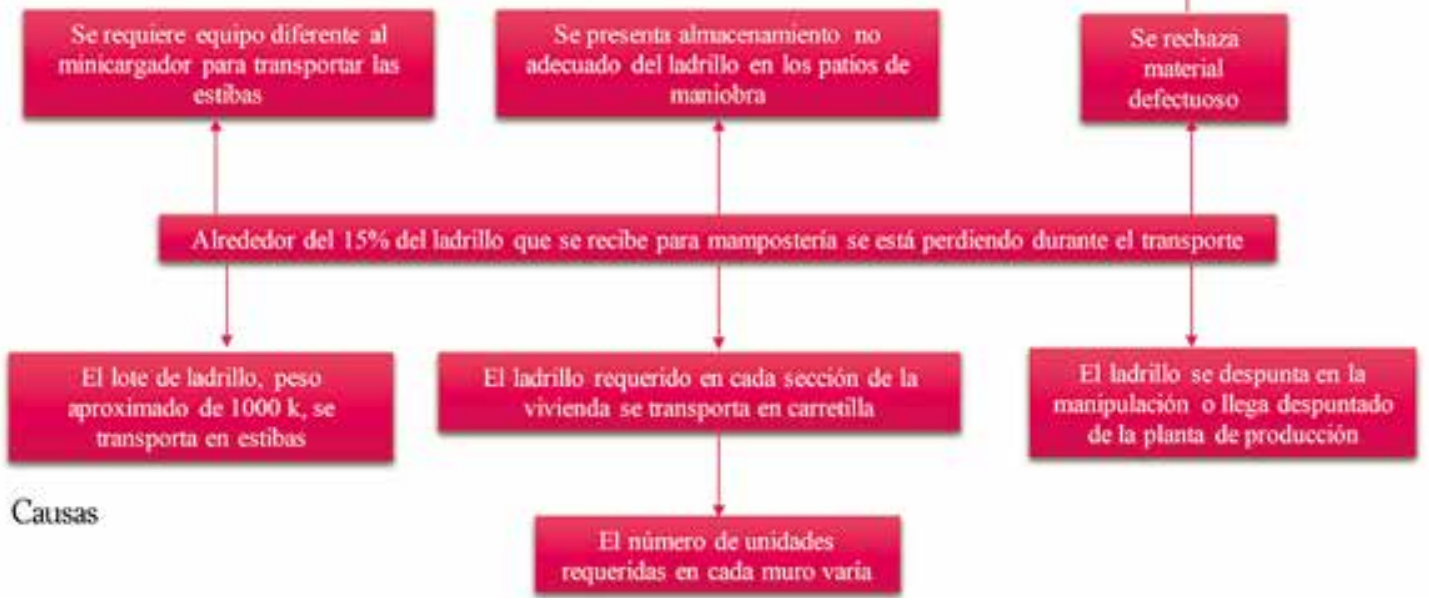

Fuente: Autores con información adaptada de Bejarano (2017). 
En cada grupo de trabajo, se plantea el árbol de objetivos, con sus correspondientes fines y medios según lo establece la metodología MGA. Tiempo de dedicación: 30 min.
El Árbol de Objetivos es propositivo al árbol de problemas y permite cerrar conceptualmente el proyecto en análisis (Figura 3).

Figura 3. Árbol de objetivos o de fines y medios

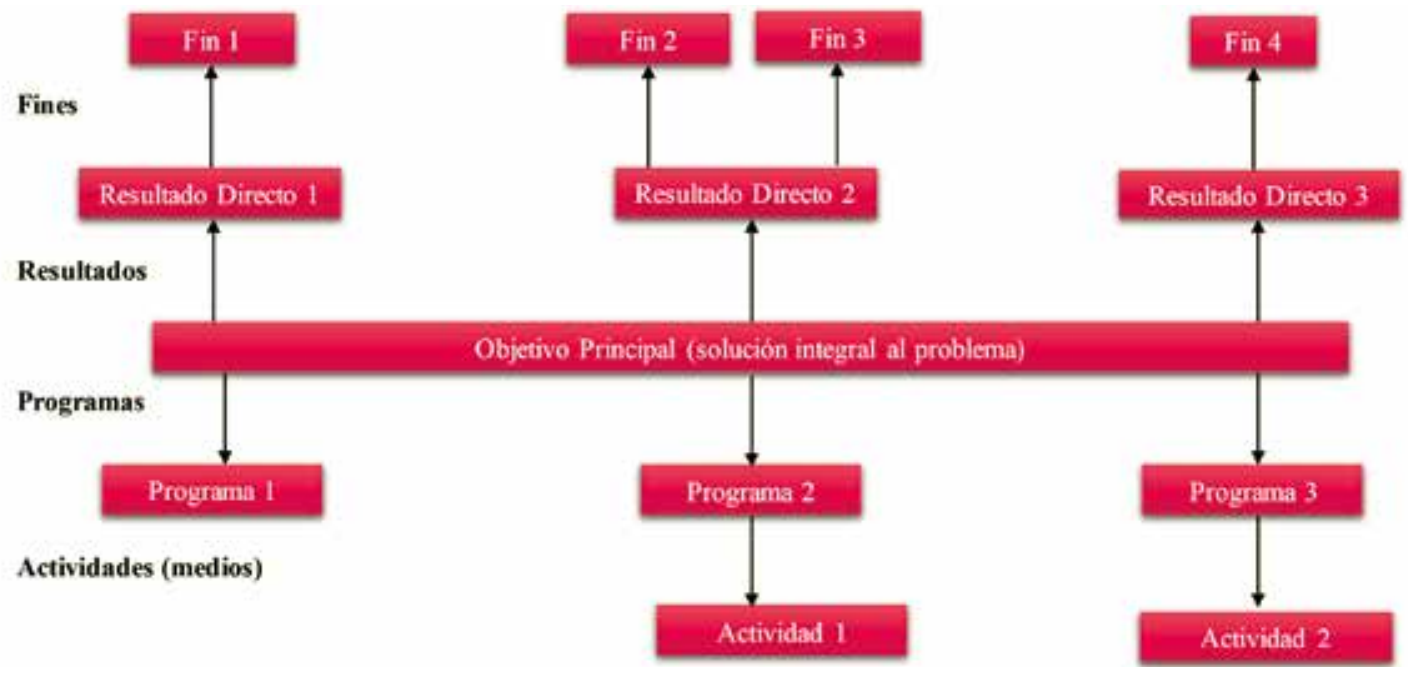

Fuente: Autores con información adaptada de Bejarano (2017).

Se espera que el estudiante genere un árbol

El tiempo destinado a esta etapa son $15 \mathrm{~min}$. de objetivos similar al indicado en la Figura 4.

Figura 4. Árbol de fines medios

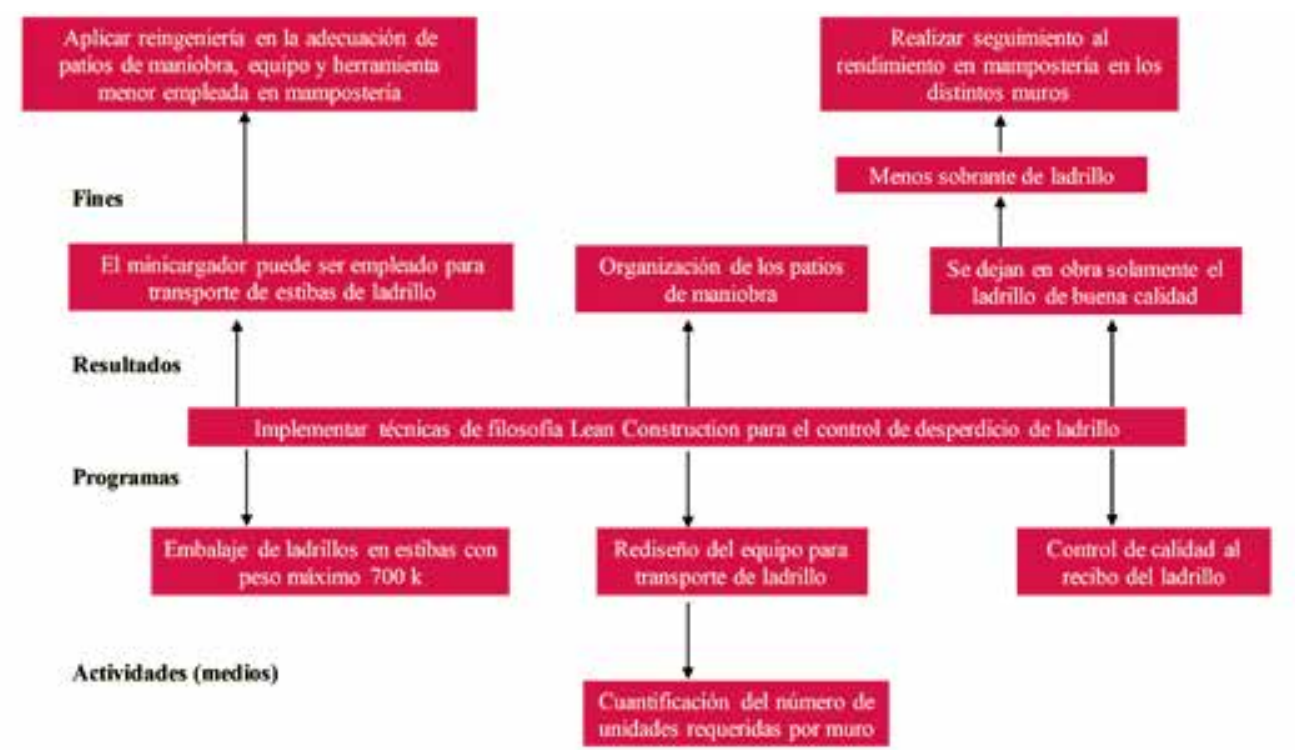

Fuente: Autores con información adaptada de Bejarano (2017). 
Reflexión para el cierre de la actividad: Se finaliza el ejercicio solicitando al grupo de estudiantes que evalúen los beneficios que acarrea la implementación de un programa de construcción sin pérdidas en otras actividades de una obra. Así mismo, que señalen las dificultades técnicas y de recurso humano a las que probablemente pudiera enfrentarse el equipo de trabajo que acomete estas actividades. Al respecto, esta actividad de reflexión le permite al estudiante aprender mediante la interacción social y práctica que recopila las vivencias de una obra lo que le permite percibir y transformar la realidad (González, et al., 2014) y adaptar lo que observa para un mejoramiento de los procesos de construcción.

Evidencias de aplicación de esta estrategia de reflexión en otros cursos: Esta actividad se ha implementado en el curso de Diseño I en donde el estudiante finalmente aprende a priorizar inversiones (Serrano et al., 2018). La experiencia adelantada en el segundo semestre de 2017 involucró a cuatro grupos de estudiantes que partieron de una información existente de comunidades del país e identificaron los proyectos que pudieran satisfacer las necesidades de los habitantes.

\subsection{Propuesta de reflexión sobre com- petencia compromiso social}

Objetivos: Propiciar espacios de reflexión sobre la importancia de modificación o cambios radicales en herramientas y equipos de construcción con miras a la implementación de la filosofía Lean en actividades de construcción; sensibilizar a los estudiantes sobre la responsabilidad social del ingeniero frente al recurso humano.

Recursos: imágenes de herramienta y equipos empleados en proyectos de construcción.

Modalidad: Grupal, entre 2 y 3 personas

Duración: 40 minutos

Descripción: La actividad consiste en profundizar sobre el concepto de reingeniería aplicada en equipos y materiales de construcción empleados en diferentes procesos en una obra.
Se parte de una lectura de un fragmento citado textualmente de (Vergara-Schmalbach, Fontalvo Herrera, \& Morelos Gómez, 2013, p. 224), en donde definen el concepto de reingeniería:

...Reingeniería es la mejora radical de los procesos con resultados de gran impacto a diferencia de otros enfoques que se caracterizan por buscar resultados incrementales y continuos... (Bustos, 2005, p. 3). [...] ...Como tendencia administrativa, la reingeniería se está centrando en la actualidad en nuevos desarrollos de proyectos basándose en el estudio de los errores y éxitos pasados (Vergara-Schmalbach, Fontalvo, \& Morelos, 2013, p. 224).

Posteriormente, se invita a los estudiantes a revisar las imágenes de la Tabla 1 y a identificar los cambios radicales que ocurrieron para llegar a las adecuaciones en los elementos constructivos.

Reflexión para el cierre de la actividad: El profesor insta al grupo a elaborar el análisis de precios unitarios de cada uno de los cambios ejecutados y a estimar el tiempo de vida útil de los elementos constructivos presentados y los posibles riesgos de los trabajadores.

Evidencias de aplicación de esta estrategia de reflexión en otros cursos: Esta estrategia se ha adaptado para estudiantes de nuevo ingreso a quienes se les plantean que identifiquen condiciones de escenarios propicios para la accidentalidad al interior de la obra. Lo anterior porque se considera que el ingeniero debe estar comprometido en defender la salud ocupacional y propiciar condiciones para mitigar los riesgos laborales que, aunque son acciones individuales que le competen al trabajador, el efecto para el normal desarrollo de las obras implica actuaciones de todos y cada uno de los miembros de una institución, en este caso de una obra (Guarro, 2005).

\subsection{Propuesta de reflexión sobre com- petencia trabajo en equipo}

Objetivo: Afianzar el conocimiento del grupo de trabajo sobre la organización en obra para la 
implementación de la filosofía Lean Construction en la actividad de mampostería.

Recursos: Papel y computador

Modalidad: Grupal, mínimo 2 y 3.

Duración: 50 min.

Descripción: Esta reflexión busca ser un mecanismo para que el grupo revise los aprendizajes logrados como grupo (Centro de Desarrollo Docente, 2017b) y se debe realizar luego de la visita a la obra. Se puede contar con la presencia de un funcionario de la obra visitada.

Se procede a realizar la lectura de los siguientes hechos encontrados en tres obras. La obra 3 se ejecutó luego de finalizada la obra 2 y la obra 2 se ejecutó una vez finalizada la obra 1.

Obra 1 (522 unidades de vivienda): El ladrillo inicialmente se entregaba en pacas de 1000 $\mathrm{kg}$ actualmente, es estibado en pacas de $700 \mathrm{~kg}$. Se procedió a generar la práctica de recolección de ladrillo despicado, fisurado o con alguna imperfección, para ser utilizado como cortes de medios, cortes especiales, culatas o se modifica según la modulación en piezas utilizables. Se hicieron modulaciones en cortes de ladrillo y se veló por la nivelación del área sobre la cual se hacía la entrega del material. Se clasificaron los mamposteros según su nivel de experticia en ciertos muros.

Obra 2 (968 unidades de vivienda): Con el aprendizaje de la obra anterior, se aplicaron las mismas estrategias, con las siguientes mejoras:
- Se asignaron dos personas encargadas constantemente de la recolección de sobrantes y desperdicios.

- Se implementaron penalidades por generación de desperdicios.

- La nivelación de los sitios de acopio de ladrillo se planificó desde el inicio del movimiento de tierra.

- La ladrillera aceptó recibir el material con imperfectos.

Las anteriores acciones tuvieron como consecuencia que se disminuyera el porcentaje de desperdicio del ladrillo medio estructural del $5 \%$ al $2 \%$.

Obra 3 (565 unidades de vivienda): adicional a lo ejecutado en las obras 1 y 2 , se realizaron los siguientes ajustes:

- Se implementó el ladrillo estructural con perforación vertical en lugar del ladrillo farol.

- Se acondicionaron los patios de maniobra para que el ladrillo viga-bloque quedara cerca de la cortadora.

- Se programó la entrega de ladrillo según programación de la obra.

\section{Tabla 1. Reingeniería en mejoramiento de los tableros eléctricos}

\begin{tabular}{|l|l|l|l|}
\hline \multirow{2}{*}{ Elemento } & \multicolumn{2}{c|}{ Características } & Cambios entre los elementos \\
\cline { 2 - 5 } & Costo & Número de usos & Entre 1 y 2 \\
\hline & & & \\
\hline
\end{tabular}




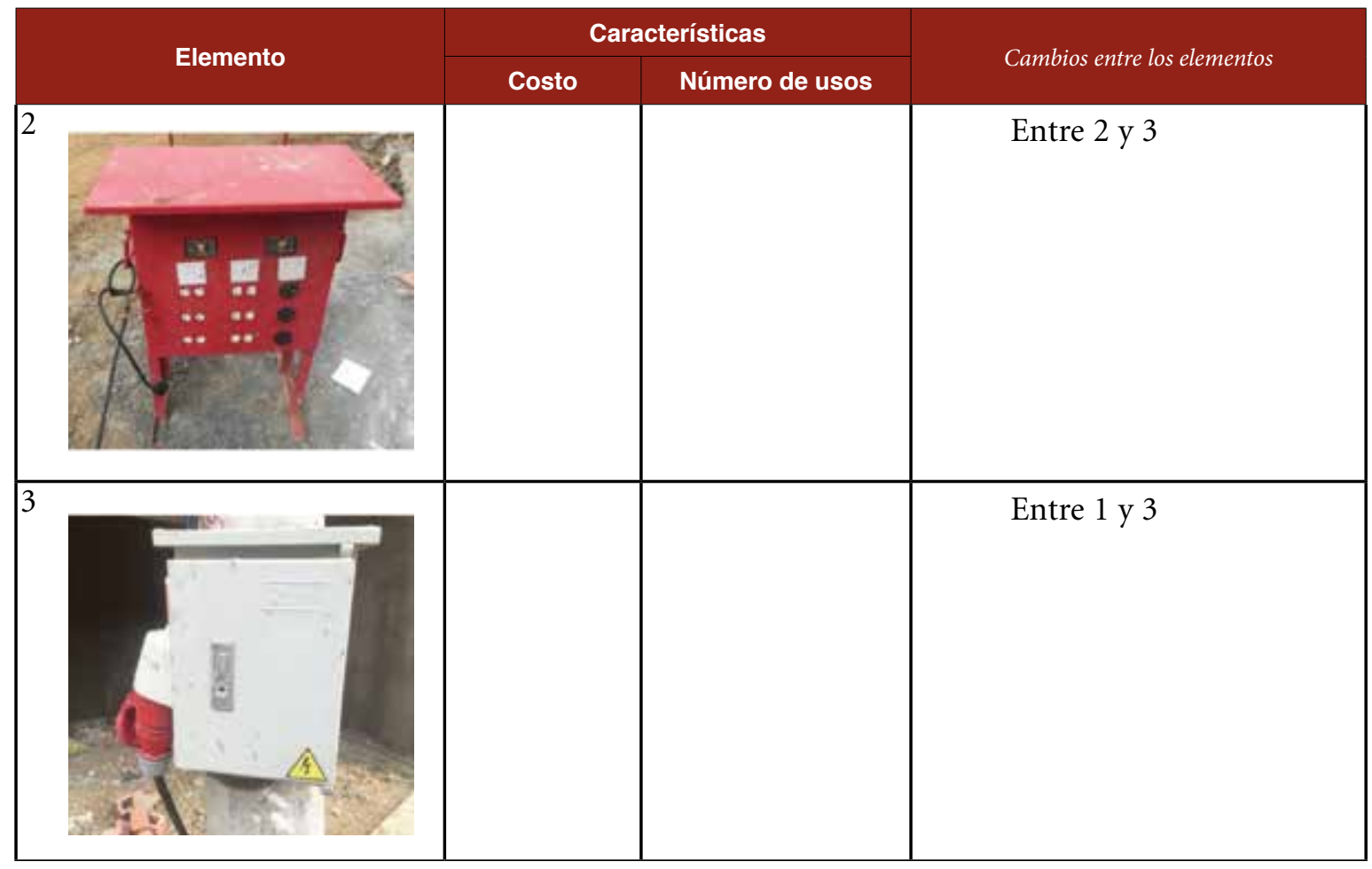

Fuente: autores partiendo de información de Bejarano (2017).

En la Tabla 2 se encuentran diferentes actividades asociadas a la mampostería. El equipo de trabajo debe organizar las actividades de la forma que garantice el cumplimiento de aspectos de Lean que fueron implementados en las tres obras para el proceso de mampostería.

Reflexión para el cierre de la actividad: Esta actividad se acompaña de una rúbrica de evaluación que recoge la coevaluación del equipo de trabajo.

El docente puede aprovechar el espacio para reflexionar sobre la relevancia de la distribución de funciones en un grupo para el buen logro de los objetivos y de la importancia de definir las funciones (roles) en una obra.

Evidencias de aplicación de esta estrategia de reflexión en otros cursos: Esta estrategia se ha empleado en Diseño I, curso prerrequisito de Diseño II y este a su vez, requisito para culminación del programa de ingeniería civil. Durante el desarrollo del programa se observó complementariedad en los equipos de trabajo, cumplimiento del cronograma de actividades para la ejecución de los proyectos del $98 \%$ y el tres de los cuatro grupos realizaron la coevaluación de sus pares de manera ecuánime. 
Tabla 2. Actividades ejecutadas para la labor de mampostería

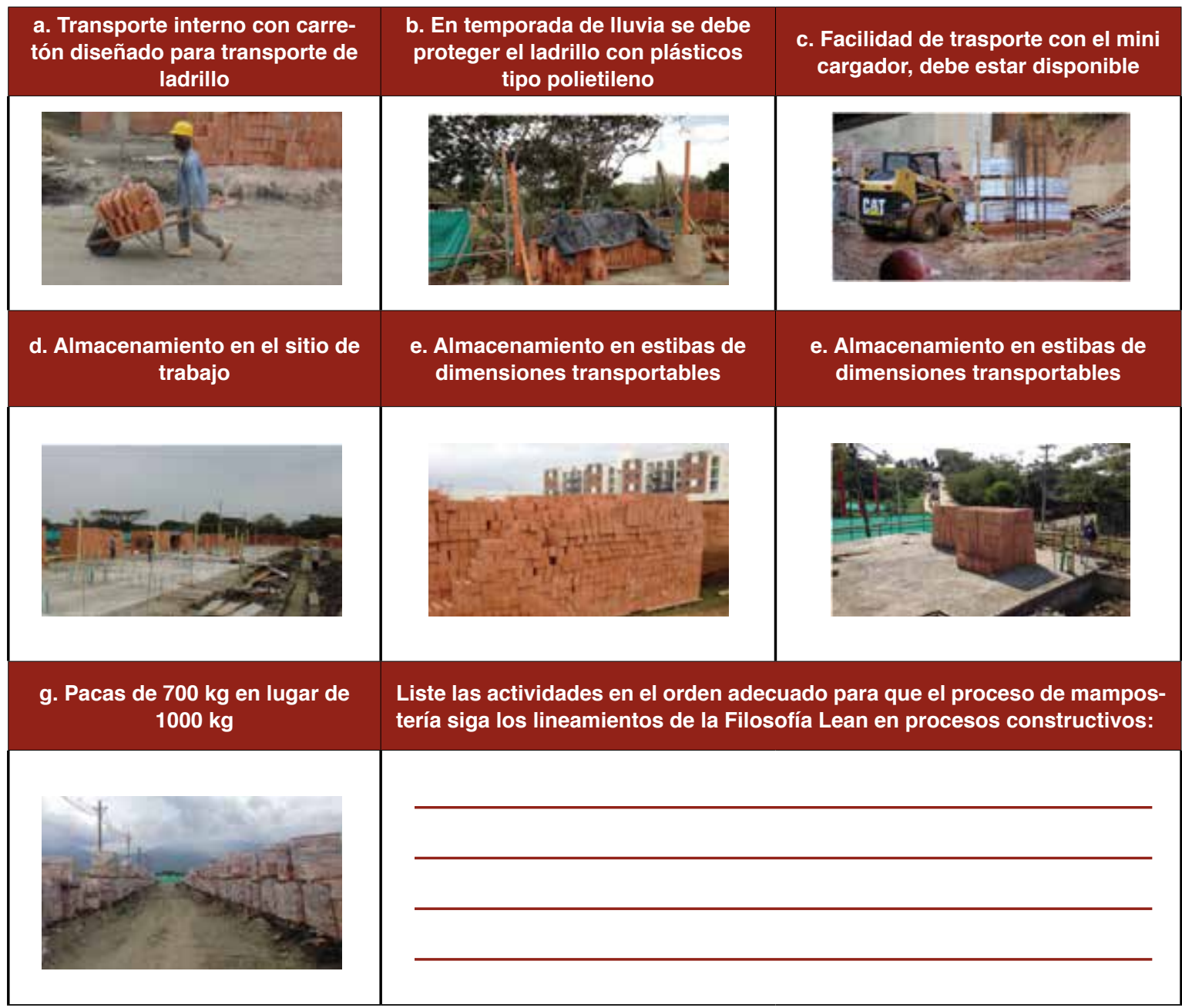

Fuente: Autores con información de Bejarano (2017).

\section{Conclusiones}

La comprensión de los procesos constructivos y las implicaciones que tiene en la calidad del producto final a ser entregado en un proyecto de construcción son factores claves para que el cliente o el usuario final sienta que el producto, bien o servicio entregado satisface completamente sus expectativas. Las estrategias de reflexión presentadas son adaptables para la enseñanza de la administración de recurso humano y de materiales bajo las modalidades de aplicación de rein- geniería y la implementación de Lean entendiendo, además, que esta filosofía de construcción sin pérdidas aporta beneficios al constructor, pero principalmente al ambiente porque se disminuyen desperdicios en materiales. Las estrategias de reflexión propuestas sirven para el desarrollo de competencias como solución de problemas, habilidades comunicativas, compromiso social, pensamiento crítico y trabajo en equipo, que en conjunto le permiten al futuro profesional emplear sus conocimientos sobre aspectos gerenciales a la solución de problemáticas que pueden 
presentarse en una obra. El diseño de las estrategias y su aplicación a la enseñanza de la ingeniería civil, específicamente a contenidos sobre proyectos de construcción, promueve la implementación de prácticas reflexivas que consideren la formación sólida, ética y solidaria del futuro profesional y la responsabilidad del ejercicio durante su desempeño ocupacional en la construcción de una sociedad justa y democrática. Se espera que estas estrategias respondan a las exigencias de la competitividad globalizada que de manera insistente exige cambios a las instituciones de educación superior durante la formación de los futuros profesionistas.

\section{Referencias bibliográficas}

Anaya, A., \& Acosta, M. (junio de 2010). El ingeniero industrial impactando el medio ambiente. Revista Educación en Ingeniería, 5(9), 179187. Recuperado de https://goo.gl/ZRLYxb

Arratia Figueroa, A. (2008). Ética, solidaridad y "Aprendizaje Servicio" en Educación Superior. Acta Bioethica, 14(1), 61-67. http://dx.doi.org/10.4067/S1726-569X2008000100008

Bejarano, A. (2017). Prácticas constructivas en proyectos de vivienda en la Constructora Jaramillo Mora S.A. Cali: Archivo de la empresa Jaramillo Mora S.A.

Bermúdez, L., \& González, L. (enero-junio de 2011). La competencia comunicativa: elemento clave en las organizaciones. Quórum Académico, 8(15), 95-110.

Berthin Siles, G. (junio de 1999). El ser humano, la corrupción y la política. Revista Ciencia y Cultura, 5, 111-120.

Bringle, R., \& Hatcher, J. (1999). Reflection in servicelearning: making meaning of experience. Educational Horizons, 179-185.

Bustos, C. (2005). La reingeniería: herramienta controversial. Visión Gerencial, 1, 3-10. Recuperado de https://goo.gl/r2VE7u

Centro de Desarrollo Docente (12 de octubre de 2017a). Aprendizajes del equipo. Campus San Joaquín, Chile: Pontificia Universidad Católica de Chile. Recuperado de https://goo.gl/NaC2ft

Centro de Desarrollo Docente (2017b). Mitad y mitades. Campus San Joaquín: Pontificia
Universidad Católica de Chile. Recuperado de https://goo.gl/yhnuH5

Erren, M. (2008). La competencia comunicativa del orador. Acta Poética, 28(1), 121-156.

Flamarion Klippel, A., Petter, C., \& Valle Antunes Jr., J. (marzo de 2008). Lean management implementation in mining industries. Dyna, 75(154). Recuperado de https://goo.gl/HjkcL3

France, D., de la Garza, M., Slade, C., Lafortune, L., Pallascio, R., \& Mongeau, P. (2003). Qué es el pensamiento dialógico crítico? Perfiles Educativos, XXV(102), 22-39.

Giroto Rebelato, M., \& Rodrigues, A. (2013). As contradicoes do Lean Sig Sigma. Revista de Administração da Unimep, 11(2), 57-81. Recuperado de https://goo.gl/HrFmKx

Good, D. J., \& McIntyre, C. (2015). Use of journal clubs within senior capstone courses: Analysis of perceived gains in reviewing scientific literature. Journal of Nutrition Education and Behavior, 47(5), 477-479. doi: https://doi. org/10.1016/j.jneb.2015.05.003

González Gómez, Y., Mieres Chacaltana, M., Denegri Coria, M., \& Sepúlveda Aravena, J. (septiembre-diciembre de 2014). La enseñanza de nociones básicas de economía en la formación docente. Una propuesta desde la experiencia de dos instituciones de Educación Superior Regional. Profesorado: Revista de currículum y formación del profesorado, 18(3), 411-430.

Guarro Pallás, A. (2005). La transformación democrática de la cultura escolar: una respuesta justa a las necesidades del alumnado de zonas desfavorecidas. Profesorado, revista de currículum y formación del profesorado, 1(1), 1-48.

Higuera Linares, M. (julio-diciembre de 2016). El mito del anillo de Giges en la República de Platón. Universitas Philosophica, 33(67), 73-102. Recuperado de https://goo.gl/8Ez6Bv

Ibarra Sáiz, M., \& Rodríguez Gómez, G. (2011). Aprendizaje autónomo y trabajo en equipo: reflexiones desde la competencia percibida por los estudiantes universitarios. Revista electrónica interuniversitaria de Formación del profesorado, 14(4), 73-85.

Iglesias Rodríguez, A., \& Beltrán Llavador, F. (2012). Practicum sin fronteras: Estudio de un caso 
de reflexión intercultural y pedagógica. Teoría de Educación, 24, 105-131.

Jouannet, C., Salas, M., \& Contreras, M. (2013). Modelo de implementación de Aprendizaje Servicio $(A+S)$ en la UC: Una experiencia que impacta positivamente en la formación profesional integral. Calidad en la Educación, 39, 197-212.

Luengo Navas, J., Luzón Trujillo, A., \& Torres Sánchez, M. (2008). Las reformas educativas basadas en el enfoque por competencias: una visión comparada. Profesorado: revista del currículum y formación del profesorado, 12(3), 1-10.

Ministerio de Educación Nacional (febrero de 1998). Consejo Nacional de Acreditación Lineamientos para la Acreditación. Bogotá: Ministerio de Educación Nacional.

Ministerio de Educación Nacional (27 de octubre de 2010). Las Pruebas Saber Pro (antes Ecaes), una ventaja competitiva en el campo laboral. Bogotá. Recuperado de https://goo. $\mathrm{gl} / 4 \mathrm{C} 2 \mathrm{rxU}$

Ministerio de Educación Nacional (18 de julio de 2017). Divulgación 2017 de Saber Pro. Bogotá. Recuperado de https://goo.gl/NHKDqD

Ministerio de Educación Nacional (15 de enero de 2018). Portal Colombia Aprende. Recuperado de https://goo.gl/W4MzQz

Montalva, J., Ponce, C., \& Llorca, C. (4 de noviembre de 2017). Elementos claves para el diseño de una reflexión de calidad en Aprendizaje Servicio. Lectura obligatoria en el Diplomado Aprendizaje+Servicio de la Pontificia Universidad Católica de Chile. Santiago de Chile: Centro de Desarrollo Docente de la Pontificia Universidad Católica de Chile.

Muñoz Gaviria, D. (enero-junio de 2011). El compromiso social de las facultades de educación: Reflexiones pedagógicas en torno a la educación y la crisis de la modernidad. El Ägora USB, 11(1), 125-152.

Oehrtman, S. J., Smolen, D., Hoblet, K. \&, Phillips, K. A. (2010). The comprehensive examination: A viable master's of science in nursing capstone course. Journal of Professional Nursing, 26(6), 360-365. doi: https://doi. org/10.1016/j.profnurs.2010.08.003

Palomer, L., Humeres, P., Sánchez, A., González, S., \& Contreras, A. (junio de 2013). Una experien- cia de "aprendizaje-servicio": fomentando el desarrollo de valores en estudiantes de odontología chilenos. FEM: Revista de la Fundación Educación Médica, 16(2), 91-96. http://dx.doi.org/10.4321/S2014-98322013000200007

Pérez de Maldonado, I., Bustamante Uzcátegui, S., \& Maldonado Pérez, M. (2009). El trabajo en equipo y el desarrollo de habilidades conversacionales en organizaciones educativas. Omnia, 15(3), 78-96.

Raposo Rosa, A., \& Cardoso Viera Machado, M. (2013). Lean Accounting: Accounting contribution for Lean Management Philosophy. Tourism y Management Studies, 3, 886-895. Recuperado de https://goo.gl/fWTfgp

Sávio Giordani, D., Cândido Moraes, E. d. J., \& Motta Barreto, M. A. (2017). Simulation of a competitive business environment: a case study in a Chemical Engineering Program. Production, 24(27), 1-12.

Serrano Guzmán, M., Pérez Ruiz, D., Torrado Gómez, L., \& Solarte Vanegas, N. (mayo-agosto de 2017). Consideraciones académicas y administrativas para implementación de Capstone en ingeniería civil: Estudio de caso. Revista Electrónica Educare, 21(2), 1-22. http://dx.doi.org/10.15359/ree.21-2.17

Serrano Guzmán, M., Pérez Ruiz, D., Torrado Gómez, L., \& Solarte Vanegas, N. (2018). Estrategias de reflexión en trabajo final requisito para grado: estudio de caso en Ingeniería Civil. Revista Dilemas Contemporáneos: Educación, Política y Valores, 3(15), 1-24, mayo.

Shin, Y.-S., Lee K-W., Ahn, J-S. \& Jung, J-W. (2013). Development of Internship \& Capstone Design Integrated Program for UniversityIndustry Collaboration. Procedia - Social and Behavioral Sciences, 102, 386-391. doi: https://doi.org/10.1016/j.sbspro.2013.10.753

Subdirección Territorial y de Inversiones Públicas del Departamento Nacional de Planeación. (2013). Prototipo Proyectos Productivos Metodología General para la Formulación y Evaluación de Proyectos de Inversión Pública- MGA, Sistema general de Regalías SGR, Versión 1.0. Bogotá. Recuperado de https://goo.gl/BvWKHM

Ucol-Ganiron Jr. T., \& Alaboodi, A. S. (2013). Cultural Learning Environment in Structural 
Engineering Courses of Architecture and Civil Engineering Students in Qassim University. Procedia - Social and Behavioral Sciences, 102, 300-310.

Vega, G. (23 de Mayo de 2015). La ética. La leyenda del anillo de Giges. Valladolid. Recuperado de https://goo.gl/aBCnQR

Vélez Gutiérrez, C. (julio-diciembre de 2012). Una reflexión interdisciplinar sobre el pensamiento crítico. Revista Latinoamericana de estudios educativos, 9(2), 11-39.

Vergara-Schmalbach, J., Fontalvo Herrera, T., \& Morelos Gómez, J. (septiembre-diciembre de 2013). ¿Es la ingeniería una moda administrativa? Revista Virtual Universidad Católica del Norte, 40, 216225. Recuperado de https://goo.gl/dHtnnj
Vellurattil, R. P., Puglisi, M. P., Johnson, C. L., \& Slonek, J. (2014). Introduction of a capstone research program in a new college of pharmacy: Student perceptions. Currents in Pharmacy Teaching and Learning, 6(3), 429-436. https://doi.org/10.1016/j.cptl.2014.02.008

Viera Bayeaux, I. (abril-junio de 2010). Algunos criterios acerca de la competencia comunicativa. EduSol, 10, 29-38.

Zelaieta Anta, E., \& Camino Ortiz de Barrón, I. (enero-marzo de 2018). El desarrollo del pensamiento crítico en la formación inicial del profesorado: análisis de una estrategia pedagógica desde la visión del alumnado. Profesorado: revista de currículo y de formación del profesorado, 22(1), 197-214. 



\section{ALTERIDAD}

enero-junio 2018

Vol. 14, No. 1, 139

\section{Normas Editoriales (Publication guidelines)}

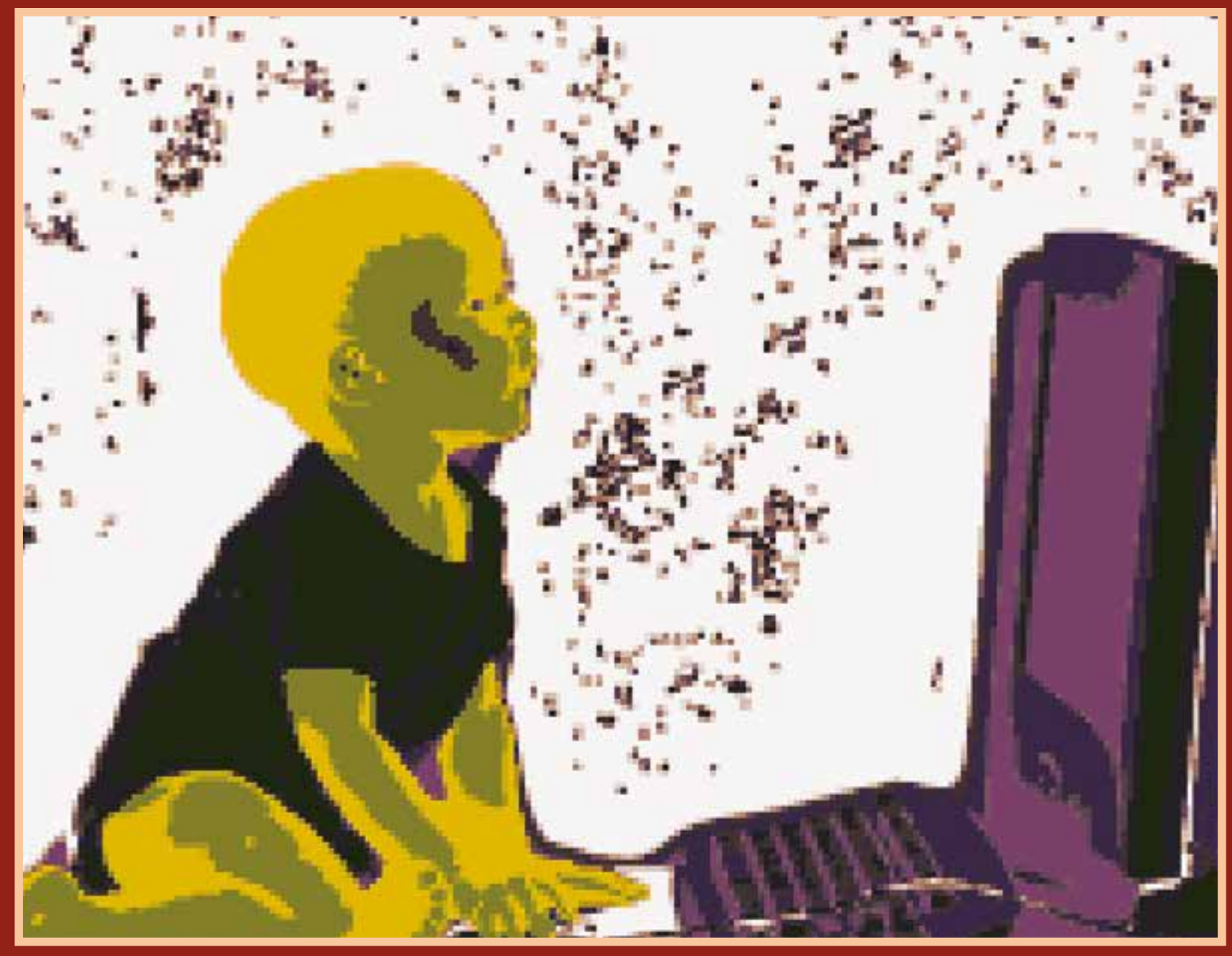

Nativo digital, ilustración digital, 18 cm x 12 cm 


\section{Alteridad. Revista de Educación http://alteridad.ups.edu.ec/ p-ISSN:1390-325X / e-ISSN:1390-8642}

\section{Normas de Publicación en "Alteridad"}

\section{Información general}

"Alteridad" es una publicación científica bilingüe de la Universidad Politécnica Salesiana de Ecuador, editada desde enero de 2006 de forma ininterrumpida, con periodicidad fija semestral, especializada en Educación y sus líneas transdisciplinares como Didáctica, Políticas Públicas, Gerencia de Centros Escolares, Educomunicación, TIC, entre otras.

Es una revista científica arbitrada, que utiliza el sistema de evaluación externa por expertos (peerreview), bajo metodología de pares ciegos (doble-blind review), conforme a las normas de publicación de la American Psychological Association (APA). El cumplimiento de este sistema permite garantizar a los autores un proceso de revisión objetivo, imparcial y transparente, lo que facilita a la publicación su inclusión en bases de datos, repositorios e indexaciones internacionales de referencia.

"Alteridad" se encuentra indexada en el directorio y catálogo selectivo del Sistema Regional de Información en Línea para Revistas Científicas de América Latina, el Caribe, España y Portugal (Latindex), en el Sistema de Información Científica REDALYC, en el Directorio de Revistas de Acceso Abierto DOAJ y en repositorios, bibliotecas y catálogos especializados de Iberoamérica.

La revista se edita en doble versión: impresa (ISSN: 1390-325X) y electrónica (e-ISSN: 13908642), en español e inglés, siendo identificado además cada trabajo con un DOI (Digital Object Identifier System).

\section{Alcance y política}

\subsection{Temática}

Contribuciones originales en materia de Educación, así como áreas afines: Didáctica, Políticas Públicas, Gerencia de Centros Escolares, Educomunicación, TIC... y todas aquellas disciplinas conexas interdisciplinarmente con la línea temática central. 


\subsection{Aportaciones}

"Alteridad" edita preferentemente resultados de investigación empírica sobre Educación, redactados en español y/o inglés, siendo también admisibles informes, estudios y propuestas, así como selectas revisiones de la literatura (state-of-the-art).

Todos los trabajos deben ser originales, no haber sido publicados en ningún medio ni estar en proceso de arbitraje o publicación. De esta manera, las aportaciones en la revista pueden ser:

- Investigaciones: 5.000 a 6.500 palabras de texto, incluyendo título,a resúmenes, descriptores, tablas y referencias.

- Informes, estudios y propuestas: 5.000 a 6.500 palabras de texto, incluyendo título, resúmenes, tablas y referencias.

- Revisiones: 6.000 a 7.000 palabras de texto, incluidas tablas y referencias. Se valorará especialmente las referencias justificadas, actuales y selectivas de alrededor de unas 70 obras.

"Alteridad" tiene periodicidad semestral (20 artículos por año), publicada en los meses de enero y julio y cuenta por número con dos secciones de cinco artículos cada una, la primera referida a un tema Monográfico preparado con antelación y con editores temáticos y la segunda, una sección de Misceláneas, compuesta por aportaciones variadas dentro de la temática de la publicación.

\section{Presentación, estructura y estilo de los manuscritos}

Los trabajos se presentarán en tipo de letra Arial 10, interlineado simple, justificado completo y sin tabuladores ni espacios en blanco entre párrafos. Solo se separarán con un espacio en blanco los grandes bloques (título, autores, resúmenes, descriptores, créditos y epígrafes). La página debe tener 2 centímetros en todos sus márgenes.

Los trabajos deben presentarse en documento de Microsoft Word (.doc o docx), siendo necesario que el archivo esté anonimizado en Propiedades de Archivo, de forma que no aparezca la identificación de autor/es.

Las Normas de publicación se basan en APA 6 (https://goo.gl/x4PyFw).

\subsection{Estructura del manuscrito}

Para aquellos trabajos que se traten de investigaciones de carácter empírico, los manuscritos seguirán la estructura IMRDC, siendo opcionales los epígrafes de Notas y Apoyos. Aquellos trabajos que por el contrario se traten de informes, estudios, propuestas y revisiones podrán ser más flexibles en sus epígrafes, especialmente en Material y métodos, Análisis y resultados y Discusión y conclusiones. En todas las tipologías de trabajos son obligatorias las Referencias.

6. Título (español) / Title (inglés): Conciso pero informativo, en castellano en primera línea y en inglés en segunda. Se aceptan como máximo 80 caracteres con espacio. El título no solo es responsabilidad de los autores, pudiéndose proponer cambios por parte del Consejo Editorial.

7. Resumen (español) / Abstract (inglés): Tendrá como extensión máxima 230 palabras, primero en español y después en inglés. En el resumen se describirá de forma concisa y en este orden: 1) Justificación del tema; 2) Objetivos; 3) Metodología y muestra; 4) Principales resultados; 5) Principales conclusiones. Ha de estar escrito de manera impersonal "El presente trabajo anali- 
za...”. En el caso del abstract no se admitirá el empleo de traductores automáticos por su pésima calidad.

8. Descriptores (español) / Keywords (inglés): Se deben exponer 6 descriptores por cada versión idiomática relacionados directamente con el tema del trabajo. Será valorado positivamente el uso de las palabras claves expuestas en el Thesaurus de la UNESCO.

9. Introducción y estado de la cuestión: Debe incluir el planteamiento del problema, el contexto de la problemática, la justificación, fundamentos y propósito del estudio, utilizando citas bibliográficas, así como la literatura más significativa y actual del tema a escala nacional e internacional.

10. Material y métodos: Debe ser redactado de forma que el lector pueda comprender con facilidad el desarrollo de la investigación. En su caso, describirá la metodología, la muestra y la forma de muestreo, así como se hará referencia al tipo de análisis estadístico empleado. Si se trata de una metodología original, es necesario exponer las razones que han conducido a su empleo y describir sus posibles limitaciones.

11. Análisis y resultados: Se procurará resaltar las observaciones más importantes, describiéndose, sin hacer juicios de valor, el material y métodos empleados. Aparecerán en una secuencia lógica en el texto y las tablas y figuras imprescindibles evitando la duplicidad de datos.

12. Discusión y conclusiones: Resumirá los hallazgos más importantes, relacionando las propias observaciones con estudios de interés, señalando aportaciones y limitaciones, sin redundar datos ya comentados en otros apartados. Asimismo, el apartado de discusión y conclusiones debe incluir las deducciones y líneas para futuras investigaciones.

13. Apoyos y agradecimientos (opcionales): El Council Science Editors recomienda a los autor/es especificar la fuente de financiación de la investigación. Se considerarán prioritarios los trabajos con aval de proyectos competitivos nacionales e internacionales. En todo caso, para la valoración científica del manuscrito, este debe ir anonimizado con XXXX solo para su evaluación inicial, a fin de no identificar autores y equipos de investigación, que deben ser explicitados en la Carta de Presentación y posteriormente en el manuscrito final.

14. Las notas (opcionales) irán, solo en caso necesario, al final del artículo (antes de las referencias). Deben anotarse manualmente, ya que el sistema de notas al pie o al final de Word no es reconocido por los sistemas de maquetación. Los números de notas se colocan en superíndice, tanto en el texto como en la nota final. No se permiten notas que recojan citas bibliográficas simples (sin comentarios), pues éstas deben ir en las referencias.

15. Referencias: Las citas bibliográficas deben reseñarse en forma de referencias al texto. Bajo ningún caso deben incluirse referencias no citadas en el texto. Su número debe ser suficiente para contextualizar el marco teórico con criterios de actualidad e importancia. Se presentarán alfabéticamente por el primer apellido del autor.

\subsection{Normas para las referencias}

\section{Publicaciones periódicas}

Artículo de revista (un autor): Valdés-Pérez, D. (2016). Incidencia de las técnicas de gestión en la mejora de decisiones administrativas [Impact of Management Techniques on the Improvement of Administrative Decisions]. Retos, 12(6), 199-213. https://doi.org/10.17163/ret.n12.2016.05

Artículo de revista (hasta seis autores): Ospina, M.C., Alvarado, S.V., Fefferman, M., \& Llanos, D. (2016). Introducción del dossier temático "Infancias y juventudes: violencias, conflictos, memorias y procesos de construcción de paz" [Introduction of the thematic dossier "Infancy and Youth: Violence, 
Conflicts, Memories and Peace Construction Processes"]. Universitas, 25(14), 91-95. https://doi. org/10.17163/uni.n25.\%25x

Artículo de revista (más de seis autores): Smith, S.W., Smith, S.L. Pieper, K.M., Yoo, J.H., Ferrys, A.L., Downs, E.,... Bowden, B. (2006). Altruism on American Television: Examining the Amount of, and Context Surronding. Acts of Helping and Sharing. Journal of Communication, 56(4), 707-727. https:// doi.org/10.1111/j.1460-2466.2006.00316.x

Artículo de revista (sin DOI): Rodríguez, A. (2007). Desde la promoción de salud mental hacia la promoción de salud: La concepción de lo comunitario en la implementación de proyectos sociales. Alteridad, 2(1), 28-40. (https://goo.gl/zDb3Me) (2017-01-29).

Libros y capítulos de libro

Libros completos: Cuéllar, J.C., \& Moncada-Paredes, M.C. (2014). El peso de la deuda externa ecuatoriana. Quito: Abya-Yala.

Capítulos de libro: Zambrano-Quiñones, D. (2015). El ecoturismo comunitario en Manglaralto y Colonche. En V.H. Torres (Ed.), Alternativas de Vida: Trece experiencias de desarrollo endógeno en Ecuador (175-198). Quito: Abya-Yala.

\section{Medios electrónicos}

Pérez-Rodríguez, M.A., Ramírez, A., \& García-Ruíz, R. (2015). La competencia mediática en educación infantil. Análisis del nivel de desarrollo en España. Universitas Psychologica, 14(2), 619-630. https://doi. org.10.11144/Javeriana.upsy14-2.cmei

Es prescriptivo que todas las citas que cuenten con DOI (Digital Object Identifier System) estén reflejadas en las Referencias (pueden obtenerse en http://goo.gl/gfruh1). Todas las revistas y libros que no tengan DOI deben aparecer con su link (en su versión on-line, en caso de que la tengan, acortada, mediante Google Shortener: http://goo.gl) y fecha de consulta en el formato indicado.

Los artículos de revistas deben ser expuestos en idioma inglés, a excepción de aquellos que se encuentren en español e inglés, caso en el que se expondrá en ambos idiomas utilizando corchetes. Todas las direcciones web que se presenten tienen que ser acortadas en el manuscrito, a excepción de los DOI que deben ir en el formato indicado (https://doi.org/XXX).

\subsection{Epígrafes, tablas y gráficos}

Los epígrafes del cuerpo del artículo se numerarán en arábigo. Irán sin caja completa de mayús-culas, ni subrayados, ni negritas. La numeración ha de ser como máximo de tres niveles: 1./ 1.1./ 1.1.1. Al final de cada epígrafe numerado se establecerá un retorno de carro.

Las tablas deben presentarse incluidas en el texto en formato Word según orden de aparición, numeradas en arábigo y subtituladas con la descripción del contenido.

Los gráficos o figuras se ajustarán al número mínimo necesario y se presentarán incorporadas al texto, según su orden de aparición, numeradas en arábigo y subtituladas con la descripción abreviada. Su calidad no debe ser inferior a 300 ppp, pudiendo ser necesario contar con el gráfico en formato TIFF, PNG o JPEG. 


\section{Proceso de envío}

Los manuscritos deben ser enviados única y exclusivamente a través del OJS (Open Journal System), en el cual todos los autores deben darse de alta previamente. No se aceptan originales enviados a través de correo electrónico u otra interfaz. Deben remitirse simultáneamente dos archivos:

1. Portada y Carta de presentación (usar el modelo oficial), en la que aparecerán:

- Título (español) / Title (inglés): Conciso pero informativo, en castellano en primera línea y en inglés en segunda. Se aceptan como máximo 80 caracteres con espacio. El título no sólo es responsabilidad de los autores, pudiéndose proponer cambios por parte del Consejo Editorial.

- Nombre y apellidos completos de cada uno de los autores, organizados por orden de prelación; seguido por la categoría profesional, centro de trabajo, correo electrónico de cada autor y número de ORCID. Es obligatorio indicar si se posee el grado académico de doctor (incluir Dr./Dra. antes del nombre).

- Resumen (español) / Abstract (inglés).

- Descriptores (español) / Keywords (inglés).

- Se incluirá además una declaración (Cover letter) de que el manuscrito se trata de una aportación original, no enviada ni en proceso de evaluación en otra revista, confirmación de las autorías firmantes, aceptación (si procede) de cambios formales en el manuscrito conforme a las normas y cesión parcial de derechos a la editorial.

2. Manuscrito totalmente anonimizado, conforme a las normas referidas en precedencia.

Todos los autores han de darse de alta, con sus créditos, en la plataforma OJS, si bien uno solo de ellos será el responsable de correspondencia. Ningún autor podrá enviar o tener en revisión dos manuscritos de forma simultánea, estimándose una carencia de cuatro números consecutivos (2 años). 


\section{Alteridad. Revista de Educación http://alteridad.ups.edu.ec/ p-ISSN:1390-325X / e-ISSN:1390-8642}

\section{Publication guidelines in "Alteridad"}

\section{General information}

"Alteridad" is a bilingual scientific publication of the Universidad Politécnica Salesiana of Ecuador, published since January 2006 in an uninterrupted manner, with a fixed biannual periodicity, specialized in Education and its transdisciplinary lines such as Didactics, Public Policies, Management of Schools, Educomunication, ICT, among others.

It is scientific journal, which uses the peer-review system, under double-blind review methodology, according to the publication standards of the American Psychological Association (APA). Compliance with this system allows authors to guarantee an objective, impartial and transparent review process, which facilitates the publication of their inclusion in reference databases, repositories and international indexing.

"Alteridad" is indexed in the directory and selective catalog of the Regional Online Information System for Scientific Journals of Latin America, the Caribbean, Spain and Portugal (Latindex), in the Scientific Information System REDALYC, in the Directory of Journals of Open Access DOAJ and in repositories, libraries and specialized catalogs of Latin America.

The journal is published in a double version: printed (ISSN: 1390-325X) and digital (e-ISSN: 1390-8642), in English and Spanish, each work being identified with a DOI (Digital Object Identifier System).

\section{Scope and policy}

\subsection{Theme}

Original contributions in Education, as well as related areas: Didactics, Public Policies, Management of Schools, Edu-communication, ICT... and all interdisciplinary disciplines related to the central theme. 


\subsection{Contributions}

"Alteridad" preferably publishes results of empirical research on Education, written in Spanish and / or English, as well as reports, studies and proposals, as well as selected state-of-the-art literature reviews.

All works must be original, have not been published in any medium or be in the process of arbitration or publication.

- Research: 5,000 to 6,500 words of text, including title, abstracts, descriptors, charts and references.

- Reports, studies and proposals: 5,000 to 6,500 words of text, including title, abstracts, charts and references.

- Reviews: 6,000 to 7,000 words of text, including charts and references. Justified references, would be specially valued. (current and selected from among 70 works)

"Alteridad" has a biannual periodicity (20 articles per year), published in January and July and counts by number with two sections of five articles each, the first referring to a Monographic topic prepared in advance and with thematic editors and the second, a section of Miscellaneous, composed of varied contributions within the theme of the publication.

\section{Presentation, structure and style of the manuscripts}

Texts will be presented in Arial 10 font, single line spacing, complete justification and no tabs or white spaces between paragraphs. Only large blocks (title, authors, summaries, descriptors, credits and headings) will be separated with a blank space. The page should be 2 centimeters in all its margins.

Papers must be submitted in a Microsoft Word document (.doc or docx), requiring that the file be anonymized in File Properties, so that the author/s identification does not appear.

These publication guidelines are based on the standards of APA 6: (http://www.apastyle.org/).

\subsection{Structure of the manuscript}

For those works that are empirical investigations, the manuscripts will follow the IMRDC structure, being optional the Notes and Supports. Those papers that, on the contrary, deal with reports, studies, proposals and reviews may be more flexible in their epigraphs, particularly in material and methods, analysis, results, discussion and conclusions. In all typologies of works, references are mandatory.

1. Title (Spanish) / Title (English): Concise but informative, in Spanish on the first line and in English on the second. A maximum of 80 characters with spaces are accepted. The title is not only the responsibility of the authors, changes being able to be proposed by the Editorial Board.

2. Abstract (Spanish) / Abstract (English): It will have a maximum extension of 230 words, first in Spanish and then in English. : 1) Justification of the topic; 2) Objectives; 3) Methodology and sample; 4) Main results; 5) Main conclusions. It must be impersonally written "This paper analyzes ... In the case of the abstract, the use of automatic translators will not be accepted due to their poor quality. 
3. Descriptors (Spanish) / Keywords (English): 6 descriptors must be presented for each language version directly related to the subject of the work. The use of the key words set out in UNESCO's Thesaurus will be positively valued.

4. Introduction and state of the issue: It should include the problem statement, context of the problem, justification, rationale and purpose of the study, using bibliographical citations, as well as the most significant and current literature on the topic at national and international level.

5. Material and methods: It must be written so that the reader can easily understand the development of the research. If applicable, it will describe the methodology, the sample and the form of sampling, as well as the type of statistical analysis used. If it is an original methodology, it is necessary to explain the reasons that led to its use and to describe its possible limitations.

6. Analysis and results: It will try to highlight the most important observations, describing, without making value judgments, the material and methods used. They will appear in a logical sequence in the text and the essential charts and figures avoiding the duplication of data.

7. Discussion and conclusions: Summarize the most important findings, relating the observations themselves with relevant studies, indicating contributions and limitations, without adding data already mentioned in other sections. Also, the discussion and conclusions section should include the deductions and lines for future research.

8. Supports and acknowledgments (optional): The Council Science Editors recommends the author (s) to specify the source of funding for the research. Priority will be given to projects supported by national and international competitive projects. In any case, for the scientific evaluation of the manuscript, it should be only anonymized with XXXX for its initial evaluation, in order not to identify authors and research teams, which should be explained in the Cover Letter and later in the final manuscript.

9. The notes (optional) will go, only if necessary, at the end of the article (before the references). They must be manually annotated, since the system of footnotes or the end of Word is not recognized by the layout systems. The numbers of notes are placed in superscript, both in the text and in the final note. The numbers of notes are placed in superscript, both in the text and in the final note. No notes are allowed that collect simple bibliographic citations (without comments), as these should go in the references.

10. References: Bibliographical citations should be reviewed in the form of references to the text. Under no circumstances should references not mentioned in the text be included. Their number should be sufficient to contextualize the theoretical framework with current and important criteria. They will be presented alphabetically by the first last name of the author.

\subsection{Guidelines for references}

\section{Periodic publications}

Journal article (author): Valdés-Pérez, D. (2016). Incidencia de las técnicas de gestión en la mejora de decisiones administrativas [Impact of Management Techniques on the Improvement of Administrative Decisions]. Retos, 12(6), 199-2013. https://doi.org/10.17163/ret.n12.2016.05

Journal Article (Up to six authors): Ospina, M.C., Alvarado, S.V., Fefferman, M., \& Llanos, D. (2016). Introducción del dossier temático "Infancias y juventudes: violencias, conflictos, memorias y procesos de con- strucción de paz" [Introduction of the thematic dossier "Infancy and Youth:Violence, Conflicts, Memories and Peace ConstructionProcesses"].Universitas, 25(14),91-95. 
https://doi.org/10.17163/uni.n25.\%25x

Journal article (more tan six authors): Smith, S.W., Smith, S.L. Pieper, K.M., Yoo, J.H., Ferrys, A.L., Downs, E.,... Bowden, B. (2006). Altruism on American Television: Examining the Amount of, and Context Surronding. Acts of Helping and Sharing. Journal of Communication, 56(4), 707-727. https:// doi.org/10.1111/j.1460-2466.2006.00316.x

Journal article (without DOI): Rodríguez, A. (2007). Desde la promoción de salud mental hacia la promoción de salud: La concepción de lo comunitario en la implementación de proyectos sociales. Alteridad, 2(1), 28-40. (https://goo.gl/zDb3Me) (2017-01-29).

Books and book chapters

Full books: Cuéllar, J.C., \& Moncada-Paredes, M.C. (2014). El peso de la deuda externa ecuatoriana. Quito: Abya-Yala.

Chaprter of book: Zambrano-Quiñones, D. (2015). El ecoturismo comunitario en Manglaralto y Colonche. En V.H. Torres (Ed.), Alternativas de Vida: Trece experiencias de desarrollo endógeno en Ecuador (175-198). Quito: Abya-Yala.

\section{Digital media}

Pérez-Rodríguez, M.A., Ramírez, A., \& García-Ruíz, R. (2015). La competencia mediática en educación infantil. Análisis del nivel de desarrollo en España. Universitas Psychologica, 14(2), 619-630. https://doi. org.10.11144/Javeriana.upsy14-2.cmei

It is prescriptive that all quotations that have DOI (Digital Object Identifier System) are reflected in the References (can be obtained at http://goo.gl/gfruh1). All journals and books that do not have DOI should appear with their link (in their online version, if they have it, shortened by Google Shortened: http://goo.gl) and date of consultation in the indicated format.

Journal articles should be presented in English, except for those in Spanish and English, in which case it will be displayed in both languages using brackets. All web addresses submitted must be shortened in the manuscript, except for the DOI that must be in the indicated format (https:// doi.org/XXX).

\subsection{Epigraphs, Figures and Charts}

The epigraphs of the body of the article will be numbered in Arabic. They should go without a full box of capital letters, neither underlined nor bold. The numbering must be a maximum of three levels: 1./ 1.1. / 1.1.1. A carriage return will be established at the end of each numbered epigraph.

The charts must be included in the text in Word format according to order of appearance, num- bered in Arabic and subtitled with the description of the content.

The graphics or figures will be adjusted to the minimum number required and will be presented incorporated in the text, according to their order of appearance, numbered in Arabic and subtitled with the abbreviated description. Their quality should not be less than $300 \mathrm{dpi}$, and it may be necessary to have the graph in TIFF, PNG or JPEG format. 


\section{Submission process}

Manuscripts must be submitted only and exclusively through the OJS (Open Journal System), in which all authors must previously register. Originals sent via email or other interfaces are not accepted. The following two files must be sent together:

1. Title page and Cover letter (use official model), in which will appear:

- Title (Spanish) / Title (English): Concise but informative, in Spanish on the first line and in English on the second. A maximum of 80 characters with spaces are accepted. The title is not only the responsibility of the authors, changes being able to be proposed by the Editorial Board.

- Full name and surnames: Of each of the authors, organized by priority. Next to the names must follow the professional category, work center, email of each author and ORCID number. It is mandatory to indicate if you have the academic degree of doctor (include Dr. / Dra. before the name).

- Resumen (Spanish) / Abstract (English).

- Descriptores (Spanish) / Keywords (English).

- A statement that the manuscript is an original contribution, not sent or being evaluated in another journal, with the confirmation of the signatory authors, acceptance (if applicable) of formal changes in the manuscript in accordance with the rules and partial transfer of rights to the publisher.

2. Manuscript totally anonymized, according to the guidelines referred in precedence.

All authors must register with their credits on the OJS platform, although only one of them will be responsible for correspondence. No author can submit or have in review two manuscripts simultane- ously, estimating an absence of four consecutive numbers (2 years). 